\title{
MARINE MICROBIAL PRODUCTION OF DIMETHYLSULFIDE FROM DISSOLVED DIMETHYLSULFONIOPROPIONATE
}

by

KATHLEEN MEI LEDYARD

B.S., Columbia University

(1987)

Submitted in partial fulfillment of the

requirement for the degree of

DOCTOR OF PHILOSOPHY

at the

\section{MASSACHUSETTS INSTITUTE OF TECHNOLOGY and the \\ WOODS HOLE OCEANOGRAPHIC INSTITUTION}

February 1993

(C) Kathleen M. Ledyard 1993

The author hereby grants to MIT and WHOI the permission to reproduce and distribute copies of this thesis in whole or in part.

Signature of Author

MIT-WHOI Joint Program in Oceanogrhphy and Applied Ocean Science and Engineering

Certified by

John W. H. Dacky

Thesis Supervisor

Certified by

Neil V. Blough

Thesis Supervisor

Accepted by

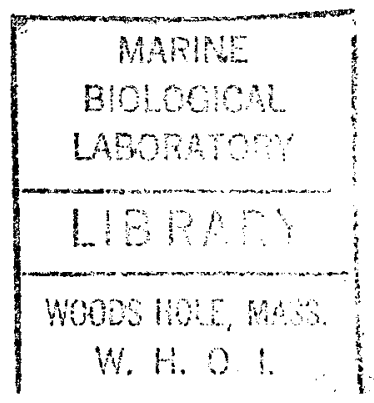

Ellen M. Druffel, Chaitperson

Joint Committee for Chemical Oceanography

Massachusetts onstatut Technology/

Woods Hol Ocg/ orapic Institution 


\title{
MARINE MICROBIAL PRODUCTION OF DIMETHYLSULFIDE FROM DISSOLVED DIMETHYLSULFONIOPROPIONATE
}

by

\author{
Kathleen M. Ledyard
}

\begin{abstract}
Dimethylsulfide (DMS) plays a central role in the transfer of sulfur from the ocean to the atmosphere, and ultimately to land. The most abundant volatile organosulfur compound in seawater, DMS is believed to account for the bulk of the sea-to-air biogenic sulfur flux. DMS has also been implicated as the major precursor of submicron-sized sulfate aerosol over the ocean. This aerosol acts as an effective site for cloud droplet condensation, suggesting a possibly important role for DMS in marine cloud formation. In the ocean, the precursor of DMS is presumed to be the zwitterionic sulfonium compound dimethylsulfoniopropionate (DMSP), a common osmoticum in certain classes of marine algae. While some algae can cleave DMSP intracellularly to form DMS, correlation of DMS concentrations with indicators of algal productivity on a local scale is poor.
\end{abstract}

This thesis focuses on an alternative pathway of DMS formation: microbial cleavage of dissolved (extracellular) DMSP. In laboratory studies, bacteria able to cleave DMSP to form DMS were isolated from seawater by a DMSP enrichment technique, and the kinetics of DMSP uptake and DMS production were examined closely in pure cultures of a bacterial isolate from the Sargasso Sea. The isolate could grow with both DMSP and acrylic acid, one of the products of DMSP cleavage, as the sole source of carbon and energy, and the enzyme catalyzing DMSP cleavage appeared to be induced by both of these compounds. Kinetic parameters were estimated for DMSP uptake and cleavage by whole cells. Comparison of the $16 \mathrm{~S}$ rRNA sequence of this isolate with that of known eubacteria showed that it was most closely related to Erythrobacter longus, an aerobic, bacteriochlorophyll-containing member of the $\alpha$ proteobacteria.

DMS production from dissolved DMSP, along with microbial DMSP and DMS removal, was investigated in seawater incubation experiments with the goal of establishing turnover times for DMSP and DMS. These were determined to be on the order of days in both coastal (Vineyard Sound) and oligotrophic (Sargasso Sea) seawater. Loss of DMSP from the dissolved phase always occurred more rapidly than production of DMS; on average, microbial removal processes turned DMSP over on timescales of less than a day. This suggests that processes which do not result in DMS production, such as demethylation, may be important sinks for DMSP. Kinetic parameters for DMSP uptake and DMS production varied, possibly as a function of season. However, more data are needed to assess the seasonal dependence of this process. 
These results imply that microbial production of DMS from dissolved DMSP is likely to be a quantitatively significant mode of DMS formation in both coastal and oligotrophic marine environments. Timescales of DMS turnover with respect to this process are comparable to published estimates of DMS turnover times due to biological consumption, indicating that coupling between these two microbiallymediated processes may constitute an important control on oceanic DMS levels.

Thesis supervisor: John W. H. Dacey

Position: Associate Scientist, WHOI

Thesis co-supervisor: Neil V. Blough

Position: Associate Scientist, WHOI 
The only thing to come now is the sea.

From between two hills a sudden wind funnels at me, Slapping its phantom laundry in my face.

These hills are too green and sweet to have tasted salt.

I follow the sheep path between them. A last hook brings me

To the hills' northern face, and the face is orange rock

That looks out on nothing, nothing but a great space

Of white and pewter lights, and a din like silversmiths

Beating and beating at an intractable metal.

Sylvia Plath

"Blackberrying"

First printed in The New Yorker, 1962. 


\section{ACKNOWLEDGEMENTS}

Financial support for this work was provided by the NASA Graduate Student Researchers Program (NGT-50456), NASA (NAGW-606), NSF (OCE-902532), the Ocean Ventures Fund, and the WHOI Education Office. The fund for research at the Bermuda Biological Station, set up by Mr. Arch Scurlock and administered by the MIT Joint Program Office, supported the costs of three field trips to the Station.

During the course of my thesis research many people have lent me their support, encouragement and friendship. Mike Bacon and Ed Sholkovitz hosted me in their labs during my first two summers in the Joint Program, and I am grateful to Ed for originally introducing me to the collaboration between John Dacey and Neil Blough that led to my thesis project. I am especially thankful to those who guided my first uncertain steps toward things microbiological: Freddy Valois, Linda Hare, John Waterbury and Diana Franks. Freddy especially fielded constant questions, walked me through numerous procedures, helped man the French press, and still had the energy to ask me how things had gone afterward. The research groups of Francois Morel and Penny Chisholm at the Parsons Lab deserve credit for initially exposing me to the fascinating machinations of single-celled organisms. Tony Michaels and Frances Howse were extremely helpful during work at the Bermuda Biological Station. I would also like to acknowledge Ed DeLong, whose assistance with the sequencing and phylogenetic analysis reported in Chapter 6 required a substantial input of time and energy. At various points, I have tapped virtually every inhabitant of Redfield for help of one sort or another. To acknowledge each of them individually would make this section formidably long, but they know who they are.

Interactions with my committee members - John Dacey, Neil Blough, Colleen Cavanaugh, Penny Chisholm and John Waterbury - have been consistently enjoyable. I think I must be one of a minority of graduate students in the world who have actually looked forward to committee meetings. Their supportive attitudes and diverse perspectives contributed substantially to my pleasure in this work. I thank them for treating me as a colleague, for responding to my enthusiasm with enthusiasm of their own, and for understanding the fascination of the "perfect bacterium." My advisor, John Dacey, deserves special thanks for providing lab space, equipment and supplies, and, just as importantly, his warmth and superb sense of humor. His automation expertise - and 24-hour technical support hotline - dramatically reduced stamina requirements for some of the longer timecourse experiments. He responded to my occasional frustration at things scientific and other with admirable tact. Although I am sure I didn't acknowledge this properly at the time, it was nonetheless greatly appreciated. 
Abbie Jackson, Jake Peirson, John Farrington and Ronni Schwartz at the WHOI Education Office and MIT Joint Program Office, and Ed Sholkovitz as Chemistry Education Coordinator, facilitated funding for conference travel, field excursions and acquisition of a microscope. Education has also made available essentials such as pizza, Visiting Scholar barbeques and the New York Times. I could never have filled out those complicated registration forms, integral to my continued enrollment in the Joint Program, without extensive personal attention from Abbie. Jake and Abbie, you have been warm and wonderful presences in and out of the Education Office, and are much more than facilitators to me.

I want to acknowledge the many friends who have seen me through various phases of this work: Beth Conte, Bonni Alpert, Rachel Smith, Laela Sayigh, Carla Curran, Abbie Jackson, Jane and Richard Ridge, Tom DiChristina, Nathalie Waser, Sarah Green, Merryl Alber, Diane Cowan, Claire and Tony Michaels, Debra Colodner, Susan Wijffels, Cecilie Mauritzen, Carol Arnosti, Ed Brook, Yair Rosenthal, Kathleen Ruttenberg, Ralf Goericke, Joe Pawlik, Brian Palenik, and Bruce Woodin. Ed DeLong is in a category by himself. He has been my closest friend, confidant and supporter during the last two years of this work.

I'll bring this to a close with an acknowledgement of my parents, who have encouraged me in academic pursuits of all stripes from the very beginning. I can't imagine these last five years without the love and support of my mother. This thesis is dedicated to her. 


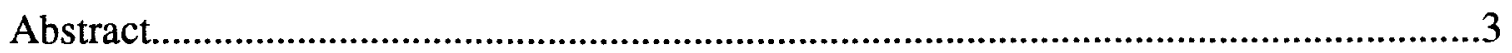

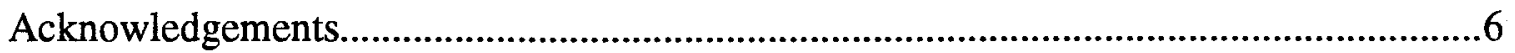

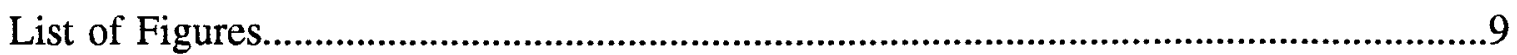

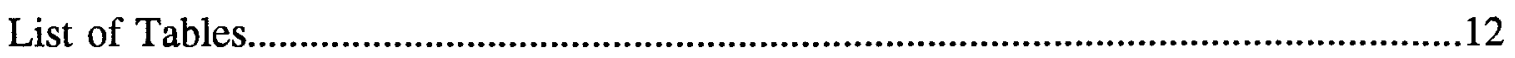

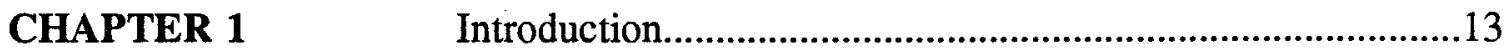

1. The ocean as a source of dimethylsulfide

$1.1 \quad$ Flux estimates

1.2 Climatic implications

1.3 Biological and chemical controls on marine DMS

2. Dimethylsulfoniopropionate: natural occurrence and properties

3. Algal production of DMSP

3.1 DMSP synthesis by marine algae

3.2 Role of DMSP in algal physiology

4. Bacterial utilization of DMSP

5. Outline of this thesis

CHAPTER 2

CHAPTER 3

CHAPTER 4

CHAPTER 5

CHAPTER 6

CHAPTER 7
A prelimary assessment of DMSP-lyase activity

in natural seawater.

Microbial cycling of DMSP and DMS in

Vineyard Sound.

Microbial cycling of DMSP and DMS in the

Sargasso Sea.

DMS production from DMSP by a marine bacterium.......155

Physiological and phylogenetic characterization

of a marine DMSP-degrading bacterial isolate.

Summary and conclusions. 


\section{LIST OF FIGURES}

\section{CHAPTER 1}

Figure 1-1. DMSP cleavage to form DMS and acrylic acid......................................24

Figure 1-2. Pathway of DMSP synthesis in the green macroalga Ulva lactuca.........29

\section{CHAPTER 2}

Figure 2-1. Effect of sterile filtration on DMSP-lyase activity in seawater. .65

Figure 2-2. Production of DMS and methanethiol in response to high-level DMSP additions to seawater. 67

Figure 2-3. Production of DMS from DMSP by marine bacterial isolates. 69

Figure 2-4. Volatile sulfur production from DMSP by Pseudomonas doudoroffii and Alteromonas macleodii. 71

Figure 2-5. Methylene chloride inhibition of DMS consumption in seawater .73

\section{CHAPTER 3}

Figure 3-1. Timecourse of DMS and soluble DMSP in response to low-level DMSP and DMS additions to Vineyard Sound seawater on 4/10/92.......90

Figure 3-2. Timecourse of DMS and soluble DMSP in response to low-level DMSP and DMS additions to Vineyard Sound seawater on 4/23/92 .......91

Figure 3-3. Schematic of potential pathways of DMSP utilization and DMS production and consumption in seawater.

Figure 3-4. Saturation curves and Eadie-Hofstee plots for dissolved DMSP removal and cleavage in Vineyard Sound seawater on 4/26/92.

Figure 3-5. Saturation curves and Eadie-Hofstee plots for dissolved DMSP removal and cleavage in Vineyard Sound seawater on 5/26/92.

Figure 3-6. Timecourse of DMS in DMS-amended controls for kinetics experiments on $4 / 26$ and $5 / 26 / 92$ 
Figure 3-7. Lack of concentration dependence of DMS removal on 5/8/92............103

Figure 3-8. Comparison of concentration dependence of DMSP removal, DMSP cleavage and DMS removal with previous work.

\section{CHAPTER 4}

Figure 4-1. Profile of DMS, soluble and particulate DMSP in the Sargasso Sea in November 1990.

Figure 4-2. Profile of DMS, soluble and particulate DMSP in the Sargasso Sea in January 1992.

Figure 4-3. Profile of DMS, soluble and particulate DMSP in the Sargasso Sea in April 1992.

Figure 4-4. Timecourse of DMS and soluble DMSP in response to low-level DMSP and DMS additions to Sargasso Sea water on 1/20/92.

Figure 4-5. Timecourse of soluble DMSP in unamended Sargasso Sea water on $10 / 30 / 90$ and $1 / 26 / 92$

Figure 4-6. Rate of DMS production as a function of soluble DMSP 11/3/90........136

Figure 4-7. Saturation curve and Eadie-Hofstee plot for DMSP cleavage $1 / 29 / 92$.

Figure 4-8. Rate of DMS production as a function of soluble DMSP in April 1992.

Figure 4-9. Scatter plot of Sargasso Sea DMSP removal data.................................142

Figure 4-10. Scatter plot of Sargasso Sea DMSP cleavage data.................................143

Figure 4-11. Scatter plot of Sargasso Sea DMS removal data.....................................144

\section{CHAPTER 5}

Figure 5-1. Effect of chloramphenicol on DMSP cleavage in strain LFR................159

Figure 5-2. Effect of SDS on DMSP cleavage in strain LFR.................................161

Figure 5-3. DMS production from DMSP by induced LFR.......................................163 
Figure 5-4. DMS production from DMSP by LFR following preincubation with DMSP, acrylic acid, mannitol, DMS or methionine.

Figure 5-5. Saturation curve for DMSP cleavage in uninduced LFR........................170

Figure 5-6. Saturation curve for DMSP cleavage in induced LFR...........................171

Figure 5-7. Eadie-Hofstee regressions for DMSP cleavage in induced LFR............173

Figure 5-8. DMS production rate data for induced LFR in the $10-250 \mathrm{nM}$ DMSP concentration range.

Figure 5-9. Timecourse of DMSP uptake and accumulation, and DMS production, in uninduced LFR.................................................................175

Figure 5-10. Kinetics of DMSP uptake in induced LFR..........................................177

Figure 5-11. Kinetics of DMSP uptake and cleavage in induced LFR......................178

Figure 5-12. Kinetics of DMSP uptake in uninduced LFR........................................179

\section{CHAPTER 6}

Figure 6-1. Phase contrast micrograph of strain LFR...............................................200

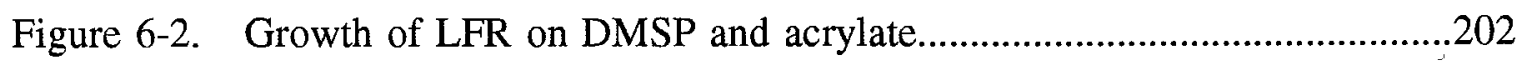

Figure 6-3. Colony sectoring in LFR....................................................................204

Figure 6-4. Absorbance spectrum of methanol extract of LFR..............................205

Figure 6-5. Phylogenetic tree based on 16S rRNA sequence similarity showing relatedness of LFR to other proteobacteria...............................207

Figure 6-6. Quantitative conversion of DMSP to DMS by LFR...............................208

Figure 6-7. Production of methanethiol from methionine by LFR.............................209 


\section{LIST OF TABLES}

\section{CHAPTER 2}

Table 2-1. Production of volatile sulfur from DMSP by well-characterized marine bacteria.

\section{CHAPTER 3}

Table 3-1. Low-level DMSP removal experiments in Vineyard Sound....................92

Table 3-2. Low-level DMS production experiments in Vineyard Sound...................93

Table 3-3. Low-level DMS removal experiments in Vineyard Sound........................94

Table 3-4. Estimated kinetic parameters for DMSP removal and

DMS production in Vineyard Sound seawater.

\section{CHAPTER 4}

Table 4-1. Sargasso Sea water column parameters...................................................124

Table 4-2. Low-level DMSP removal experiments in the Sargasso Sea..................128

Table 4-3. Low-level DMS production experiments in the Sargasso Sea.................129

Table 4-4. Low-level DMS removal experiments in the Sargasso Sea....................130

\section{CHAPTER 5}

Table 5-1. Description of kinetics experiments........................................................157

Table 5-2. Kinetic parameters of DMSP uptake and cleavage estimated for induced and uninduced LFR.............................................................168

\section{CHAPTER 6}

Table 6-1. Growth and physiological characteristics of strain LFR 199

\section{CHAPTER 7}

Table 7-1. Summary of rate and turnover time data in Chapters 3 and 4. 220 


\section{CHAPTER 1}

\section{INTRODUCTION}

\section{The ocean as a source of dimethylsulfide.}

The first marine measurements of dimethylsulfide (DMS) by Lovelock et al. (101) prompted these authors to hypothesize that DMS might supply the "missing" component in existing models of the sulfur cycle. These models could not account for the transfer of sulfur to the atmosphere needed $\left(1-9 \mathrm{Tmol} \mathrm{yr}^{-1}(59,68)\right)$ to balance that delivered to the earth's surface via precipitation and dry deposition. The early data of Lovelock et al. initiated a prodigious accumulation of seawater DMS measurements $(7,9,11,16,19,24,38,65,75,108,142,143)$. The consensus of these investigations is that DMS ranges between 0.5 and $2 \mathrm{nM}$ in the surface waters of the oligotrophic gyres, with somewhat higher values in coastal and upwelling areas. Significantly elevated concentrations are reported in the waters around mainland Britain (143), in the vicinity of blooms of the prymnesiophyte Phaeocystis pouchetii $(15,65,66)$, and in some upwelled waters (11). These studies straddle or fall into one of two broad categories: those that attempt to identify the important biological and chemical controls on DMS concentrations, and those that seek representative concentration data on which to base estimates of the sea-to-air DMS flux. Recently, the need to understand the climatic impact of atmospheric sulfur has enhanced the urgency of both initiatives.

\subsection{Flux estimates.}

Calculations of the sea-to-air flux of dimethylsulfide generally rely on some 
formulation of the stagnant film model $(27,98,100)$, in which the flux is proportional to the concentration gradient across a hypothetical stagnant boundary layer between water and air; the proportionality constant is the molecular diffusivity of the compound in question. Measurements of atmospheric DMS $(10,11,16,24,142)$ and consideration of the Henry's Law constant for DMS (45) reveal that DMS in surface seawater is highly supersaturated with respect to the atmosphere. In calculations of the DMS flux, therefore, atmospheric concentrations are usually considered negligible. The thickness of the hypothetical stagnant film appears to be controlled by wind speed (99); however, large uncertainties are associated with this relation. The diffusivity of DMS has not been quantified, and is usually estimated with the aid of various empirical relations $(72,113,155)$; sometimes the diffusivity of oxygen is directly substituted. Alternatively, the piston velocity of DMS (the ratio of diffusivity to film thickness) is estimated from the GEOSECS ${ }^{222} \mathrm{Rn}$ disequilibrium data set or from empirical formulas for the radon piston velocity. Most sea-to-air flux estimates for DMS by these techniques range between 0.7 and $2 \mathrm{Tmol} \mathrm{S} \mathrm{yr}^{-1}(10,11,16,20,108)$. Modelling approaches which utilize satellite data and chemical/photochemical rate constants for DMS have also been used $(12,58,139)$, obtaining similar estimates. These flux estimates seemed both internally consistent and "geochemically consistent" - i.e., they satisfied the lower-end estimates of the sulfur needed to complete the global budget.

However, it has been recently pointed out that levels of atmospheric DMS are lower than our current assumptions about sea/air transfer and photochemical destruction of DMS lead us to expect (39). The largest uncertainty appears to be associated with flux estimates, which rely heavily on approximations of the molecular 
diffusivity of DMS based on its similarity to radon or oxygen. Preliminary laboratory measurements using a stirred vessel to study the comparative fluxes of DMS and a number of other gases suggest that radon and oxygen may not be suitable analogues for DMS (121); the exchange rate of DMS is much lower than relations such as that of Wilke and Chang (155) predict. Revising our estimates of the diffusivity of DMS downward would result in a halving of the projected sea-to-air DMS flux (121), and open again the gap in the sulfur budget that had been so neatly bridged by the discovery of DMS.

\subsection{Climatic implications.}

The extensive efforts detailed above to quantify the sea-to-air flux of DMS were initially motivated by a desire to balance the sulfur budget. However, toward the end of the 1980's a new incentive emerged, with the publication of a number of papers on the potential climatological impact of submicron-sized sulfate aerosol resulting from gas-phase oxidation of DMS and other biogenic sulfur gases $(17,36,106,124,126,154)$. The radiative role attributed to this aerosol is twofold: it may interact strongly with visible radiation, the net effect being scattering in a non-cloud situation $(25,125)$, and it may act as a nucleation site for cloud droplets. The potential significance of the latter role is dramatically posited by Charlson et al. (36). They hypothesize that sulfate aerosol resulting from gas-phase photooxidation of DMS provides most of the cloud condensation nuclei (CCN) in the marine atmosphere, such that changes in the flux of DMS from the ocean would result in changes in the number density of CCN in marine clouds, and hence in their albedo. The authors speculate that marine DMS emissions and climate form a feedback loop that has enabled earth-surface 
temperatures to remain relatively constant while the luminosity of the sun has increased over geological time. (This scheme was independently proposed by Meszaros (106), and Shaw (125) had proposed earlier a similar thermostasis scenario which had as its cooling mechanism the direct scattering of incoming solar radiation by sulfate aerosol.)

This suggestion touched off an animated debate. Schwartz (124) responded that if cloud albedo and temperature are sensitive functions of non-sea-salt sulfate aerosol, the increasing production of anthropogenic $\mathrm{SO}_{2}$ during the twentieth century (now estimated (8) to be at least twice the oceanic emissions of volatile sulfur) constitutes a "global experiment" whose effects can be used to test the validity of the hypothesis. Since anthropogenic sulfur input has occurred mainly in the northern hemisphere, the current cloud component of albedo, and the temperature record for the last century, should be compared for both hemispheres. Schwartz (124) concluded from his investigation of these parameters that there is no important interhemispheric difference in either albedo or the temperature record, and hence no apparent climatic role for sulfate aerosol. His analysis was in turn criticized $(37,63,64,74)$ for the inadequacy of the cited data in quantity, quality and application to refute the hypothesis of Charlson et al. (36).

At present, attempts to establish links between DMS emissions and aerosol concentrations $(14,17,18)$ and to distinguish between marine and continental sources of non-sea-salt sulfate (123) are under way. Recent work (60) comparing independent satellite data sets of chlorophyll in the ocean's surface and the albedo of marine stratus clouds offers compelling evidence that the variability in albedo over the North Atlantic 
Ocean can be explained largely by biogenic sulfur production: the effect of anthropogenic sulfur inputs, although large, appears confined to the area immediately adjacent to the input. These observations have taken an important qualitative step toward resolution of the debate, which will require distinguishing the biogenic and anthropogenic contributions to atmospheric non-sea-salt sulfate.

\subsection{Biological and chemical controls on DMS concentrations.}

A definite pattern emerges from the numerous oceanic depth profiles of DMS collected: DMS is enriched in the photic zone, usually displaying a sub-surface or surface maximum, and decreases to subnanomolar levels below the photic zone. The early work of Haas (71) and Challenger $(32,35)$ on DMS and its sulfonium precursor, dimethylsulfoniopropionate (DMSP), investigated the origin of DMS in marine macroalgae, and subsequent reports on the production of DMS and DMSP by marine macro- and microalgae accumulated steadily $(1,6,30,41,69,118,140,153)$. At least four studies have documented the production of DMS from DMSP by crude algal enzyme preparations or axenic cultures of marine phytoplankton $(6,30,77,81)$. These have lent credence to the idea that in the ocean DMS is enzymatically generated, by algae, from a precursor within algae. This idea is supported by the observation that DMS covaries, in a general way, with chlorophyll $a$ in profiles and surface water transects $(7,9,11,15,16)$. However, there is considerable scatter in this correlation; Andreae and Barnard (9) can explain only $33 \%$ of the variance by a regression of DMS versus chlorophyll. This has been attributed to, variously, the uneven relationship between algal production and chlorophyll, algal speciation, physiological state of the phytoplankton, and different rates of removal for chlorophyll and DMS. Efforts to 
correlate DMS with specific phytoplankton taxa $(15,29,65,66,75,95,96,143)$ have met with somewhat more success. In particular, significant correlations are found when dinoflagellates or prymnesiophytes, especially Phaeocystis pouchetii, dominate the water column. However, in the course of these studies more persuasive correlations have become apparent. Leck et al. (95) found a correlation of DMS with copepod number in the upper 20 meters of the water column at a station in the Baltic Sea considerably more significant than the correlations with various phytoplankton species. Although particulate DMSP is arguably the most direct measure of the DMSproducing potential of an algal community, Turner et al. (143) recorded a poorer correlation $(r=0.77)$ of DMS with particulate DMSP than with dissolved DMSP $(r=0.86)$. These observations support the notion that, while DMS in seawater ultimately originates in phytoplankton DMSP, a number of processes may decouple DMS from its algal source. These include both consumption and production processes, as detailed below.

\section{Consumption processes}

Chemical and photochemical degradation. The routes and rates of DMS oxidation in the atmosphere are at this point considered fairly well-known $(10,13,114,141)$. Reaction with hydroxyl radical appears to be the dominant atmospheric sink for DMS, except in polluted areas where the reaction of ozone with $\mathrm{NO}_{x}$ leads to significant night-time formation of nitrate radical, with which DMS also reacts. Photochemical decomposition of DMS in seawater has received less attention. It is difficult to make inferences about the photolysis of aqueous-phase DMS in situ, due to its biological activity. The laboratory work to date on this problem (26) reveals 
that DMS in aqueous solution is susceptible to photooxidation, with the pattern of oxygen consumption consistent with formation of dimethylsulfoxide (DMSO). Added photosensitizers accelerate photolysis, and it was determined that North Sea coastal water contains enough natural photosensitizers that photodegradation of DMS might occur on a timescale comparable to that of ventilation. Photochemical oxidation as a sink for DMS clearly merits further attention. Studies of chemical (dark) oxidation of DMS by hydrogen peroxide and oxygen $(3,127)$ show that while DMS appears fairly stable to autoxidation, the rate of reaction with hydrogen peroxide is more rapid. However, at the low ambient concentrations of hydrogen peroxide in the surface ocean, the residence time of DMS with respect to this process is estimated at 230 days (127), considerably longer than the turnover time with respect to ventilation (estimated to be on the order of ten days or more (89)).

Bacterial consumption. A number of culture studies $(47,83,132,135,136)$ document the utilization of DMS as a carbon, energy and sulfur source by species of Thiobacillus and Hyphomicrobium. Methanogenic growth on DMS has also been reported $(61,112)$. Wakeham et al. $(152)$ demonstrated light-dependent consumption of DMS by assemblages of photosynthetic green and purple sulfur bacteria from the anoxic hypolimnion of a coastal salt pond, and subsequently Zeyer et al. (157) isolated purple phototrophic bacteria from this environment able to oxidize DMS to DMSO. Aerobic marine bacteria which utilize DMS have not been isolated. However, Kiene and Service (91) have attempted to establish the concentration dependence of this process in estuarine waters. They note that DMS uptake is generally proportional to concentration in the range studied (0-25 nM) but do not observe saturation of uptake 
activity in this range. A recent study (89) determined that DMS removal activity in the eastern tropical Pacific is antibiotic-sensitive and demonstrated enhanced consumption of DMS in response to DMS additions. Claiming specific inhibition of $\mathrm{C}_{1}$ metabolism by chloroform, these workers used chloroform treatments to separate the effects of simultaneous DMS production and consumption. This approach yields an average turnover time for DMS with respect to biological consumption in the East Pacific on the order of a few days.

\section{Production processes}

Zooplankton grazing on phytoplankton; other lytic processes. Dacey and Wakeham (44) have observed significant acceleration of DMS production in a dinoflagellate culture when copepods are added. Although the mechanism for this increase is not known, it may involve direct release of DMS from algal cells broken open during grazing, or production by bacteria in zooplankton guts or fecal matter. Available field data $(23,95)$ support the environmental significance of zooplankton grazing to DMS levels. Other lytic processes include osmolysis, senescence, mechanical disruption and virus-induced lysis. Nguyen et al. (109) report that DMS production is most rapid during the senescent phase of a diatom bloom.

Abiotic hydroxide decomposition of DMSP. Base cleavage of DMSP to form DMS and acrylic acid (33) forms the basis of the standard assay for DMSP, but the kinetics of this process were not investigated until recently (42). DMSP was determined to have a half-life of eight years with respect to hydroxide decomposition at the $\mathrm{pH}$ and temperature of seawater, indicating that this is probably not a major formation pathway for DMS in the ocean. Visscher and van Gemerden (148) have 
pointed out, however, that the $\mathrm{pH}$ in marine microbial mats during photosynthesis may get as high as 10.5 , at which point the contribution of chemical breakdown to DMS production can become significant. Other work (102) has shown that the $\mathrm{pH}$ within colonies of Phaeocystis pouchetii can exceed 9 . This may contribute significantly to DMS production by blooms of this prymnesiophyte, which number among the few instances in which DMS and chlorophyll are highly correlated on a small scale. Decomposition of DMSP to DMS by free enzyme.

Studies that have investigated the production of DMS from soluble DMSP in seawater usually examine the fate of DMSP in a $0.2 \mu \mathrm{m}$-filtered seawater control to assess abiological decomposition. In three studies $(88,143,152)$, these controls yield significant production of DMS, while autoclaved seawater displays no activity $(88,152)$. Since chemical breakdown of DMSP is too slow to explain this production, cell-free enzymatic activity is implicated (although in the study of Kiene (88), activity was attributed to bacterial contamination). In the most striking example (143), 0.2 $\mu \mathrm{m}$-filtered seawater quantitatively converted $125 \mathrm{nM}$ endogenous soluble DMSP to DMS in a day. Although Turner et al. (143) cautioned that sterile techniques were not used, the lack of an obvious lag in DMS production makes it unlikely that bacteria mediated this decomposition. The authors emphasized that the filtration itself is likely to have enhanced release of cytoplasmic enzyme into the seawater by lysing fragile algal cells, making an assessment of the true rate of cell-free DMSP-lyase activity difficult. Visual inspection of these data yields the high initial rate of DMS production in $0.2 \mu \mathrm{m}$-filtered North Sea water of $6 \mathrm{nM} \mathrm{hr}^{-1}$. Even if this is largely due to the disturbance introduced by filtration, these results afford an estimate of the 
potential for DMS production resulting from breakdown in the compartmentalization of DMSP and DMSP-lyase in algal cells, such as might arise through the lytic processes enumerated above.

Bacterial production of DMS from dissolved DMSP.

I will briefly summarize the data concerning this process, which is the subject of this thesis (a more thorough literature review is given in Section 4 of this introduction). The earliest reference to aerobic bacterial formation of DMS from DMSP appears in the Japanese literature (111), where it is noted that DMS is produced when bacteria epiphytic on Ulva pertusa are inoculated into sterile extracts of the alga. Subsequent reports document bacterial production of DMS from DMSP under anaerobic conditions in culture (149), in slurries of salt marsh and coastal marine sediments $(90,92,93)$ and in a microbial mat $(148)$. Wakeham et al. $(152)$ were the first to report aerobic bacterial conversion of DMSP to DMS, in incubations of seawater from a coastal salt pond. Shortly thereafter, Dacey and Blough (42) isolated a bacterium from seawater which cleaves DMSP to form DMS and can grow on DMSP as the sole source of carbon and energy. Further studies of aerobic microbial conversion to DMS of DMSP in estuarine water $(88,91)$ have investigated the effects of temperature, substrate concentration and various antibiotics and inhibitors on this process. These results established the existence of organisms in seawater able to break down dissolved DMSP to form DMS, and set the stage for a closer look at the mechanism and in situ rates of this process. 


\section{Dimethylsulfoniopropionate: natural occurrence and properties.}

Dimethylsulfoniopropionate (DMSP) is a tertiary sulfonium compound synthesized by certain taxa of marine algae. It is assumed to be the major precursor of DMS in marine systems via enzymatic cleavage. Some basic information about its chemistry and occurrence in natural systems is summarized below as a prelude to consideration of its function in algae and importance as a bacterial substrate.

DMSP, $\left(\mathrm{CH}_{3}\right)_{2} \mathrm{~S}^{+} \mathrm{CH}_{2} \mathrm{CH}_{2} \mathrm{COOH}$ (2-carboxyethyldimethylsulfonium), belongs to the class of tertiary sulfonium compounds, meaning that it contains a sulfur atom bonded to three carbons and bearing a positive charge. Compounds of this type are analogous to the quaternary ammonium compounds, in which the defining group consists of four bonds to a positively-charged nitrogen atom. Although chemists have been familiar with sulfonium compounds as a class since the nineteenth century, their function in a biological context was not considered seriously until the attempts of Challenger and Simpson (35) to identify the source of dimethylsulfide evolved by the red alga Polysiphonia lanosa (then referred to as P. fastigiata) (71). They isolated a sulfonium compound that was enzymatically cleaved to dimethylsulfide and acrylic acid. The same cleavage was observed to result from treatment with strong base. Although the mechanism of this reaction has not been studied in detail, the lability of the protons on the carbon $\alpha$ to the carboxyl group (153), as well as the identity of the products (42), favors an E2 elimination (Figure 1-1).

Dimethylsulfoniopropionate, also referred to as dimethyl- $\beta$-propiothetin, was the first natural sulfonium compound to be isolated (35). Its isolation coincided with a number of studies on the methylating abilities of sulfonium compounds $(32,55,103)$, 


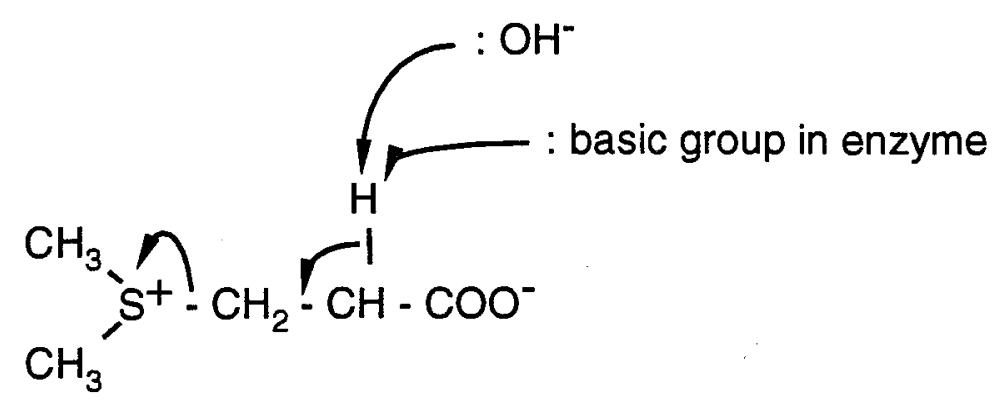

DMSP

$\mathrm{CH}_{3}{ }^{-} \mathrm{CH}_{3}$

$+\quad \mathrm{CH}_{2}=\mathrm{CHCOO}^{-}$

\section{DMS}

acrylate

Figure 1-1. Possible mechanism for cleavage of DMSP, involving deprotonation of the $\alpha$-carbon followed by elimination of dimethylsulfide. 
which highlighted their propensity for a different C-S bond cleavage, resulting in loss of a methyl group. This pathway forms the basis for the activity of S-adenosyl-Lmethionine (SAM), a ubiquitous sulfonium derivative of methionine responsible for methyl transfer in a very wide range of metabolic reactions. In this regard, DMSP has been found to act as a methyl donor to homocystine (the oxidized form of homocysteine) in both in vitro $(53)$ and in vivo $(55,103)$ studies. Few tertiary sulfonium compounds have been unequivocally isolated from natural systems. Maw (104) cites four: DMSP, S-methyl-L-methionine, S-adenosyl-L-methionine, and the decarboxylated derivative of SAM. A sulfonium analogue of phosphatidyl choline isolated from the marine diatom, Nitzschia alba (5) should be added to this list. Despite the limited number isolated to date, these compounds seem to be widespread and essential to metabolic function.

Initial isolation of DMSP from Polysiphonia lanosa (35) and other macrophytes (34) was followed by reports of its isolation from Syracosphaera (now Pleuromonas) carterae, a prymnesiophyte, and Ulva lactuca, a macrophyte member of the Chlorophyceae $(69,140)$, and from Gyrodinium cohnii, a heterotrophic dinoflagellate (77). A large number of marine unicellular phytoplankton, including representatives of the Dinophyceae, Bacillariophyceae, Chlorophyceae, Prasinophyceae and Prymnesiophyceae $(1,40,41)$ as well as numerous macrophyte representatives of the red and green algae (Rhodophyceae, Chlorophyceae) have also been found to contain DMSP (118). White (153) extended these observations to include the Phaeophyceae (brown algae). DMSP has also been identified in the tissues of a few higher plants from salt marsh or coastal habitats, namely Spartina alterniflora (43), Spartina anglica 
$(94,147)$ and Zostera marina (153)*. Motohiro (107) identified DMSP in the tissue of

North Pacific salmon and in the zooplankter that formed the salmon's principal prey.

In accord with the results of Ackman et al. (2), this suggests that at least in some instances DMSP may be transferred a considerable distance up the food chain.

\section{Algal production of DMSP.}

Synthesis of DMSP by many, but not all, species of marine algae has now been confirmed by numerous reports. An extensive compilation of the DMSP content of marine single-celled phytoplankton, representing twelve classes of algae, has been assembled (87). Dinophyceae and Prymnesiophyceae, with a few exceptions among the Bacillariophyceae and Chrysophyceae, appear to contain the most DMSP. These measurements are in accord with field results that have implicated blooms of coccolithophorids and Phaeocystis pouchetii (both prymnesiophytes) and dinoflagellates as major sources of DMS. The marine cyanobacteria, as represented by five species of Synechococcus and one Trichodesmium sp., do not produce DMSP (87). In contrast, among freshwater algae the cyanobacteria seem to be the only significant producers of DMS (117). Although the DMS precursor in freshwater algae has not been characterized, Anabaena spp., freshwater cyanobacteria, appear

* The observation that DMSP is associated with Zostera marina (eelgrass) tissues (153) should probably be interpreted with caution. Moribund, heavily epiphytized leaves of Thalassia testudinum, another sea grass, have been found to have a higher DMSP content than young, healthy leaves (J. Dacey, G. King, and P. Lobel, unpublished data), suggesting that DMSP may be associated with epiphytic algae rather than with the host plant. 
to contain DMSP (D. T. Rudnick and R. W. Howarth, personal communication). DMS emission appears greatest during the senescent phase of freshwater cyanophyte blooms $(21,79)$, although algal and bacterial production are difficult to distinguish. It seems likely that this production, regardless of the agent, is the result of enzymatic degradation, in which case the identity of the precursor is of interest. In freshwater environments a compound other than DMSP, such as S-methylmethionine or a hitherto-unidentified sulfonium compound, may act as the major precursor of DMS. In an extensive series of measurements along salinity gradients of eastern U.S. rivers, both dissolved and particulate DMSP increase non-linearly with salinity; this is concluded to be an effect of phytoplankton population dynamics rather than varying DMSP content of similar assemblages (78). This section compiles the available theoretical and experimental evidence on how and why marine algae synthesize DMSP.

\subsection{DMSP synthesis by marine algae.}

The amino acid methionine appears to be the direct precursor of DMSP in the biosynthetic pathway of marine algae. This has been demonstrated with Ulva lactuca, a chlorophyte able to take up methionine. Using radiolabelling techniques, Greene (69) has shown that Ulva incorporates the methyl- and $\alpha$ - carbons and sulfur of methionine into DMSP. By isolating the DMSP formed and subjecting it to base cleavage, he deduces that the methyl-carbon and sulfur appear in the DMS fraction and the $\alpha$-carbon in the carboxylate group of the acrylate. From double-labelling experiments, it appears possible that both of the methyls of DMSP derive from a methionine methyl. (Kahn (82) subsequently demonstrated that the 2-carbon of 
glycine, without prior incorporation into methionine, could serve as a partial source of the methyl groups of DMSP in Ulva lactuca). Greene concluded (69) that DMSP is derived from methionine by deamination, decarboxylation, oxidation and methylation, although he could not deduce the order of the sequence. He noted that $\beta$ methylthiopropionic acid, $\mathrm{CH}_{3} \mathrm{SCH}\left(\mathrm{CH}_{3}\right) \mathrm{CH}_{2} \mathrm{COOH}$, is a possible intermediate. However, Pokorny et al. (115), examining the incorporation of radiolabelled methionine into DMSP and other sulfur-containing compounds in bacteria, fungi, algae and lower and higher plants, considered this unlikely. They found $\beta$-methylthiopropionic acid as a minor product of methionine in a few lower plants, but not at all among marine algae. A hypothetical sequence of the biosynthesis of DMSP from methionine consistent with Greene's results is outlined in Figure 1-2.

The pathway of DMSP biosynthesis in unicellular algae has been characterized much less thoroughly. Ishida (77) demonstrated that the heterotrophic dinoflagellate Gyrodinium cohnii, in which DMSP may constitute up to $55 \%$ of the cell's sulfur, can incorporate the methyl carbon of acetate into the methyl(s) of DMSP; the carboxyl carbon is respired. He also showed that this organism, although capable of uptake of a number of dissolved organic compounds, is not able to take up DMSP. The role of methionine in DMSP biosynthesis was not examined in this study.

\subsection{Role of DMSP and DMS production in algal physiology.}

Ever since the original isolation of DMSP from a marine alga the physiological function of this compound has invited much speculation, but almost fifty years later still eludes consensus. However, consolidation of the large amount of data accumulated on this subject allows some general conclusions. 


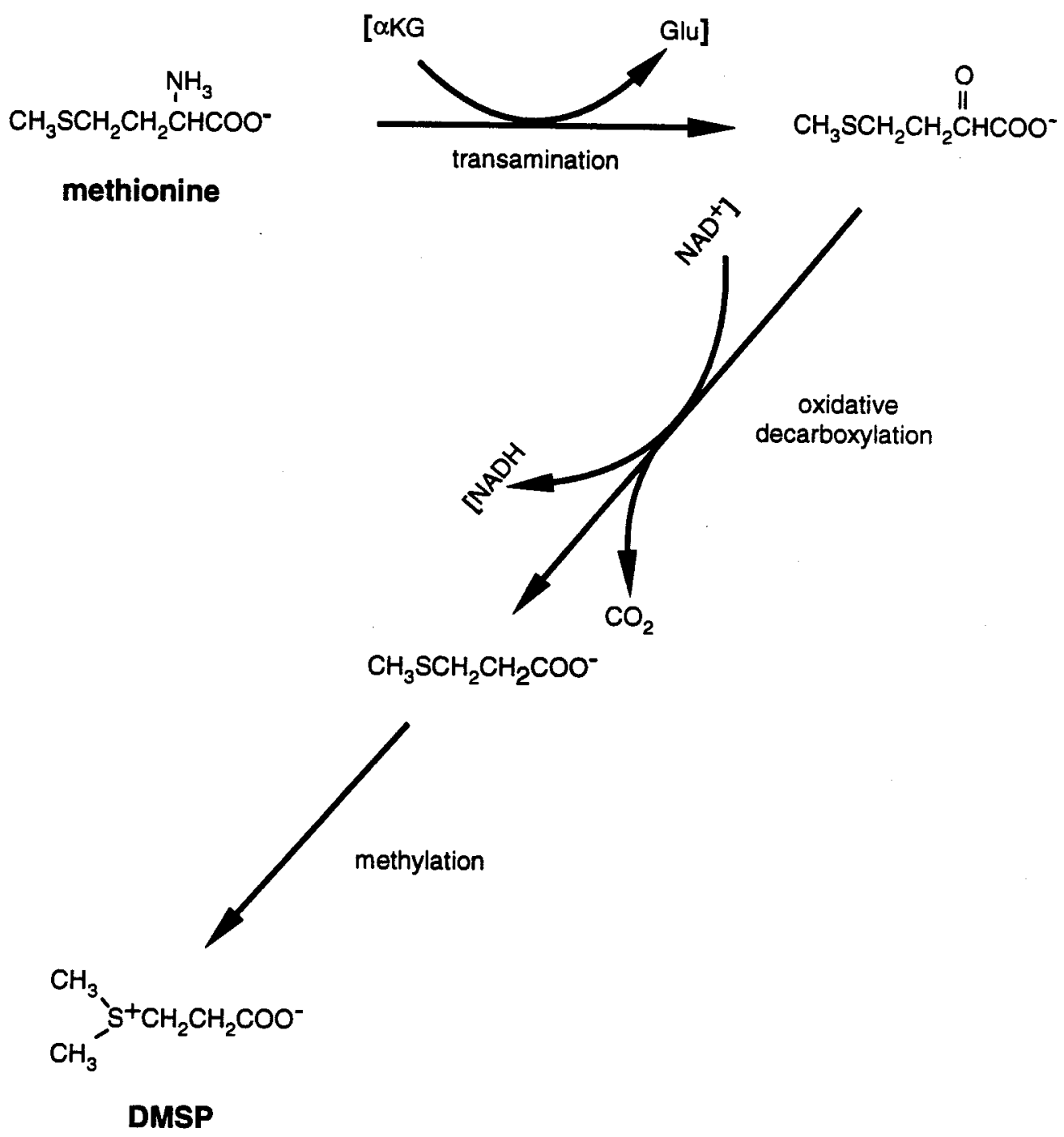

Figure 1-2. Putative pathway of DMSP synthesis in the green macroalga Ulva lactuca, after Greene (69). The sequence of reactions is uncertain. Bracketed expressions represent plausible, but hypothetical, participants in these reactions. $\alpha \mathrm{KG}=\alpha$-ketoglutarate, $\mathrm{Glu}=$ glutamate,$\quad \mathrm{NAD}^{+} / \mathrm{NADH}=$ oxidized/reduced form of nicotinamide adenine dinucleotide. 
The early observation (35) that DMSP resembles the betaines structurally prompted consideration of an osmoregulatory role for DMSP. As mentioned above, research on transmethylation by sulfonium compounds was gathering force at about the same time biogenic DMSP was first identified, and the discovery that DMSP could act as a methyl donor to homocystine in certain cases had spurred interest in its role in methylation in vivo. While I am not aware of any current research on DMSP's role as a methyl donor, speculation about its osmotic function has continued up to the present, and can be said to dominate the debate on the function of DMSP in algae. A third role for DMSP was proposed by Sieburth (129-131), who hypothesized that acrylic acid, the other product of the cleavage which produces DMS from DMSP (Figure 1-1), acts as an antibiotic in the prymnesiophyte Phaeocystis pouchetii. The evidence in favor of these three roles for DMSP is considered below. The possible function of DMSP in photoprotection (6) and buoyancy control $(6,15,146)$ has been mentioned briefly in the literature. It has also been suggested (80) that acrylate resulting from DMSP cleavage serves as a precursor of alanine in marine algae. However, due to lack of direct evidence for these hypotheses, they will not be considered here.

Acrylic acid as an antibiotic. This hypothesis originated in the observation by Sieburth (128) that certain bacteria are not active in the guts of Antarctic pygoscelid penguins. Sieburth traced this phenomenon to the euphausids which constituted the main food of the penguins, and finally to the colonial alga Phaeocystis pouchetii (129). Using bacterial bioassays, he subsequently isolated and identified the putative antibiotic agent in these algae as acrylic acid $(130,131)$. When Phaeocystis blooms, it dominates the water column biota dramatically, and acrylic acid may make up as much 
as $1-2 \%$ of its carbon $(70,130)$. In supporting experiments (76), acrylate was observed in extracts of a dinoflagellate rejected as a food source by copepods, and copepod feeding on otherwise palatable algae was suppressed by the addition of acrylate. Davidson and Marchant (46), examining the sequestering of manganese by Phaeocystis pouchetii, noted that bacteria, although present, are not significantly associated with rapidly dividing cells, but increase in number as Phaeocystis reaches stationary phase. They associated this pattern with acrylic acid production by the algae. However, since the acrylate presumably remains as algal growth slows, this could as easily be indicative of bacterial growth on the acrylate itself. In xenic algal cultures, an increase in bacterial numbers as algae near stationary phase, and excretion or leakage of dissolved organic matter accelerates, is a familiar phenomenon (22). Acrylate has been implicated as an inhibitor of D-amino acid oxidase (62) and aspects of fatty acid metabolism $(120,138)$. Sieburth himself speculated that the putative antibiotic role of acrylate is probably secondary to some other role - that of a food supply or component in the mucilage that appears to bind Phaeocystis cells into a colony. However, the DMS literature following his work often contains references to algal production of acrylic acid as a possible motivation for DMSP synthesis, and Barnard et al. (15) directly proposed that release of DMS is incidental to the production of acrylic acid as a putative antibiotic. Although acrylate may have an inhibitory effect on bacteria in some instances, many instances of bacterial uptake and metabolism are noted below (section 4), and acrylate has been determined to be an attractant for at least one bacterium (133).

DMSP as a methylating agent. Challenger (32) and Maw (104) have reviewed 
the early work on the role of DMSP as a methyl donor in transmethylation. Briefly, it has been observed $(55,103)$ that the combination of DMSP and homocystine relieves the effects of methionine deprivation in rats, as do choline, $\left(\mathrm{CH}_{3}\right)_{3} \mathrm{~N}^{+} \mathrm{CH}_{2} \mathrm{CH}_{2} \mathrm{OH}$, and betaine, $\left(\mathrm{CH}_{3}\right)_{3} \mathrm{~N}^{+} \mathrm{CH}_{2} \mathrm{COOH}$, in combination with homocystine; DMSP can transfer one of its methyl groups to homocystine in vivo to form methionine. This is not true of the sulfonium analogue of choline, and successive replacement of the methyl groups of DMSP with ethyls results in increasing loss of activity. Dubnoff and Borsook (53) demonstrated methyltransferase activity of DMSP in tissues of rat liver and kidney. Interestingly, the DMSP homolog $\left(\mathrm{CH}_{3}\right)_{2} \mathrm{~S}^{+} \mathrm{CH}_{2} \mathrm{COOH}$ (informally called dimethylthetin or sulfobetaine), which has not been found to occur naturally, also displays methylating activity in both in vitro and in vivo experiments. As expected, no DMS is produced from DMSP when it functions in this capacity.

DMSP as osmotic agent or compatible solute. Algae rely on a variety of organic solutes, in addition to inorganic ions, to maintain appropriate pressure gradients across the cell wall (turgor pressure) $(28,73)$. A number of amino acids and quaternary ammonium compounds have been identified as osmoprotective compounds in marine algae $(49,50)$, as well as in some higher plant halophytes such as Spartina spp. $(134,147,156)$. The presence of DMSP at high concentrations in many marine algae, and its structural similarity to known osmolytes, has led to examination of its function as an osmoregulant. Initial studies focused on intertidal macroalgae, which must have mechanisms for protection against frequent salinity changes and even dessication. Dickson et al. (51) have found that DMSP contributes significantly to the intracellular osmotic potential of the green macroalga Ulva lactuca, and, based on its 
response to steady-state salinity regimes, suggest that DMSP functions as a compatible solute in this organism. DMSP levels in Ulva have been demonstrated to respond mildly to sinusoidal changes in salinity, and dramatically in response to square-wavetype changes (52). No light dependence was observed. Reed (118) noted a positive relation between DMSP content and intracellular DMSP in four marine macroalgae. In the same study, he undertook an extensive screening of DMSP contents of macroalgae belonging to the Chlorophyceae, Phaeophyceae and Rhodophyceae and reported that numerous species, especially among the chlorophytes, contain "osmotically significant" (about $20 \mathrm{mmol} \mathrm{kg}^{-1}$ fresh weight) concentrations of DMSP. The contribution of other osmotica was not detailed. A more rigorous analysis of DMSP's role as an osmolyte in Polysiphonia lanosa (119) has shown that DMSP and $\mathrm{KCl}$ make up the major fraction of the internal osmotic potential in this alga, and that intracellular levels of DMSP shift in response to hyper- and hyposaline conditions, with differences between estuarine and marine isolates. Basal levels of DMSP are higher in the marine than in the estuarine strain at ambient seawater salinity. Although DMSP content increases in P. lanosa from both environments in response to upshock, DMSP content of the estuarine alga appears higher at very low $\mathrm{NaCl}$ and increases more slowly with increasing $\mathrm{NaCl}$. When these results are normalized to total cell turgor, however, this translates into a larger change in internal osmotic potential than exhibited by the marine alga. Vairavamurthy et al. (146) demonstrated that DMSP content increases in the coccolithophorid Hymenomonas (Pleuromonas) carterae in response to increased $\mathrm{NaCl}$ and sucrose, and other reports (48-50) have confirmed the behavior of DMSP as an osmolyte in a number of unicellular 
phytoplankton. Edwards et al. (56), however, saw no such adjustment of DMSP in response to salt stress in the green macroalga Enteromorpha intestinalis. The observation in Spartina anglica that DMSP does not appear to accumulate in response to increased $\mathrm{NaCl}$ has provoked the suggestion (147) that DMSP in these plants might serve some other purpose, such as a repository for excess sulfur when sulfide levels are high.

To be categorized as true "compatible solutes," organic osmotica must meet a number of criteria. Their accumulation to high cytoplasmic concentrations should not interfere with cellular metabolic function, especially enzyme activity. Studies of glycinebetaine (equivalent to "betaine," whose formula is given above) have shown that this compound is compatible with a number of essential cell functions or properties including protein synthesis, polysome stability, $\mathrm{CO}_{2}$ fixation by chloroplasts, and coupled mitochondrial oxidative phosphorylation (116,156). Accumulation of compatible solutes to high concentrations also requires a structure and polarity precluding their passive diffusion through the cell membrane. Compatible solutes should not occupy a central role in cell metabolism, yet to keep synthetic costs down they should not be too far from major metabolic pathways. DMSP meets the structural criteria of a compatible solute: its size and zwitterionic properties would be expected to result in good retention by biological membranes. If routinely synthesized from methionine, it is certainly not too far removed from major metabolic pathways. Although there are indications that acrylate is an intermediate in $\beta$-alanine synthesis in certain bacteria $(144,145)$, there is as yet no evidence that $\beta$-alanine or alanine is produced from DMSP in marine algae; DMSP does not appear to be centrally involved 
in cell metabolism.

Recently, Nishiguchi and Somero (110) examined the effect of DMSP on enzyme activity as a function of temperature and DMSP concentration. They found that DMSP acts as a compatible solute under certain conditions. It stabilizes phosphofructokinase against cold inactivation, and at a concentration of $0.2 \mathrm{M}$, also stabilizes lactate dehydrogenase (LDH) against heat inactivation. At a somewhat higher concentration of $0.3 \mathrm{M}$, however, it does not preserve $\mathrm{LDH}$ activity at all. Moreover, in the case of glutamate dehydrogenase, the presence of DMSP actually destabilizes the enzyme at all concentrations assayed. The authors have pointed out that the results of tests with individual enzymes can be misleading, since it is plausible that, in vivo, incompatibility of one compound under a given set of circumstances is masked by the accumulation of other compounds that "can restore the overall osmolyte pool of the cell to one of compatibility." Similarly, the circumstances under which any one compatible solute is able to alleviate stress are likely to vary, leading ultimately to the employment of different osmolytes, or different regulation of osmolyte function, for organisms occupying different environmental niches. The differences observed by Reed (119) between estuarine and marine isolates of Polysiphonia lanosa may be illustrative.

For the most part, these observations support the theory that the primary role of DMSP is that of an osmolyte. Despite the energetic cost of synthesizing (and catabolizing) organic osmotica, all marine algae must manufacture them; inorganic ions, although abundant and easy to transport, cannot completely satisfy the osmotic 
needs of the cell because of their potential to disrupt cell function at high physiological concentrations. Why, then, do all marine algae not synthesize DMSP, when sulfate is abundant in seawater, and nitrogen comparatively scarce? The fact that certain groups of algae regulate their osmotic potential by manipulation of nitrogen-based osmolytes may be due to differences in their nitrogen metabolism. Also, as Nishiguchi and Somero (110) emphasized, the synthesis of a particular osmoticum may be dictated by the need to complement the activity of other osmotic agents present in the cell. These considerations suggest that evolution of the ability to synthesize DMSP for osmoregulatory purposes is likely to be contingent on factors other than an abundant supply of sulfate.

This brings us to a key feature of DMSP: unlike the quaternary ammonium and amino acid osmotica, it lacks nitrogen. Some have speculated $(8,143)$ that this feature makes DMSP an attractive alternative to nitrogen-based osmolytes for algae in lownitrogen environments, a category into which large parts of the open ocean fit. Andreae (8) points out that while sulfate is energetically more expensive to assimilate than nitrate, the cost of sulfate assimilation is comparable to that of nitrogen fixation, which is not an option for most marine algae. He further notes that the nitrogenfixing cyanobacteria assayed appear not to contain DMSP. Turner et al. (143) carried out experiments to assess the potential of the coccolithophore Emiliania huxleyi to regulate DMSP synthesis in response to fluctuating nitrate levels. They showed that the per-cell complement of DMSP decreases under nitrate-replete conditions. Environmental examples of this are difficult to identify because water parcels with differing nitrate levels often have different algal assemblages, rendering them not 
directly comparable. However, in the one instance among their field data suitable for such a comparison, Turner et al. (143) found that mean cytoplasmic concentrations of DMSP were significantly higher when nitrate was lower. Leck et al. (95) note a strong inverse correlation of DMS with nitrate in the Baltic Sea, but this is difficult to distinguish from a correlation with the algal production responsible for nitrate depletion. Experiments with nitrogen-fixing freshwater cyanobacteria have indicated that the DMSP content of cultures actively fixing nitrogen is more than double that of cultures supplied with ammonium as the nitrogen source (D. T. Rudnick and R. W. Howarth, personal communication). In this context, the question remains as to why, if nitrogen limitation is assumed to motivate DMSP synthesis, and nitrogen fixation and sulfate assimilation are of comparable energy cost, algae that can fix nitrogen should synthesize DMSP at all. However, these data imply that in some cases DMSP synthesis may be nitrogen-regulated, strengthening the case for DMSP as a sulfonium substitute of $\mathrm{N}$-based osmolytes in marine algae. With regard to alternative roles for DMSP, the effects of environmental parameters, such as nitrogen availability and light $(84,85)$ on DMSP synthesis remain to be explored in detail. The search for possible sulfonium derivatives of DMSP should also be more actively pursued, especially in light of the intriguing finding that phosphatidyl choline, a major eukaryotic phospholipid component, is completely replaced with its sulfonium analogue in the marine diatom Nitzschia alba (5).

Potential explanations for the synthesis of DMSP by marine algae are offered above, but the motivation for algal cleavage of this compound to form dimethylsulfide remains to be addressed. Early work with Polysiphonia lanosa $(35,71)$ indicated that 
DMS is formed when the alga senesces, is mechanically disrupted, or experiences osmotic shock. Boiling or extraction with alcohol eliminates this activity. These observations are consistent with enzymatic cleavage activity associated with the alga. Cantoni and Anderson (30) provided conclusive evidence of this when they partially isolated from the same macrophyte an enzyme catalyzing the cleavage of DMSP to form DMS and acrylic acid. The lyase requires glutathione for activity, implying that the active site contains a cysteine residue, and has a $\mathrm{pH}$ optimum of 5.1. Smethylmethionine, S-adenosylmethionine, betaine and choline are not substrates. The enzyme also appears to be membrane-bound. Partial isolation and characterization of a DMSP-lyase from the heterotrophic dinoflagellate Gyrodinium cohnii $(77,81)$ yields a $\mathrm{pH}$ optimum for DMS production between 6 and 6.5 , although the $\mathrm{pH}$ optimum for stability of the enzyme (determined by two-hour incubations at various $\mathrm{pH}$ before assaying for lyase activity) is 5.1. $p$-Chloromercuribenzoic acid and iodoacetamide, which modify sulfhydryl groups, reversibly inhibit lyase activity; however, no mention is made of an absolute requirement for reducing power. A sodium chloride concentration of at least $0.3 \mathrm{M}$ is required for full activity, and chlorides enhance activity more effectively than other salts. A $\mathrm{K}_{\mathrm{m}}$ of $1.5 \mathrm{mM}$ was determined.

Even once it had been established that at least some algae which synthesize DMSP have the enzymatic means to break it down to DMS, the purpose of this breakdown remained mysterious. Environmental DMS production is occasionally associated with senescing algal blooms, and some uncertainty persists as to whether low-level production of DMS by healthy, growing phytoplankton is a normal metabolic function or results from stresses due to "bottle effects." Andreae (6) 
reported that axenic cultures of marine unicellular phytoplankton produce DMS during log phase growth, although no data were shown to support this contention directly. Dacey and Wakeham (44) have observed DMS production at a rate of $23 \pm 16 \mathrm{fmol}$ cell $^{-1}$ day $^{-1}$ in cultures of the dinoflagellate Gymnodinium nelsoni. Vairavamurthy et al. (146) calculated a DMS production rate of $1.3 \mathrm{fmol} \mathrm{cell}^{-1}$ day $^{-1}$ for axenic Hymenomonas carterae. They further showed that this rate increases (along with DMSP content) with increasing salinity while sulfate is held constant. Decrease in DMSP content in response to downshock is accompanied by an equivalent production of DMS. These results suggest that cleavage of DMSP to form DMS may be a way to regulate internal DMSP levels. DMS presumably diffuses out of the cell passively; there is no evidence as to the fate of the acrylic acid moiety.

Why would algae in the open ocean, which presumably do not encounter sizable salinity fluctuations, need to synthesize DMSP to regulate their osmotic potential? An ancillary question is posed by Andreae (8): why is DMSP broken down at a low but continuous rate in the absence of salinity stress, as some culture results suggest? In response to the first question, we do not have incontrovertible evidence that DMSP regulates internal osmotic potential in all algae that synthesize it. It may constitute a relatively static pool in many phytoplankton, contributing significantly to cell turgor but not necessarily changing much in response to salinity changes. In many marine algae it may be an evolutionary remnant whose original role - that of an osmoregulant as opposed to an osmoprotectant - is no longer essential, but which is still useful in an osmostatic capacity. As to the second question, it is not difficult to imagine that normal metabolic activity perpetually turns the intracellular pool of DMSP over at 
a low rate. Rather than coming to a full stop, the mechanisms that regulate synthesis and destruction of DMSP may adjust the rates of these processes up or down in response to a number of factors. An alternative explanation for continuous low levels of DMS production is that the partitioning which must be maintained within algal cells to separate the DMSP lyase from its substrate is not completely effective.

\section{Bacterial utilization of DMSP.}

In the second half of the 1980's the first published profiles and distributions of soluble (also referred to as free, extracellular or dissolved) DMSP began to appear $(143,151,152)$. These measurements revealed that free DMSP ranges between 4 and $200 \mathrm{nM}$ in seawater - concentrations that are frequently higher than those of DMS at the same sites. The lytic processes enumerated in section 1.3 are thought to account for the presence of free DMSP in seawater, since its structure and charge make passive diffusion across algal membranes unlikely. Once considered to be localized primarily in particulate matter, DMSP is now acknowledged to have a second major reservoir in the dissolved phase, which moreover appears fairly dynamic. These observations point to soluble DMSP as a potentially major precursor of marine DMS. The strong correlation between dissolved DMSP and DMS noted by Turner et al. (143) is consistent with such a role. This section reviews the available data on bacterial utilization of dissolved DMSP.

Cleavage of DMSP to form DMS. The earliest report (149) of bacterial decomposition of DMSP describes a Clostridium sp. isolated from soil by a DMSP enrichment method. This bacterium ferments DMSP to acetic acid, propionic acid, 
DMS and carbon dioxide, and can grow on DMSP supplemented with yeast extract. The authors hypothesize that cleavage of DMSP to acrylate and DMS is the first step in the reaction, analogous to the algal system (30), followed by fermentation of acrylate. While acrylate cannot be detected as an intermediate when DMSP is the substrate, the organism can ferment acrylic acid to propionic acid, acetic acid and $\mathrm{CO}_{2}$ according to the following stoichiometry:

$$
3 \mathrm{CH}_{2}=\mathrm{CHCOOH}+2 \mathrm{H}_{2} \mathrm{O} \rightarrow 2 \mathrm{CH}_{3} \mathrm{CH}_{2} \mathrm{COOH}+\mathrm{CH}_{3} \mathrm{COOH}+\mathrm{CO}_{2}
$$

Presumably, one mole of acrylic acid is hydrated to form lactic acid, oxidized to pyruvate and decarboxylated, forming acetic acid and carbon dioxide at the expense of reducing the other two moles of acrylic acid to propionic acid. Fermentation of acrylate to form a similar ratio of these products had been previously observed in Clostridium propionicum (31) and a bacterium (later named Megasphaera elsdenii) isolated from sheep rumen $(57,97)$, and aspects of the pathway elucidated by work with these organisms $(4,31,57,80,97,122,144,145)$. The finding that fermentation of $\beta$-alanine by $C$. propionicum involves initial deamination to form acrylic acid led to speculation about the reverse reaction as a pathway for alanine synthesis in algae (86), which to my knowledge has not been pursued. To date, the "acrylate pathway" (67), in which lactate is metabolized to propionate by way of an acrylyl-CoA intermediate, has not been reported in any other bacteria; the succinate-propionate pathway is used by other propionate producers.

Reports of microbial DMS production from DMSP in anoxic sediment slurries $(92,93)$ and in cyanobacteria-dominated microbial mats $(148,158)$ have confirmed the environmental occurrence of this process. While DMS is the major product of DMSP 
addition in these studies, methanethiol $\left(\mathrm{CH}_{3} \mathrm{SH}\right)$ is also produced $(90,93)$.

Investigation of aerobic, bacterially-mediated production of DMS from DMSP is relatively recent, although the first reference to this process dates back to 1951 (111). Attention focused on algal production of DMS in the fairly long hiatus that followed; over three decades passed before the study of aerobic bacterial mediation of this process began in earnest. At that time Wakeham et al. (152) carried out incubations of coastal salt pond water and seawater amended with DMSP. They observed that 30$100 \%$ of the added DMSP $(500 \mu \mathrm{M})$ is decomposed to DMS within four days. Shortly thereafter, Dacey and Blough (42) reported the isolation of an aerobic bacterium capable of rapid and quantitative conversion of DMSP to DMS. This isolate grows on acrylate as the sole source of carbon, suggesting, as in the case of the bacterium isolated by Wagner and Stadtman (149), that DMSP cleavage may be primarily a means to obtain acrylate.

The sensitivity of marine microbial DMSP cleavage to a number of inhibitors or poisons has been examined in a productive tidal creek $(88,91)$. The inhibitors tested included azide, kanamycin, vancomycin, chloroform, chloramphenicol (CAP), tetracycline (TET), and a CAP/TET combination. Inhibition of lyase activity ranges from little, in response to chloroform concentrations of $250 \mu \mathrm{M}-1.25 \mathrm{mM}$, to variable in other cases. In general, addition of these compounds does not prevent DMS production from added DMSP, but often changes the initial or overall rate. A method to inhibit DMS production or consumption would be useful for the purposes of determining the rates of these two processes in seawater, and selective inhibition of DMS consumption has been claimed for chloroform $(88,89)$. 
The effects of temperature and substrate concentration on the rate of DMS production from DMSP in the same tidal creek were also investigated (91). DMS production and DMSP consumption appear proportional to added DMSP, but kinetic parameters could not be inferred due to the fact that saturation was not observed in the concentration range assayed. The rates of these processes show a temperature dependence consistent with mediation by marine microorganisms: rates increase as a function of temperature from 4 to $30^{\circ} \mathrm{C}$, and little activity is observed at $40^{\circ} \mathrm{C}$.

How do microorganisms able to catalyze cleavage of the sulfonium bond of DMSP benefit from this reaction? No net change in the redox state of the products results: the one-electron reduction of the sulfur atom is accompanied by an equivalent oxidation of the $\alpha$-carbon. Wagner and Stadtman (149) noted that cleavage of the sulfonium bond in methyl-group transfer by S-adenosylmethionine and dimethylacetothetin (the sulfur analogue of glycinebetaine) is estimated to release a large amount of energy (54), and they speculated that this energy may be coupled to cell metabolism, especially in anaerobic organisms, by a process such as ATP synthesis. Although Wagner and Stadtman stated their intention to investigate this possibility, their attention was apparently diverted by the pathway of DMSP fermentation, and the idea does not seem to have been pursued further.

Acrylate is a demonstrated source of carbon and energy for both anaerobic $(31,97,149)$ and aerobic $(42,88)$ bacteria. Two enzymes have been identified, acrylylCoA aminase and acrylyl-CoA hydrase $(144,145)$, that highlight the role of this compound in the metabolism of some bacteria. These findings point to the procurement of acrylic acid for the satisfaction of growth and energy requirements as a 
possible motivation for DMSP cleavage by bacteria. The ability of bacteria which cleave DMSP to also take up and metabolize acrylic acid $(42,88,149)$ further suggests that evolutionary development of these capabilities may be intertwined.

Three apparently discrete bacterial enzymes which catalyze the production of DMS from sulfonium compounds have been partially purified and characterized. Two of these decompose S-methylmethionine to DMS and homoserine (105, and reference therein). One requires pyridoxyl $5^{\prime}$-phosphate for activity and appears to have a sulfhydryl at the active site, while the other requires no cofactors and is not inhibited by $p$-chloromercuribenzoate, a sulfhydryl inhibitor. The third enzyme (150) catalyzes the transfer of a methyl group from trimethylsulfonium chloride to tetrahydrofolate with the concomitant release of DMS. The DMSP-lyase in marine bacteria is distinct from these enzymes, as DMSP does not serve as a substrate in any of the three cases.

Other pathways of DMSP utilization. Kiene and Service (91) have noted that not all DMSP metabolized in incubations of estuarine water is converted to DMS. Similarly, this thesis reports that rates of DMSP loss usually exceed rates of DMS production in seawater. These data may indicate the existence of other degradation routes for DMSP. Biological demethylation of DMSP to form 3-mercaptopropionate (MPA, $\mathrm{HSCH}_{2} \mathrm{CH}_{2} \mathrm{COOH}$ ) was observed in anoxic slurries of marine coastal sediment (92). This prompted the proposal of an alternative pathway for DMSP decomposition, involving successive demethylation to form 3-methiolpropionate (MMPA, $\mathrm{CH}_{3} \mathrm{SCH}_{2} \mathrm{CH}_{2} \mathrm{COOH}$ ) and then MPA. Taylor and Gilchrist (137), working with aerobic marine bacterial isolates, confirmed this pathway and noted a branch: the demethiolation of MMPA to form MeSH. They did not observe the demethylation of 
DMS to form MeSH, which Kiene and Taylor (92) surmised constitutes the major pathway for MeSH production in anoxic sediments. In light of these findings, it is possible that the major fate of marine bacterial utilization of DMSP may not involve production of volatile sulfur.

\section{Outline of this thesis.}

I have attempted to review some of the literature on the marine cycling of DMS and its sulfonium precursor, DMSP, in the hopes of providing a background and justification for the work presented here. This thesis focuses on one aspect of DMS cycling in the water column: DMS production from dissolved DMSP by marine microbes. Chapter 2 presents evidence for the presence of DMSP-lyase activity in Vineyard Sound seawater and in marine bacteria, and sets the stage for examination of DMS production from DMSP at ambient DMSP levels. Chapters 3 and 4 examine in situ rates of DMSP loss and DMS production, and the concentration dependence of these processes, at a coastal and an oligotrophic ocean site. Chapter 3 also provides a detailed description of the analytical methods used throughout this thesis. Chapter 5 investigates the kinetics of DMSP uptake and DMS production in a bacterium isolated from Sargasso Sea water. Since nothing is known of the identity of aerobic bacteria which produce DMS from DMSP, the bacterium used for these kinetic studies was characterized physiologically and phylogenetically; this work is presented in Chapter 6. Chapter 7 summarizes the main findings and briefly speculates on their implications. 


\section{REFERENCES}

1. Ackman, R. G., C. S. Tocher, and J. McLachlan. 1966. Occurrence of dimethyl- $\beta$-propiothetin in marine phytoplankton. J. Fish. Res. Bd. Canada 23:357-364.

2. Ackman, R. G., J. Dale, and J. Hingley. 1966. Depositions of dimethyl- $\beta$ propiothetin in Atlantic cod during feeding experiments. J. Fish. Res. Bd. Canada 23:487-497.

3. Adewuyi, Y. G., and G. R. Carmichael. 1986. Kinetics of oxidation of dimethyl sulfide by hydrogen peroxide in acidic and alkaline medium. Environ. Sci. Technol. 20:1017-1022.

4. Akedo, M., C. L. Cooney, and A. J. Sinskey. 1983. Direct demonstration of lactate-acrylate interconversion by Clostridium propionicum. Bio/Technology 1:791-794.

5. Anderson, R., and M. Kates. 1976. Sulphonium analogue of lecithin in diatoms. Nature 263:51-53.

6. Andreae, M. O. 1980. The production of methylated sulfur compounds by marine phytoplankton, pp. 253-259. In: P. A. Trudinger, M. R. Walter, and B. J. Ralph (eds.), Biogeochemistry of ancient and modern environments. Springer-Verlag, New York.

7. Andreae, M. O. 1985. Dimethylsulfide in the water column and the sediment porewaters of the Peru upwelling area. Limnol. Oceanogr. 30:1208-1218.

8. Andreae, M. O. 1990. Ocean-atmosphere interactions in the global biogeochemical sulfur cycle. Mar. Chem. 30:1-29.

9. Andreae, M. O., and W. R. Barnard. 1984. The marine chemistry of dimethylsulfide. Mar. Chem. 14:267-279.

10. Andreae, M. O., R. J. Ferek, F. Bermond, K. P. Byrd, R. T. Engstrom, S. Hardin, P. D. Houmere, F. LeMarrec, and H. Raemdonck. 1985. Dimethyl sulfide in the marine atmosphere. J. Geophys. Res. 90:12891-12900.

11. Andreae, M. O., and H. Raemdonck. 1983. Dimethyl sulfide in the surface ocean and the marine atmosphere: A global view. Science 221:744-747.

12. Aneja, V. P., and J. H. Overton. 1990. The emission rate of dimethyl sulfide at the atmospheric-oceanic interface. Chem. Eng. Comm. 98:199-209. 
13. Atkinson, R., J. N. Pitts, Jr., and S. M. Aschmann. 1984. Tropospheric reactions of dimethyl sulfide with $\mathrm{NO}_{3}$ and $\mathrm{OH}$ radicals. J. Phys. Chem. 88:1584-1587.

14. Ayers, G. P., and J. L. Gras. 1991. Seasonal relationships between cloud condensation nuclei and aerosol methanesulphonate in marine air. Nature 353:834-835.

15. Barnard, W. R., M. O. Andreae, and R. L. Iverson. 1984. Dimethylsulfide and Phaeocystis pouchetii in the southeastern Bering Sea. Cont. Shelf Res. 3:103-111.

16. Barnard, W. R., M. O. Andreae, W. E. Watkins, H. Bingemer, and H.-W. Georgii. 1982. The flux of dimethylsulfide from the oceans to the atmosphere. J. Geophys. Res. 87:8787-8793.

17. Bates, T. S., R. J. Charlson, and R. H. Gammon. 1987. Evidence for the climatic role of marine biogenic sulphur. Nature 329:319-321.

18. Bates, T. S., A. D. Clarke, V. N. Kapustin, J. E. Johnson, and R. J. Charison. 1989. Oceanic dimethylsulfide and marine aerosol: Difficulties associated with assessing their covariance. Global Biogeochem. Cycles 3:299-304.

19. Bates, T. S., and J. D. Cline. 1985. The role of the ocean in a regional sulfur cycle. J. Geophys. Res. 90:9168-9172.

20. Bates, T. S., J. D. Cline, R. H. Gammon, and S. R. Kelly-Hansen. 1987. Regional and seasonal variations in the flux of oceanic dimethylsulfide to the atmosphere. J. Geophys. Res. 92:2930-2938.

21. Bechard, M. J., and W. R. Rayburn. 1979. Volatile organic sulfides from freshwater algae. J. Phycol. 15:379-383.

22. Bell, W., and R. Mitchell. 1972. Chemotactic and growth responses of marine bacteria to algal extracellular products. Biol. Bull. 143:265-277.

23. Belviso, S., S.-K. Kim, R. Rassoulzadegan, B. Krajika, B. C. Nguyen, N. Mihalopoulos, and P. Buat-Menard. 1990. Production of dimethylsulfonium propionate (DMSP) and dimethylsulfide (DMS) by a microbial food web. Limnol. Oceanogr. 35:1810-1821.

24. Berresheim, H. 1987. Biogenic sulfur emissions from the Subantarctic and Antarctic oceans. J. Geophys. Res. 92:13245-13262.

25. Bolin, B., and R. J. Charlson. 1978. On the role of the trophospheric sulfur cycle in the shortwave radiative climate of the earth. Ambio 5:47-54. 
26. Brimblecombe, P., and D. Shooter. 1986. Photo-oxidation of dimethylsulphide in aqueous solution. Mar. Chem. 19:343-353.

27. Broecker, W. S., and T. H. Peng. 1974. Gas exchange rates between air and sea. Tellus 26:21-35.

28. Brown, L. M., and J. A. Hellebust. 1980. The contribution of organic solutes to osmotic balance in some green and eustigmatophyte algae. J. Phycol. 16:265-270.

29. Burgermeister, S., R. L. Zimmermann, H.-W. Georgii, H. G. Bingemer, G. O. Kirst, M. Janssen, and W. Ernst. 1990. On the biogenic origin of dimethylsulfide: Relation between chlorophyll, ATP, organismic DMSP, phytoplankton species, and DMS distribution in Atlantic surface water and atmosphere. J. Geophys. Res. 95:20607-20615.

30. Cantoni, G. L., and D. G. Anderson. 1956. Enzymatic cleavage of dimethylpropiothetin by Polysiphonia lanosa. J. Biol. Chem. 222:171-177.

31. Cardon, B. P., and H. A. Barker. 1947. Amino acid fermentations by Clostridium propionicum and Diplococcus glycinophilus. Arch. Biochem. 12:165-180.

32. Challenger, F. 1951. Biological methylation. Adv. Enzymol. 12:429-491.

33. Challenger, F. 1959. Aspects of the organic chemistry of sulfur, pp. 33-34. Academic Press, London.

34. Challenger, F., R. Bywood, P. Thomas, and B. J. Hayward. 1957. The natural occurrence and chemical reactions of some thetins. Arch. Biochem. Biophys. 69:514-523.

35. Challenger, F., and M. I. Simpson. 1948. Studies on biological methylation. Part XII. J. Chem. Soc. 1948:1591-1597.

36. Charlson, R. J., J. E. Lovelock, M. O. Andreae, and S. G. Warren. 1987. Oceanic phytoplankton, atmospheric sulphur, cloud albedo and climate. Nature 326:655-661.

37. Charlson, R. J., J. E. Lovelock, M. O. Andreae, and S. G. Warren. 1989. Sulphate aerosols and climate. Nature 340:437-438.

38. Cline, J. D., and T. S. Bates. 1983. Dimethyl sulfide in the equatorial Pacific ocean: A natural source of sulfur to the atmosphere. Geophys. Res. Let. 10:949-952. 
39. Cooper, D. J., and E. S. Saltzman. Ocean-atmosphere exchange of dimethylsulfide: An evaluation of current field data. J. Geophys. Res. (Atmospheres), submitted.

40. Craigie, J. S., J. McLachlan, W. Majak, R. G. Ackman, and C. S. Tocher. 1966. Photosynthesis in algae. II. Green algae with special reference to Dunaliella spp. and Tetraselmis spp. Can J. Bot. 44:1247-1254.

41. Craigie, J. S., J. McLachlan, R. G. Ackman, and C. S. Tocher. 1967. Photosynthesis in algae. III. Distribution of soluble carbohydrates and dimethyl$\beta$-propiothetin in marine unicellular Chlorophyceae and Prasinophyceae. Can. J. Bot. 45:1327-1334.

42. Dacey, J. W. H., and N. V. Blough. 1987. Hydroxide decomposition of dimethylsulfoniopropionate to form dimethylsulfide. Geophys. Res. Let. 14:1246-1249.

43. Dacey, J. W. H., G. M. King, and S. G. Wakeham. 1987. Factors controlling emission of dimethylsulphide from salt marshes. Nature 330:643-645.

44. Dacey, J. W. H., and S. G. Wakeham. 1986. Oceanic dimethylsulfide: Production during zooplankton grazing on phytoplankton. Science 233:1314-1316.

45. Dacey, J. W. H., S. G. Wakeham, and B. L. Howes. 1984. Henry's Law constants for dimethylsulfide in freshwater and seawater. Geophys. Res. Let. 11:991-994.

46. Davidson, A. T., and H. J. Marchant. 1987. Binding of manganese by Antarctic Phaeocystis pouchetii and the role of bacteria in its release. Mar. Biol. 95:481-487.

47. De Bont, J. A. M., J. P. Van Dijken, and W. Harder. 1981. Dimethyl sulphoxide and dimethyl sulphide as a carbon, sulphur and energy source for growth of Hyphomicrobium S. J. Gen. Microbiol. 127:315-323.

48. Dickson, D. M. J., and G. O. Kirst. 1986. The role of $\beta$-dimethylsulfoniopropionate, glycine betaine and homarine in the osmoacclimation of Platymonas subcordiformis. Planta 167:536-543.

49. Dickson, D. M., and G. O. Kirst. 1987a. Osmotic adjustment in marine eukaryotic algae: The role of inorganic ions, quaternary ammonium, tertiary sulphonium and carbohydrate solutes I. Diatoms and a rhodophyte. New Phytol. 106:645-655. 
50. Dickson, D. M., and G. O. Kirst. 1987b. Osmotic adjustment in marine eukaryotic algae: The role of inorganic ions, quaternary ammonium, tertiary sulphonium and carbohydrate solutes II. Prasinophytes and haptophytes. New Phytol. 106:657-666.

51. Dickson, D. M., R. G. Wyn Jones, and J. Davenport. 1980. Steady state osmotic adaptation in Ulva lactuca. Planta 150:158-165.

52. Dickson, D. M. J., R. G. Wyn Jones and J. Davenport. 1982. Osmotic adaptation in Ulva lactuca under fluctuating salinity regimes. Planta 155:409-415.

53. Dubnoff, J. W., and H. Borsook. 1948. Dimethylthetin and dimethyl- $\beta$ propiothetin in methionine synthesis. J. Biol. Chem. 176:789-796.

54. Durrell, J., and J. M. Sturtevant. 1957. The synthesis of methionine by enzymic transmethylation. II. Enthalpy change in the methyl-transfer from dimethylacetothetin. Biochim. Biophys. Acta 26:282-286.

55. Du Vigneaud, V., A. W. Moyer, and J. P. Chandler. 1948. Dimethylthetin as a biological methyl donor. J. Biol. Chem. 174:477-480.

56. Edwards, D. M., R. H. Reed, J. A. Chudek, R. Roster, and W. D. P. Stewart. 1987. Organic solute accumulation in osmotically-stressed Enteromorpha intestinalis. Mar. Biol. 95:583-592.

57. Elsden, S. R., B. E. Volcani, F. M. C. Gilchrist, and D. Lewis. 1956. Properties of a fatty acid forming organism isolated from the rumen of sheep. J. Bacteriol. 72:681-689.

58. Erickson, D. J., S. J. Ghan, and J. E. Penner. 1990. Global ocean-toatmosphere dimethyl sulfide flux. J. Geophys. Res. 95:7543-7552.

59. Eriksson, E. 1963. The yearly circulation of sulfur in nature. J. Geophys. Res. 68:4001-4008.

60. Falkowski, P. G., Y. Kim, Z. Kolber, C. Wilson, C. Wirick, and R. Cess. 1992. Natural versus anthropogenic factors affecting low-level cloud albedo over the North Atlantic. Science 256:1311-1313.

61. Finster, K., Y. Tanimoto, and F. Bak. 1992. Fermentation of methanethiol and dimethylsulfide by a newly isolated methanogenic bacterium. Arch. Microbiol. 157:425-430. 
62. Frisell, W. R., H. J. Lowe, and L. Hellerman. 1956. Flavoenzyme catalysis. Substrate-competitive inhibition of D-amino acid oxidase. J. Biol. Chem. 223:75-83.

63. Gavin, J., G. Kukla, and T. Karl. 1989. Sulphate aerosols and climate. Nature 340:438.

64. Ghan, S. J., J. E. Penner, and K. E. Taylor, ibid.

65. Gibson, J. A. E., R. C. Garrick, H. R. Burton, and A. R. McTaggart. 1988. Dimethylsulfide concentrations in the ocean close to the Antarctic continent. Geomicrobiol. J. 6:179-184.

66. Gibson, J. A. E., R. C. Garrick, H. R. Burton, and A. R. McTaggart. 1990. Dimethylsulfide and the alga Phaeocystis pouchetii in Antarctic coastal waters. Mar. Biol. 104:339-346.

67. Gottschalk, G. 1986. Bacterial metabolism, pp. 242-244. Springer-Verlag, New York.

68. Granat, L., H. Rodhe, and R. U. Hallberg. 1976. The global sulfur cycle. In: B. H. Svensson and R. Soderland (eds.), Nitrogen, phosphorus, and sulfur global cycles, Ecol. Bull. Stockholm 22:89-134.

69. Greene, R. C. 1962. Biosynthesis of dimethyl- $\beta$-propiothetin. J. Biol. Chem. 237:2251-2254.

70. Guillard, R. R. L., and J. A. Hellebust. 1971. Growth and the production of extracellular substances by two strains of Phaeocystis pouchetii. J. Phycol. 7:330-338.

71. Haas, P. 1935. The liberation of methyl sulfide in seaweed. Biochem. J. 29:1297-1299.

72. Hayduk, W., and H. Laudie. 1974. Prediction of diffusion coefficients for nonelectrolytes in dilute aqueous solutions. Am. Ind. Chem. Eng. J. 20:611-615.

73. Hellebust, J.A. 1976. Osmoregulation. Ann. Rev. Plant Physiol. 27:485-505.

74. Henderson-Sellers, A., and K. McGuffie. 1989. Sulphate aerosols and climate. Nature 340:436-437.

75. Holligan, P. M., S. M. Turner, and P. S. Liss. 1987. Measurements of dimethyl sulphide in frontal regions. Cont. Shelf Res. 7:213-224. 
76. Huntley, M., R. Capon, V. Marin, P. Sykes, J. Jordan, K. Barthel, and S. Rohan. 1983. Acrylic acid in a dinoflagellate suppresses copepod feeding. EOS 64:1036.

77. Ishida, Y. 1968. Physiological studies on evolution of dimethyl sulfide from unicellular marine algae. Mem. Coll. Agric. Kyoto 94:47-82.

78. Iverson, R. L., F. L. Nearhoof, and M. O. Andreae. 1989. Production of dimethylsulfonium propionate and dimethylsulfide by phytoplankton in estuarine and coastal waters. Limnol. Oceanogr. 34:53-67.

79. Jenkins, D., L. L. Medsker, and J. F. Thomas. 1967. Odorous compounds in natural waters. Some sulfur compounds associated with blue-green algae. Environ. Sci. Technol. 1:731-735.

80. Johns, A. T. 1952. The mechanism of propionic acid formation by Clostridium propionicum. J. Gen. Microbiol. 6:123-127.

81. Kadota, H., and Y. Ishida. 1968. Effect of salts on enzymatical production of dimethyl sulfide from Gyrodinium cohnii. Bull. Jap. Soc. Sci. Fish. 34:512-518.

82. Kahn, V. 1963. Glycine as a methyl donor in dimethyl- $\beta$-propiothetin synthesis. J. Exp. Bot. 15:225-231.

83. Kanagawa, T., and D. P. Kelly. 1986. Breakdown of dimethyl sulphide by mixed cultures and by Thiobacillus thioparus. FEMS Microbiol. Let. 34:13-19.

84. Karsten, U., C. Wiencke, and G. O. Kirst. 1990. The $\beta$-dimethylsulphoniopropionate (DMSP) content of macroalgae from Antarctica and Southern Chile. Botanica Mar. 33:143-146.

85. Karsten, U., C. Wiencke, and G. O. Kirst. 1991. Growth pattern and $\beta$-dimethylsulphoniopropionate (DMSP) content of green macroalgae at different irradiances. Mar. Biol. 108:151-155.

86. Katayama, T. 1964. Biochemical significance of the existence of acrylic acid in algae. Bull. Jap. Soc. Phycol. 12:14-19.

87. Keller, M. D., W. K. Bellows, and R. R. L. Guillard. 1988. The importance of taxonomy in the production of dimethyl sulfide by marine phytoplankton, pp. 167-182. In: E. S. Saltzman and W. J. Cooper (eds.), Biogenic sulfur in the environment. ACS Symposium Ser. 393, American Chemical Society, Washington, D.C. 
88. Kiene, R. P. 1990. Dimethyl sulfide production from dimethylsulfoniopropionate in coastal seawater samples and bacterial cultures. Appl. Environ. Microbiol. 56:3292-3297.

89. Kiene, R. P., and T. S. Bates. 1990. Biological removal of dimethyl sulphide from sea water. Nature 345:702-705.

90. Kiene, R. P., and D. G. Capone. 1988. Microbial transformations of methylated sulfur compounds in anoxic salt marsh sediments. Microb. Ecol. 15:275-291.

91. Kiene, R. P., and S. K. Service. 1991. Decomposition of dissolved DMSP and DMS in estuarine waters: dependence on temperature and substrate concentration. Mar. Ecol. Prog. Ser. 76:1-11.

92. Kiene, R. P., and B. F. Taylor. 1988. Demethylation of dimethylsulfoniopropionate and production of thiols in anoxic marine sediments. Appl. Environ. Microbiol. 54:2208-2212.

93. Kiene, R. P., and P. T. Visscher. 1987. Production and fate of methylated sulfur compounds from methionine and dimethylsulfoniopropionate in anoxic salt marsh sediments. Appl. Environ. Microbiol. 53:2426-2434.

94. Larher, F., J. Hamelin, and G. R. Stewart. 1977. L'acide dimethylsulfonium-5 pentanoique de Spartina anglica. Phytochem. 16:2019-2020.

95. Leck, C., U. Larsson, L. E. Bagander, S. Johannson, and S. Hajdu. 1990. DMS in the Baltic Sea: Annual variability in relation to biological activity. J. Geophys. Res. 95:3353-3363.

96. Leck, C., and H. Rodhe. 1991. Emissions of marine biogenic sulfur to the atmosphere of northern Europe. J. Atm. Chem. 12:63-86.

97. Lewis, D., and S. R. Elsden. 1955. The fermentation of L-threonine, L-serine, L-cysteine and acrylic acid by a Gram-negative coccus. Biochem. J. 60:683-692.

98. Liss, P.S. 1973. Processes of gas exchange across an air-water interface. Deep-Sea Res. 20:221-238.

99. Liss, P. S., and L. Merlivat. 1986. Air-sea exchange rates: Introduction and synthesis, pp. 113-127. In: P. Buat-Menard (ed.), The role of air-sea exchange in geochemical cycling, D. Reidel, Hingham, MA.

100. Liss, P. S., and P. G. Slater. 1974. Flux of gases across the air-sea interface. Nature 247:181-184. 
101. Lovelock, J. E., R. J. Maggs, and R. A. Rasmussen. 1972. Atmospheric dimethyl sulphide and the natural sulphur cycle. Nature 237:452-453.

102. Lubbers, G. W., W. W. C. Gieskes, P. del Castillo, W. Salomons, and J. Bril. 1990. Manganese accumulation in the high $\mathrm{pH}$ microenvironment of Phaeocystis sp. (Haptophyceae) colonies. Mar. Ecol. Prog. Ser. 59:285-293.

103. Maw, G. A., and V. du Vigneaud. 1948. Compounds related to dimethylthetin as sources of labile methyl groups. J. Biol. Chem. 176:1037-1045.

104. Maw, G. A. 1981. The biochemistry of sulphonium salts, pp. 703-770. In: C. J. M. Stirling and S. Patai (eds.), The chemistry of the sulphonium group, John Wiley \& Sons Ltd., New York.

105. Mazelis, M., B. Levin, and N. Mallinson. 1965. Decomposition of methyl methionine sulfonium salts by a bacterial enzyme. Biochim. Biophys. Acta 105:106-114.

106. Meszaros, E. 1988. On the possible role of the biosphere in the control of atmospheric clouds and precipitation. Atmos. Environ. 22:423-424.

107. Motohiro, T. 1962. Studies on the petroleum odour in canned chum salmon. Mem. Fac. Fish., Hokkaido Univ. 10:1-65.

108. Nguyen, B. C., A. Gaudry, B. Bonsang, and G. Lambert. 1978. Reevaluation of the role of dimethyl sulphide in the sulphur budget. Nature 275:637-639.

109. Nguyen, B. C., S. Belviso, N. Mihalopoulos, J. Gostan, and P. Nival. 1988. Dimethyl sulfide production during natural phytoplankton blooms. Mar. Chem. 24:133-141.

110. Nishiguchi, M. K., and G. N. Somero. 1992. Temperature- and concentration dependence of compatibility of the organic osmolyte $\beta$-dimethylsulfoniopropionate. Cryobiol. 29:118-124.

111. Obata, Y., H. Igarashi, and K. Matano. 1951. Studies on the flavor of seaweeds (I). On the component of flavor of some green algae. Bull. Jap. Soc. Sci. Fish. 17:60-62.

112. Oremland, R. S., R. P. Kiene, I. Mathrani, M. J. Whiticar, and D. R. Boone. 1989. Description of an estuarine methylotrophic methanogen which grows on dimethyl sulfide. Appl. Environ. Microbiol. 55:994-1002.

113. Othmer, D. F., and M. S. Thakar. 1953. Correlating diffusion coefficients in liquids. Ind. Eng. Chem. 45:589-593. 
114. Plane, J. M. C. 1989. Gas-phase atmospheric oxidation of biogenic sulfur compounds: A review, pp. 404-423. In: E. S. Saltzman and W. J. Cooper (eds.), Biogenic sulfur in the environment. ACS Symposium Ser. 393, American Chemical Society, Washington, D.C.

115. Pokorny, M., E. Marcenko, and D. Keglevic. 1970. Comparative studies of L- and D-methionine metabolism in lower and higher plants. Phytochem. 9:2175-2188.

116. Pollard, A., and R. G. Wyn Jones. 1979. Enzyme activities in concentrated solutions of glycinebetaine and other solutes. Planta 144:291-298.

117. Rasmussen, R. A. 1974. Emission of biogenic hydrogen sulfide. Tellus 26:254-260.

118. Reed, R. H. 1983. Measurement and osmotic significance of $\beta$-dimethylsulfoniopropionate in marine macroalgae. Mar. Biol. Lett. 4:173-181.

119. Reed, R. H. 1983. The osmotic responses of Polysiphonia lanosa (L.) Tandy from marine and estuarine sites: Evidence for incomplete recovery of turgor. J. Exp. Mar. Biol. Ecol. 68:169-193.

120. Robinson, J. D., R. O. Brady, and R. M. Bradley. 1963. Biosynthesis of fatty acids: IV. Studies with inhibitors. J. Lipid Res. 4:144-150.

121. Saltzman, E. S., K. Holmen, and D. J. Cooper. 1988. Measurement of the piston velocity of dimethylsulfide: Implications for its sea/air exchange. EOS 69:1073.

122. Sanseverino, J., B. S. Montenecourt, and J. A. Sands. 1989. Detection of acrylic acid formation in Megasphaera elsdenii in the presence of 3-butynoic acid. Appl. Microbiol. Biotechnol. 30:239-242.

123. Savoie, D. L., and J. M. Prospero. 1989. Comparison of oceanic and continental sources of non-sea-salt sulphate over the Pacific Ocean. Nature 339:685-687.

124. Schwartz, S. E. 1988. Are global cloud albedo and climate controlled by marine phytoplankton? Nature 336:441-445.

125. Shaw, G. E. 1983. Bio-controlled thermostasis involving the sulfur cycle. Climatic Change 5:297-303.

126. Shaw, G. E. 1987. Aerosols as climate regulators: A climate-biosphere linkage? Atmos. Environ. 21:985-986. 
127. Shooter, D., and P. Brimblecombe. 1989. Dimethylsulphide oxidation in the ocean. Deep-Sea Res. 36:577-585.

128. Sieburth, J. M. 1959. Gastrointestinal microflora of Antarctic birds. J. Bacteriol. 77:521-531.

129. Sieburth, J. M. 1959. Antibacterial activity of Antarctic marine phytoplankton. Limnol. Oceanogr. 4:419-424.

130. Sieburth, J. M. 1960. Acrylic acid, an "antibiotic" principle in Phaeocystis blooms in Antarctic waters. Science 132:676-677.

131. Sieburth, J. M. 1961. Antibiotic properties of acrylic acid, a factor in the gastrointestinal antibiosis of polar marine animals. J. Bacteriol. 82:72-79.

132. Sivelä, S., and V. Sundman. 1975. Demonstration of Thiobacillus-type bacteria, which utilize methyl sulphides. Arch. Microbiol. 103:303-304.

133. Sjoblad, R. D., and R. Mitchell. 1979. Chemotactic responses of Vibrio alginolyticus to algal extracellular products. Can. J. Microbiol. 25:964-967.

134. Stewart, G. R., and J. A. Lee. 1974. The role of proline accumulation in halophytes. Planta 120:279-289.

135. Suylen, G. M. H., and J. G. Kuenen. 1986. Chemostat enrichment and isolation of Hyphomicrobium EG. Antonie van Leeuwenhoek 52:281-293.

136. Suylen, G. M. H., G. C. Stefess, and J. G. Kuenen. 1986. Chemolithotrophic potential of a Hyphomicrobium species, capable of growth on methylated sulphur compounds. Arch. Microbiol. 146:192-198.

137. Taylor, B. F., and D. C. Gilchrist. 1991. New routes for aerobic biodegradation of dimethylsulfoniopropionate. Appl. Environ. Microbiol. 57:3581-3584.

138. Thijsse, G. J. E. 1964. Fatty-acid accumulation by acrylate inhibition of $\beta$-oxidation in an alkane-oxidizing Pseudomonas. Biochim. Biophys. Acta 84:195-197.

139. Thompson, A. M., W. E. Esaias, and R. L. Iverson. 1990. Two approaches to determining the sea-to-air flux of dimethyl sulfide: Satellite ocean color and a photochemical model with atmospheric measurements. J. Geophys. Res. 95:20551-20558. 
140. Tocher, C. S., R. G. Ackman, and J. McLachlan. 1966. The identification of dimethyl- $\beta$-propiothetin in the algae Syracosphaera carterae and Ulva lactuca. Can. J. Biochem. 44:519-522.

141. Toon, O. B., J. F. Kasting, R. P. Turco, and M. S. Liu. 1987. The sulfur cycle in the marine atmosphere. J. Geophys. Res. 92:943-963.

142. Turner, S. M., and P. S. Liss. Measurement of various sulphur gases in a coastal marine environment. J. Atm. Chem. 2:223-232.

143. Turner, S. M., G. Malin, P. S. Liss, D. S. Harbour, and P. M. Holligan. 1988. The seasonal variation of dimethyl sulfide and dimethylsulfoniopropionate concentrations in nearshore waters. Limnol. Oceanogr. 33:364-375.

144. Vagelos, P. R., J. M. Earl, and E. R. Stadtman. 1959. Propionic acid metabolism I. The purification and properties of acrylyl coenzyme A aminase.

J. Biol. Chem. 234:490-497.

145. Vagelos, P. R., J. M. Earl, and E. R. Stadtman. 1959. Propionic acid metabolism II. Enzymatic synthesis of lactyl pantetheine. Ibid, 765-769.

146. Vairavamurthy, A., M. O. Andreae, and R. L. Iverson. 1985. Biosynthesis of dimethylsulfide and dimethylpropiothetin by Hymenomonas carterae in relation to sulfur source and salinity variations. Limnol. Oceanogr. 30:59-70.

147. Van Diggelen, J., J. Rozema, D. M. J. Dickson, and R. Broekman. 1986. $\beta$-3-Dimethylsulphoniopropionate, proline and quaternary ammonium compounds in Spartina anglica in relation to sodium chloride, nitrogen and sulphur. New Phytol. 103:573-586.

148. Visscher, P. T., and H. van Gemerden. 1991. Production and consumption of dimethylsulfoniopropionate in marine microbial mats. Appl. Environ. Microbiol. 57:3237-3242.

149. Wagner, C., and E. R. Stadtman. 1962. Bacterial fermentation of dimethyl- $\beta$-propiothetin. Arch. Biochem. Biophys. 98:331-336.

150. Wagner, C., S. M. Lusty, Jr., H.-F. Kung, and N. L. Rogers. 1967. Preparation and properties of trimethylsulfonium-tetrahydrofolate methyltransferase. J. Biol. Chem. 242:1287-1293.

151. Wakeham, S. G., and J. W. H. Dacey. 1989. Biogeochemical cycling of dimethyl sulfide in marine environments, pp. 152-166. In: E. S. Saltzman and W. J. Cooper (eds.), Biogenic Sulfur in the Environment. ACS Symposium Ser. 393, American Chemical Society, Washington, D.C. 
152. Wakeham, S. G., B. L. Howes, J. W. H. Dacey, R. P. Schwarzenbach, and J. Zeyer. 1987. Biogeochemical cycling of dimethyl sulfide in a seasonally stratified coastal salt pond. Geochim. Cosmochim. Acta 51:1675-1684.

153. White, R. H. 1982. Analysis of dimethyl sulfonium compounds in marine algae. J. Mar. Res. 40:529-536.

154. Wigley, T. M. L. 1989. Possible climate change due to $\mathrm{SO}_{2}$-derived cloud condensation nuclei. Nature 339:365-367.

155. Wilke, C. R., and P. Chang. 1955. Correlation of diffusion coefficients in dilute solutions. Am. Ind. Chem. Eng. J. 1:264-270.

156. Wyn Jones, R. G., and R. Storey. 1981. Betaines, pp. 171-204. In: L. G. Paleg and D. Aspinall (eds.), The physiology and biochemistry of drought resistance in plants, Academic Press, Sydney.

157. Zeyer, J., P. Eicher, S. G. Wakeham, and R. P. Schwarzenbach. 1987. Oxidation of dimethylsulfide to dimethylsulfoxide by phototrophic purple bacteria. Appl. Environ. Microbiol. 53:2026-2032.

158. Zinder, S. H., W. N. Doemel, and T. D. Brock. 1977. Production of volatile sulfur compounds during the decomposition of algal mats. Appl. Environ. Microbiol. 34:859-860. 


\section{CHAPTER 2}

\section{A PRELIMINARY ASSESSMENT OF DMSP-LYASE ACTIVITY IN NATURAL SEAWATER}

Microbial decomposition of dissolved dimethylsulfoniopropionate (DMSP) to form dimethylsulfide (DMS) has only recently begun to be considered a viable mechanism for DMS production in seawater. The first account of aerobic microbial production of DMS from dissolved DMSP in the marine environment was provided by Wakeham et al. (35), who observed rapid turnover of DMSP and DMS in incubation experiments with coastal salt pond water. Shortly thereafter, Dacey and Blough (4) reported that, while abiotic cleavage of DMSP to DMS was unlikely to contribute significantly to oceanic DMS levels, they had isolated a bacterium able to mediate this conversion rapidly. Turner et al. (30) demonstrated that considerable dissolved DMSP (5-200 $\mathrm{nM})$ is present in coastal seawater and subject to decomposition to DMS, presumably enzymatic, on extremely short timescales. These reports provided the initial motivation for the investigation of marine microbial production of DMS from DMSP undertaken in this thesis. Since then, other work has confirmed the environmental importance of this process $(17,19,33)$.

This chapter is intended to provide a transition into the field data presented in Chapters 3 and 4, which examine microbial DMSP cleavage at low substrate concentrations with the aim of determining in situ turnover times for both DMS and DMSP. Preliminary incubation experiments using high-level (hundreds of nanomolar to micromolar) DMSP additions were carried out to assess the ubiquity of DMSP-lyase 
activity in marine environments and in well-characterized marine bacteria and marine bacterial isolates. (The term "DMSP-lyase activity" here denotes cleavage of dissolved, extracellular DMSP to form DMS, as distinct from algal DMSP-lyase activity, in which intracellular pools of DMSP are transformed.) The potential of DMS to itself act as a substrate for marine microbes, and the feasibility of selective inhibition of microbial DMS consumption, are briefly commented on.

\section{Materials and methods}

Analytical. Volatile sulfur compounds were separated and detected as described in Chapter 3, with the exception that a SRI 8610 gas chromatograph was used instead of a Varian 3700 for analysis of James Bay and Sargasso Sea samples. The column temperature was $74^{\circ} \mathrm{C}$. DMS levels in most incubation experiments were high enough to permit analysis of headspace. When this was the case, $0.25-1 \mathrm{~mL}$ headspace was withdrawn by gas-sampling syringe from serum bottles and injected directly onto the column. Otherwise, the preconcentration method outlined in Chapter 3 was used, with slight modifications, as follow, for James Bay and Sargasso Sea timecourses. Water samples were stripped with helium at a flow rate of $50-70 \mathrm{~mL} \mathrm{~min}{ }^{-1}$, and DMS cryofocused in a 1/4" Teflon (FEP) loop packed with glass beads, submerged in liquid nitrogen. Water was removed from the sample flow by passage through a glass tube containing $\mathrm{KOH}$ pellets. When the sample was injected, the loop was manually transferred to hot water $\left(100^{\circ} \mathrm{C}\right)$. Aqueous DMS standards were prepared as described in Chapter 3. The presence of methanethiol (MeSH) in some experiments was confirmed by comparison of its retention time with that of genuine MeSH. However, 
stable MeSH standards could not be prepared due to apparently rapid removal of this compound, possibly via abiotic oxidation to dimethyldisulfide (DMDS). DMDS, also identified by coelution with genuine dimethyldisulfide, was present whenever MeSH was detected. Because thiols react with base, MeSH would not be expected to be detected when $\mathrm{KOH}$ was used to dry the sample stream. Since MeSH could be detected only when its rate of production exceeded that of oxidation, MeSH signals recorded here are assumed to be lower limits.

For analysis of soluble DMSP, water samples were filtered through $0.2 \mu \mathrm{m}$ Gelman Supor-200 membrane filters or Whatman GF/F (glass fiber) filters, stripped of DMS by bubbling with helium or nitrogen, amended with $16 \mathrm{~N} \mathrm{KOH}$ to a final concentration of $2 \mathrm{~N}$ and allowed to react for six hours at room temperature. For particulate DMSP analysis, the filter was suspended in $2 \mathrm{~N} \mathrm{KOH}$ and allowed to react overnight to ensure that cellular DMSP was completely released and decomposed. These treatments quantitatively converted DMSP to DMS, which was then analyzed as above. Standards for DMSP samples were made up by preparing DMS standards in base-amended seawater, for soluble DMSP, or in $2 \mathrm{~N} \mathrm{KOH}$ containing the appropriate filter, for particulate DMSP.

Sampling. Seawater was collected in a $10-\mathrm{L}$ acid-washed carboy or $1-\mathrm{L}$ acidwashed polycarbonate screwtop flask. Vineyard Sound seawater was collected from a pier in Woods Hole, MA. Surface Sargasso Sea water was obtained by bucket from a small vessel three to five miles off the eastern end of Bermuda. Brackish water samples were collected from James Bay, Ontario, a large, shallow, seasonally icecovered southward extension of Hudson Bay. Depth samples from the Bay were 
collected with a Van Doren bottle, and various fresh and brackish bodies of standing water in the vicinity of the Bay were sampled by hand. Water was transferred to experimental sampling bottles within an hour of collection in the case of Vineyard Sound and Sargasso Sea samples, and within six to seven hours in the case of James Bay samples. When water could not be immediately returned to the lab it was kept dark and cool until incubation experiments were begun.

Filter-fractionation of DMSP-lyase activity. For sterile-filtration, $0.2 \mu \mathrm{m}$ Gelman Supor-200 membrane filters were used. Where activity in sterile-filtered or autoclaved seawater was assessed, filter units, filters and sample bottles were sterilized by autoclaving, and sterile procedure was observed during transfers. In these treatments, bottle stopper surfaces and gas-sampling needles were wiped with $95 \%$ ethanol before withdrawing headspace to minimize contamination, but because room air was injected into sample bottles to avoid creating a vacuum when headspace was withdrawn, sampling procedures were not sterile.

DMSP and DMS additions. A sterile-filtered $500 \mu \mathrm{M}$ stock solution of DMSP$\mathrm{HBr}$ in distilled water was prepared and stored at $4^{\circ} \mathrm{C}$. This stock was always handled aseptically and a sterile DMSP control was run for all DMSP addition experiments. Eppendorf pipets fitted with sterile tips were used for DMSP additions. A sterile stock of DMS was prepared by injecting a known volume of pure DMS into autoclaved distilled water, and added to samples with a sterile syringe. In the interest of repeating the results of previous attempts to inhibit DMS consumption by means of chloroform or methylene chloride additions (J. Dacey, unpublished data; 20), pure $\mathrm{CH}_{2} \mathrm{Cl}_{2}$ was added by syringe to final concentrations of 100 and $500 \mu \mathrm{M}$ in some 
DMS addition samples. In the experiment examining the effect of methylene chloride on DMS consumption, seawater was screened through $10 \mu \mathrm{m}$ nylon mesh. Incubations were either carried out in silylated (Prosil, PCR, Inc.), acid-washed, 1-L amber Qorpak bottles (All-Pak) sealed with silicone rubber stoppers, or similarly treated $125-\mathrm{mL}$ serum bottles capped with Teflon-faced butyl rubber septa. Sample bottles were inverted once following additions, to homogenize the contents, but otherwise were not agitated during timecourses. However, if analysis was by headspace, samples were shaken gently prior to sampling to accelerate equilibration between solution and gas phases.

Isolation and assay of DMS-producing bacteria. Bacterial isolates were obtained by a DMSP enrichment method. Seawater samples were incubated for a week after being amended with 0.5-1 $\mu \mathrm{M}$ DMSP. Enrichments were then streaked on a solid medium consisting of seawater enriched with $\mathrm{f} / 2$ (13) nutrients, $0.4 \mathrm{mM}$ ammonium chloride and $1 \mathrm{mM}$ DMSP. Single colonies were suspended in nutrientenriched sterile seawater and assayed for DMS production from DMSP. Bacteria displaying activity relative to a sterile control were maintained on Difco marine agar 2216. For sample assays shown here, bacteria were removed from 2216 plates by means of a sterile cotton swab after 1-5 days, depending on the growth rate of individual strains, suspended to a light turbidity in sterile seawater amended with DMSP and nutrients, and DMS was monitored in the culture headspace. The isolation of strain LFR is described in detail in Chapter 6. Cells of this strain were enumerated by the acridine-orange direct count method; cell counts were not carried out during assay of other isolates. 
Screening well-characterized marine bacteria for DMSP-lyase activity. Bacterial strains were from the American Type Culture Collection with the exception of $S C 2, P$. phosphoreum, P. leiognathi and V. fischeri. Identification, origin and ATCC numbers where applicable are provided in Table 2-1. Colonies were removed with a sterile swab from overnight plate cultures (marine agar 2216 in the case of ATCC strains and SC2, and SWC (21) in the case of other strains) and suspended in nutrient-enriched seawater to a light turbidity. DMS production from $300 \mathrm{nM}$ added DMSP was monitored in headspace over a period of four hours.

Reagents and chemicals. Dimethylsulfide and methanethiol were purchased from Fluka Chemical Corp., Ronkonkoma, NY. DMSP, as the HBr salt, was synthesized by J. Dacey according to the method of Challenger and Simpson (3) and checked for purity by melting point determination and by comparison of base-treated samples to standards of known DMS concentration. Media ingredients were obtained from Becton Dickinson Microbiology Systems, Cockeysville, MD. All other reagents and chemicals were of analytical grade.

\section{Results}

Filter-fractionation of DMSP-lyase activity. Figure 2-1 displays the results of 1 $\mu \mathrm{M}$ DMSP additions to unfiltered, $0.2 \mu \mathrm{m}$ sterile-filtered and autoclaved Woods Hole dock water. DMSP was converted to DMS by unfiltered water at an initial rate of $25.9 \pm 0.6 \mathrm{nM} \mathrm{hr}^{-1}$ (based on first two hours' measurements). Rates calculated for each duplicate treatment differed by $3 \%$. No decrease in rate was observed over 23 hours; in fact, an apparent increase in rate occurred, possibly due to bacterial growth. 


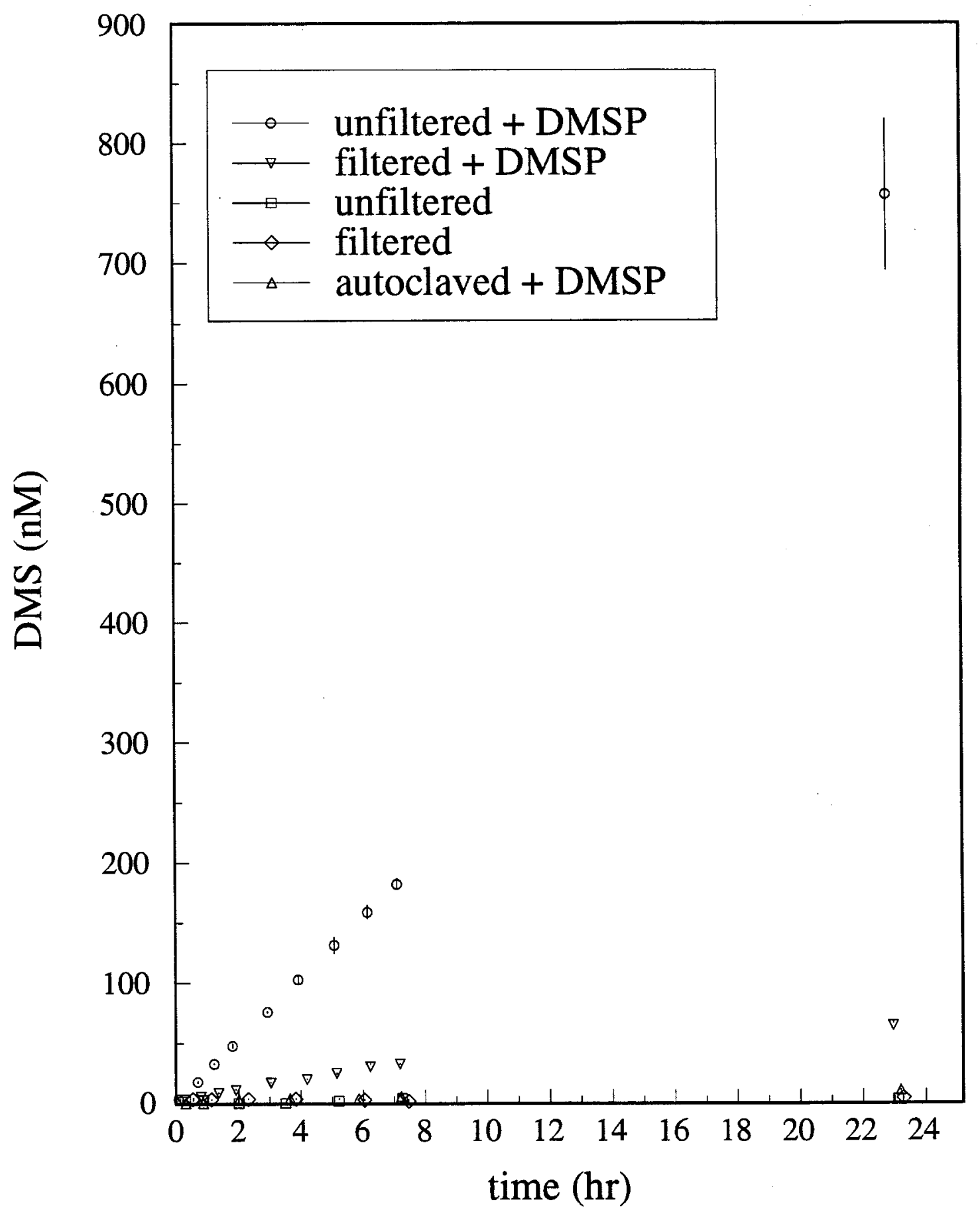

Figure 2-1. Comparison of DMSP-lyase activity in unfiltered and $0.2 \mu \mathrm{m}$ sterilefiltered Vineyard Sound seawater, in response to a $1 \mu \mathrm{M}$ DMSP addition. Over 23 hours, the rate of DMS production in the unfiltered addition increased slightly, while that in the filtered addition treatments gradually diminished. Points represent the average, and bars the range, of duplicate bottles. 
Production of DMS was also observed from a $1 \mu \mathrm{M}$ DMSP addition to sterile-filtered seawater, although at a lower initial rate of $5.7 \pm 0.7 \mathrm{nM} \mathrm{hr}^{-1}$, which decayed gradually throughout the timecourse. In the case of the addition to filtered water, rates differed by $31 \%$ between duplicate bottles. DMS was not produced in controls that included autoclaved, DMSP-amended seawater and unamended filtered and unfiltered seawater. No cells were observed in acridine orange direct counts of sterile-filtered samples.

DMS production from DMSP in estuarine, coastal and oligotrophic seawater. Figure 2-2a shows DMS production by unfiltered Sargasso Sea (November 1990) and Vineyard Sound water (February 1991) in response to 500 nM DMSP additions. Initial rates of DMS production were on the order of 5-6 $\mathrm{nM} \mathrm{hr}^{-1}$ for both the coastal and oligotrophic marine samples. In the coastal water methanethiol as well as DMS was produced from DMSP. Figure 2-2b shows the response to a similar high-level DMSP addition to fresh and estuarine waters in and around James Bay, Ontario. DMS was produced from $1 \mu \mathrm{M}$ DMSP in all James Bay samples assayed; the many not shown here included a coastal fen and samples of Bay water from 1 to $5 \mathrm{~m}$ depth. The only completely fresh water samples shown here are from Kinoje Lake (a small inland lake) and the coastal marsh pond. The other samples range from a few parts per thousand (Moose River, coastal marsh flat) to about $18 \mathrm{ppt}$ salinity. The slowest initial rates of DMS production occurred in the fresh water samples, but initial rates were uniformly rapid in the other samples, regardless of their seawater content. In samples that were incubated sufficiently long for this effect to become apparent, DMS was removed from solution, presumably by bacterial activity, before all of the added 
(a)

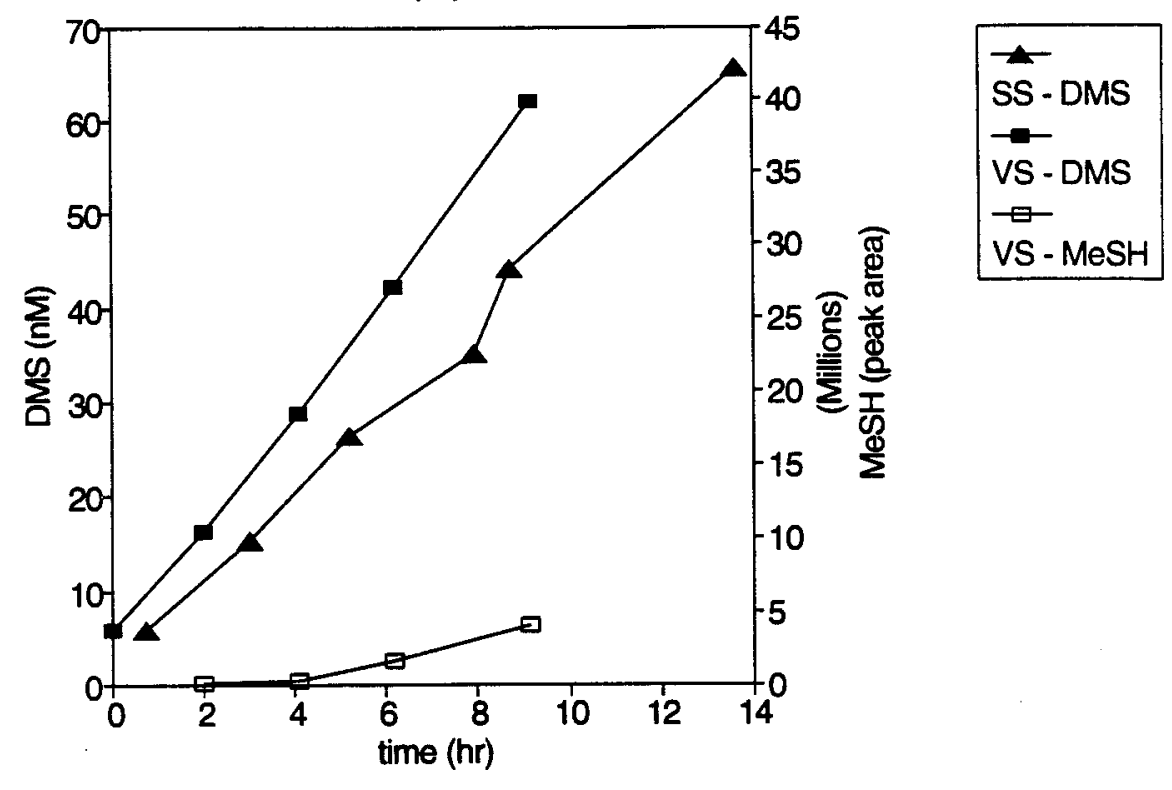

(b)

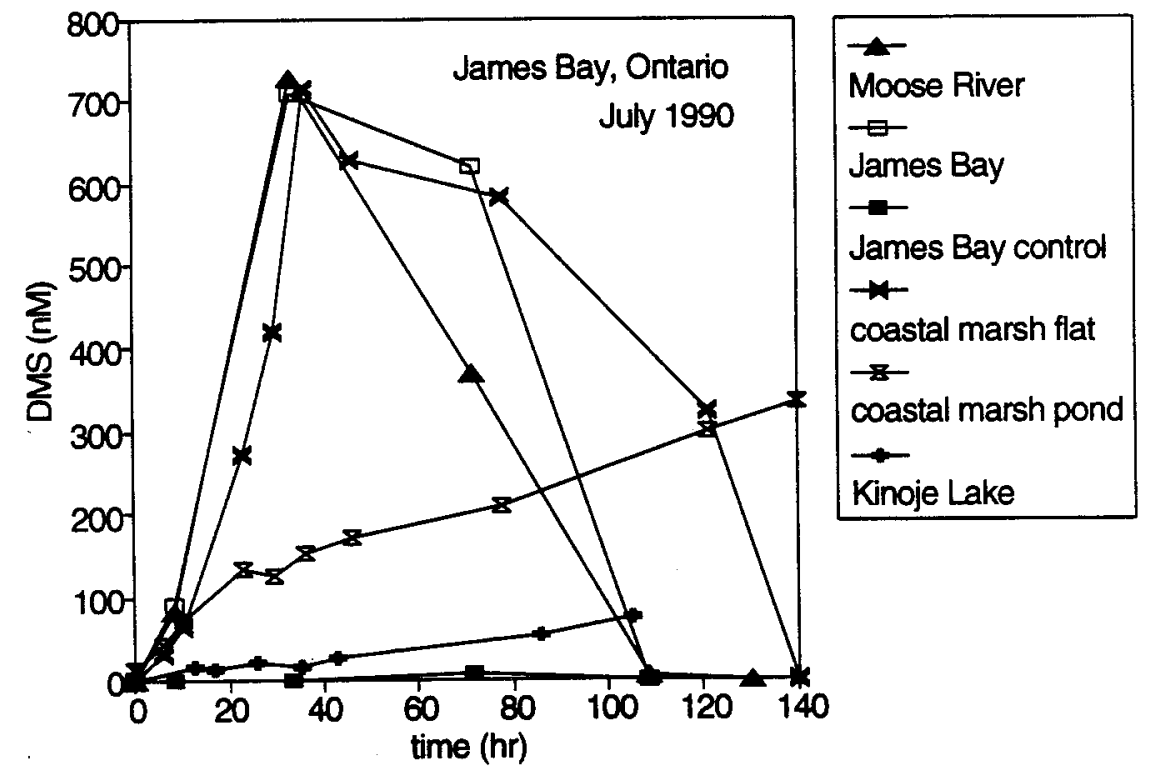

Figure 2-2. Production of DMS in response to high-level DMSP additions to unfiltered seawater. (a) Sargasso Sea (SS) and Vineyard Sound (VS) water (500 nM addition). Methanethiol is not standardized, but the y-axes are scaled to display the relative integrator response to MeSH and DMS. (b) James Bay, Ontario, and adjacent wetlands (1 $\mu \mathrm{M}$ addition). Methanethiol as well as DMS was produced in response to the DMSP addition to Vineyard Sound seawater. 
DMSP had been converted to DMS. MeSH would not have been detected in the Sargasso Sea or James Bay timecourses due to the fact that a $\mathrm{KOH}$ water trap was placed in line upstream of the cold trap.

DMS production from DMSP by marine bacterial isolates. Bacteria were isolated from the coastal and oligotrophic Atlantic seawater, coastal Gulf of Mexico water and a brackish marsh in Woods Hole, MA. The four isolates shown display diverse DMS production patterns (Figure 2-3). The isolates from Vineyard Sound and Sargasso Sea water exhibited a pronounced lag in DMS production, while isolates from the coastal marsh and Gulf of Mexico did not. Lyase activity in the Gulf isolate appears to saturate at considerably lower DMSP concentrations than in the other isolates. The Sargasso Sea isolate, LFR, received an $820 \mathrm{nM}$ DMSP addition while all others received $1 \mu \mathrm{M}$. Cell counts were carried out for only for the Sargasso Sea isolate $\left(3.7 \times 10^{6} \mathrm{~mL}^{-1}\right)$. Because of this, differences in absolute rates are not addressed here.

DMS production from DMSP by well-characterized marine bacteria. Results are summarized in Table 2-1. Of the fifteen strains of marine bacteria assayed for DMS production from DMSP, only one, Pseudomonas doudoroffii, unequivocally displayed this activity (Figure 2-4). Small amounts of DMS appeared in the medium of Shewanella putrefaciens, but did not accumulate to a great extent relative to a sterile DMSP control. Interestingly, Alteromonas macleodii produced methanethiol in response to DMSP addition. Dimethyldisulfide appeared in the medium of $A$. macleodii concomitantly with MeSH. Traces of MeSH were also detected in the medium of A. haloplanktis, S. putrefaciens and SC2. 


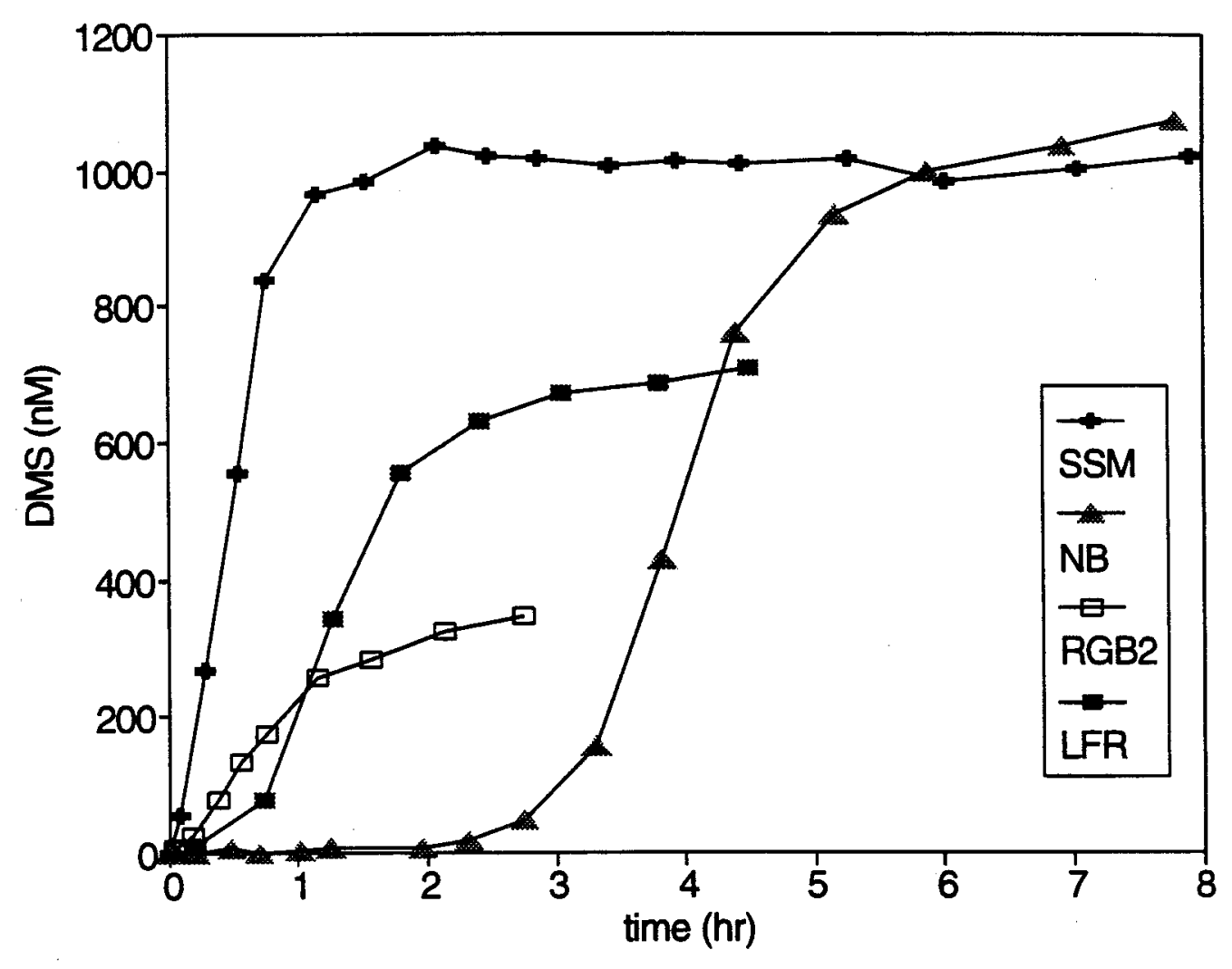

Figure 2-3. Production of DMS from high-level DMSP additions by marine bacterial isolates. SSM was isolated from a brackish marsh, NB from Vineyard Sound, RGB2 from nearshore Gulf of Mexico seawater, and LFR from Sargasso Sea water. All isolates received $1 \mu \mathrm{M}$ DMSP additions, with the exception of LFR, which received $820 \mathrm{nM}$. 
Table 2-1. Production of dimethylsulfide and methanethiol from DMSP by well-characterized marine bacteria.

\begin{tabular}{|c|c|c|c|c|}
\hline Species & $\mathrm{ATCC}^{\mathrm{a}} \#$ & $\begin{array}{l}\text { Strain \# } \\
\text { or source }\end{array}$ & DMS & $\mathrm{MeSH}$ \\
\hline Deleya venusta & 35137 & 84 & $-{ }^{b}$ & - \\
\hline Deleya pacifica & 27122 & 62 & - & - \\
\hline Deleya cupida & 27124 & 79 & - & - \\
\hline Deleya aesta & 27128 & 134 & - & - \\
\hline Pseudomonas doudoroffii & 27123 & 70 & + & - \\
\hline Pseudomonas nautica & 27132 & 179 & - & - \\
\hline Alteromonas haloplanktis & 27127 & 121 & - & $(+)$ \\
\hline Alteromonas macleodii & 27126 & 107 & - & + \\
\hline Shewanella putrefaciens & 8071 & 95 & - & $(+)$ \\
\hline$S C 2$ & & c & $(+)$ & $(+)$ \\
\hline Vibrio alginolyticus & 33787 & 90 & - & - \\
\hline Vibrio harveyi & 33843 & 392 & - & - \\
\hline Vibrio fischeri & & $\mathrm{mJ}-1^{\mathrm{d}}$ & - & - \\
\hline Photobacterium leiognathi & & LR-1a & - & - \\
\hline Photobacterium phosphoreum & & $\mathrm{HE}-1 \mathrm{a}^{\mathrm{e}}$ & - & - \\
\hline
\end{tabular}

a ATCC, American Type Culture Collection (Rockville, MD).

b Symbols: -, no DMS/MeSH produced;,$+>150 \mathrm{nM}$ produced from a $300 \mathrm{nM}$ DMSP addition in 4 hours; $(+)$, up to $20 \mathrm{nM}$ produced.

c (36). SC2 is closely related to representatives of the genus Shewanella by 16S rRNA homology (E. F. DeLong, personal communication).

d (26).

e $(10)$. 


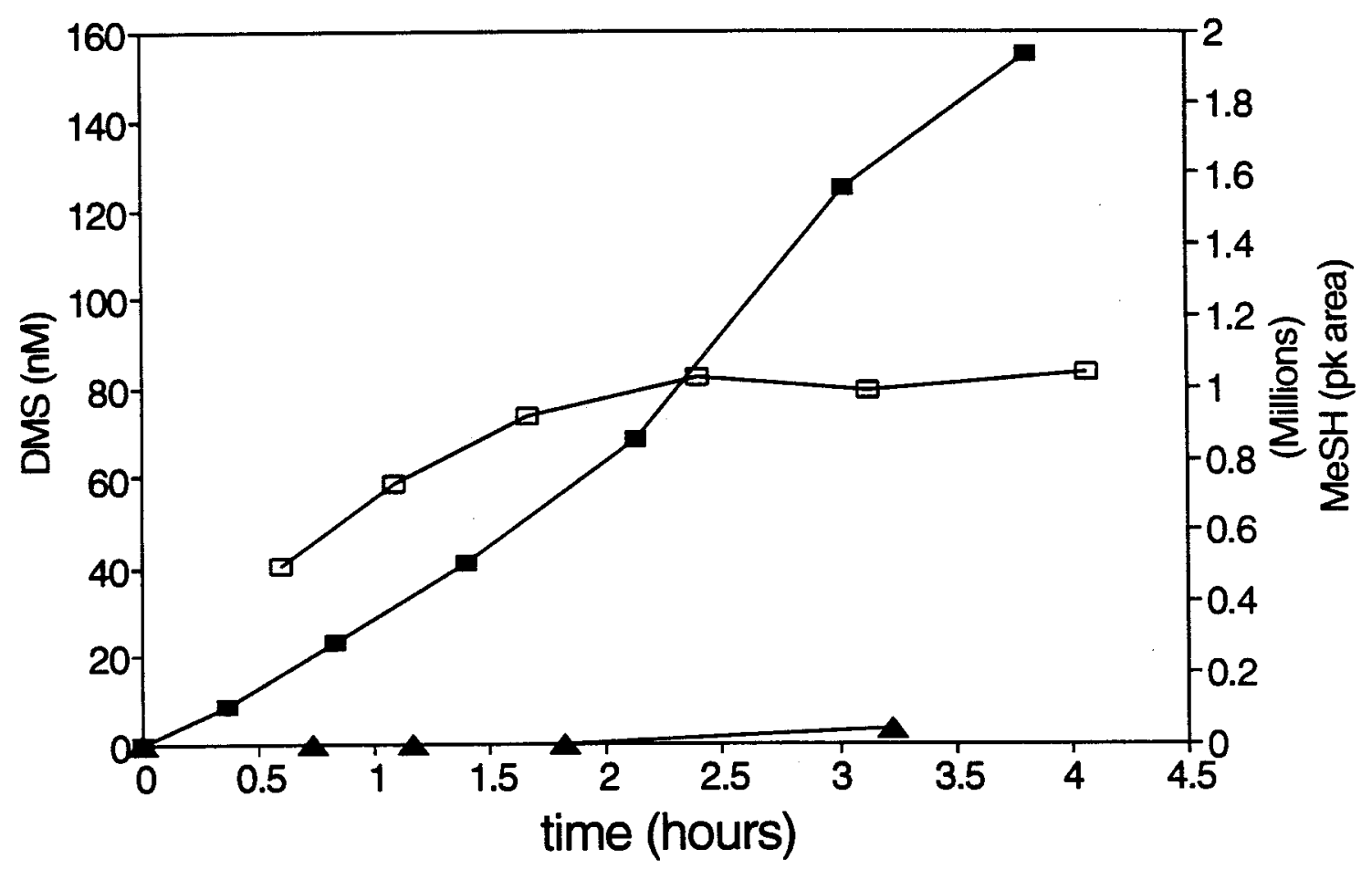

\section{$\rightarrow-$ Ps. doudoroffii $\square-$ A. macleodii $\rightarrow$ DMSP control}

Figure 2-4. Production of volatile sulfur in response to a $300 \mathrm{nM}$ DMSP addition to suspensions of the marine bacteria Pseudomonas doudoroffii and Alteromonas macleodii. Relative scaling of the y-axes is determined as in Figure 2-2a (however, note that in Figure 2-2a DMS was preconcentrated, whereas in this case headspace was sampled). 
DMS consumption by Vineyard Sound seawater. A $54 \mathrm{nM}$ DMS addition to Vineyard Sound seawater was consumed following a fairly long lag time of 17 hours (Figure 2-5; also see Figure 2-2b). Two of the DMS-amended bottles received 100 $\mu \mathrm{M}$ and $500 \mu \mathrm{M} \mathrm{CH}_{2} \mathrm{Cl}_{2}$, respectively. Although both levels of methylene chloride appeared effective at preventing DMS removal, the timecourses were fairly noisy, and not all removal was suppressed. Background DMS levels in seawater which had received no DMS addition remained at their original value, but DMS in the uninhibited control declined slightly relative to the methylene chloride-treated control.

\section{Discussion}

In marine waters, DMSP has long been assumed the major precursor of dimethylsulfide, primarily through transformations occurring within the phytoplankton which synthesize DMSP $(2,15)$. Although no quantitative studies have been done, recent biogeochemical investigations have highlighted microbial cleavage of dissolved DMSP as a possibly important pathway of DMS formation. The high-level DMSP addition experiments carried out here illustrate that DMS is produced from dissolved DMSP in whole seawater and cultures of marine bacterial isolates and wellcharacterized marine bacteria.

The contested role of DMSP as an osmotic agent in algae $(8,9,11,25,31,32)$ has led to a focus on its intracellular nature, distracting attention from the fate of extracellular, dissolved DMSP, which is present in seawater at levels comparable to particulate DMSP (30). Like many organic compounds synthesized by phytoplankton, DMSP is likely to be released into seawater whenever algal cells lyse or leak due to 


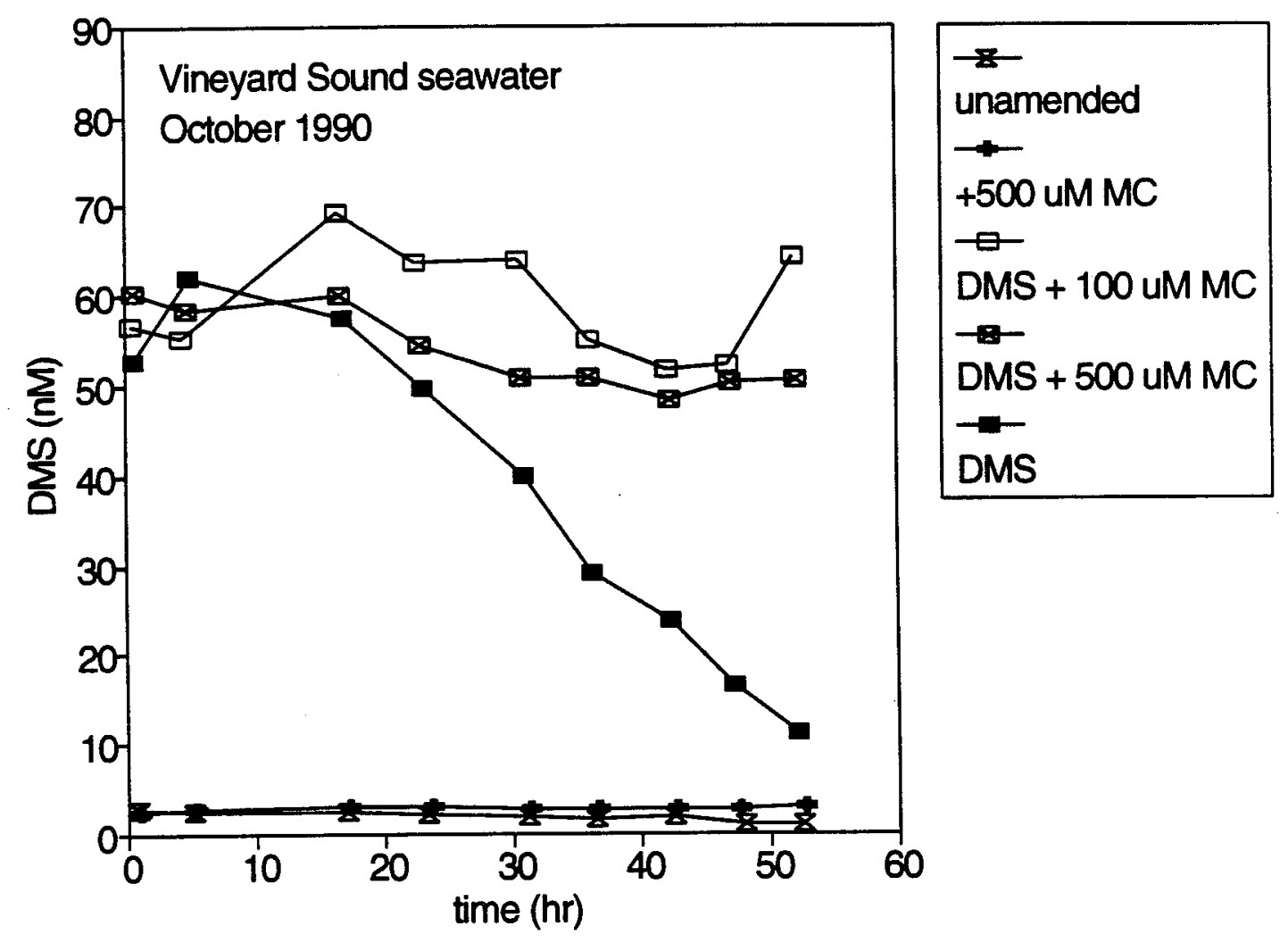

Figure 2-5. Inhibition of microbial DMS consumption by addition of 100 and 500 $\mu \mathrm{M}$ methylene chloride to Vineyard Sound seawater. 
osmotic stress (33), zooplankton grazing (5), senescence, or other processes, and there become available as a substrate for microbial activity. Production of DMS from DMSP, mediated by bacteria in pure culture and by environmental assemblages, has been observed under both aerobic $(4,17,19,35)$ and anaerobic $(20,33,34)$ conditions. Reports of aerobic environmental DMS production from DMSP have focused on highly productive waters: a coastal salt pond $(35)$ and an estuary $(17,19)$. In this work these observations are extended to coastal and oligotrophic seawater, and the first reports of this activity in samples from a variety of northern wetland environments is presented, attesting to the ubiquity of DMSP-lyase activity in aerobic marine, brackish and to some extent freshwater wetland environments.

DMS production from added DMSP in Vineyard Sound seawater is greatly reduced by sterile filtration, implying that it is biologically mediated. Activity is eliminated by autoclaving but continues at a diminished level, with no discernible lag, in sterile-filtered samples. The DMS production observed in the filtrate cannot be attributed to chemical cleavage of DMSP, as DMSP has been demonstrated to have a half-life of 8 years with respect to this process at the temperature and $\mathrm{pH}$ of seawater (4). If the filtrate activity is attributed to bacteria smaller than $0.2 \mu \mathrm{m}$, approximately a quarter of the cells in unfiltered seawater would have had to pass through the 0.2 $\mu \mathrm{m}$ filter, judging from the relative initial rates of DMS production in filtered and unfiltered seawater. This number would have been easily detectable by direct counts of the filtrate, in which no cells were observed. These observations implicate dissolved enzyme as an agent of DMS production from DMSP. If the algal DMSP lyase is cytoplasmic, it may be released by disturbance of algal cell integrity during 
filtration. Because filtration conditions may be completely or partially responsible for the DMSP-lyase activity observed in the filtrate, the results of this experiment do not permit a quantitative assessment of the relative importance of this pathway in the environment. However, if filtration in this experiment is considered a proxy for environmental processes resulting in algal lysis, it would appear that free enzyme can produce DMS from DMSP at a significant rate. Here, the initial rate of DMS production in sterile-filtered water was an appreciable fraction (24\%) of the rate observed in unfiltered water, although it should be noted that this is an upper limit, since microbial sinks for DMS would be removed by filtration. Moreover, although this rate appeared to taper off during the first seven hours of measurement, DMS concentrations at 23 hours in the filtered, amended sample were almost double those at 7 hours (Figure 2-1b), indicating that the putative activity of dissolved enzyme may have more than an ephemeral lifetime in seawater, It is interesting that the decomposition of DMSP to DMS in $0.2 \mu \mathrm{m}$-filtered seawater observed by Turner et al. (30) occurs at a similar rate $\left(\sim 6 \mathrm{nM} \mathrm{hr}^{-1}\right)$.

These observations confirm that the bulk of DMSP-lyase activity is cellassociated. Metabolic inhibitors of prokaryotic activity have been utilized in an attempt to localize DMSP-lyase activity in the bacterial fraction (17), but with ambiguous results. These inhibitors may suppress growth while constitutive enzymatic activity, at least on a short timescale, is unaffected. Moreover, some of these agents may not operate effectively in seawater (tetracycline, for example, is inactivated by high concentrations of $\mathrm{Ca}^{2+}$ ), while individual strains of bacteria may be resistant to others. Azide, chloramphenicol, tetracycline, kanamycin and vancomycin (17) were 
found in some cases to affect DMSP-lyase activity, but never to eliminate or even diminish it substantially. Lastly, the effects of inhibitor additions on eukaryotic members of microbial assemblages may be difficult to predict, rendering this a problematic method of determining whether environmental DMSP-lyase activity is bacterial.

Although little is known about utilization of dissolved organic material by eukaryotic organisms in seawater, direct uptake or extracellular deamination by phytoplankton of nitrogen-containing compounds has received some attention $(12,22,24)$. Use of high-molecular-weight polysaccharide by heterotrophic flagellates has also been described (27). However, algae and heterotrophic eukaryotes are commonly assumed to be outcompeted by smaller bacteria for dissolved organic matter because of surface-to-volume ratio considerations. Bacteria appear to constitute the major sink for dissolved organic carbon, even in the presence of high DOC concentrations which render irrelevant the relative specific affinities of bacteria and algae $(1,23)$. These findings suggest that uptake and transformation of a small, nonnitrogenous organic compound such as DMSP is unlikely to be controlled by eukaryotic organisms in the water column. At least one alga able to synthesize DMSP, a heterotrophic dinoflagellate, has been reported to be incapable of taking it up (15). Isolation of bacteria able to produce DMS from dissolved DMSP $(4,17,29$; Figure 2-3) indicates that at least some environmental DMSP-lyase activity may be attributable to bacteria. However, we do not have conclusive evidence that eukaryotic microorganisms do not mediate this process. In light of this, environmental conversion of dissolved DMSP to DMS will be referred to as microbial, as distinct 
from bacterial, throughout the remainder of this thesis.

No published information is available on the identity of bacteria that mediate breakdown of DMSP to form DMS in seawater. In this study, one of fifteen wellcharacterized strains of marine bacteria belonging to the $\gamma$ subdivision of the proteobacteria assayed here, Pseudomonas doudoroffii, produced DMS from DMSP. Ps. doudoroffii has been placed by DNA:rRNA hybridization (7) in the rRNA branch of the enteric genus Aeromonadaceae. However, representatives of the enteric genera Photobacterium and Vibrio did not display activity. In Chapter 6, a marine bacterial isolate with DMSP-lyase activity is physiologically and phylogenetically described. Comparison of the isolate's $16 \mathrm{~S}$ rRNA sequence with that of known eubacteria placed this bacterium in the $\alpha$ subdivision of the proteobacteria. These results indicate that, while not all marine bacteria are able to cleave DMSP to DMS, this activity is probably distributed fairly nonspecifically among marine representatives of the proteobacteria.

The disparate responses to DMSP addition by the four bacterial cultures displayed in Figure 2-3 suggest that these isolates regulate DMSP-lyase activity in different ways. A pronounced lag was associated with DMS production in strains NB and LFR, possibly indicating induction of the cleavage enzyme, while no lag was observed in isolate SSM. A spectrum of kinetic responses was recorded as well, with activity in the Gulf Coast isolate saturating well before that of the other isolates. The observation that $A$. macleodii produced methanethiol from DMSP, with no detectable intermediate production of DMS, and that MeSH was produced in response to a DMSP addition to Vineyard Sound seawater, indicates the existence of pathways for 
DMSP breakdown in the marine environment other than cleavage to form DMS (29).

In several of the James Bay incubations, DMS produced from DMSP was subsequently consumed. While both aerobic and anaerobic bacterial consumption of DMS have been reported in numerous culture studies $(6,16,28,37)$, no aerobic marine bacteria able to use DMS as a source of carbon or energy have yet been isolated. As a sink for marine DMS, microbial consumption has been estimated to vie in quantitative importance with ventilation from the sea surface (18). This process appears to occur concomitantly in seawater with DMS production from dissolved DMSP, and can potentially interfere with rate estimates of DMS production from DMSP in seawater. Methylene chloride additions to DMS-amended seawater were observed to prevent DMS removal in seawater. Chloroform is reported to have a similar inhibitory effect on biological DMS consumption, without affecting microbial production of DMS from DMSP $(18,19)$. However, inhibitors such as methylene chloride or chloroform must be used with caution; here, methylene chloride treatment does not result in complete suppression of removal activity. As we do not yet have information on the mechanism of inhibition, the identity of DMS-consuming organisms, or indirect effects on other biota, it may be premature to rely on this technique for selective inhibition of microbial DMS removal. The potential pitfalls of this approach are discussed in more detail in Chapter 3.

These simple incubation experiments illustrate the ubiquity of microbial DMSPlyase activity in marine and brackish environments and marine bacterial isolates. Quantitative assessment of the environmental importance of this process must now be undertaken by means of in situ rate measurements. 


\section{REFERENCES}

1. Azam, F., and R. E. Hodson. 1977. Size distribution and activity of marine microheterotrophs. Limnol. Oceanogr. 22:492-501.

2. Cantoni, G. L., and D. G. Anderson. 1956. Enzymatic cleavage of dimethylpropiothetin by Polysiphonia lanosa. J. Biol. Chem. 222:171-177.

3. Challenger, F., and M. I. Simpson. 1948. Studies on biological methylation. J. Chem. Soc. 1948:1591-1597.

4. Dacey, J. W. H., and N. V. Blough. 1987. Hydroxide decomposition of dimethylsulfoniopropionate to form dimethylsulfide. Geophys. Res. Let. 14:1246-1249.

5. Dacey, J. W. H., and S. G. Wakeham. 1986. Oceanic dimethylsulfide: Production during zooplankton grazing on phytoplankton. Science 233:1314-1316.

6. De Bont, J. A. M., J. P. van Dijken, and W. Harder. 1981. Dimethyl sulphoxide and dimethyl sulphide as a carbon, sulphur and energy source for growth of Hyphomicrobium S. J. Gen. Microbiol. 127:315-323.

7. De Vos, P., A. van Landschoot, P. Segers, R. Tytgat, M. Gillis, M. Bauwens, R. Rossau, M. Goor, B. Pot, K. Kersters, P. Lizzaraga, and J. de Ley. 1989. Genotypic relationships and taxonomic localization of unclassified Pseudomonas and Pseudomonas-like strains by deoxyribonucleic acidrribosomal ribonucleic acid hybridizations. Int. J. Syst. Bacteriol. 39:35-49.

8. Dickson, D. M. J., and G. O. Kirst. 1986. The role of $\beta$-dimethylsulfoniopropionate, glycine betaine and homarine in the osmoacclimation of Platymonas subcordiformis. Planta 167:536-543.

9. Dickson, D. M. J., R. G. Wyn-Jones, and J. Davenport. 1980. Steady state osmotic adaptation in Ulva lactuca. Planta 155:409-415.

10. Dunlap, P. V. 1984. The ecology and physiology of the light organ symbiosis between Photobacterium leiognathi and ponyfishes. Ph.D. Thesis, University of California at Los Angeles. $290 \mathrm{pp}$.

11. Edwards, D. M., R. H. Reed, J. A. Chudek, R. Roster, and W. D. P. Stewart. 1987. Organic solute accumulation in osmotically-stressed Enteromorpha intestinalis. Mar. Biol. 95:583-592. 
12. Flynn, K. J., and I. Butler. 1986. Nitrogen sources for the growth of marine microalgae: Role of dissolved free amino acids. Mar. Ecol. Prog. Ser. 34:281-304.

13. Guillard, R. R. L. 1975. Culture of phytoplankton for feeding marine invertebrates, pp. 29-60. In: W. L. Smith and M. H. Chanley (eds.), Culture of marine invertebrate animals, Plenum Press, New York.

14. Hobbie, J. E., R. J. Daley, and S. Jasper. 1977. Use of Nuclepore filters for counting bacteria by fluorescence microscopy. Appl. Environ. Microbiol. 33:1225-1228.

15. Ishida, Y. 1968. Physiological studies on evolution of dimethyl sulfide from unicellular marine algae. Mem. Coll. Agric. Kyoto 94:47-82.

16. Kanagawa, T., and D. P. Kelly. 1986. Breakdown of dimethyl sulphide by mixed cultures and by Thiobacillus thioparus. FEMS Microbiol. Let. 34:13-19.

17. Kiene, R. P. 1990. Dimethyl sulfide production from dimethylsulfoniopropionate in coastal seawater samples and bacterial cultures. Appl. Environ. Microbiol. 56:3292-3297.

18. Kiene, R. P., and T. S. Bates. 1990. Biological removal of dimethyl sulphide from sea water. Nature 345:702-705.

19. Kiene, R. P., and S. K. Service. 1991. Decomposition of dissolved DMSP and DMS in estuarine waters: Dependence on temperature and substrate concentration. Mar. Ecol. Prog. Ser. 76:1-11.

20. Kiene, R. P., and P. T. Visscher. 1987. Production and fate of methylated sulfur compounds from methionine and dimethylsulfoniopropionate in anoxic salt marsh sediments. Appl. Environ. Microbiol. 53:2426-2434.

21. Nealson, K. H. 1978. Isolation, identification, and manipulation of luminous bacteria. Meth. Enzymol. 57:153-166.

22. Palenik, B. P., and F. M. M. Morel. 1990. Amino acid utilization by phytoplankton: A novel mechanism. Limnol. Oceanogr. 35:260-269.

23. Parsons, T. R., L. J. Albright, F. Whitney, C. S. Wong, and P. LeB. Williams. 1981. The effect of glucose on the productivity of seawater: An experimental approach using controlled aquatic ecosystems. Mar. Environ. Res. 4:229-242. 
24. Paul, J. H. 1983. Uptake of organic nitrogen, pp. 275-308. In: E. J. Carpenter and D. G. Capone (eds.), Nitrogen in the environment. Academic Press, New York.

25. Reed, R. H. 1983. The osmotic responses of Polysiphonia lanosa (L.) Tandy from marine and estuarine sites: Evidence for incomplete recovery of turgor. J. Exp. Mar. Biol. Ecol. 68:169-193.

26. Ruby, E. G., and K. H. Nealson. 1971. Symbiotic association of Photobacterium fischeri with the marine luminous fish Monocentris japonica: A model of symbiosis based on bacterial studies. Biol. Bull. 151:574-586.

27. Sherr, E. B. 1988. Direct use of high molecular weight polysaccharide by heterotrophic flagellates. Nature 335:348-351.

28. Suylen, G. M. H., G. C. Stefass, and J. G. Kuenen. 1986. Chemolithotrophic potential of a Hyphomicrobium species, capable of growth on methylated sulphur compounds. Arch. Microbiol. 146:192-198.

29. Taylor, B. F., and D. C. Gilchrist. 1991. New routes for aerobic biodegradation of dimethylsulfoniopropionate. Appl. Environ. Microbiol. 57:3581-3584.

30. Turner, S. M., G. Malin, P. S. Liss, D. S. Harbour, and P. M. Holligan. 1988. The seasonal variation of dimethyl sulfide and dimethylsulfoniopropionate concentrations in nearshore waters. Limnol. Oceanogr. 33:364-375.

31. Vairavamurthy, A., M. O. Andreae, and R. L. Iverson. 1985. Biosynthesis of dimethylsulfide and dimethylpropiothetin by Hymenomonas carterae in relation to sulfur source and salinity variations. Limnol. Oceanogr. 30:59-70.

32. Van Diggelen, J., J. Rozema, D. M. J. Dickson, and R. Broekman. 1986. $\beta$-3-Dimethylsulphoniopropionate, proline and quaternary ammonium compounds in Spartina anglica in relation to sodium chloride, nitrogen and sulphur. New Phytol. 103:573-586.

33. Visscher, P. T., and H. van Gemerden. 1991. Production and consumption of dimethylsulfoniopropionate in marine microbial mats. Appl. Environ. Microbiol. 57:3237-3242.

34. Wagner, C., and E. R. Stadtman. 1962. Bacterial fermentation of dimethyl- $\beta$ propiothetin. Arch. Biochem. Biophys. 98:331-336.

35. Wakeham, S. G., B. L. Howes, J. W. H. Dacey, R. P. Schwarzenbach, and J. Zeyer. 1987. Biogeochemistry of dimethylsulfide in a seasonally stratified coastal salt pond. Geochim. Cosmochim. Acta 51:1675-1684. 
36. Yayanos, A. A., A. S. Dietz, and R. van Boxtel. 1982. Dependence of reproduction rate on pressure as a hallmark of deep-sea bacteria. Appl. Environ. Microbiol. 44:1356-1361.

37. Zeyer, J., P. Eicher, S. G. Wakeham, and R. P. Schwarzenbach. 1987. Oxidation of dimethylsulfide to dimethylsulfoxide by phototrophic purple bacteria. Appl. Environ. Microbiol. 53:2026-2032. 


\section{CHAPTER 3}

\section{MICROBIAL CYCLING OF DMSP AND DMS IN VINEYARD SOUND}

Many marine algae synthesize the tertiary sulfonium compound dimethylsulfoniopropionate (DMSP), now recognized as a ubiquitous component of particulate and dissolved organic matter in seawater (21-23). Microbial utilization of dissolved DMSP in aerobic seawater, in particular cleavage of DMSP to form dimethylsulfide (DMS), is increasingly well-documented $(12,14,20,23)$. Inhibition of this process by autoclaving and sterile filtration (Chapter 2) and the fact that it displays a temperature maximum (13) are consistent with biological mediation. Dissolved DMSP in seawater may be a substrate primarily for bacteria, although attempts to suppress DMSP-lyase activity using inhibitors of prokaryotic metabolism have met with equivocal results (12). Abiotic hydroxide decomposition of DMSP takes place too slowly at typical seawater temperature and $\mathrm{pH}$ to support observed marine DMS concentrations (5).

Our best evidence that environmental uptake and utilization may be bacterially mediated lies in the isolation of marine bacteria able to break DMSP down via a number of pathways $(5,12,20)$. An enzyme has been partially isolated from two marine algae, the red macroalga Polysiphonia lanosa and the heterotrophic dinoflagellate Gyrodinium cohnii, which catalyzes the cleavage of DMSP to form dimethylsulfide (DMS) and acrylic acid (4,11). The algal enzyme is presumably employed intracellularly to regulate internal levels of DMSP or possibly acrylic acid. One mode of bacterial utilization of dissolved (extracellular) DMSP identified to date 
(5) is analogous to the algal breakdown, in that DMS is an endproduct. Bacteria which mediate this cleavage often appear able to take up and metabolize acrylic acid $(5,12)$, implying that acrylate may be a product of the bacterial as well as the algal cleavage reaction. The process of microbial formation of DMS from dissolved DMSP, referred to here as DMSP-lyase activity, may be a possibly important source of marine dimethylsulfide. It should be noted, however, that alternative pathways for DMSP breakdown exist. Taylor and Gilchrist (20), in a study of marine bacterial isolates from coastal seawater, hypothesize an additional route, involving demethylation to form 3-methiolpropionate (MMPA). MMPA may in turn be either demethylated, forming 3-mercaptopropionate, or demethiolated, resulting in methanethiol formation.

While microbial metabolism now constitutes an accepted sink for dissolved DMSP, as well as a source of DMS, we as yet have no information on the in situ rates of these processes. A previous study has examined the concentration dependence of DMSP uptake and DMSP-lyase activity in a highly productive tidal creek (14). This study investigates the ambient rates and concentration dependence of these processes in coastal seawater (Vineyard Sound, Cape Cod, MA) during a period of a month and a half in the spring of 1992 .

\section{Materials and methods}

Analytical. DMS was quantified by sulfur-specific gas chromatography using a Varian 3700 gas chromatograph equipped with a Sievers 350 sulfur chemiluminescence detector (SCD). Volatile sulfur compounds were separated on a FEP column of Chromosil 330 (Supelco) at a column temperature of $54^{\circ} \mathrm{C}$, with 
nitrogen as the carrier gas at a flow rate of $35 \mathrm{~mL} \mathrm{~min}^{-1}$. DMS was preconcentrated from solution as follows. $1-3 \mathrm{~mL}$ of liquid sample was stripped of DMS in a fritted glass tube by a stream of nitrogen gas $\left(100 \mathrm{~mL} \mathrm{~min}^{-1}\right)$ for 4-6 minutes, depending on sample volume. DMS was cryofocused in a 1/8" FEP loop packed with the solid adsorbent Tenax (35/60 mesh size; Alltech Associates) submerged in a 50/50 water/methanol circulating bath held at $-20^{\circ} \mathrm{C}$. During trapping, water was removed from the sample stream by a glass cold-finger trap submerged in the same bath used for cryofocusing. When trapping was complete, the sample was injected by diverting carrier, by means of a six-port switching valve, to backflush the contents of the loop onto the chromatographic column. At this time the loop was raised from the cold bath, and DMS thermally desorbed from the Tenax by passing current through a stainless steel sheath encasing the loop. The detection limit of the SCD is about 0.5 pmol S-DMS. DMS sampling and analysis were automated, which allowed unattended operation of the system and minimized error due to manual sample handling and variability in timing the various phases of the trapping procedure. Quantitative recovery of DMS by this preconcentration technique was confirmed by comparing oncolumn injection of headspace with identical injections into the sparger. For analysis of dissolved DMSP, 8-mL aliquots were filtered by gentle vacuum through a $25 \mathrm{~mm}$, $0.2 \mu \mathrm{m}$ Gelman Supor-200 membrane filter. The filtrate was stripped of DMS by a flow of nitrogen for ten minutes, brought by addition of $16 \mathrm{~N} \mathrm{KOH}$ to a final base concentration of $1 \mathrm{~N}$, and allowed to react overnight at room temperature. This treatment quantitatively converted DMSP to DMS, which was then analyzed as above. For measurements of particulate DMSP, Whatman GF/F filters $(0.8 \mu \mathrm{m}$ nominal pore 
size) were used rather than the Gelman filters, which we have observed to adsorb significant DMS during overnight incubations, and samples filtered with a 50-mL Hamilton gas-tight syringe rather than the vacuum apparatus. Aqueous standards were prepared the day of the experiment analogously to samples with respect to matrix, bottles and headspace:solution ratio.

Sampling. Vineyard Sound seawater for incubation experiments was collected in an acid-washed plastic carboy from a pier in Woods Hole, MA adjacent to the laboratory. The time elapsed between seawater collection and the start of incubation experiments was usually less than thirty minutes.

Incubation experiments. Seawater was gently screened through $75 \mu \mathrm{m}$ Nitex mesh to remove large grazers, and $0.95 \mathrm{~L}$ distributed into 1-L amber Qorpak bottles that had been sequentially silylated, soaked overnight in $1 \mathrm{~N} \mathrm{HCl}$, rinsed thoroughly with distilled water, and rinsed $3 \mathrm{X}$ with the same seawater used for the experiment. These bottles were placed in a circulating water bath held at the ambient temperature of the seawater. During incubations sample bottles were sealed with silicone rubber stoppers; analysis of standards during the course of experiments revealed no detectable uptake of DMS by stoppers. Aliquots were periodically drawn from bottles through lengths of 1/16" FEP tubing directly into the sparger. The timecourse of soluble DMSP was monitored in aliquots withdrawn manually by syringe at hourly intervals. DMSP and DMS stock solutions were prepared as described in Chapter 2. Following additions sample bottles were inverted gently to mix contents, but were otherwise not disturbed during sampling.

Two types of experiments, referred to as low-level addition and kinetics 
experiments, were carried out. Low-level addition experiments were intended to determine net rates of DMSP disappearance from the dissolved phase, DMS production from dissolved DMSP, and DMS consumption at ambient and near-ambient substrate concentrations. Loss of soluble DMSP and accumulation of DMS were monitored in response to DMSP addition, and DMS consumption monitored in response to DMS addition. Ambient concentrations of DMS or DMSP were usually doubled or tripled by substrate additions (see Table 3-1). Timecourses lasted from 8 to 10 hours. In low-level addition experiments, duplicate treatments were carried out where possible. Since standards were run between each set or two sets of samples, time constraints did not always permit each treatment to be run in duplicate. No attempts were made to inhibit DMS production or consumption selectively.

Kinetics experiments, on the other hand, examined the concentration dependence of these processes. DMS production and dissolved DMSP loss were monitored in response to six DMSP concentrations (ambient and five additions) on 4/26/92 and 5/26/92. A single low-level DMS addition was also monitored during each of these kinetics experiments to investigate possible concomitant DMS consumption. The concentration dependence of DMS consumption was also investigated on $5 / 8 / 92$. Duplicates were not run during kinetics experiments due to the number of treatments and need for adequate sampling frequency. However, when duplicate treatments were monitored in low-level addition experiments, rates estimated from each set of duplicates always agreed to within $6 \%$.

Controls for both types of experiments included unamended seawater (used to estimate ambient rates) and sterile DMSP and DMS controls. The latter were not run 
during every experiment, but frequently enough to ascertain the sterility of DMSP and DMS stocks. Activity was never observed in sterile controls.

Rate estimation and determination of kinetic parameters. Removal and production rates were estimated from the slope of the initial linear part of the DMS or DMSP timecourse, as determined by linear regression of the relevant portion of the assay. In some DMS production timecourses, the rate tapered off noticeably after six hours, due to competing DMS consumption or other processes. In these cases, and in the case of most high-level additions in the kinetics experiments, rates were estimated from the first 3-5 hours' data (from 4 to 10 timepoints, depending on whether duplicates were run). If the extent of substrate depletion was small and the rate of accumulation or depletion appeared constant, longer timecourses were used to calculate rates. The errors associated with these rates indicate the error of the least squares fit to the data by linear regression analysis. When duplicates were run, rates estimated from each duplicate treatment always agreed within this margin of error. Rate calculations were based on the smallest extent of depletion possible. In DMS production and DMSP uptake timecourses, initial DMSP concentrations changed by less than $35 \%$ during the portion of the experiment from which rates were estimated, and usually by less than $10 \%$. The single exception to this was the ambient DMSP timecourse displayed in Figure 3-1b. In samples which received DMS additions, an initial increase in DMS was often observed, followed by a decrease. In this case regressions were based only on the decreasing portion of the timecourse. The maximum extent of depletion in DMS consumption timecourses was $7 \%$.

Rate versus concentration curves for removal of dissolved DMSP and 
production of DMS from dissolved DMSP were linearized by means of the single reciprocal (Eadie-Hofstee) plot (7), in which the half-saturation constant, $\mathrm{K}_{\mathrm{m}}$, is given by the negative of the slope, and $\mathrm{V}_{\max }$, the maximum rate, by the y-intercept. In this study these parameters describe the activity of whole cells rather than enzyme preparations and, moreover, of assemblages of diverse microorganisms rather than single species. Parameterizing DMSP cleavage in environmental microbial populations is particularly problematic, as we do not know whether DMSP cleavage is an intracellular process or occurs at the cell surface, and therefore whether the DMSP lyase is responding to physiological or extracellular concentrations of DMSP. In recognition of these limitations, the term half saturation "value" is used in place of "constant," and the symbol $\mathrm{K}_{\text {mapp }}$ rather than $\mathrm{K}_{\mathrm{m}}$. For simplicity, $\mathrm{K}_{\mathrm{mapp}}$ and $\mathrm{V}_{\max }$ are used to denote the half-saturation value and maximum velocity of both DMSP removal and cleavage, rather than using $\mathrm{K}_{\text {tapp }}$ and $\mathrm{J}_{\max }$ when referring to the transport process. Reagents and chemicals. DMS and DMSP were obtained as in Chapter 2; all other chemicals used were of analytical grade.

\section{Results}

Low-level addition experiments. The results of these experiments are displayed in Figures 3-1 and 3-2 and summarized in Tables 3-1, 3-2 and 3-3. Relevant data from the kinetics experiments on $4 / 26$ and $5 / 26$ are also included in these tables.

At the ambient substrate levels in unamended seawater controls, DMS production and consumption alternated in dominance throughout the sampling period. Net DMS production was observed at ambient substrate levels on both $4 / 26$ and 5/26; 
(a)

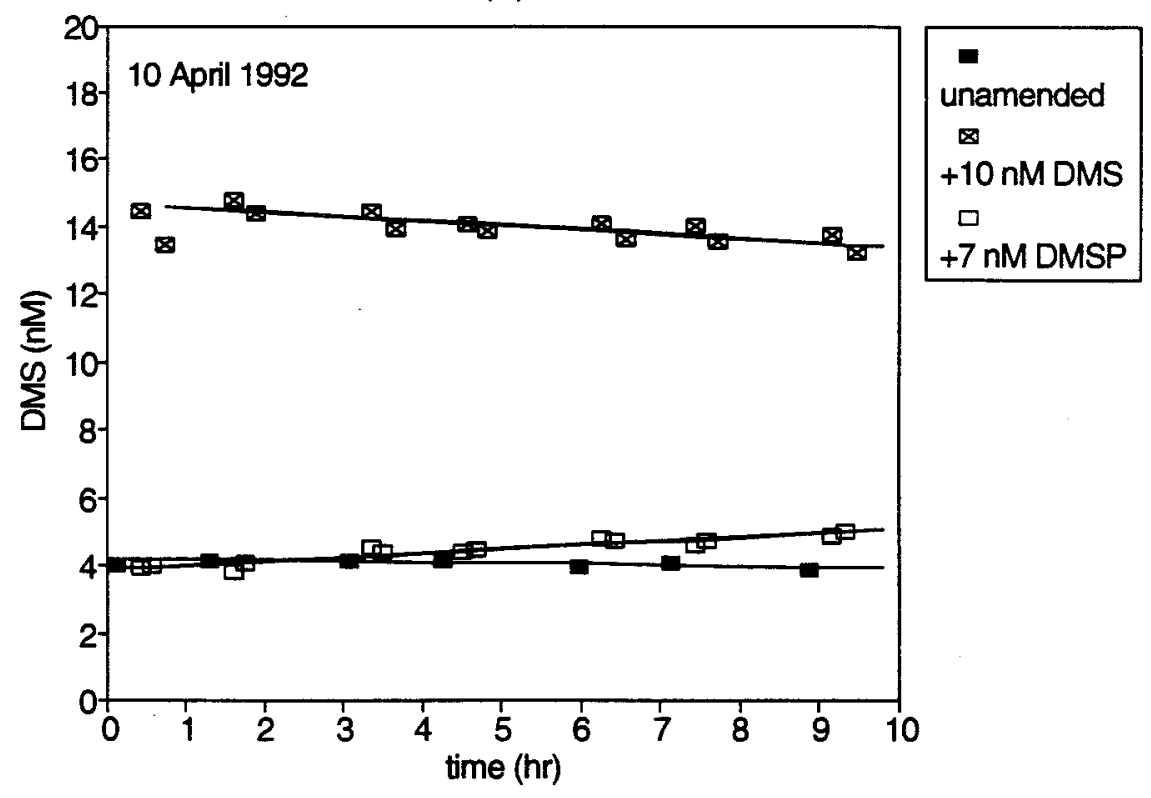

(b)

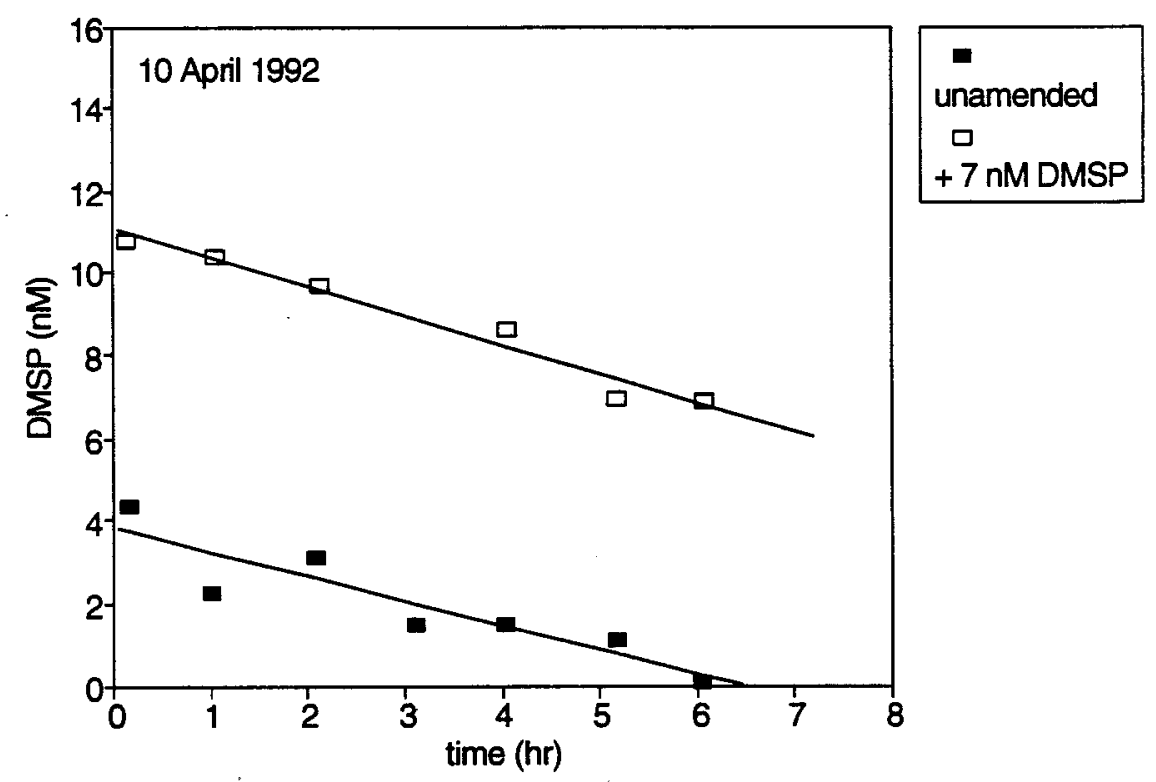

Figure 3-1. Low-level additions to Vineyard Sound seawater on 4/10/92.

(a) Timecourse of DMS in response to DMS and DMSP additions. Where duplicate samples were run, duplicates are shown. (b) Timecourse of dissolved DMSP in unamended and DMSP-amended samples. The considerable scatter in the ambient sample, and the apparent $100 \%$ depletion in substrate, probably contribute to the large calculated error (16\%) in this rate. See Tables 3-1, 3-2 and 3-3 for rates. 
(a)

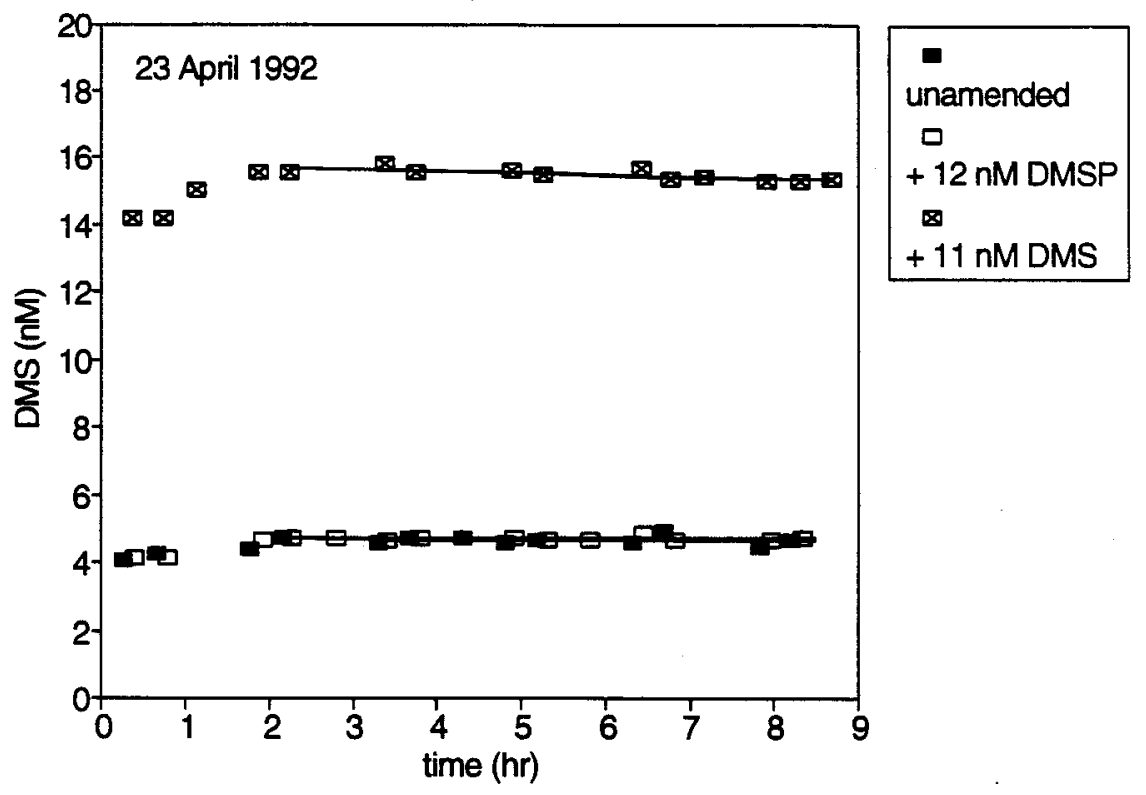

(b)

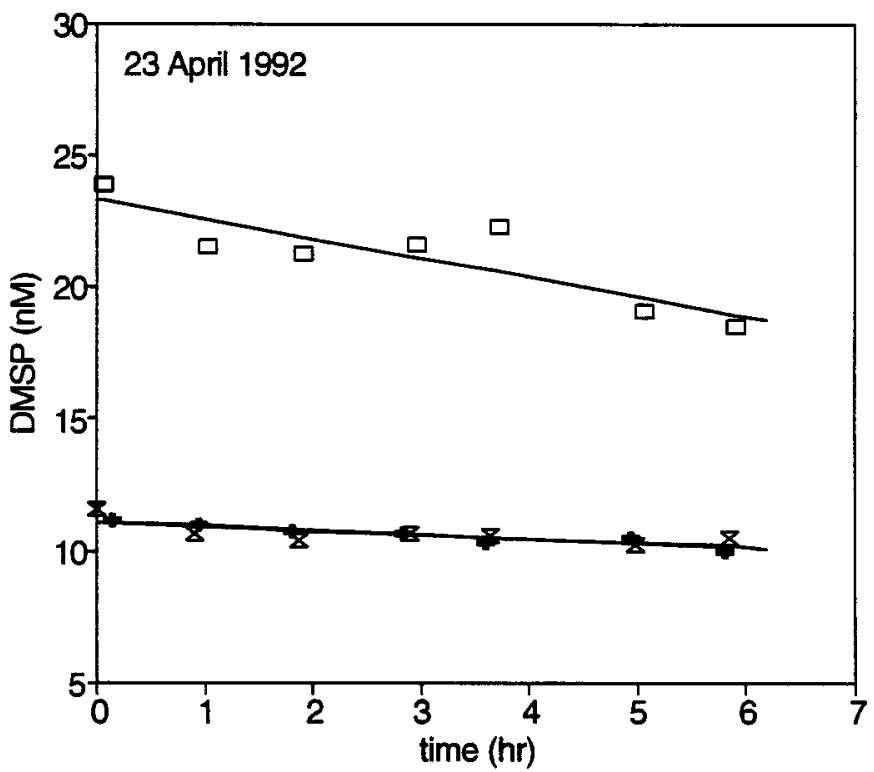

$\mathbf{z}$

unamended

unamended

口

+ 12 nM DMSP

Figure 3-2. Low-level additions on 4/23/92. (a) Timecourses of DMS in response to DMS and DMSP additions. The timecourses of DMS in the DMSP amended and unamended bottles are indistinguishable. Note the $2 \mathrm{nM}$ rise in DMS at the start of the DMS-amended timecourse, not observed in the unamended control.

(b) Timecourses of DMSP in unamended and DMSP-amended samples. One of the "unamended" duplicates (】) had actually received a DMS addition, to see whether the DMS rise in the DMS-amended sample in (a) was due to more rapid breakdown of dissolved DMSP in this treatment. As can be seen, this does not seem to be the case. 


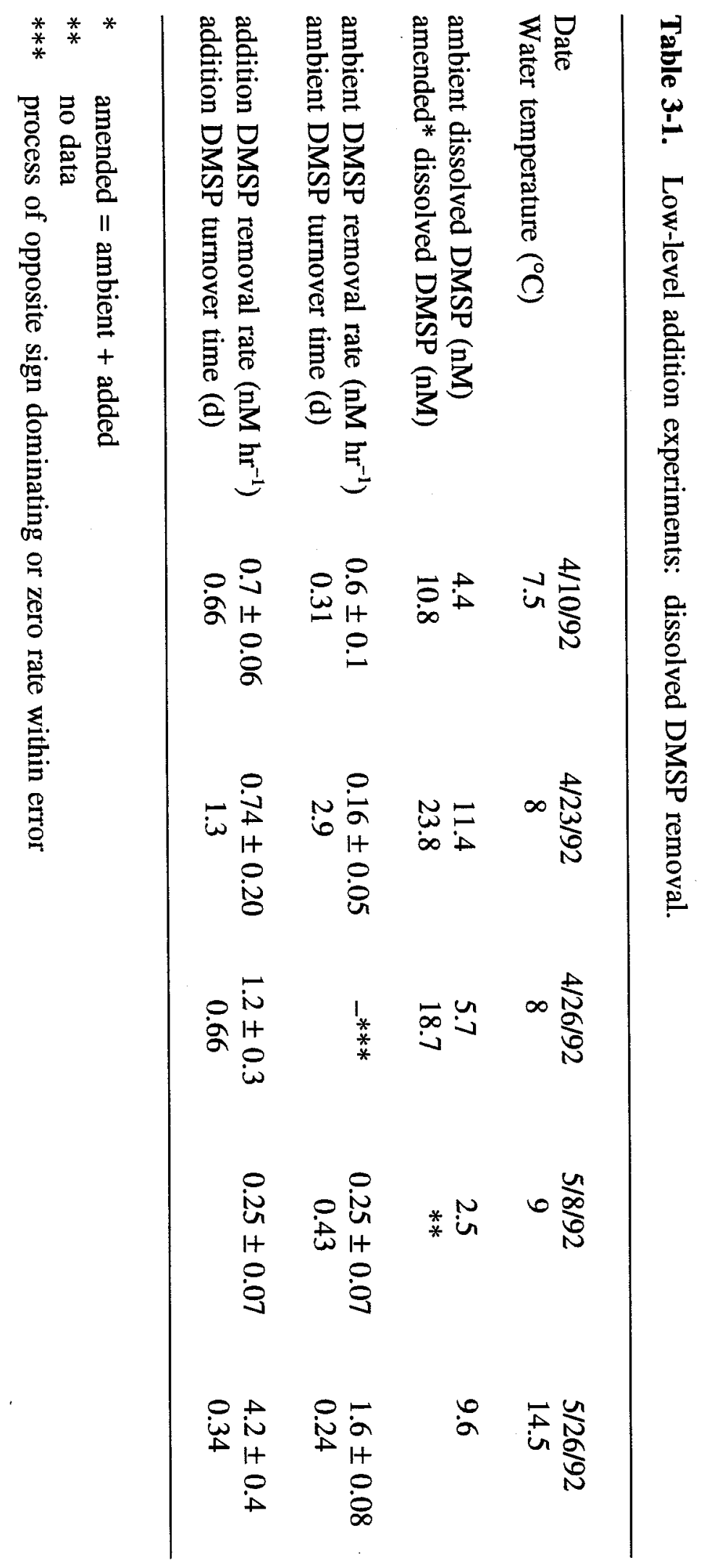




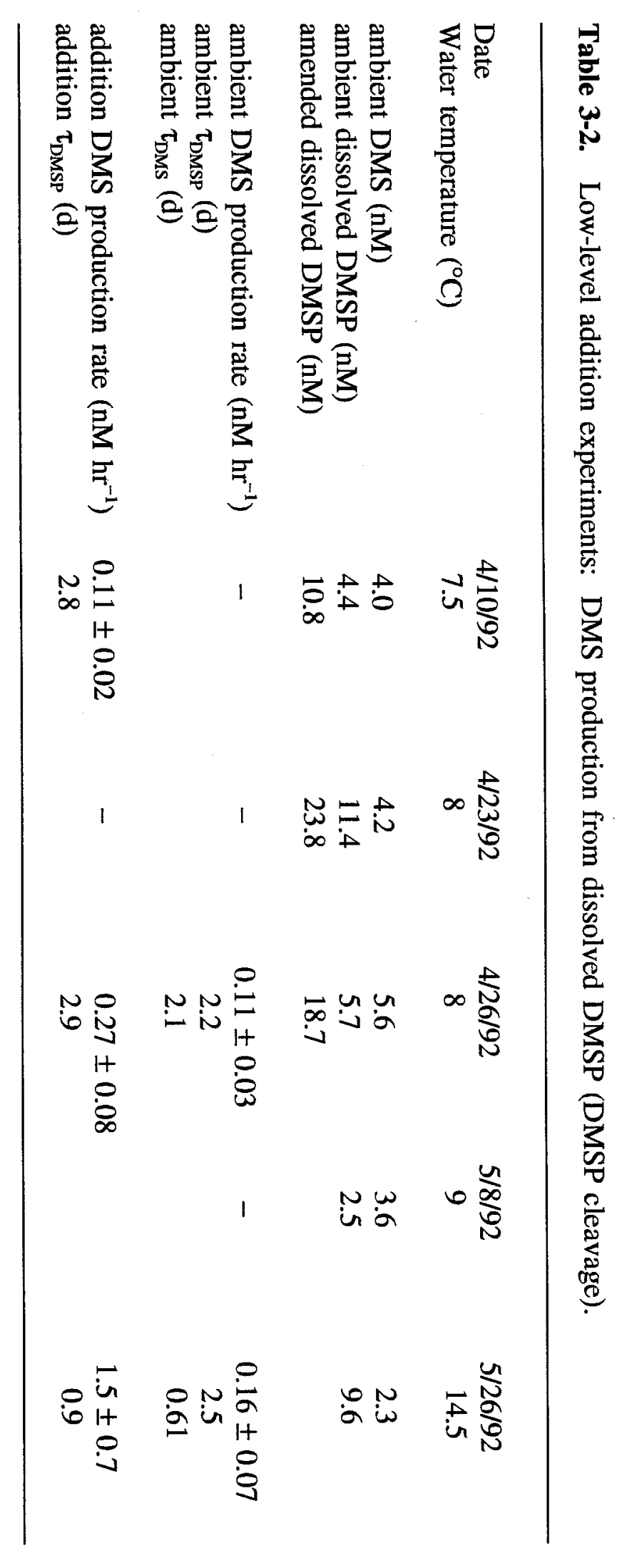

:

官. 


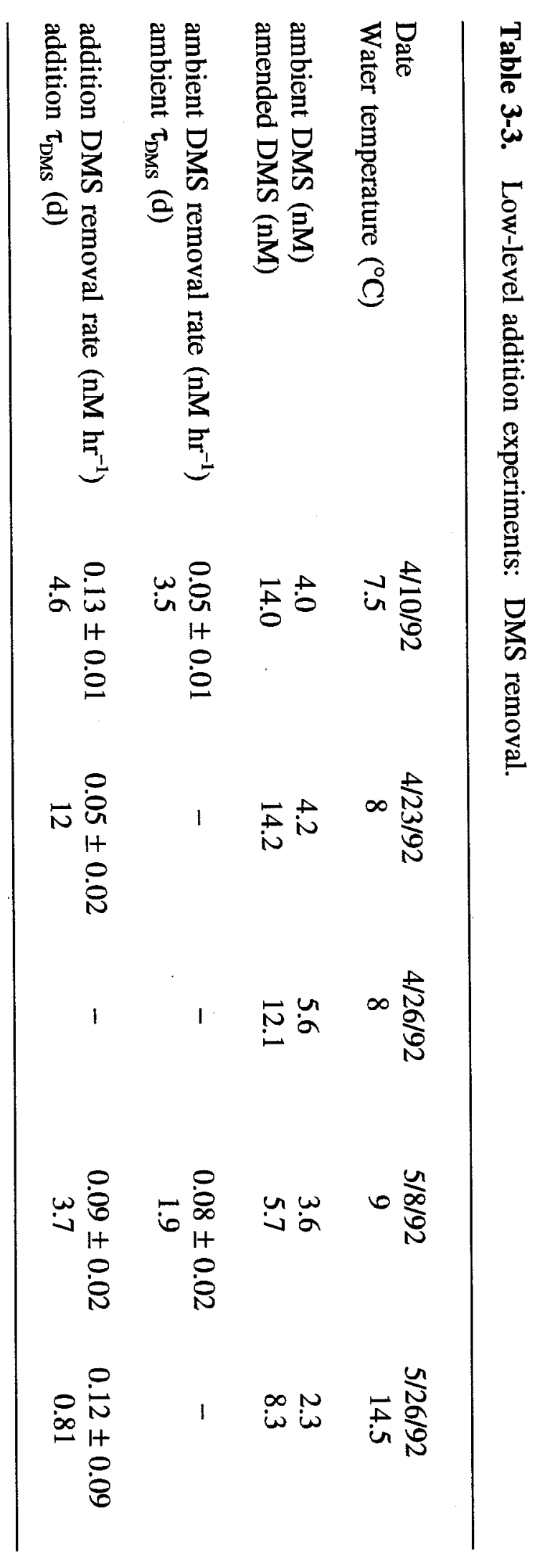


the rate of DMS production on these two occasions, averaging about $0.13 \mathrm{nM} \mathrm{hr} r^{-1}$, was the same within the error of the rate calculation. Net DMS consumption was observed on $4 / 10$ and $5 / 8$, at an average rate of about $0.06 \mathrm{nM} \mathrm{hr}^{-1}$. On 4/10, DMSP and DMS additions stimulated comparable rates of DMS production and DMS consumption, respectively. On 4/23, however, neither DMS production nor consumption was observed in the unamended control; moreover, doubling ambient DMSP concentrations did not result in any enhancement of DMS production, even though the DMSP loss rate increased slightly. In general, rates of all three processes were considerably lower on $4 / 23$ than on other occasions: a circumstance seemingly unrelated to water temperature or ambient substrate levels. Rates of dissolved DMSP loss were both higher and more variable $\left(0.16-1.6 \mathrm{nM} \mathrm{hr}^{-1}\right)$ than rates of DMS production from DMSP or DMS consumption, and appeared generally independent of ambient soluble DMSP concentrations.

As can be seen from the simple schematic in Figure 3-3, DMSP may be degraded in seawater by a variety of pathways which cannot be distinguished by the measurements made here. However, the turnover time of dissolved DMSP can be calculated, as it is determined by the total loss rate of DMSP from solution. Data in this chapter suggest that DMSP cleavage accounts for only a fraction of DMSP loss. Therefore, when describing DMSP turnover with respect to cleavage to form DMS, the symbol $\tau$ is used, rather than the term "turnover time." For instance, " $\tau_{\text {DMSP }}$ (cleavage)" refers to the amount of time in which a given level of DMSP would be completely turned over by cleavage to form DMS if DMSP cleavage were the only process responsible for DMSP loss. A similar convention is followed when alluding 

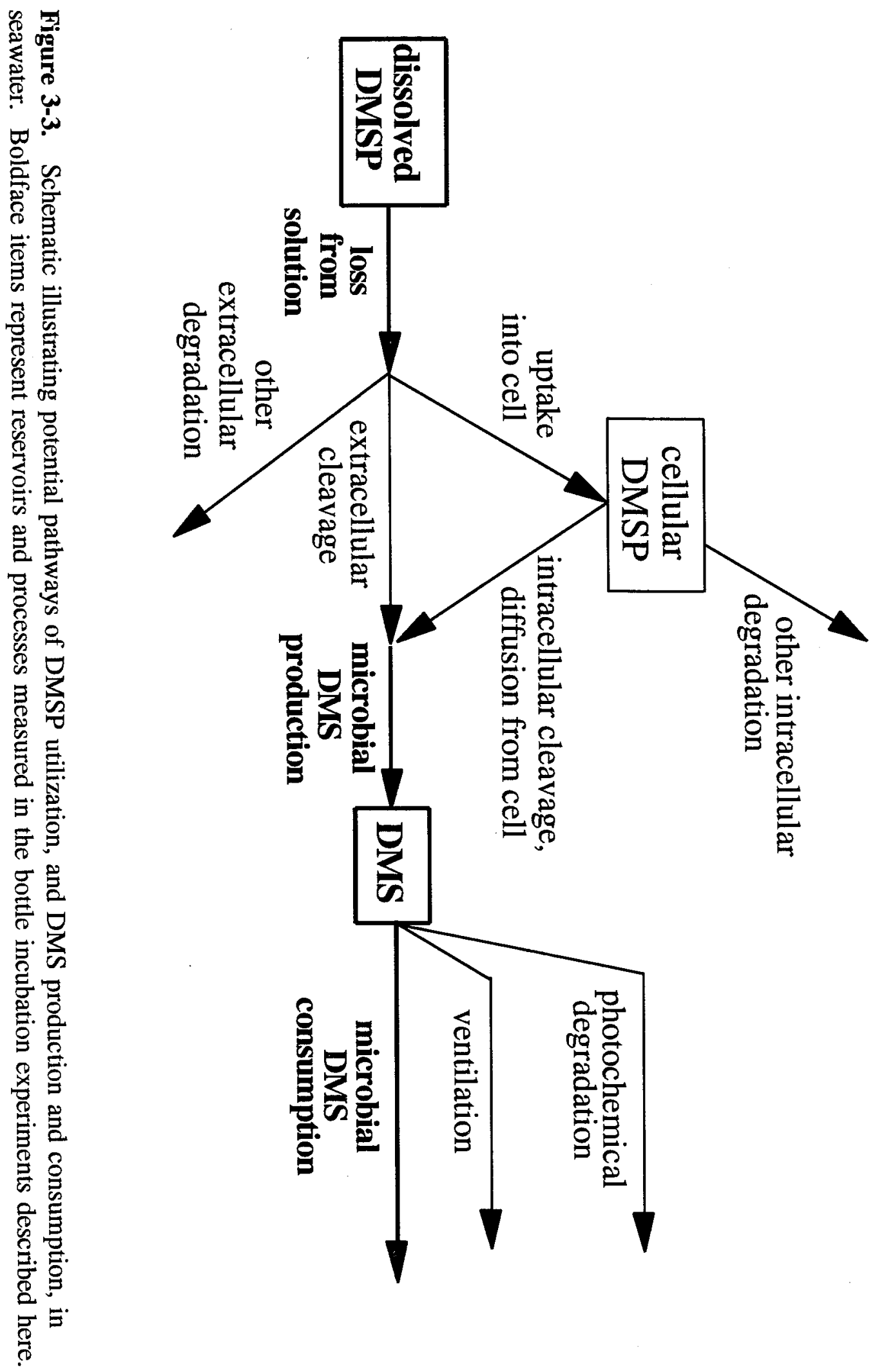
to DMS turnover. However, in the case of DMS, turnover with respect to both production from dissolved DMSP and DMS consumption is symbolized by $\tau$ 's. This is because the total loss rate of DMS, and therefore the true turnover time of DMS, cannot be determined in dark bottle experiments, which exclude the processes of photochemical destruction and ventilation.

On all but one of the four occasions on which dissolved DMSP consumption at ambient levels was measurable, the turnover time of DMSP was less than half a day (6-10 hours). The exception occurred on $4 / 23$, when rates of all processes appeared depressed. $\tau_{\mathrm{DMS}}$, both with respect to production from ambient DMSP and consumption, ranged from 15 hours to 3.5 days. $\tau_{\mathrm{DMSP}}$ (cleavage) had a similar value of about 2.5 days, considerably longer than the turnover time of DMSP as determined from its total loss rate.

Kinetics of DMSP removal and DMSP-lyase activity. Data from kinetics experiments are displayed in Figures 3-4 and 3-5 and Table 3-4. Although presumably reflecting the average affinity of a population of diverse microorganisms, both DMSP consumption and DMS production from DMSP appeared amenable to modelling by Michaelis-Menten kinetics. Rate versus concentration data for the kinetics experiment conducted on 4/26 is displayed in Figure 3-4. Net DMSP production rather than removal was observed at ambient concentrations on this occasion; therefore, only the five addition rates are shown. Apparent half-saturation values for removal and cleavage of dissolved DMSP, 48 and $24 \mathrm{nM}$ respectively, were similar in magnitude. Maximal rates, however, differed significantly; the saturated rate of DMSP cleavage to form DMS was only $14 \%$ that of dissolved DMSP loss. The kinetics experiment on 
(a)

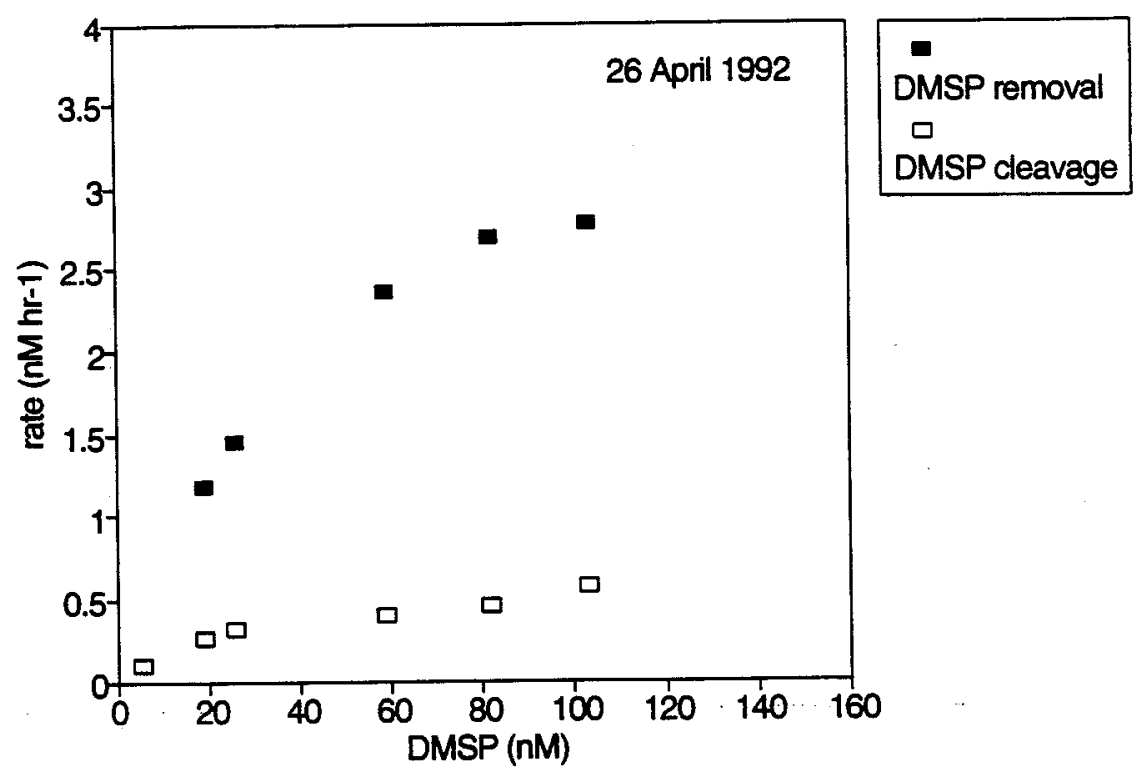

(b)

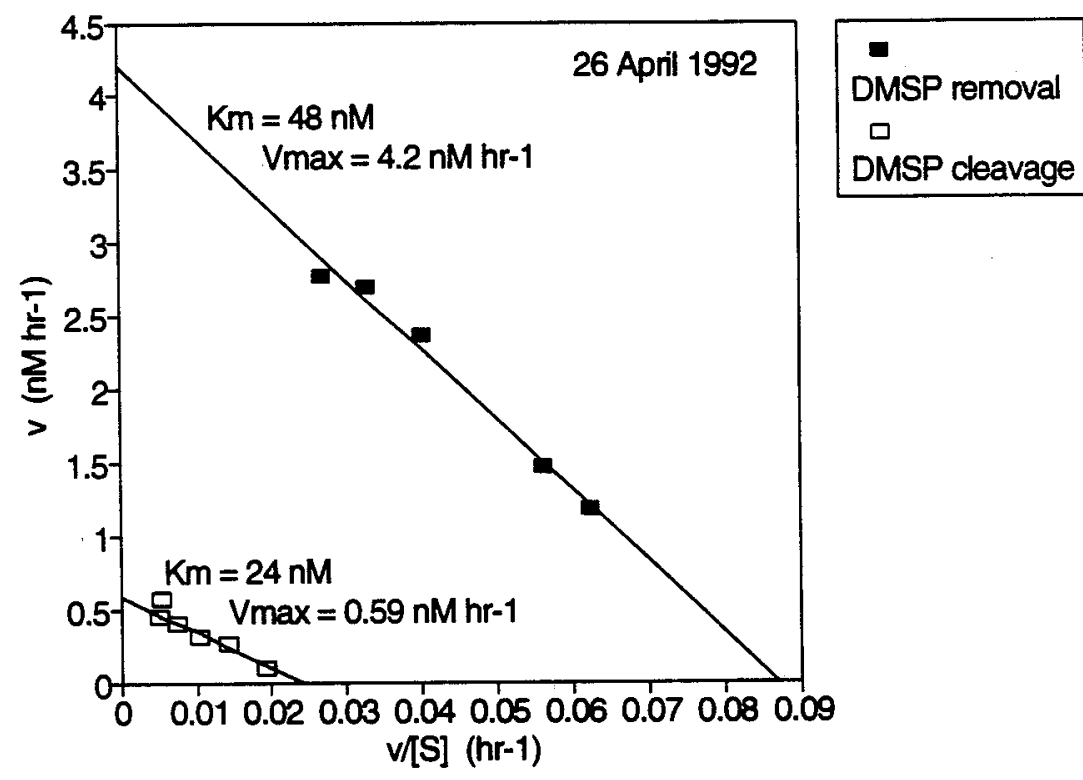

Figure 3-4. Kinetics of DMSP removal and DMSP-lyase activity on 4/26/92. (a) Saturation curves. Production of DMSP, rather than removal, was observed at ambient DMSP levels during this experiment; only the five addition rates are displayed (uncorrected for production in the ambient sample). (b) Single reciprocal (Eadie Hofstee) plot of data in (a). The DMSP-lyase kinetics regression is based on the five rates $<0.5 \mathrm{nM} \mathrm{hr}^{-1}$. 
(a)

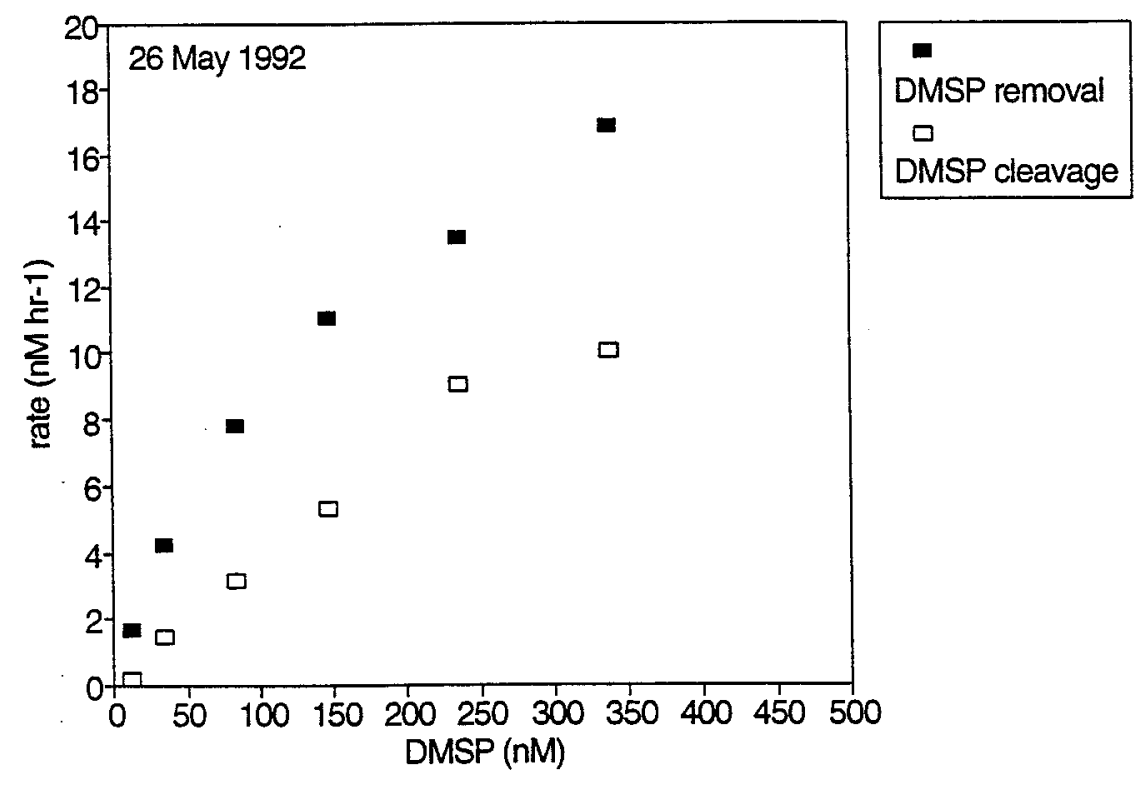

(b)

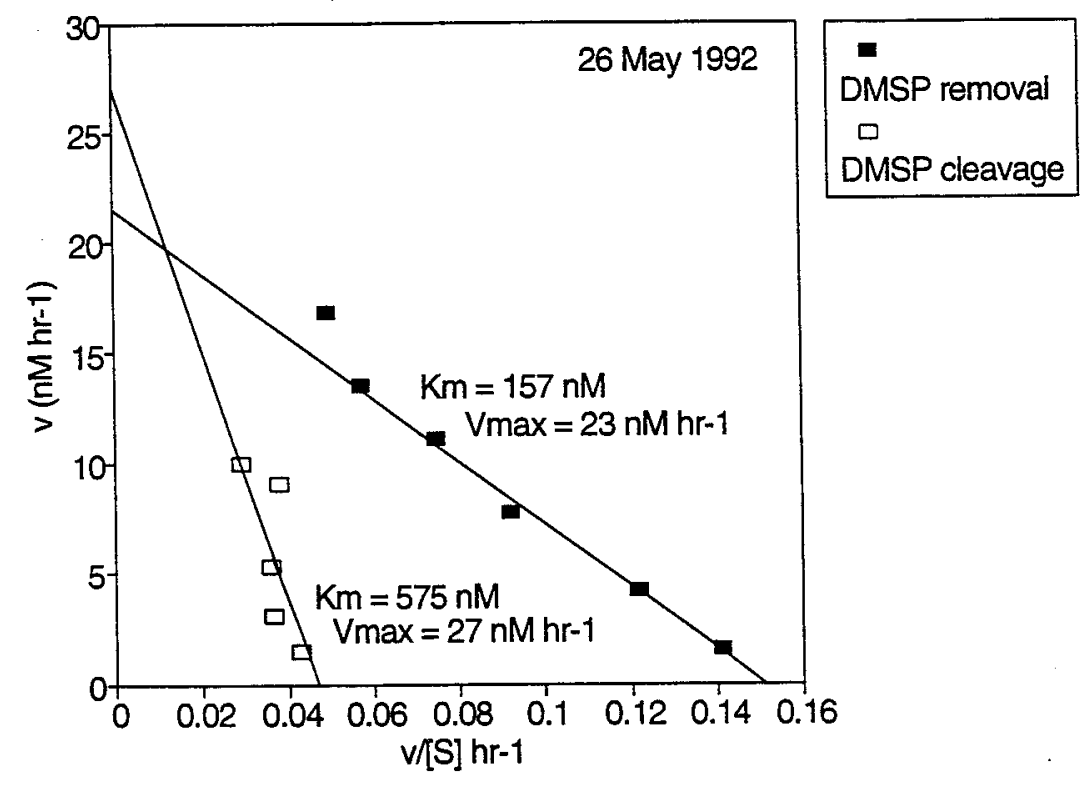

Figure 3-5. Kinetics of DMSP removal and DMSP-lyase activity on 5/26/92. (a) Saturation curve. (b) Single-reciprocal plot of data in (a). 
Table 3-4. Estimated kinetic parameters.

\begin{tabular}{lccc}
\hline Date & Process & $\begin{array}{l}\mathrm{K}_{\operatorname{mapp}} \\
(\mathrm{nM})\end{array}$ & $\begin{array}{c}\mathrm{V}_{\max } \\
\left(\mathrm{nM} \mathrm{h}^{-1}\right)\end{array}$ \\
\hline $4 / 26 / 92$ & DMSP removal & 48 & 4.2 \\
$4 / 26 / 92$ & DMS production & 24 & 0.59 \\
$5 / 8 / 92$ & DMS removal & no concentration dependence & \\
$5 / 26 / 92$ & DMSP removal & 157 & 23 \\
$5 / 26 / 92$ & DMS production & 575 & 27 \\
\hline
\end{tabular}


$5 / 26$, one month later, revealed a significant change in both the relative and absolute values of these parameters. Apparent half-saturation values for uptake and lyase activity had risen to 157 and $575 \mathrm{nM}$, and $V_{\max }$ values to 23 and $27 \mathrm{nM} \mathrm{hr}^{-1}$, respectively.

Controls examining the extent of DMS consumption in DMS-amended seawater were monitored during both kinetics experiments (Figure 3-6). DMS was not removed to a measurable extent in the $4 / 26$ control; in fact production was observed, analogous to the unamended control. On 5/26, the DMS addition timecourse was noisier, and may indicate some stimulation of DMS removal.

Kinetics of DMS consumption. The concentration dependence of DMS removal in the $0-25 \mathrm{nM}$ concentration range was assessed on $5 / 8 / 92$. Rates calculated from the first 5-6 hours of each timecourse showed no concentration dependence (Figure 3-7). Initial rates of DMS removal were between 0.08 and $0.1 \mathrm{nM} \mathrm{hr}^{-1}$ at all DMS concentrations assayed, and were equal within the regression errors.

\section{Discussion}

Low-level addition experiments carried out in the spring of 1992 reveal that, with one exception, the absolute rates of dissolved DMSP removal, DMS production from DMSP, and DMS removal, examined at ambient substrate levels, varied only slightly between experiments. Microbially mediated DMS production and consumption alternated in dominance under ambient conditions. DMS consumption at ambient DMS levels generally occurred more slowly than DMS production. $\tau_{\mathrm{DMS}}$ with respect to both processes, estimated at ambient levels of DMSP and DMS, did not 
(a)

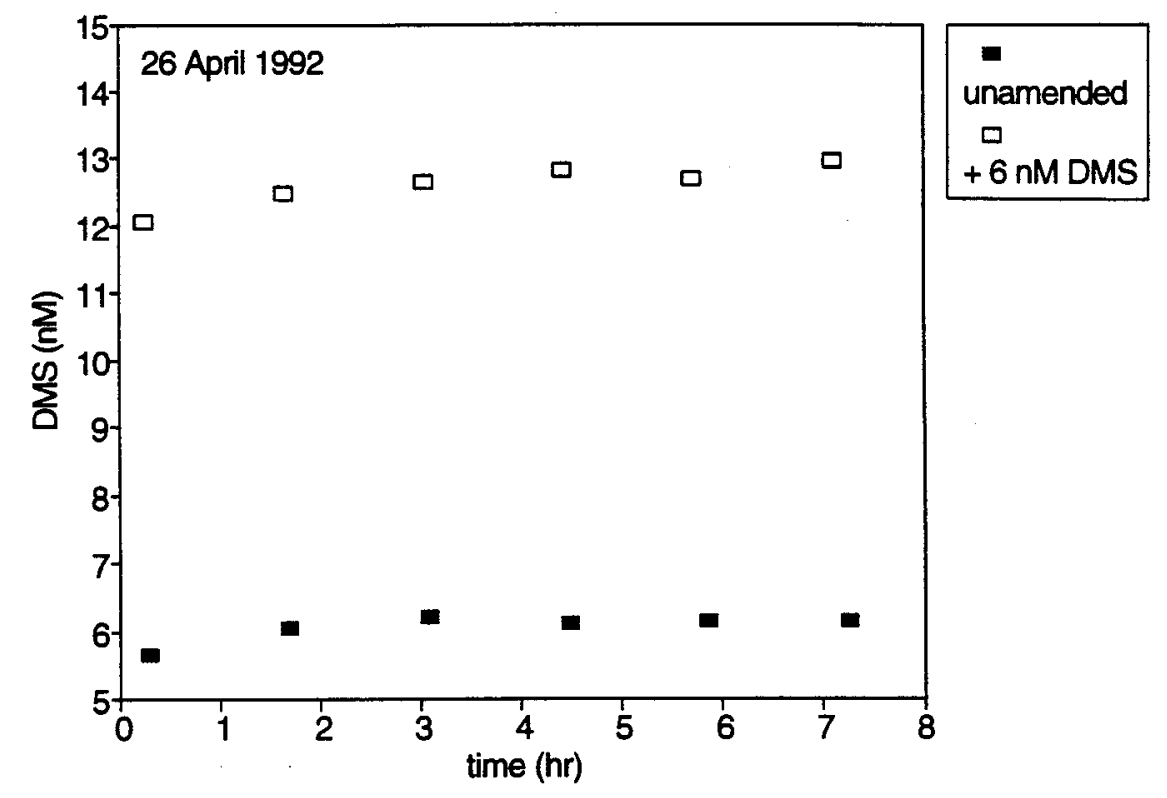

(b)

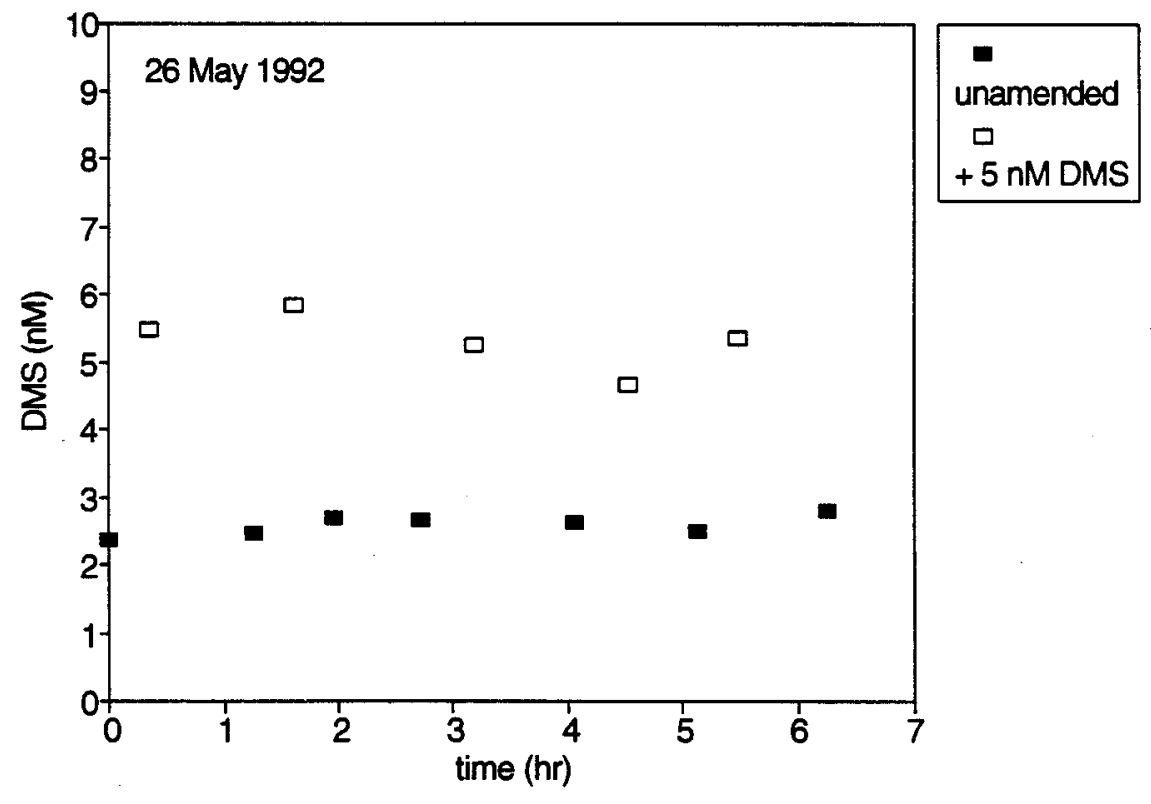

Figure 3-6. Timecourse of DMS in DMS-amended controls for kinetics experiments on (a) $4 / 26 / 92$ and (b) $5 / 26 / 92$. The level of the DMS addition was based on ambient DMS concentrations. These controls were not run in duplicate. 


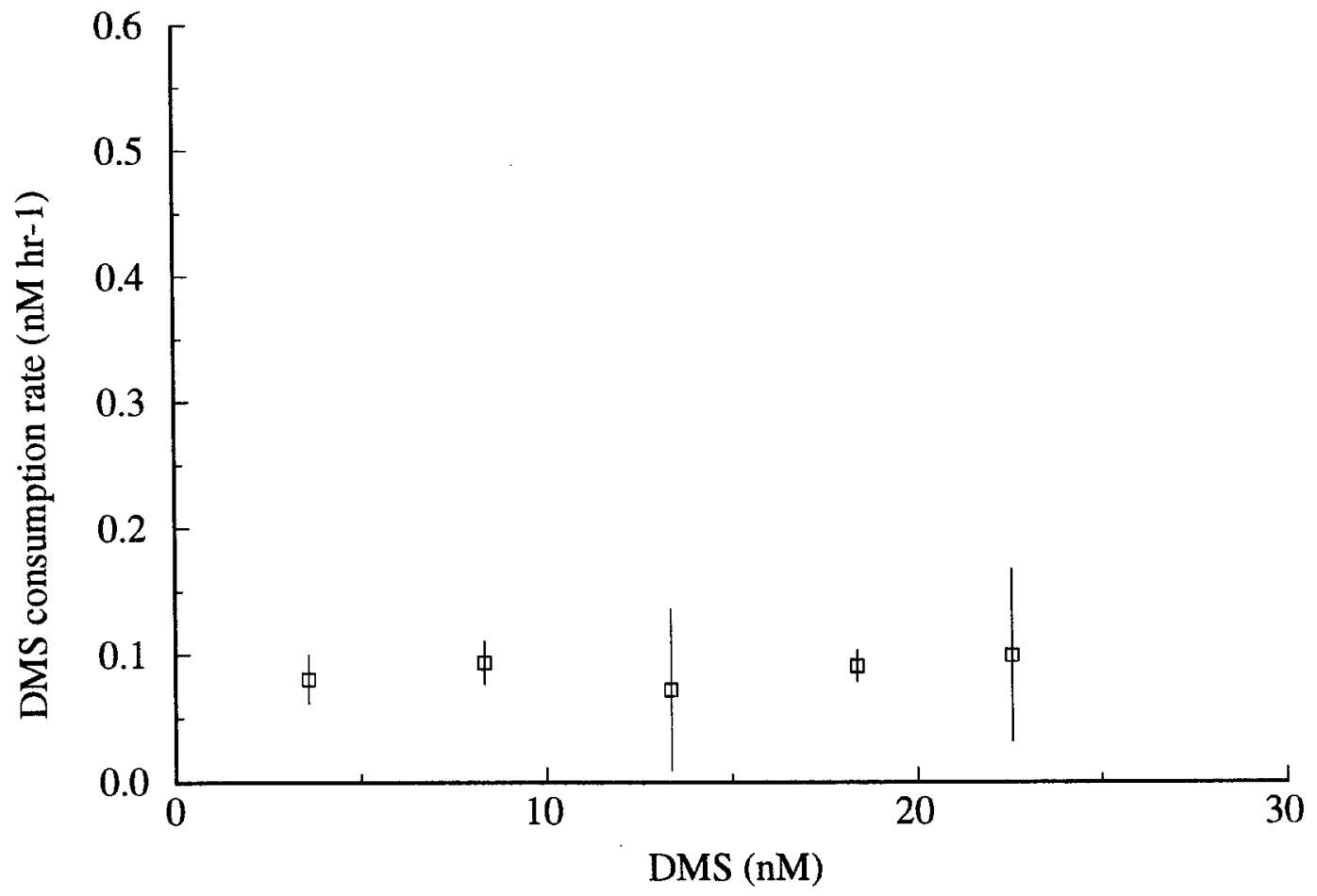

Figure 3-7. Rate versus concentration data for the DMS consumption kinetics experiment on 5/8/92. Bars represent the standard error of the regression slopes. 
differ drastically, however. Removal of dissolved DMSP was, with one exception, the most rapid of the three processes, often turning DMSP over on timescales of several hours.

For all three processes, substrate additions generally yielded longer turnover times than were calculated at ambient concentrations (with one exception: DMSP uptake on 4/23), reflecting the effects of saturation at only double or triple ambient substrate levels. Accurate assessment of in situ turnover times will require rate measurement in either unamended water, if detection methods allow, or in water that has received radiotracer additions. However, despite their limitations in this regard, low-level substrate additions in some cases revealed the relative importance of simultaneously occurring processes. For instance, the sluggish DMS consumption in response to a substantial DMS addition on 4/23 (Figure 3-2) indicates that metabolism of DMS is probably not responsible for the observed lack of DMS production from both ambient and amended DMSP.

The results of both low-level additions and kinetics experiments imply that, during the period of measurement, cleavage to form DMS is the fate of only a fraction of DMSP removed from solution. However, the kinetic assessments here show that this fraction changed strikingly between the experiments conducted in April and May. While rates of DMS production averaged only about $20 \%$ of DMSP removal rates on $4 / 26 / 92$, they increased to $35-67 \%$ a month later. Kiene and Service (14) have observed that cleavage to form DMS cannot account for all of the DMSP consumed in their incubations, and conclude from this that "DMS is not the major sulfur product of DMSP metabolism in estuarine waters." This study illustrates rather that the fraction 
of DMSP resulting in DMS formation is a dynamic quantity, and that at times cleavage to form DMS may indeed constitute the major fate of soluble DMSP. The two kinetics experiments reported here, which bracket a period of one month and a $6^{\circ} \mathrm{C}$ increase in water temperature, are not sufficient to establish the possible seasonal dependence of this change. However, results from similar experiments with Sargasso Sea water confirm that the kinetics of DMSP-lyase activity may indeed undergo a seasonal change.

Kinetic parameters estimated for DMSP removal and cleavage also differed significantly between these two experiments. Apparent $\mathrm{K}_{\mathrm{m}}$ 's, which in April are on the order of ambient soluble DMSP levels of 2-15 nM, rose in May to $157 \mathrm{nM}$ for DMSP removal and $575 \mathrm{nM}$ for cleavage. Although concentrations as high as $160 \mathrm{nM}$ have not been measured in Vineyard Sound, Wakeham et al. (23) have observed soluble DMSP concentrations of up to $60 \mathrm{nM}$ in a coastal salt pond adjacent to the sampling site, and summer levels approaching $85 \mathrm{nM}$ have been recorded in nearby Waquoit Bay (K. Ledyard, unpublished). However, the apparent change in $\mathrm{K}_{\mathrm{mapp}}$ for DMSP removal and cleavage between April and May does not seem to reflect an obvious change in dissolved DMSP concentrations in seawater during the same period. High apparent half-saturation values for glucose in natural assemblages of marine bacteria (1) have been interpreted to support the notion that small, high-concentration patches of dissolved organic matter $(3,19)$ exist in the immediate vicinity of algal cells. Mitchell et al. (18) calculated that these "microzones" can occur only when turbulence is extremely low, but a re-examination of the effect of turbulence on diffusive flux (16) suggests that microzones may be far more stable than previously 
thought. Manahan (17) postulates an inverse relationship between volume (of relevant medium) and maximum possible DOM concentration encountered in that volume. By this analysis extremely high DMSP concentrations may be frequently encountered in volumes of seawater relevant to micrometer-scale cells. The observed increase in $\mathrm{K}_{\mathrm{mapp}}$ for DMSP removal in May may thus reflect changes in ambient dissolved DMSP levels not detectable in bulk water measurements. This increase is presumably brought about by a change in microbial assemblage composition, favoring organisms with halfsaturation values for uptake optimally related to ambient DMSP substrate concentration. This condition will be met when the enzyme controlling DMSP uptake is operating at a reasonable fraction of its capacity and yet can still display a substantial response to changes in concentration (10).

The increase in the $\mathrm{K}_{\text {mapp }}$ for DMSP-lyase activity is less easy to interpret. As previously mentioned, lyase activity may be governed by intracellular, not environmental, DMSP levels, depending on whether activity is surface-associated. Examination of this process in a pure culture of a marine bacterium (Chapter 5) indicates that in this organism DMSP uptake and accumulation precede DMS formation. If the lyase is intracellular in environmental microbial populations, an increase in DMSP uptake rates, which could result in higher average cellular DMSP levels, might be expected to have an effect on half-saturation value governing DMSP cleavage. The observation that the $\mathrm{K}_{\text {mapp }}$ for cleavage in May greatly exceeds ambient dissolved DMSP concentrations, and moreover is several times larger than the $\mathrm{K}_{\mathrm{mapp}}$ for DMSP removal, is consistent with this concept.

The maximum rate of DMSP removal is dramatically higher than that of DMS 
production in the April kinetics experiment, but maximum rates of both processes increase in May, approximately 5-fold for DMSP removal and 45-fold for DMSP-lyase activity, until they are nearly equal. Again, without knowing more about the nature of DMSP-lyase activity, it is difficult to interpret the changing relation between uptake and lyase activity. It is only possible to observe that the affinity of the microbial population for DMSP decreases and that the maximum rate at which DMSP is removed from solution and cleaved increase.

In general, the uptake data regress more cleanly than the DMS production data. Noise in the latter may arise from a number of sources. One possible explanation is that DMS production rate estimates are subject to error due to competing DMS consumption. DMS-amended controls (amended DMS concentrations of 12 and 5.5 $\mathrm{nM}$, respectively, on $4 / 26$ and 5/26) provide an estimate of the possible error due to this process. On $4 / 26$, net DMS production rather than consumption was observed in both an unamended control and a DMS addition (Figure 3-6a); the rate of production was even slightly enhanced in the latter. As no more than $10 \mathrm{nM}$ DMS, less than the concentration in the DMS-amended control, accumulated in any one rate assay, DMS consumption was unlikely to interfere with DMS production rate estimates on 4/26. On $5 / 26$, while no net consumption was observed at ambient DMS levels, the amended DMS concentration of $5.5 \mathrm{nM}$ decreased after an initial rise, and then rose again, with a maximum removal rate of about $0.4 \mathrm{nM} \mathrm{hr}^{-1}$ (Figure 3-6b) estimated from the third, fourth and fifth timepoints. It is unclear whether the decrease reflects noise in the data or true DMS consumption. DMS removal rates documented by Kiene and Service (14) range between 0.2 and $0.5 \mathrm{nM} \mathrm{hr}^{-1}$ at DMS levels of 6-26 nM. Most of 
the rates of DMS production recorded on 5/26 (2-10 $\left.\mathrm{nM} \mathrm{hr}^{-1}\right)$ would not have been severely perturbed by these comparatively modest DMS consumption rates. However, the possibility of some scatter from this source cannot be ruled out.

A second explanation for noise in the lyase data is that the kinetics of DMS production from DMSP reflect more than one enzymatic process. At present we have no knowledge of the nature of DMSP lyase that mediates this process in environmental assemblages. Depending on the localization of the enzyme, cleavage of DMSP may necessitate prior uptake and accumulation, precluding accurate modelling of DMSP-lyase activity by observation of the endproduct DMS. In some organisms, a threshold internal concentration may need to be exceeded before DMSP-lyase activity is initiated. If uptake of even small amounts of DMSP results in DMS formation, and DMSP uptake and DMS diffusion from the cell are fast relative to cleavage, measurement of DMS formation may be an acceptable way to quantify DMSP-lyase activity in the environment. Unfortunately, this is the only means available at present to distinguish DMSP uptake resulting in DMS formation from total DMSP uptake. As we currently have no way to assess the reliability of this approach, the interpretation of the DMS production data presented here is necessarily uncertain.

Biological DMS removal in seawater and estuarine water has been previously reported $(13,14,23)$. The use of DMS-amended controls has in some cases provided upper limits on the extent of DMS consumption during these timecourses. Because rates of concomitant DMS consumption have not been rigorously quantified, however, estimates of DMS production in this study must necessarily be regarded as lower limits. Treatment with $0.5 \mathrm{mM}$ chloroform has been used in the past by some workers 
$(13,14)$ to inhibit DMS consumption selectively. This approach was not utilized in the present study. While experiments with chloroform and methylene chloride inhibition of DMS consumption have confirmed that these treatments prevent the bulk of DMS removal and do not appear to affect rates of DMS accumulation from DMSP (J. Dacey, unpublished; 14), they seem to increase the amplitude of background fluctuations in DMS, and do not completely inhibit DMS removal. Chloroform has been found to inhibit methanogenesis in cow rumen contents (2) and the reduction of methyl coenzyme M to methane in Methanobacterium thermoautotrophicum (9).

While we do not know the identity of the marine DMS-utilizing organisms affected by chloroform, aerobic methylotrophic bacteria are possible candidates. In view of the fundamental difference between these eubacteria and methanogens, which are archaebacteria, equating methane production and DMS consumption under the rubric of $\mathrm{C}_{1}$ metabolism (13) with respect to chloroform inhibition is probably not justified. Additionally, the effects of chloroform on other reactions relevant to DMS and DMSP cycling are not known. Demethylation to form 3-methiolpropionate (MMPA) has been identified as a pathway of DMSP breakdown in anaerobic marine sediments (15). Isolation of MMPA-metabolizing bacteria from seawater (20) suggests that this breakdown may also be operative in the aerobic marine water column. If chloroform indeed inhibits aspects of $\mathrm{C}_{1}$ metabolism, it may suppress demethylation of DMSP. This might tend to favor organisms that metabolize DMSP by cleavage to form DMS, such that DMSP removal would not necessarily decrease, and DMS production might increase. In this scenario, the net effect would be not only to inhibit DMS consumption but to amplify DMS production by changing the relative proportions of 
DMSP-utilizing microorganisms. Although this is a simplistic illustration, it highlights our need to understand the mechanism of chloroform inhibition of DMS consumption, and the potential pitfalls of using inhibitors in whole water samples. DMS cycling in seawater, which involves diverse levels of the food web, should be perceived as especially vulnerable to such manipulations.

The lack of concentration dependence in DMS consumption observed in the kinetics experiment on $5 / 8$ may simply reflect extremely low levels of this activity on the day of measurement. On other occasions (see Table 3-3), single-level DMS additions did enhance DMS uptake rates. An alternate explanation might be that the length of the assay in this experiment - approximately eight hours - precluded observation of significant DMS removal. In Chapter 2, a 17-hour lag preceded significant DMS metabolism (Figure 2-5). The data of Kiene and Service (14) show a similar 15 -hour lag. The authors caution that this does not necessarily represent a lag in DMS consumption, but may instead indicate no net consumption. However, if DMS removal is a concentration-dependent process, and background levels of DMS production from DMSP are reasonably similar in all treatments, it is difficult to see how this phenomenon results from anything other than a lag in DMS consumption. The lag may indicate that the effect of DMS consumption on short-term DMS production timecourses is negligible. However, it is probably not safe to make this assumption. In some instances, for example the low-level addition experiments on 4/10 and 4/23, DMS removal in response to DMS addition was evident after only one to two hours.

The explanation for the low level of concentration-independent DMS removal 
observed on $5 / 8$ is not apparent. If this removal is not biologically mediated, it may indicate the existence of other pathways for DMS consumption in seawater. The experiment was conducted in dark bottles, and there was no decrease in standard concentrations during the period of measurement (for instance, due to DMS uptake by silicone bottle stoppers or glass bottle walls). These observations rule out photochemical decomposition or analytical artifacts as sinks for DMS in this experiment. Sorption onto particles may play a role in DMS removal; however, no such removal was noted on $4 / 23$, even when DMS production was not detectable in either ambient or DMSP-amended seawater.

It is interesting to compare the magnitude and concentration dependence of rates estimated in this study with published data. DMS consumption rates estimated here range from undetectable to $0.12 \mathrm{nM} \mathrm{hr}^{-1}$ for DMS concentrations between 2.3 and 14.2 nM. Kiene and Bates (13), comparing untreated and chloroform-treated seawater samples, calculate DMS consumption rates of $0.05-0.75 \mathrm{nM} \mathrm{hr}^{-1}$ in the east tropical Pacific ( 5 of 8 assays yielded rates $<0.06 \mathrm{nM} \mathrm{hr}^{-1}$ ) at DMS levels between 0.8 and $10.3 \mathrm{nM}$. Kiene and Service (14) note a definite concentration dependence of DMS consumption in estuarine water, with rates on the order of $0.2-0.5 \mathrm{nM} \mathrm{hr}^{-1}$ for the concentration range between about 7 and $26 \mathrm{nM}$. Although the attempt to quantify DMS consumption kinetics presented here is not comparable to the data of Kiene and Service (14) because of the different part of the timecourse used for rate calculation, it is interesting that the linear regression through their data results in a positive $y^{-}$ intercept similar in value to the low but constant level of DMS consumption observed in our assay bottles (Figure 3-8a). In general, the DMS consumption rates reported in 
Kiene and Bates (13) and Kiene and Service (14) are similar to those estimated here.

A comparison of existing rate versus concentration data for the processes of DMSP removal and DMS production from DMSP is displayed in Figures 3-8b and 3-8c. For DMSP $<50 \mathrm{nM}$, rates estimated for both processes on $5 / 26$ are in general agreement with the Kiene and Service (14) data set. However, Kiene and Service report considerably higher rates of both DMSP removal and DMS production between 50 and $100 \mathrm{nM}$, and do not observe saturation of activity in their range of measurement. The regression lines that fit their data for both processes have significantly negative y-intercepts, precluding comparison of DMSP uptake rates for DMSP $<13 \mathrm{nM}$ and DMS production rates for DMSP $<21 \mathrm{nM}$, the concentration range into which Vineyard Sound ambient DMSP levels fit at the time these experiments were carried out. The meaning of these negative intercepts is not clear. They may reflect extremely low rates of DMSP uptake and DMSP-lyase activity at ambient soluble DMSP levels in this estuarine environment (approximately $23 \mathrm{nM}$ ). Alternatively, these intercepts may be real; that is, significant release of soluble DMSP may be occurring concomitantly with removal during their experiment, perhaps due to processes such as zooplankton grazing $(\sigma)$ or to cell lysis in response to chloroform addition. No mention was made of prefiltration in the experiments of Kiene and Service (14), while seawater used for incubations in this study was screened through $75 \mu \mathrm{m}$ mesh to remove large grazers. At any rate, it is clear from the results presented here that both the absolute and relative rates of dissolved DMSP removal and DMS production from DMSP may change dramatically in short periods of time, such that the comparison attempted above would be best made between data sets 
(a)

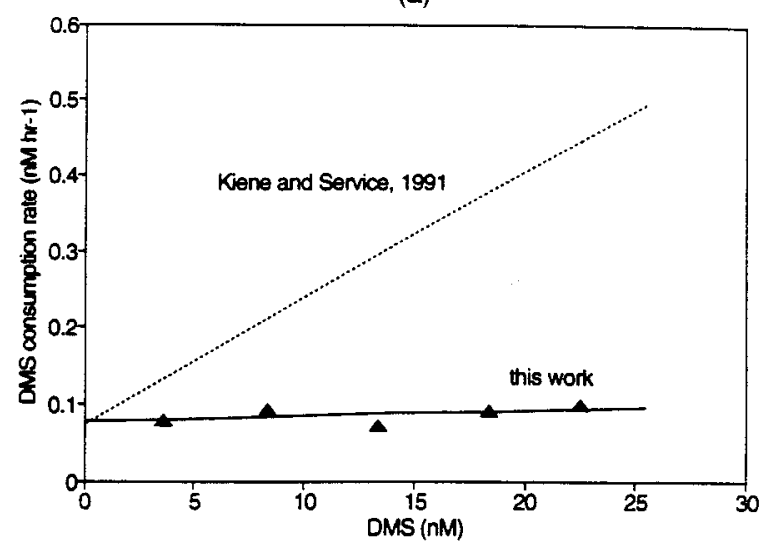

(b)

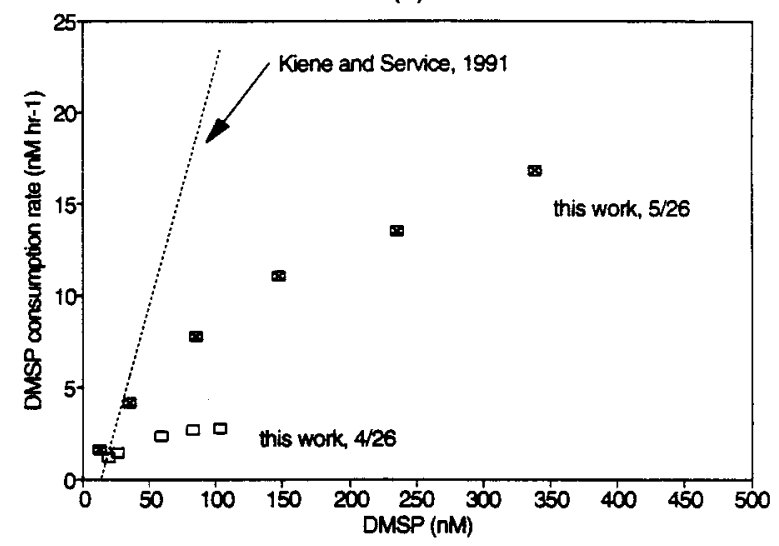

(c)

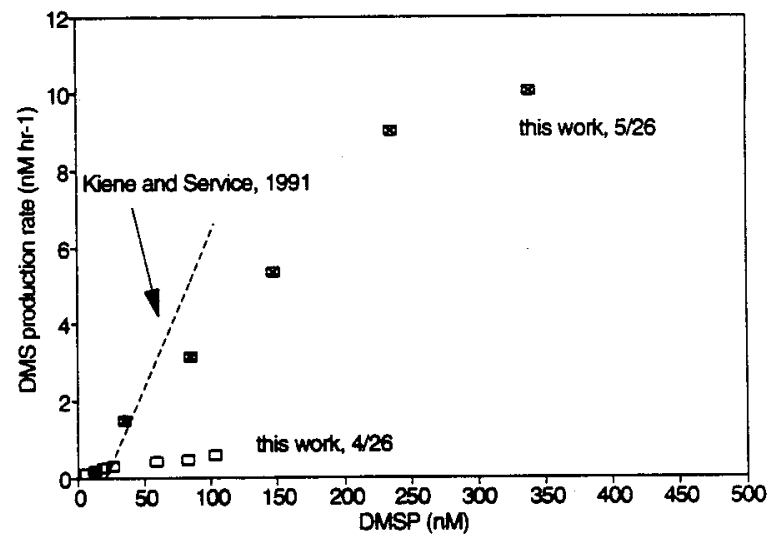

Figure 3-8. Comparison of data sets showing concentration dependence of DMSP removal and DMSP-lyase activity in Vineyard Sound on 4/26/92 and 5/26/92 (this work) and in the Duplin River estuary (Kiene and Service, 1991). Dotted lines are based on equations supplied in the latter study, which describe the least squares fit to the Duplin River data. (a) DMS consumption, (b) DMSP removal, (c) DMS production from dissolved DMSP. 
collected under similar seasonal conditions.

This study estimates rates of DMSP removal, DMS production from DMSP, and DMS removal. It is stressed that these are net rates, and that therefore calculated turnover times are overestimates. At ambient substrate concentrations, $\tau_{\mathrm{DMS}}$ ranged from 0.6 to 3.5 days, and $\tau_{\mathrm{DMSP}}$ from 0.2 to 2.9 days during the period of study. In general, ambient rates of DMS production and consumption were similar to but slower than rates of DMSP consumption. In agreement with the data of Kiene and Service (14), only a fraction of DMSP removed from solution could be accounted for by DMS formation, indicating that alternative routes of DMSP metabolism may be important in aerobic marine systems. Judging from its rate of removal, dissolved DMSP must also be rapidly (on timescales of hours) released into seawater. Actual net production of dissolved DMSP was observed on only one occasion in this study; much dissolved DMSP production may be episodic in nature and therefore not apparent in short-term incubation experiments. The fact that particles larger than $75 \mu \mathrm{m}$ were excluded from seawater in these experiments means that the effect of grazing by this size class of organisms, a possible natural source of soluble DMSP, would not have been observed.

The large shift in the kinetic parameters of both DMSP removal and DMSPlyase activity documented here for a $6^{\circ} \mathrm{C}$ rise in water temperature raises intriguing questions about the possible seasonality of these processes. While total bacterial numbers vary little in the surface ocean with season (8), certain subpopulations of marine bacteria may be highly seasonally dependent, as has been observed for Synechococcus spp. in temperate coastal waters (24). If the activity observed here is largely prokaryotic, these data provide evidence for the dynamic nature of the 
heterotrophic bacterial community, for which seasonal changes in speciation are difficult to document.

Clearly, no single kinetics experiment - or pair of experiments - can fully parameterize these processes in a given environment. Accurate modelling of the biological DMS cycle in marine waters will require a data set that charts the variations in relevant kinetic parameters on a seasonal basis. 


\section{REFERENCES}

1. Azam, F., and R. E. Hodson. 1981. Multiphasic kinetics for D-glucose uptake by assemblages of natural marine bacteria. Mar. Ecol. Prog. Series 6:213-222.

2. Bauchop, T. 1967. Inhibition of rumen methanogenesis by methane analogues. J. Bacteriol. 94:171-175.

3. Bell, W., and R. Mitchell. 1972. Chemotactic and growth responses of marine bacteria to algal extracellular products. Biol. Bull. 143:265-277.

4. Cantoni, G. L., and D. G. Anderson. 1956. Enzymatic cleavage of dimethylpropiothetin by Polysiphonia lanosa. J. Biol. Chem. 222:171-177.

5. Dacey, J. W. H., and N. V. Blough. 1987. Hydroxide decomposition of dimethylsulfoniopropionate to form dimethylsulfide. Geophys. Res. Let. 14: 1246-1249.

6. Dacey, J. W. H., and S. G. Wakeham. 1986. Oceanic dimethylsulfide: production during zooplankton grazing on phytoplankton. Science 233:1314-1316.

7. Fersht, A. 1985. Enzyme structure and mechanism, pp. 106-107. W. H. Freeman and Company, New York.

8. Fogg, G. E. 1986. Picoplankton. Proc. R. Soc. London Ser. B 228:1-30.

9. Gunsalus, R. P., and R. S. Wolfe. 1978. ATP activation and properties of the methyl coenzyme $\mathbf{M}$ reductase system in Methanobacterium thermoautotrophicum. J. Bacteriol. 135:851-857.

10. Hochachka, P. W., and G. N. Somero. 1984. Biochemical adaptation, p. 389. Princeton University Press, Princeton, NJ.

11. Ishida, Y. 1968. Physiological studies on evolution of dimethyl sulfide from unicellular marine algae. Mem. Coll. Agric. Kyoto 94:47-82.

12. Kiene, R. P. 1990. Dimethyl sulfide production from dimethylsulfoniopropionate in coastal seawater samples and bacterial cultures. Appl. Environ. Microbiol. 56:3293-3297.

13. Kiene, R. P., and T. S. Bates. 1990. Biological removal of dimethyl sulphide from sea water. Nature 345:702-705. 
14. Kiene, R. P., and S. K. Service. 1991. Decomposition of dissolved DMSP and DMS in estuarine waters: Dependence on temperature and substrate concentration. Mar. Ecol. Prog. Ser. 76:1-11.

15. Kiene, R. P., and B. F. Taylor. 1988. Demethylation of dimethylsulfoniopropionate and production of thiols in anoxic marine sediments. Appl. Environ. Microbiol. 54:2208-2212.

16. Lazier, J. R. N., and K. H. Mann. Turbulence and the diffusive layers around small organisms. Deep-Sea Res. 36:1721-1733.

17. Manahan, D. T. 1990 . Adaptations by invertabrate larvae for nutrient acquisition from seawater. Am. Zool. 30:147-160.

18. Mitchell, J. G., A. Okubo, and J. A. Fuhrman. 1985. Microzones surrounding phytoplankton form the basis for a stratified marine microbial ecosystem. Nature 316:58-59

19. Sjoblad, R. D., and R. Mitchell. 1979. Chemotactic responses of Vibrio alginolyticus to algal extracellular products. Can. J. Microbiol. 25:964-967.

20. Taylor, B. F., and D. C. Gilchrist. 1991. New routes for aerobic degradation of dimethylsulfoniopropionate. Appl. Environ. Microbiol. 57:3581-3584.

21. Turner, S. M., G. Malin, P. S. Liss, D. S. Harbour, and P. M. Holligan. 1988. The seasonal variation of dimethylsulfide and dimethylsulfoniopropionate concentrations in nearshore waters. Limnol. Oceanogr. 30:364-375.

22. Wakeham, S. G., and J. W. H. Dacey. 1989. Biogeochemical cycling of dimethylsulfide in marine environments, pp. 152-166. In: E. S. Saltzman and W. J. Cooper (eds.), Biogenic sulfur in the environment. ACS Symposium Ser. 393, American Chemical Society, Washington, D.C.

23. Wakeham, S. G., B. L. Howes, J. W. H. Dacey, R. P. Schwarzenbach and J. Zeyer. 1987. Biogeochemistry of dimethylsulfide in a seasonally stratified coastal salt pond. Geochim. Cosmochim. Acta 51:1675-1684.

24. Waterbury, J. B., S. W. Watson, F. W. Valois, and D. G. Franks. 1986. Biological and ecological characterization of the marine unicellular cyanobacterium Synechococcus. In: T. Platt and W. K. Li (eds.), Photosynthetic picoplankton. Can. Bull. Fish. Aquatic Sci. 214:71-120. 


\section{CHAPTER 4}

\section{MICROBIAL CYCLING OF DMSP AND DMS IN THE SARGASSO SEA}

The subtropical gyres, in spite of their low chlorophyll, contribute significantly to marine dimethylsulfide emissions (1). This is not by virtue of their extensive surface area alone; Andreae (1) points out that these regions produce more DMS per unit area than might be expected on the basis of their algal biomass, and suggests that this is due to variable phytoplankton species composition. The coccolithophorid Emiliania huxleyi, a common bloom-forming alga in the Sargasso Sea, is known to synthesize DMSP (14), although its contribution to DMS and DMSP levels in nonbloom situations is not known. DMS levels in the Sargasso Sea have been recently observed to be seasonally dependent, varying from subnanomolar in the winter to 1-2 $\mathrm{nM}$ in the spring and fall (see below), with mixed layer maxima in the summer as high as $7 \mathrm{nM}$ (John Dacey, personal communication). Averaged over the annual cycle, a value of about $2 \mathrm{nM}$ is obtained for the Sargasso Sea, in agreement with measurements in other areas of the oligotrophic ocean $(1,23$; see other surveys cited in Chapter 1).

Microbial cycling of DMS has not been examined in low-nutrient areas of the open ocean, although productive marine environments have received considerable attention (15-17,22; Chapter 3). The low-nutrient, low-chlorophyll surface waters of the Sargasso Sea present a marked contrast to the productive nearshore seawater examined in the previous chapter, in which seasonal fluctuations in primary production 
are superimposed upon a relatively high-chlorophyll background supported by plentiful nutrient supply from runoff and sediments. In this regard, questions that need to be addressed include: How do absolute rates of DMS production and DMS and DMSP uptake compare to those in coastal water? What are the turnover times of DMS and DMSP with respect to these microbially-mediated processes? Can a seasonal trend be discerned? If a high regeneration efficiency paradigm (9) aptly describes productivity in these oligotrophic waters, can this metaphor be extended to the DMS cycle? This chapter presents the results of incubation experiments with Sargasso Sea water designed to assess turnover times of DMS and DMSP with respect to the microbiallymediated processes of DMSP uptake, DMS production from DMSP, and DMS consumption. These experiments were carried out during three stays at the Bermuda Biological Station for Research (BBSR) in fall of 1990, winter of 1991-1992, and spring of 1992.

\section{MATERIALS AND METHODS}

Sampling. Seawater for incubation experiments was collected about 3 miles east of the mouth of Ferry Reach on the southeast side of Bermuda, where water depths reached approximately a thousand meters, from the Bermuda Biological Station vessel BBS-2 or from a small motorboat. On three occasions, 1/20/92, 1/28/92 and 4/3/92, weather conditions prevented off-reef sampling, and water was collected about 1.5 miles offshore. On $1 / 20$ and $1 / 28$, water was probably representative of off-reef conditions due to prevailing winds from the southeast; however, on 4/3 wind direction was changeable. Collection was from just beneath the surface by plastic bucket; 
seawater was decanted into a polycarbonate carboy that had been soaked overnight in $10 \% \mathrm{HCl}$ and rinsed with distilled water and seawater. Water was immediately transported to the laboratory, and no more than an hour elapsed between sampling and the start of incubation experiments. On $11 / 1 / 90,1 / 29 / 92$ and $4 / 2 / 92$, water was collected in a Niskin bottle from $1 \mathrm{~m}$ depth at Hydrostation $\mathrm{S}\left(32^{\circ} 10^{\prime} \mathrm{N}, 64^{\circ} 30^{\prime} \mathrm{W}\right)$, and returned to the lab within 3 to 5 hours. On one occasion (1/23/92), seawater was collected from $15 \mathrm{~m}$ depth at the BATS station $\left(31^{\circ} 50^{\prime} \mathrm{N}, 64^{\circ} 30^{\prime} \mathrm{W}\right)$, in which case six hours elapsed before the beginning of the experiment. In instances where more than an hour elapsed between water collection and its return to the laboratory, water was stored in the dark at ambient temperature.

Incubation experiments. Incubations were conducted, and rates and kinetic parameters determined, as in Chapter 3. However, due to the relatively low particulate burden of Sargasso Sea water, water was used unfiltered rather than screened through $75 \mu \mathrm{m}$ Nitex mesh. As in the previous chapter, both low-level addition experiments, in which simultaneous rates of DMS production, DMS removal, and in some cases dissolved DMSP removal were monitored, and kinetics experiments, in which the concentration dependence of DMS production from DMSP was determined, were carried out. The concentration dependence of DMSP and DMS removal was not examined. Some of the additions resulted in elevation of DMS and DMSP concentrations to greater than 2-3 times ambient. This was particularly true for DMS in January, when ambient concentrations were always subnanomolar and additions ranged from 3 to $12 \mathrm{nM}$. For convenience, "low-level" is operationally defined as less than $15 \mathrm{nM}$ for both DMS and DMSP, although some rate estimates for concentrations 
greater than this are included in tabulations of low-level addition results below. As in Chapter 3, turnover of DMSP with respect to cleavage and of DMS with respect to DMSP cleavage and microbial consumption are described by the time constant $\tau$ rather than the term "turnover time," to reflect the fact that these processes do not determine true turnover times for their respective substrates.

Analytical. Analysis of DMS was by the automated system described in Chapter 3; volatile sulfur compounds were measured by gas chromatography with detection by sulfur chemiluminescence. DMSP monitored in bacterial timecourses was sufficiently high to allow analysis by direct injection of headspace gas.

Bacterial isolation procedures. To enrich for DMSP-utilizing bacteria, $500 \mathrm{~mL}$ unfiltered Sargasso Sea surface water (January 1992) was incubated in autoclaved 1liter polycarbonate flasks for a one-week period following addition of DMSP to a final concentration of $1 \mathrm{mM} .5-\mathrm{mL}$ aliquots were inoculated into $100 \mathrm{~mL}$ of the modified $\mathrm{f} / 2$ medium described in Chapter 6, enriched with $1 \mathrm{mM}$ DMSP, and incubated for an additional week. These enrichment cultures were streaked on plates of the same medium containing 1.5\% Bacto-agar (Difco), with $1 \mathrm{mM}$ DMSP added from a sterile stock once the medium had cooled sufficiently to pour. Single colonies were then picked and restreaked on marine agar 2216 until pure.

Assay of volatile sulfur production and DMSP utilization by bacterial isolates. For assays of volatile sulfur production, colonies were removed from overnight 2216 plates with a sterile swab and suspended in $3 \mathrm{~mL}$ sterile seawater to a high turbidity. This suspension was then used to inoculate $70-\mathrm{mL}$ volumes of modified $\mathrm{f} / 2$ medium amended with DMSP in sterile 125 -mL serum bottles capped with Teflon-coated butyl 
rubber septa. $1 \mathrm{~mL}$ headspace gas was withdrawn at 20 -minute intervals for up to four hours by a gas-sampling syringe and analyzed by sulfur-specific gas chromatography. An identically prepared but uninoculated treatment served as a sterile DMSP control.

To monitor DMSP removal from the dissolved phase, 4-mL aliquots were withdrawn from sample bottles by sterile 10-mL B-D Plastipak syringes (BectonDickinson) and passed through $0.2 \mu \mathrm{m}$ Gelman Supor-200 filters in $25 \mathrm{~mm}$ Swin-Lok filter holders (Nuclepore Corp.) into 10-mL serum bottles. The filtrate was stripped for 10 minutes with nitrogen gas to remove DMS, $16 \mathrm{~N} \mathrm{KOH}$ added to a final concentration of $1 \mathrm{~N}$, and the treatments allowed to react overnight at room temperature. In this way dissolved DMSP was quantitatively converted to DMS, and headspace gas analyzed by gas chromatography as above.

\section{RESULTS}

Water column properties. Supporting data on water column properties during the three sampling periods are provided in Table 4-1. These data were collected as part of the Bermuda Atlantic Time Series (BATS) program to monitor seasonal variation in water column structure and productivity, and were provided by A. F. Michaels at the Bermuda Biological Station. Figures 4-1, 4-2, and 4-3 display depth profiles of DMS, soluble DMSP and particulate DMSP during each of these periods.

Low-level addition experiments. Tables 4-2, 4-3 and 4-4 summarize the results of low-level additions to Sargasso Sea water. Measurements of background DMS, soluble DMSP and particulate DMSP for each experiment are provided in these tables, 
Table 4-1. Water column parameters for the three sampling periods in this study

\begin{tabular}{llcc}
\hline Date & $11 / 1 / 90$ & $1 / 29 / 92$ & $4 / 2 / 92$ \\
Mixed layer depth $(\mathrm{m})$ & 60 & 240 & 46 \\
Temperature of mixed layer $\left({ }^{\circ} \mathrm{C}\right)$ & 25 & 19.5 & 19 \\
Depth of chlorophyll maximum $(\mathrm{m})$ & 112 & $-*$ & 59 \\
Nitrate $(\mu \mathrm{M})$ & $\mathrm{ND}^{* *}$ & 0.5 & $\mathrm{ND}$ \\
\hline
\end{tabular}

* - -, no data available

** ND, below detection limit of $0.05 \mu \mathrm{M}$ 


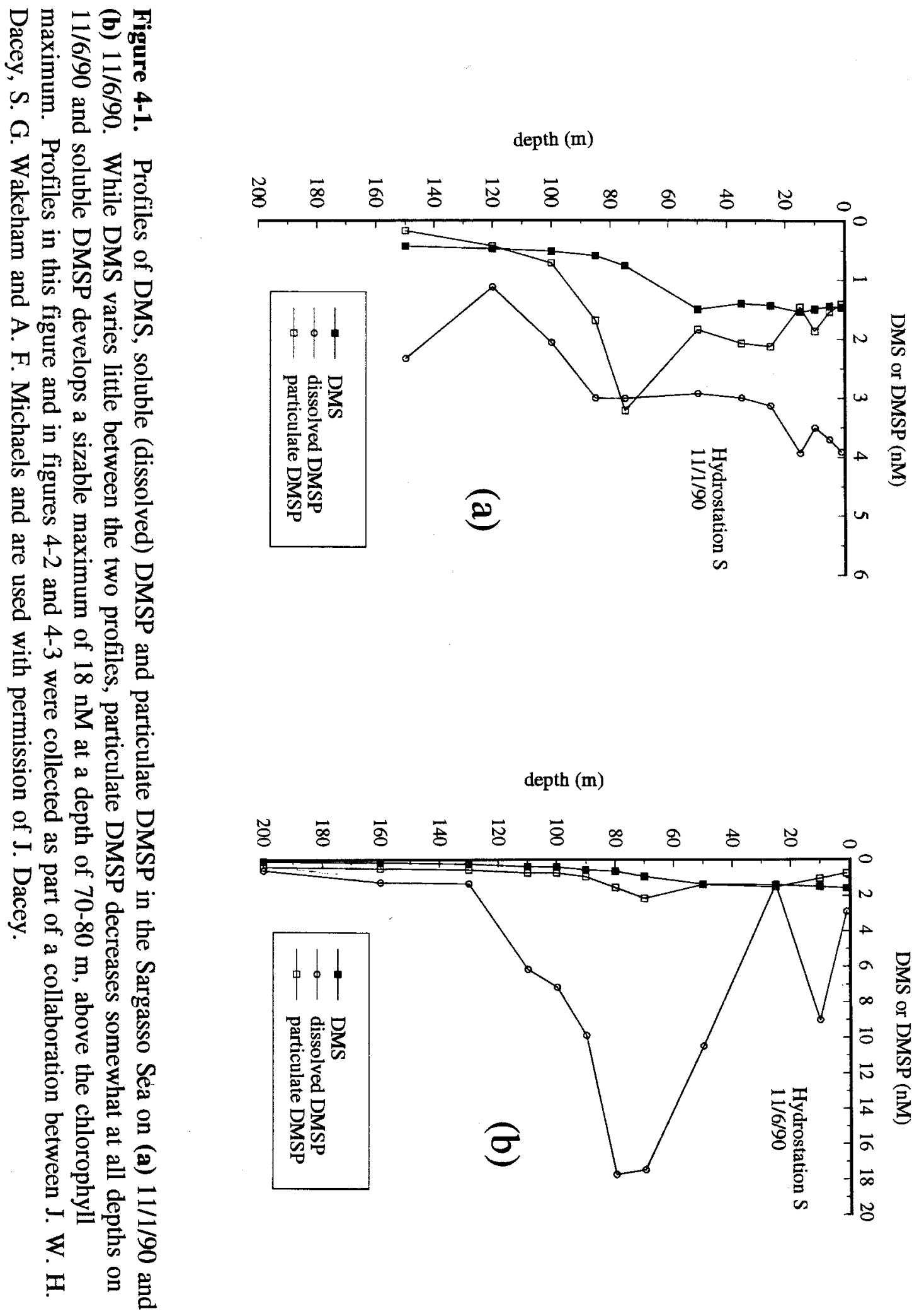




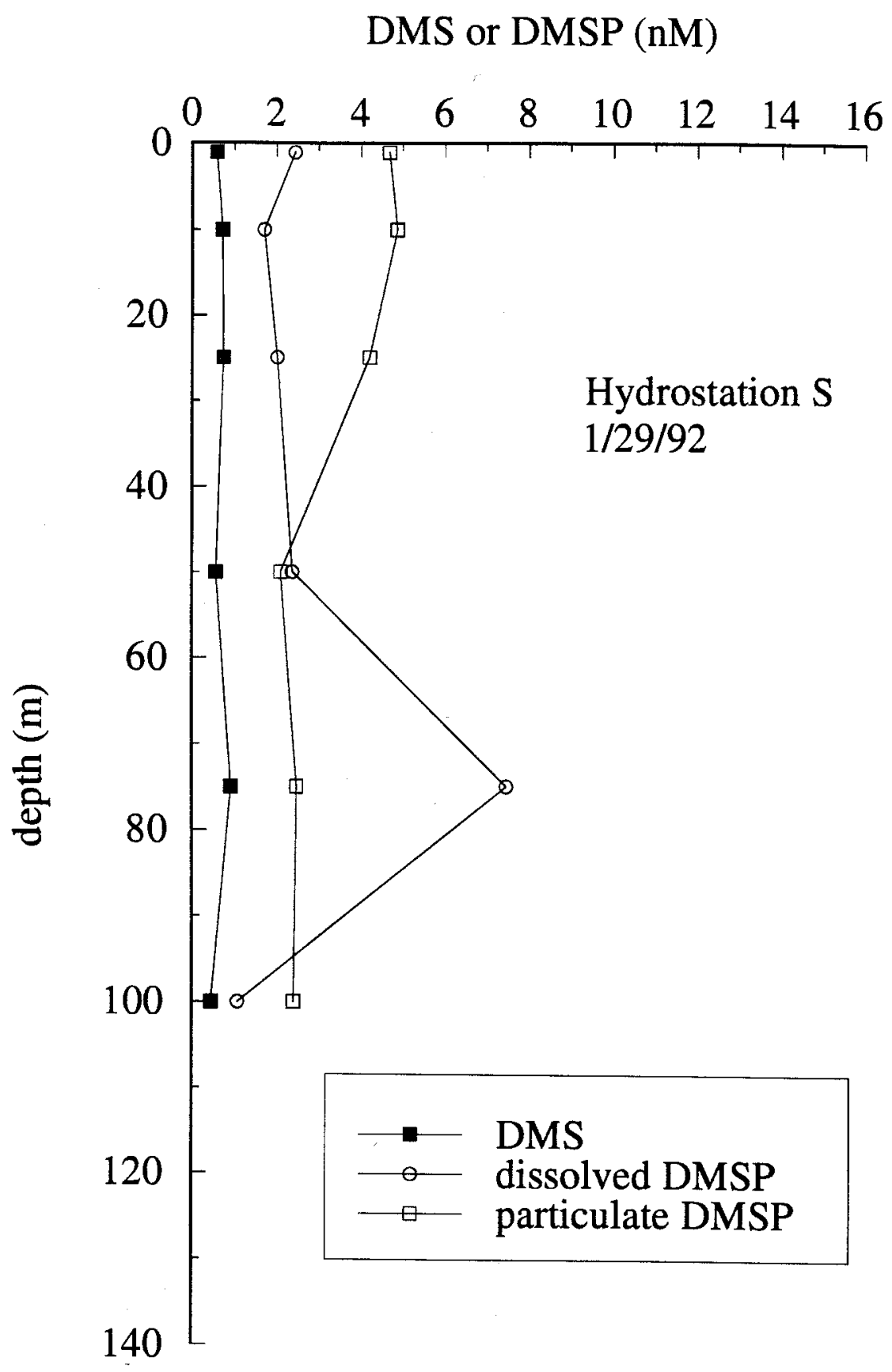

Figure 4-2. Profile of DMS, soluble DMSP and particulate DMSP in the Sargasso Sea on $1 / 29 / 92$. At this time the mixed layer is close to 250 meters in depth, and DMS concentrations are uniformly low. There is, however, some structure to the DMSP profiles, indicating that timescale of biological cycling is shorter than that of mixing. 


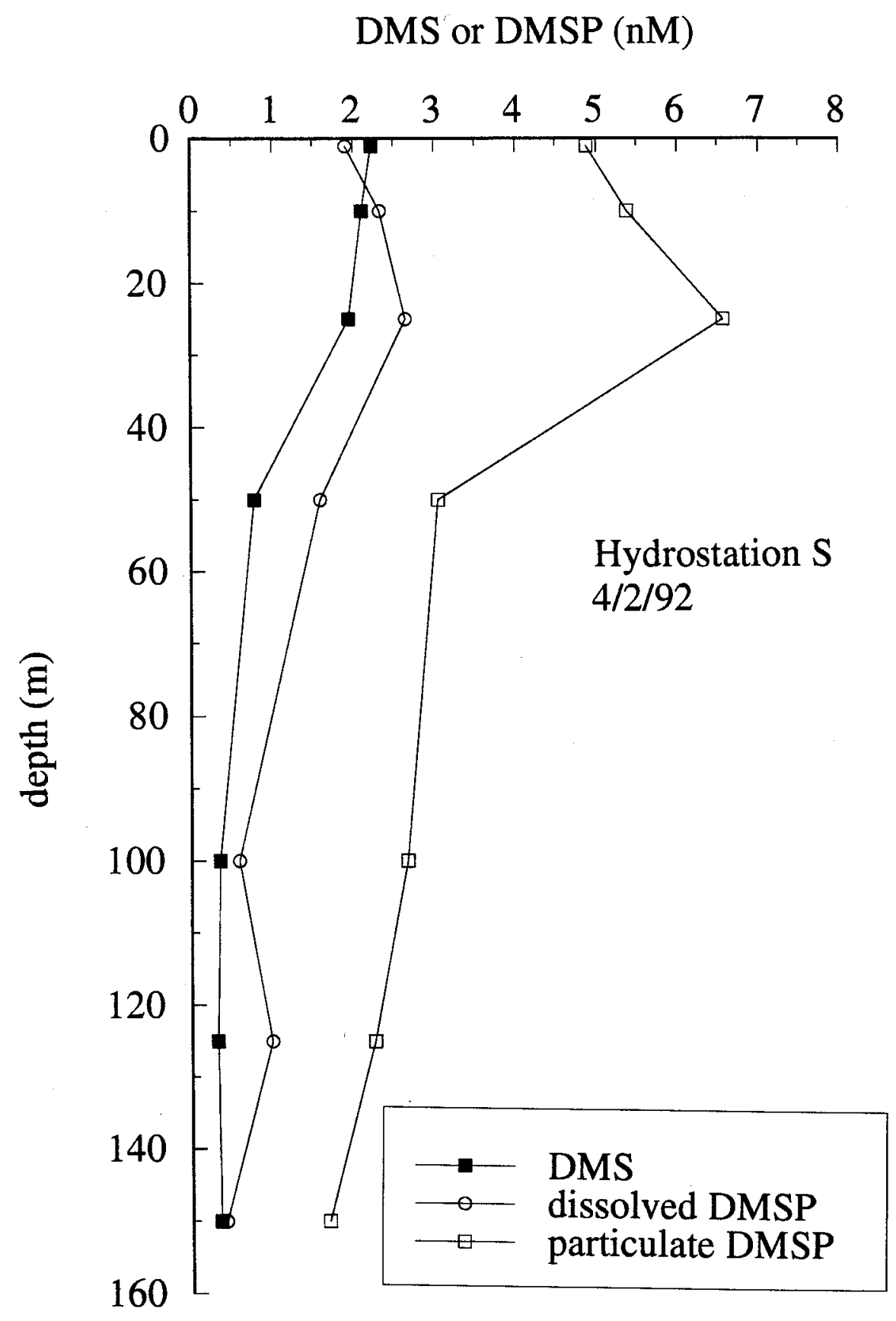

Figure 4-3. Profile of DMS, soluble DMSP and particulate DMSP in the Sargasso Sea on $4 / 2 / 90$. Here the mixed layer depth has decreased again to about $50 \mathrm{~m}$, and DMS concentrations have risen to $2 \mathrm{nM}$. Soluble DMSP and particulate DMSP roughly covary, with a maximum between 20 and $30 \mathrm{~m}$. 


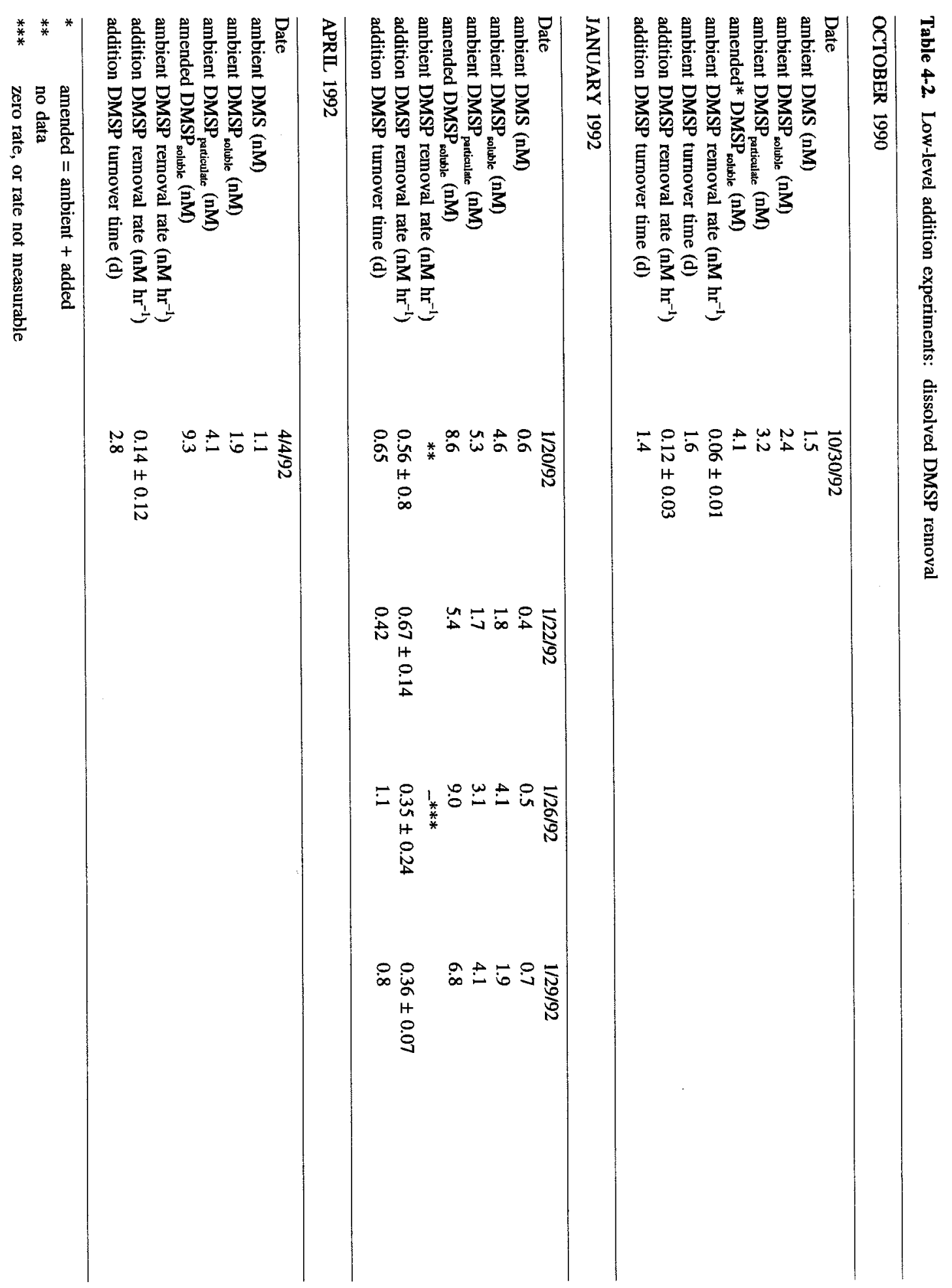




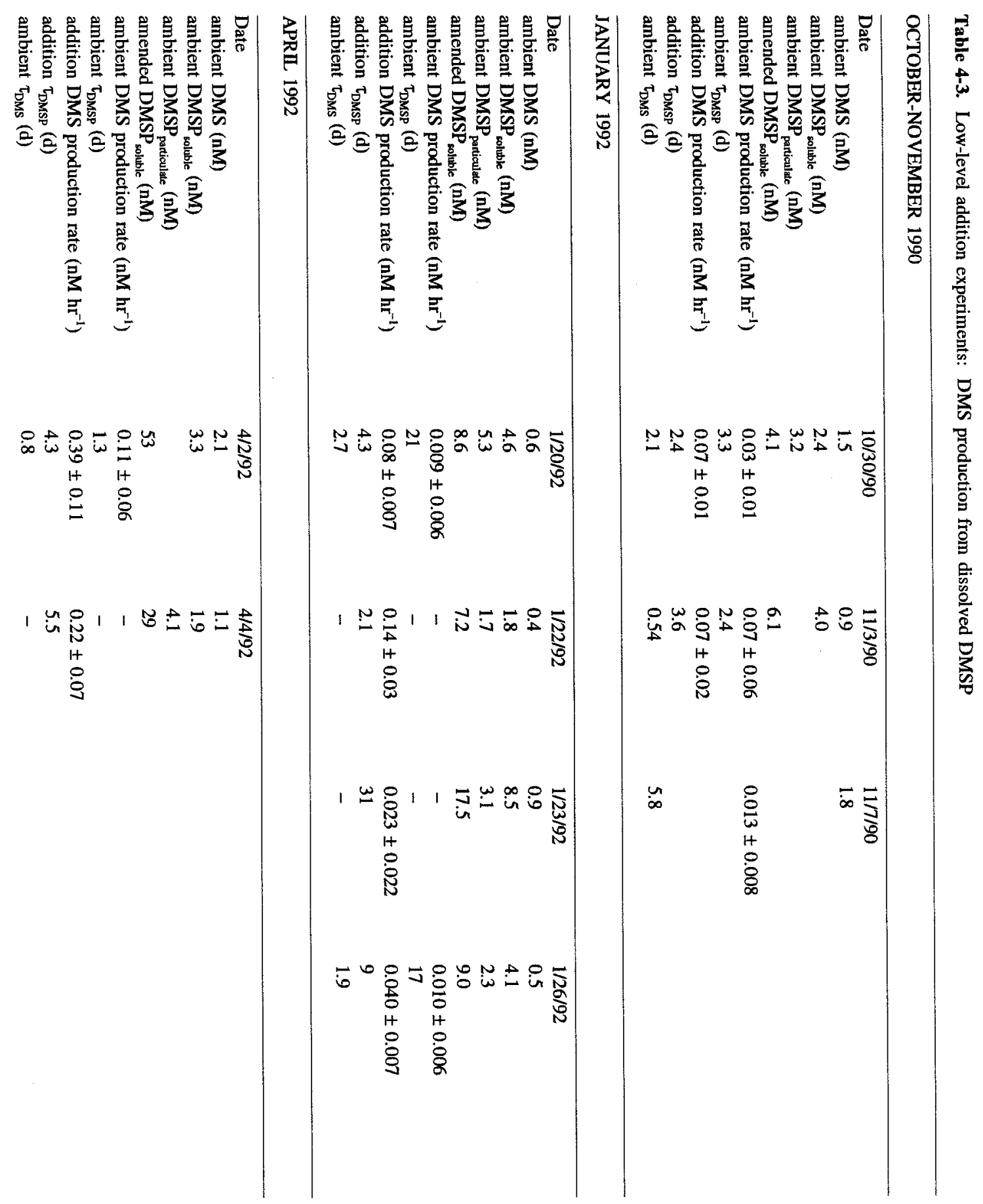




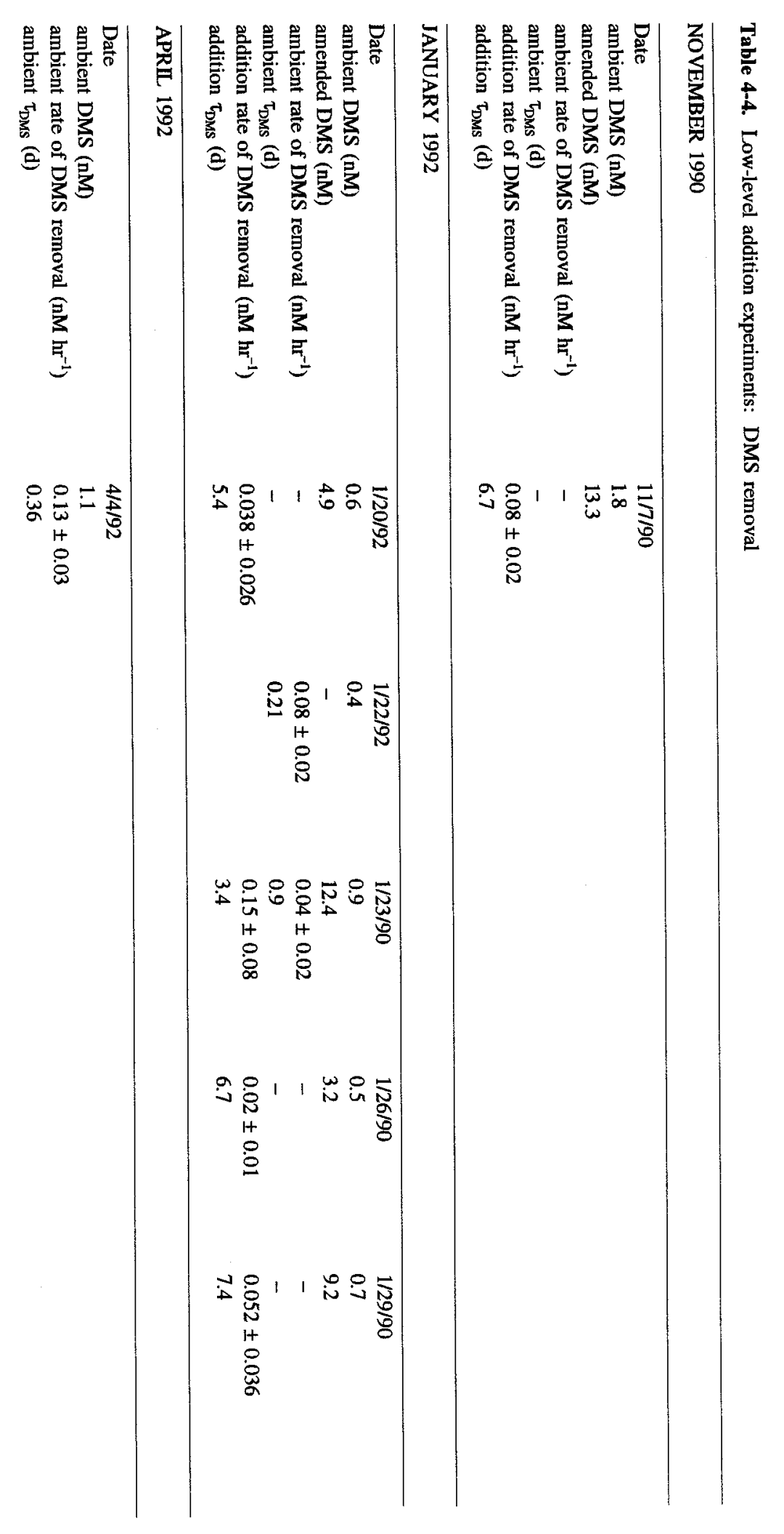


as well as amended levels of DMSP and DMS where additions were made. A typical timecourse of simultaneous DMS production and consumption, and DMSP uptake, is shown for a January low-level addition experiment in Figure 4-4. Absolute rates of DMSP uptake varied between about 0.06 and $0.7 \mathrm{nM} \mathrm{hr}^{-1}$ over a DMSP concentration range of 2-11 nM, leading to turnover times for DMSP with respect to uptake of 0.42.8 days. Measurement of dissolved DMSP removal at ambient DMSP concentrations was only attempted on two occasions (Figure 4-5). On 10/30/92, a rate of $0.06 \mathrm{nM}$ $\mathrm{hr}^{-1}$ and corresponding DMSP turnover time of 1.6 days were obtained. On this occasion, removal in reponse to a doubling of ambient DMSP yielded a similar DMSP turnover time of 1.4 days, confirming the ambient estimate. On $1 / 26 / 92$, the timecourse was too noisy to permit a rate calculation. Although only three low-level assays of DMSP removal were made during the fall 1990 and April 1992 periods, these appeared to yield generally lower DMSP removal rates, and longer DMSP turnover times, than observed in January of 1992. Moreover, since all of the removal rates measured in January were in response to a doubling or tripling of ambient DMSP, true in situ turnover times may have been even shorter than the 0.42-1.1 day range observed for that period.

Rates of DMSP cleavage (DMS production from DMSP) were, with a single exception, always less than those of DMSP removal. The proportion of DMSP loss resulting in DMS formation ranged from stoichiometric in an intermediate-level (44 nM) DMSP addition on 11/3/90 to consistently low during the assays in January 1992 . Unfortunately, the structure of the experiments carried out in April 1992 did not permit a direct comparison of the dissolved DMSP removal and cleavage rates to see 
(a)

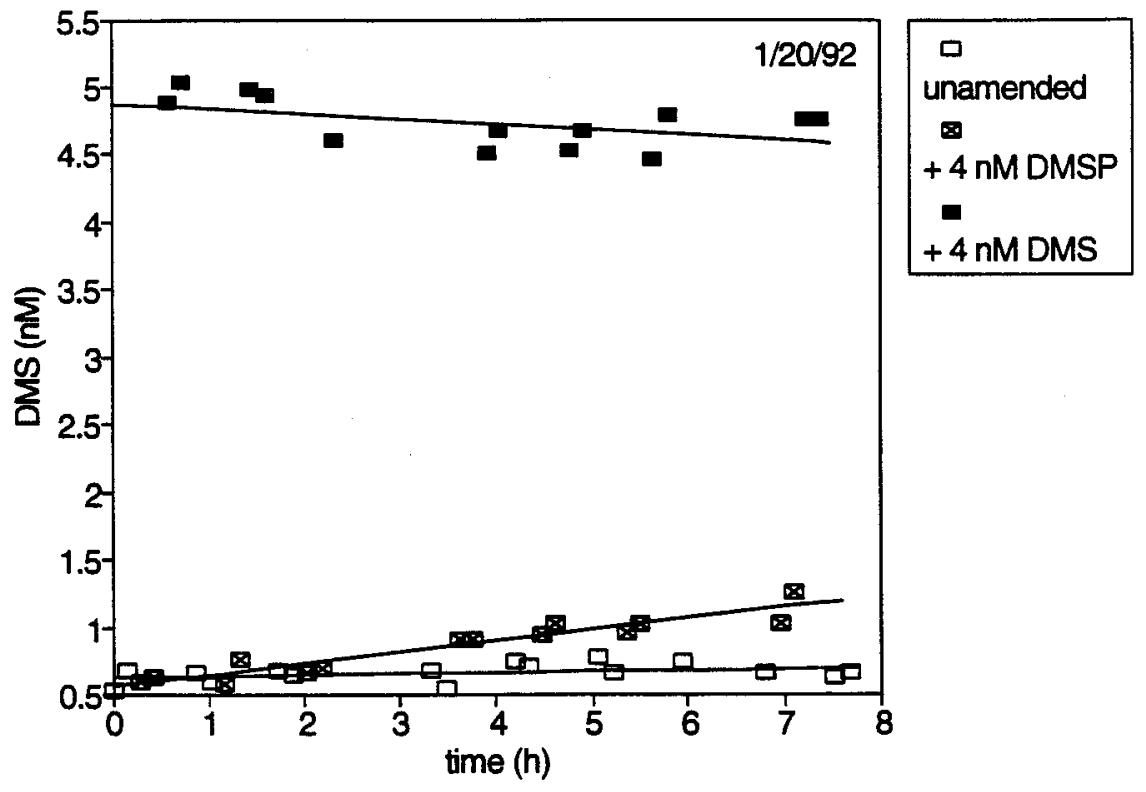

(b)

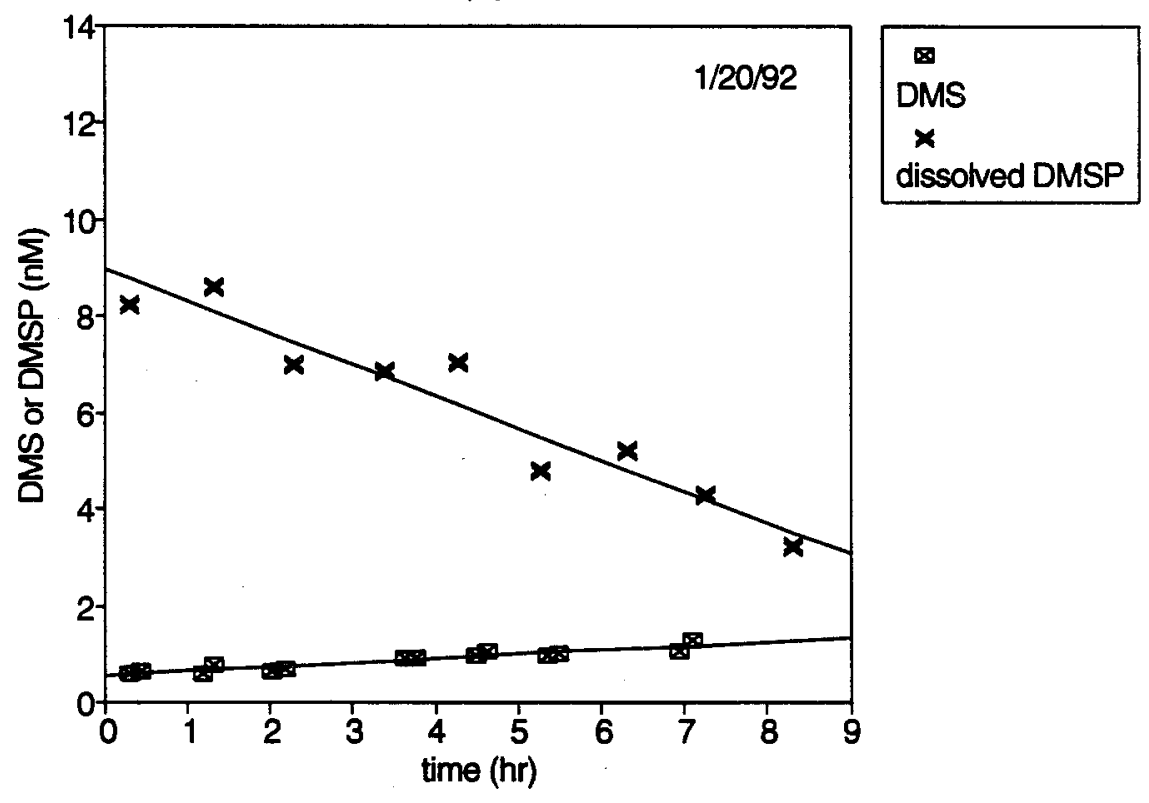

Figure 4-4. Timecourse of DMS and soluble DMSP in response to low-level additions to Sargasso Sea water on 1/20/92. (a) DMS production in response to a 4 nM DMSP addition, and DMS removal in response to a $4 \mathrm{nM}$ DMS addition. (b) DMS production from $4 \mathrm{nM}$ DMSP addition compared to total dissolved DMSP loss in the same bottle. A comparison of rates suggests that only $14 \%$ of DMSP removal can be accounted for by cleavage to form DMS. Duplicate treatments, where carried out, are shown. 


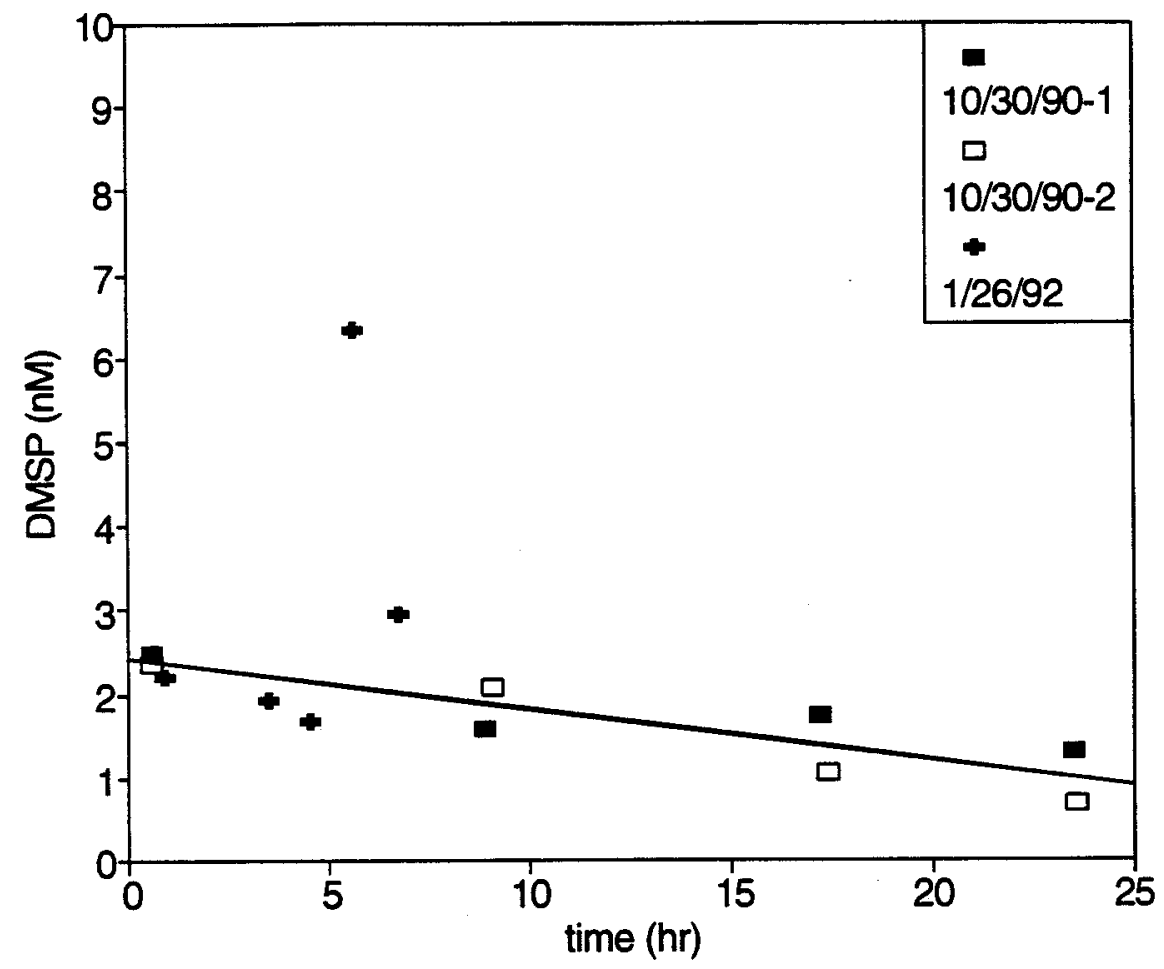

Figure 4-5. Timecourse of soluble DMSP in unamended seawater on 10/30/90 (duplicates shown) and on 1/26/92. On 10/30/90 a rate estimate of $0.06 \pm 0.01$ $\mathrm{nM} \mathrm{hr}{ }^{-1}$ for ambient DMSP uptake was obtained, while the 1/26/92 timecourse was too noisy to permit a rate calculation. Duplicates were not run for this timecourse, and the origin of the noise is not understood. 
whether DMS production again became a more significant fate of DMSP in the spring. Rates of DMS production from DMSP ranged from 0.009 to $0.14 \mathrm{nM} \mathrm{hr}^{-1}$ for a DMSP concentration range of $2.4-9 \mathrm{nM}$, resulting in $\tau_{\mathrm{DMSP}}$ (cleavage) values of $2.4-31$ days. As in Chapter 3, it is important to keep in mind that rates of DMS production or consumption measured at ambient substrate concentrations represent net rates. A low net rate of either process may in fact reflect high but similar rates of both processes. The latter case is usually unmasked by observing the response of the system to a DMSP or DMS addition, which will preferentially stimulate one process over the other. However, this approach yields only qualitative information, since it is not possible to determine the exact extent to which a substrate addition alters the competition between these two processes (unless the addition is quite high). Moreover, raising substrate levels moves the rate farther out along the saturation curve, such that addition turnover times would be expected to exceed turnover times at ambient substrate concentrations. Nonetheless, comparison of "ambient" and "addition" turnover times can yield useful information. On 1/20/92 and 1/26/92, for instance, $\tau_{\mathrm{DMSP}}$ calculated from ambient rates of DMSP cleavage were 21 and 17 days, as opposed to 4.3 and 9 days for the corresponding addition rates. This implies that calculated rates of DMS production from ambient dissolved DMSP levels on these occasions are significant underestimates, possibly due to concomitant microbial DMS consumption. In cases such as these, $\tau_{\mathrm{DMSP}}$ with respect to cleavage calculated from the addition rate is probably a closer approximation of the true in situ $\tau_{\mathrm{DMSP}}$ than that calculated in unamended seawater. Within the resolution of the data, DMSP cleavage rates at near-ambient DMSP levels are for the most part similar among the fall, winter 
and spring periods. However, DMSP turnover times longer than a week were only observed in the winter.

$\tau_{\mathrm{DMS}}$ (DMSP cleavage) was also calculated when the ambient rate of DMS production could be estimated, and are included in Table 4-3. These values ranged from 0.2 to 6 days. In the winter, when DMS concentrations were subnanomolar, even low rates of DMS production were adequate to turn ambient DMS pools over on the order of two days. Since the evidence indicates that these production rates are almost certainly underestimates, DMS production from dissolved DMSP potentially contributes importantly to DMS inventories during the winter months.

Removal rates of $0.2-13 \mathrm{nM}$ DMS ranging from 0.02 to $0.15 \mathrm{nM} \mathrm{hr}^{-1}$ were comparable to those of DMS production, and yielded $\tau_{\mathrm{DMS}}$ values on the order of half a day to a week. In four of seven experiments, net production rather than comsumption of DMS was observed in unamended controls (Table 4-4). However, on occasions when ambient rates of DMS removal could be quantified, $\tau_{\mathrm{DMS}}$ with respect to removal was always less than a day. Again, due to concomitant DMS production, these may be overestimates. Amending DMS concentrations (to levels of 3.2-13.3 $\mathrm{nM}$ ) increased $\tau_{\mathrm{DMS}}$ to as much as a week, suggesting that additions resulted in saturation of activity. These results were independent of season, although the fall and spring are underrepresented with respect to DMS consumption data.

Kinetics experiments. Rate versus concentration data for kinetics experiments are displayed in Figures 4-6, 4-7 and 4-8. On 11/3/90, additions of dissolved DMSP between 2 and $420 \mathrm{nM}$ resulted in rates of DMS production of up to $5 \mathrm{nM} \mathrm{hr}^{-1}$ (Figure 4-6). Linear regression of the rate data $\left(\mathrm{r}^{2}=0.999\right)$ yielded a slope of $0.0108 \mathrm{hr}^{-1}$, or 


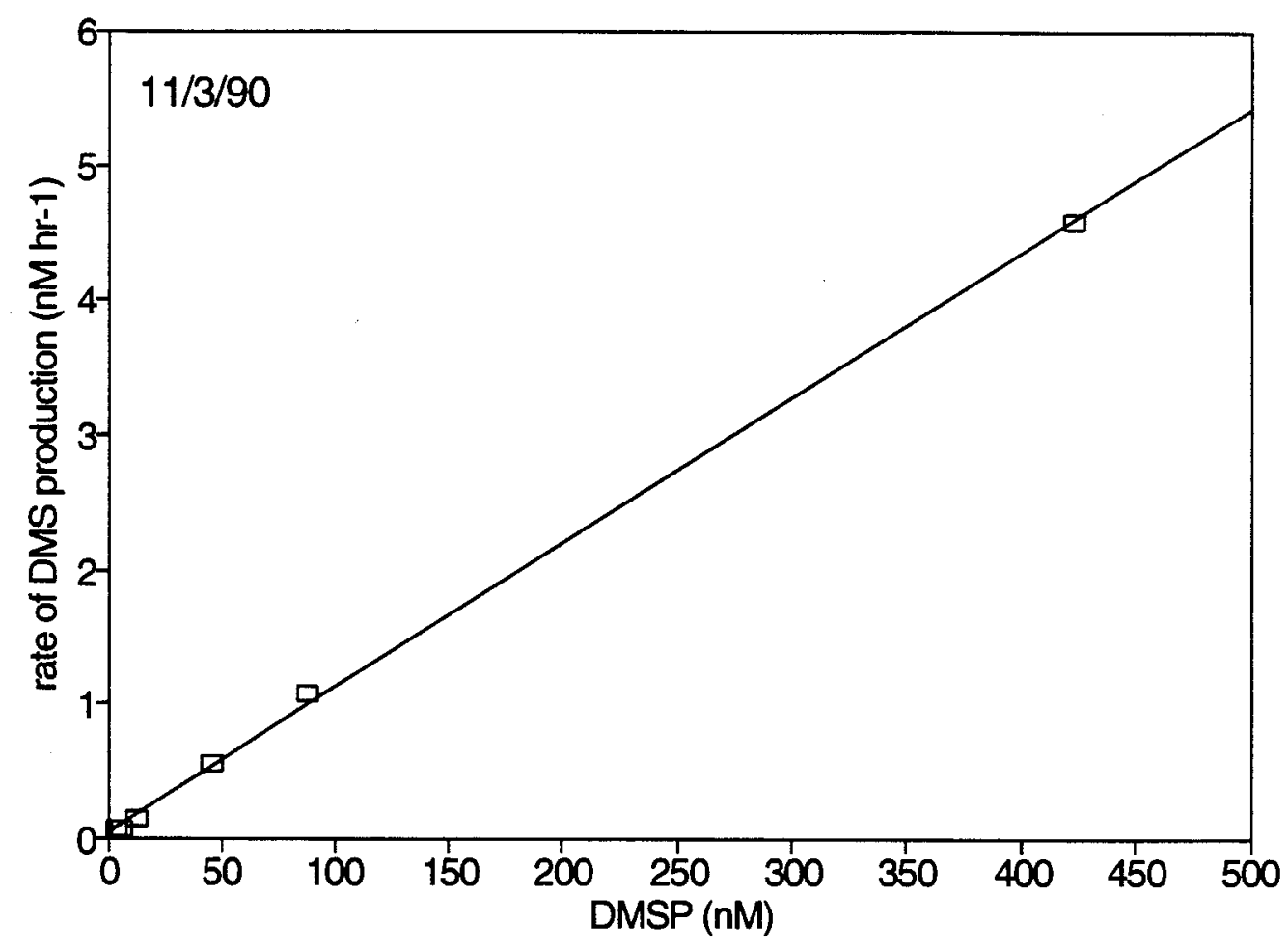

Figure 4-6. Rate versus concentration data for the DMS production kinetics experiment on 11/3/90. A linear regression of these points yields a slope of $0.0108 \pm$ $0.0001 \mathrm{hr}^{-1}$ and a y-intercept of $0.041 \pm 0.048\left(\mathrm{r}^{2}=0.999\right)$. The inverse of the slope of this line gives an average $\tau_{\mathrm{DMSP}}$ with respect to cleavage of 3.9 days. 
(a)

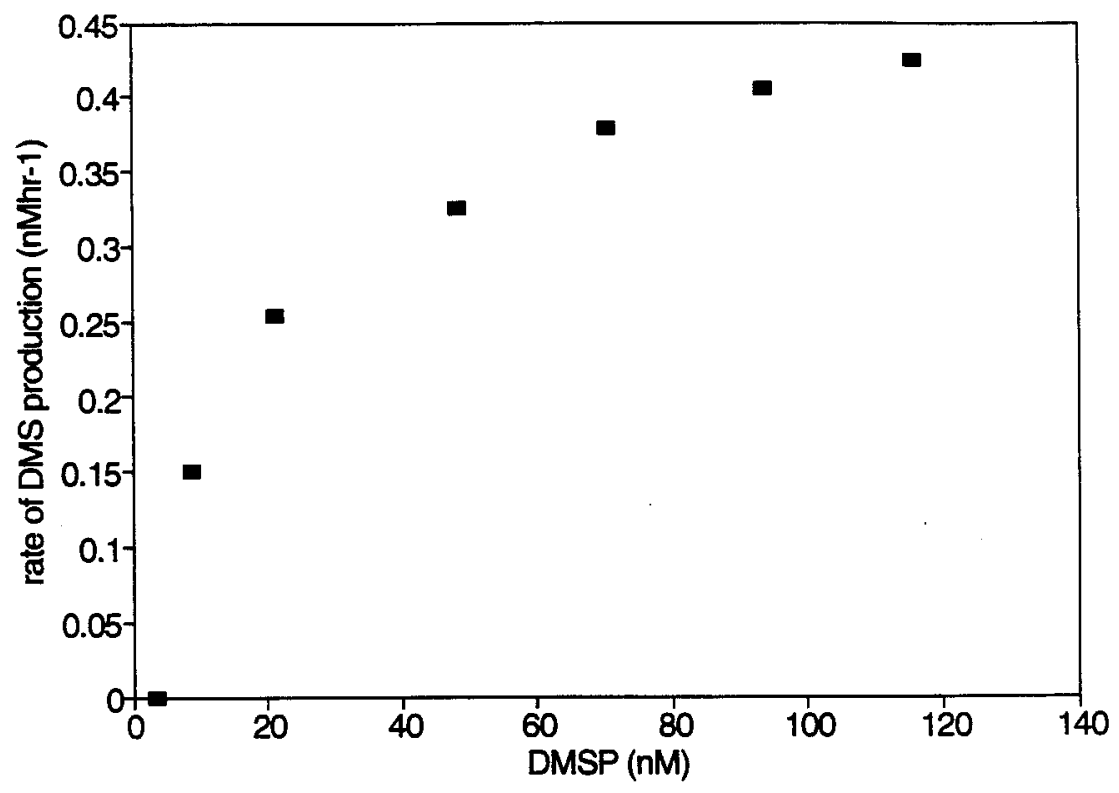

(b)

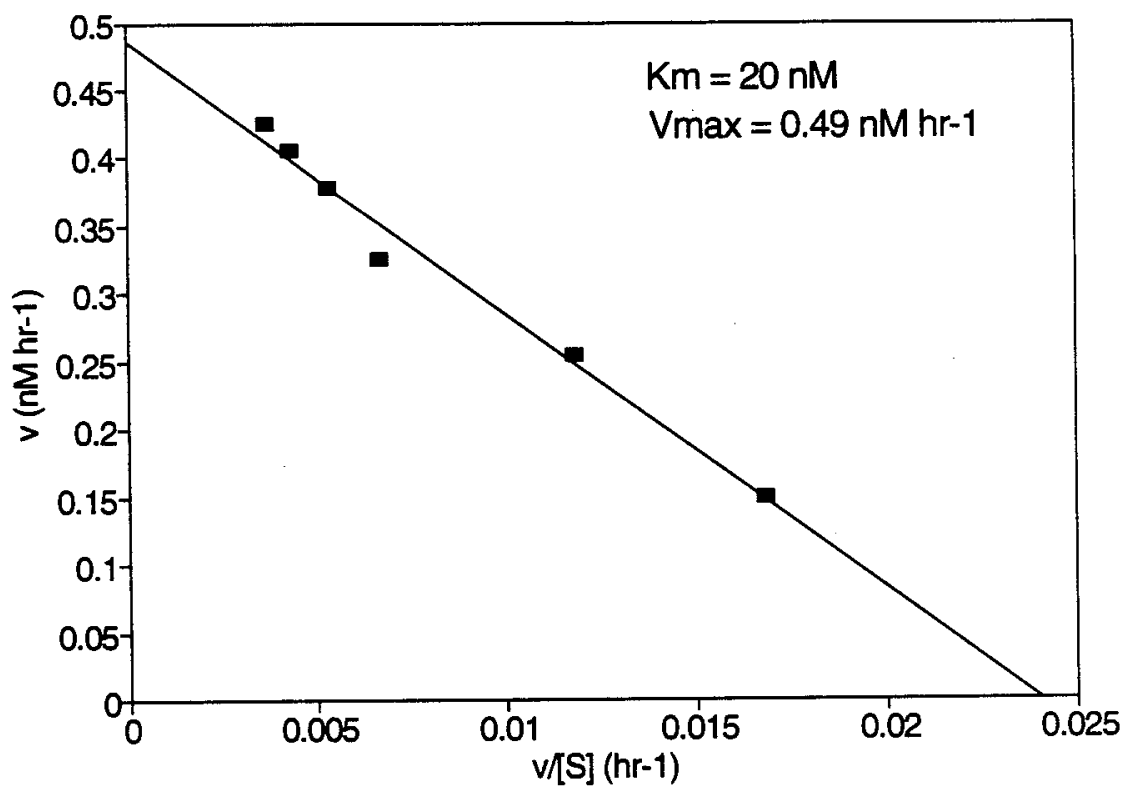

Figure 4-7. (a) Saturation curve for the DMS production kinetics experiment on 1/29/92. All rate data have been corrected for a net DMS consumption rate of 0.05 $\mathrm{nM} \mathrm{hr}{ }^{-1}$. (b) Corresponding single-reciprocal plot of rate data, yielding an apparent half saturation value of $20 \mathrm{nM}$ and a maximal velocity of $0.49 \mathrm{nM} \mathrm{hr}^{-1}$ for DMSP cleavage. The ambient rate was not included in this transformation. 


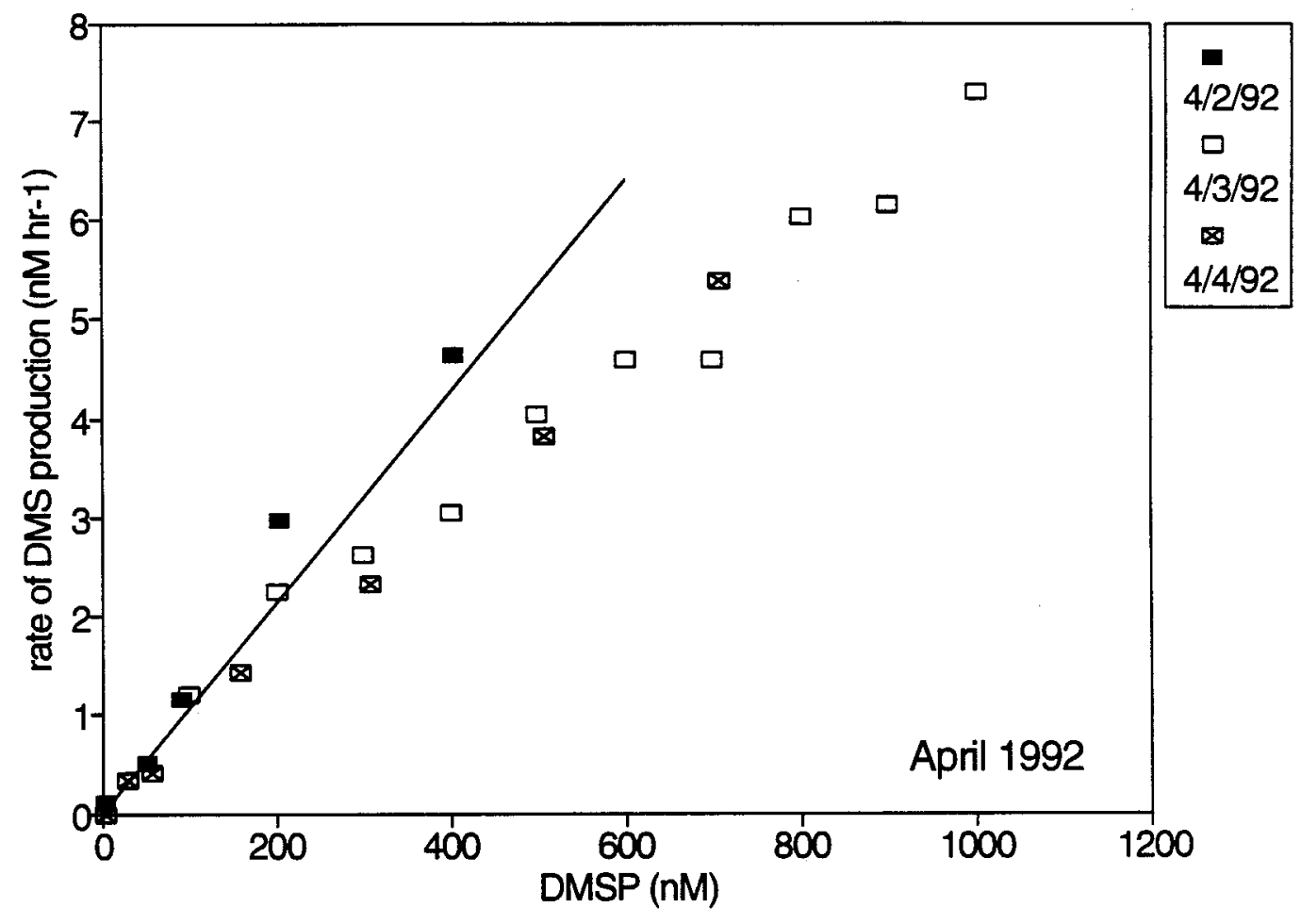

Figure 4-8. Rate versus concentration data for the DMS production kinetics experiments in April 1992. Linear regression of data for DMSP concentrations below $200 \mathrm{nM}$ yielded a slope of $0.0107 \pm 0.0008 \mathrm{hr}^{-1}$, corresponding to a $\tau_{\mathrm{DMSP}}$ with respect to cleavage of 3.9 days, and a y-intercept of zero $\left(r^{2}=0.958\right)$. Linear regressions of all data for each experiment give turnover times of 3.5, 6.6 and 5.6 days for the experiments on $4 / 2,4 / 3$ and $4 / 4$, respectively. 
an average $\tau_{\mathrm{DMSP}}$ (cleavage) of 3.9 days. Although somewhat shorter $\tau$ values (2.5 and 3.2 days) are associated with the two lowest rates estimated in this experiment, activity does not appear to saturate over the rest of the concentration range. Therefore, no kinetic parameters can be estimated from this experiment. However, $\mathrm{V}_{\max }$ must be at least $5 \mathrm{nM} \mathrm{hr}^{-1}$, and the apparent half-saturation value is probably not less than a few hundred nanomolar. If DMS consumption were competing significantly with DMS production in this experiment, shorter turnover times would be observed at higher DMSP levels than at ambient or near-ambient concentrations, as consumption would be expected to become relatively less important as rates of DMS production increased. This does not seem to be the case here.

On $1 / 22 / 92$ the kinetics of this process were quite different. DMSP additions up to approximately $120 \mathrm{nM}$ yielded the saturation curve displayed in Figure 4-7a. Net DMS consumption was observed in the unamended control. All production rates were corrected for this; however, since the actual extent of DMS consumption was not known, corrections are conservative. When the corrected rate data (with the exception of the ambient rate) were linearized by an Eadie-Hofstee plot (Figure 4-7b), a $\mathrm{K}_{\text {mapp }}$ of $20 \mathrm{nM}$ and a $\mathrm{V}_{\max }$ of $0.49 \mathrm{nM} \mathrm{hr}^{-1}$ were obtained.

The concentration dependence of DMSP cleavage was also examined on three consecutive days in April 1992. As in the fall of 1990, obvious saturation was not observed in any of the three experiments (Figure 4-8). Linear regression of these data yielded $\tau_{\mathrm{DMSP}}$ values of $3.5,6.6$, and 5.6 days, respectively, for the experiments on $4 / 2$, $4 / 3$ and 4/4/92. A separate linear regression excluding the rate data for DMSP concentrations above $200 \mathrm{nM}$ from all three experiments had a zero y-intercept, 
resulting in a $\tau_{\mathrm{DMSP}}$ of 3.9 days $\left(\mathrm{r}^{2}=0.96\right)$. This somewhat shorter average turnover time for the low end of the concentration range suggests that the higher rates were affected by saturation; a larger concentration range must be assayed to define the saturation curve adequately.

Volatile sulfur production and DMSP utilization by bacterial isolates. Seven different (on the basis of colony morphology) bacterial isolates were selected at random and assayed from DMS production from DMSP. The primary enrichment emitted large amounts of DMS. However, although the seven isolates examined from this enrichment removed DMSP from solution, none produced DMS in response to DMSP addition. Methanethiol (MeSH) production was not observed either. Chromatographic conditions may have been inappropriate for analysis of this compound, since other observations were consistent with MeSH production. When culture bottles were uncapped at the end of the timecourse, the smell of MeSH in some of them was clearly detectable. Moreover, a late peak identified as dimethyldisulfide, an oxidation product of $\mathrm{MeSH}$, was also present in some samples.

\section{DISCUSSION}

Although microbial processes have been established as both sources and sinks for DMS in the marine environment $(15-17,21,22)$, the in situ rates of these processes have received little attention. Incubation experiments reported in Chapter 3 yielded estimates of these rates in Vineyard Sound seawater during spring of 1992. In that environment, turnover times for DMSP were less than a day on average, while $\tau_{\mathrm{DMSP}}$ (cleavage) and $\tau_{\mathrm{DMS}}$ (DMS removal) were somewhat longer, on the order of a few 
days or more. The proportion of dissolved DMSP removal resulting in DMS

formation, and the kinetic parameters of the two processes, varied widely between two experiments a month apart, but data were not sufficient to confirm that the shift was seasonal in nature. The relevant data available for comparison in the literature are extensively discussed in the previous chapter.

The experiments undertaken in the present study of Sargasso Sea water were intended to obtain similar information for the oligotrophic ocean, and data were collected over more of the annual cycle with the aim of examining possible seasonal variation in rates of microbial DMSP and DMS cycling. Scatter plots of rate and turnover time data for all low-level and kinetics experiments in this study are shown in Figures 4-9, 4-10 and 4-11. At ambient and near-ambient substrate concentrations, rates of DMS production from dissolved DMSP and of DMS uptake did not differ appreciably between the fall, winter and spring (as represented by the three sampling periods). In general, DMS production appeared capable of turning both DMSP and DMS over on timescales of a few days. However, extremely low rates were encountered more frequently in January, leading to several long $\tau_{\mathrm{DMSP}}$ (cleavage) values at that time. These rates, however, are considered to be underestimates due to competition between DMS production and consumption at ambient substrate levels, as evidenced by the shorter turnover times measured in response to DMSP addition (see experiments on $1 / 20 / 92$ and $1 / 26 / 92$ in Table 4-3). This was not observed during the spring and fall experiments; turnover times estimated from addition rates either agreed with those estimated from ambient rates, or exceeded them, in agreement with expected saturation effects. This raises the possibility that DMS production and 
(a)

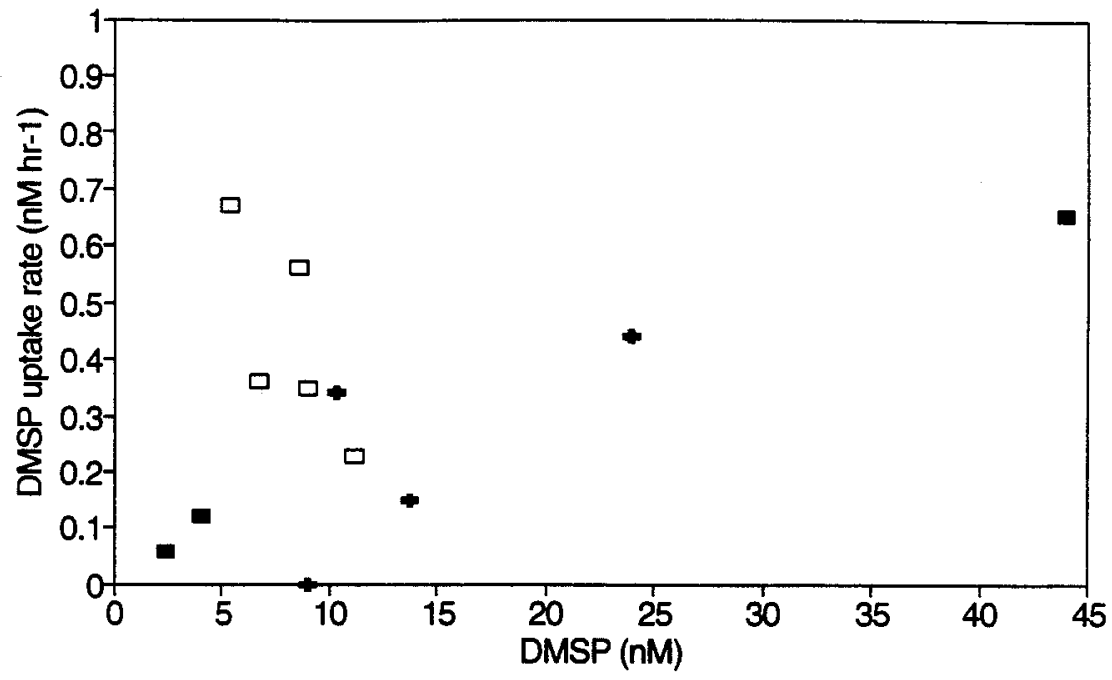

(b)

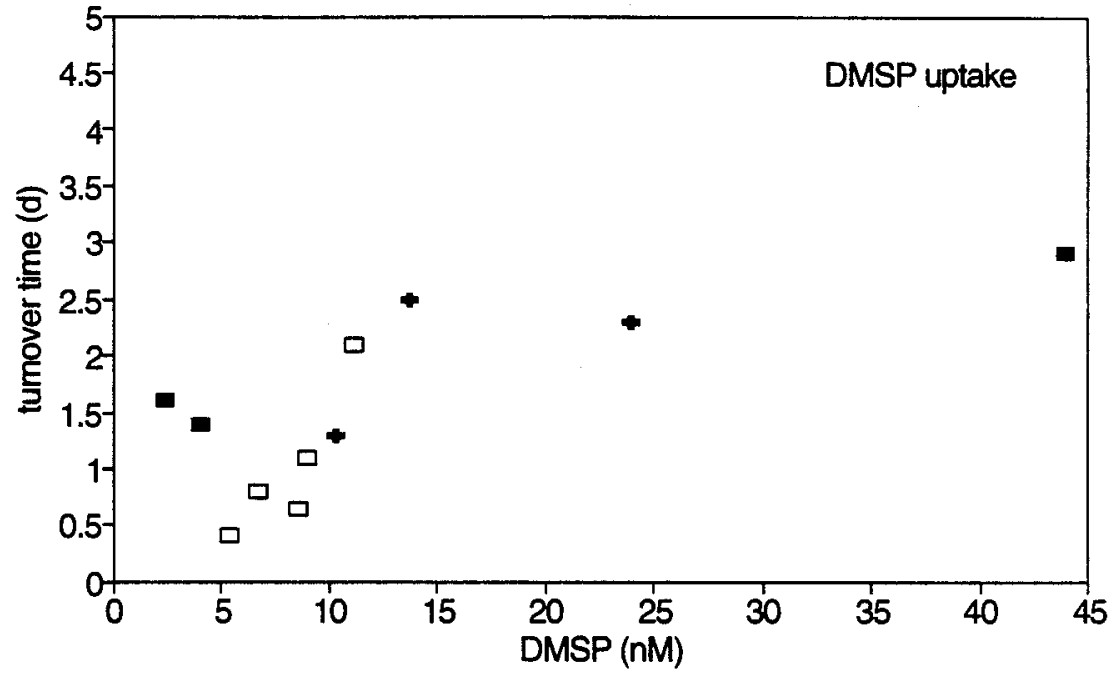

- OCT-NOV 90 口 JAN $92+$ APR 92

Figure 4-9. Scatter plot of DMSP removal data from all experiments. (a) DMSP removal rate versus DMSP concentration. (b) DMSP turnover time with versus DMSP concentration. 
(a)

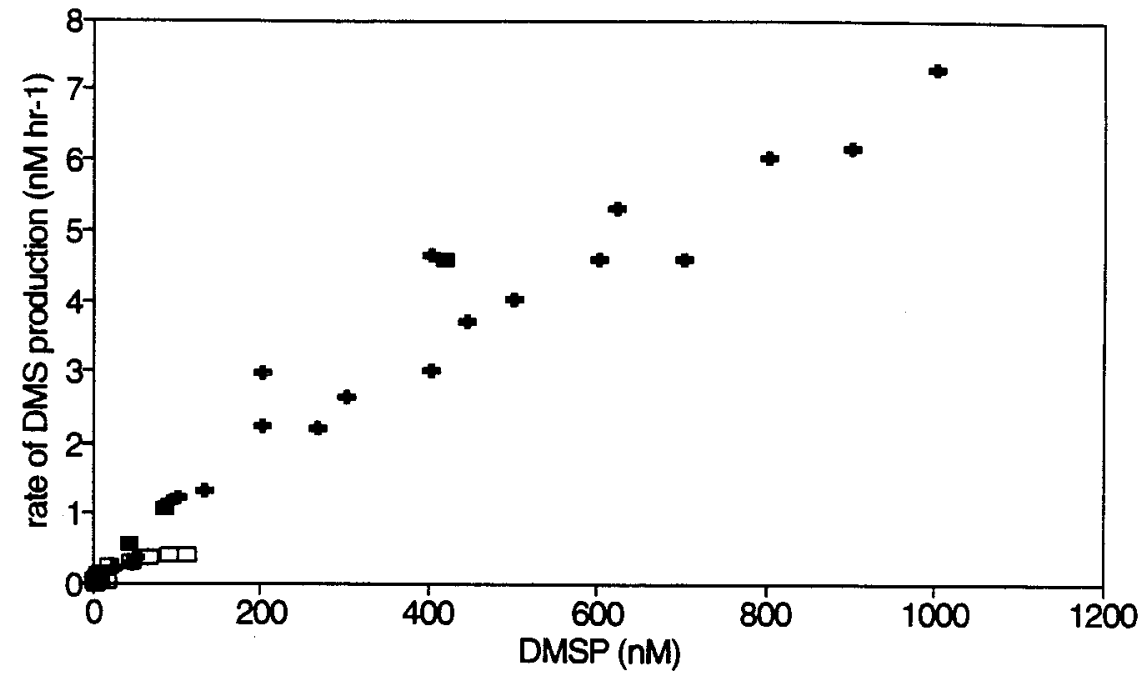

(b)

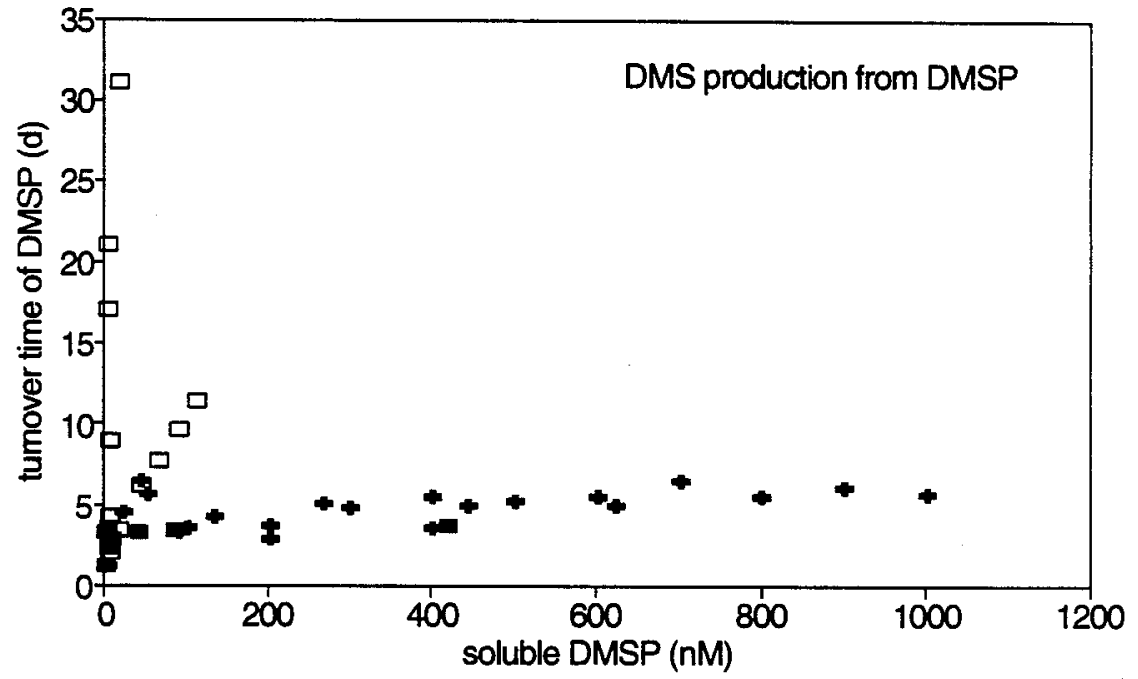

- OCT-NOV 90 口 JAN $92 *$ APR 92

Figure 4-10. Scatter plot of DMSP cleavage (DMS production from dissolved DMSP) data from all experiments. (a) Rate of DMS production versus DMSP concentration. (b) $\tau_{\mathrm{DMSP}}$ with respect to cleavage versus DMSP concentration. 
(a)

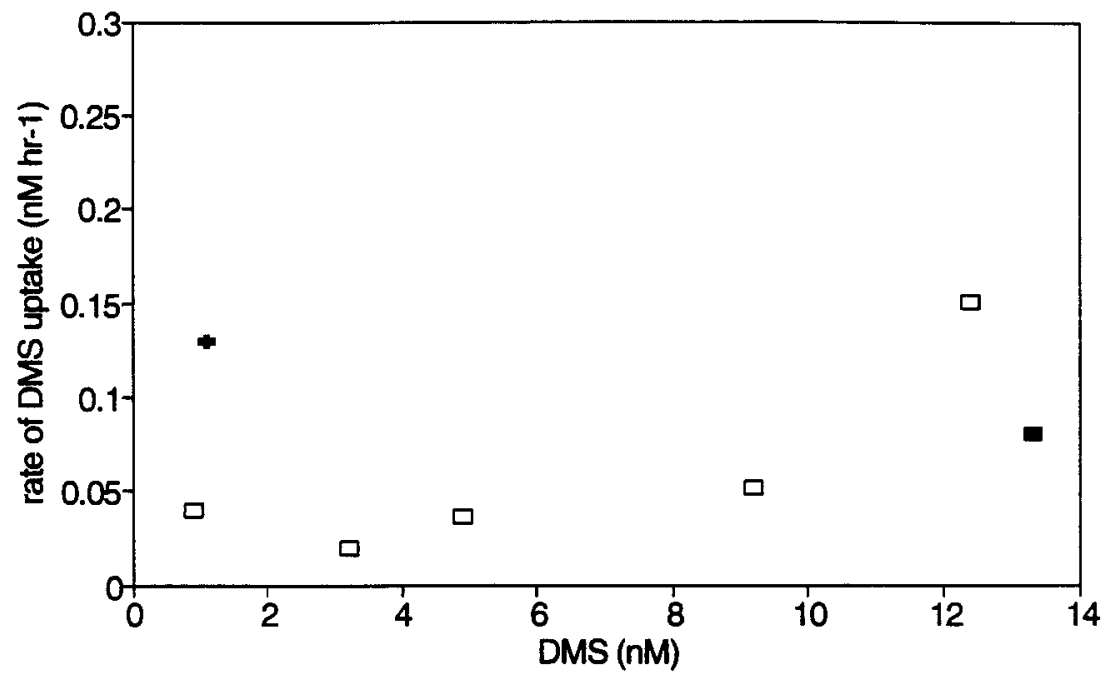

(b)

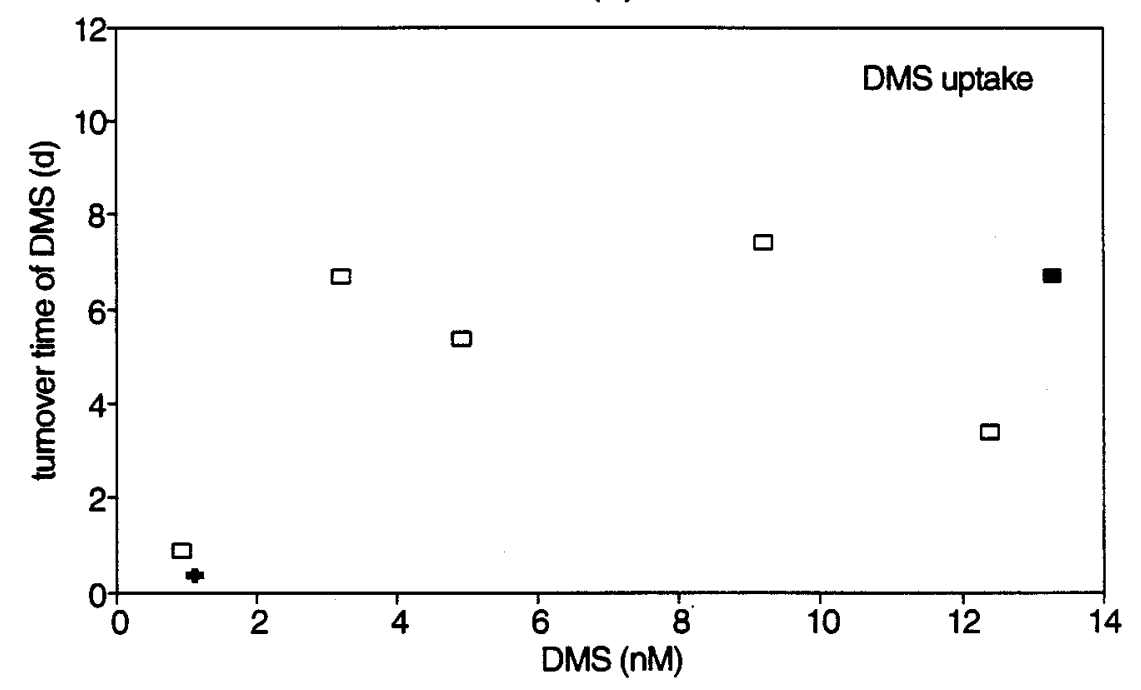

- NOV 90 口 JAN $92+$ APR 92

Figure 4-11. Scatter plot of DMS removal data from all experiments. (a) Rate of DMS removal versus DMS concentration. (b) $\tau_{\mathrm{DMS}}$ with respect to DMS removal versus DMS concentration. 
consumption may be more tightly coupled in the winter, perhaps due to higher affinity kinetics of both processes, but a larger data set covering more than one seasonal cycle would be required to confirm this. DMS consumption rates in unamended seawater, when measurable, led to $\tau_{\mathrm{DMS}}$ values of less than a day. DMSP removal rates were slightly higher in January than in the fall or spring. Because ambient soluble DMSP levels did not change appreciably between the sampling periods, this was reflected in DMSP turnover times, which were usually less than a day in January, and 1-3 days in the fall and spring.

The concentration dependence of DMS production from DMSP varied significantly between sampling periods. The spring and fall data sets, although each was collected in a different annual cycle, are quite coherent (see Figure 4-10). DMS production from DMSP did not appear to saturate in response to DMSP additions up to $400 \mathrm{nM}-1 \mu \mathrm{M}$ in the spring and fall, and the highest rates observed were on the order of 5-8 $\mathrm{nM} \mathrm{hr}^{-1}$. In January of 1992, however, an apparent half-saturation value of $20 \mathrm{nM}$ and a $\mathrm{V}_{\max }$ of $0.49 \mathrm{nM} \mathrm{hr}^{-1}$, an order of magnitude lower than the highest rates observed in the spring and fall, were recorded for this activity. The amplitude of this shift is similar to that observed between April and May in Vineyard Sound water, and raises the question of the basis for seasonal variability in the Sargasso Sea data.

Temperature in Vineyard Sound may vary from below zero to about $24^{\circ} \mathrm{C}$ over a seasonal cycle, and cyanobacterial numbers in that water, for example, have been shown to exhibit a strong temperature dependence (24). In contrast, the seasonal cycle in productivity in the Sargasso Sea is controlled by wind-driven changes in the depth of the mixed layer $(18,19)$. Vigorous mixing in the winter results in a maximal mixed 
layer depth by spring, usually sufficient to raise nitrate levels in the photic zone and induce onset of the spring bloom. Summer warming re-establishes surface stratification, and nutrients in the mixed layer are again depleted. These dramatic shifts in nutrient and productivity status are accompanied by a minor (relative to Vineyard Sound) change in surface temperatures. The temperature of the surface mixed layer in the Sargasso Sea does not vary by more than $12^{\circ} \mathrm{C}$ over an annual cycle, and usually does not drop below $18^{\circ} \mathrm{C}$. However, although ambient surface water temperature varied between only $19^{\circ} \mathrm{C}$ and $25^{\circ} \mathrm{C}$ in this study, this is nonetheless a significant proportion of the total amplitude of temperature variation, and thus cannot be ruled out as a possible determinant of microbial assemblage composition in this environment.

Substrate concentration is an obvious alternative environmental cue. The observed changes in kinetic parameters, and in the fraction of dissolved DMSP loss resulting in DMS production, suggest that a microbial population with a lower affinity for DMSP, and higher $\mathrm{V}_{\max }$, may mediate cleavage of dissolved DMSP in fall and spring as opposed to winter. In Chapter 3 an increase in the $\mathrm{K}_{\text {mapp }}$ for DMSP removal in Vineyard Sound was accompanied by an increase in the $\mathrm{K}_{\mathrm{mapp}}$ for DMSP cleavage. It was hypothesized that while the kinetics of bacterial DMSP cleavage may reflect physiological (intracellular) rather than ambient DMSP concentrations, a change in the kinetics of DMSP uptake, driven by changes in ambient DMSP, might possibly result in a shift in average physiological concentrations, and thus a change in the kinetics of DMSP cleavage. Although the kinetics of DMSP removal were not quantified in the Sargasso Sea, the shifts in DMS production kinetics observed there might have a 
similar basis. However, surface concentrations of soluble and particulate DMSP in the Sargasso Sea did not change substantially between the sampling periods. In this respect, the observed change in the kinetic parameters for DMSP cleavage cannot be linked to obvious seasonal shifts in either bulk soluble or particulate DMSP concentrations. It is possible, however, that the resolution of sampling in this study was inadequate to resolve such shifts. Time-series data on DMS and dissolved and particulate DMSP concentrations currently being collected in the Sargasso Sea do reveal seasonal shifts in the standing stocks of these compounds (J. Dacey, personal communication). Analogous to the situation described in Vineyard Sound in the previous chapter, however, these shifts are smaller than the observed changes in the apparent $\mathrm{K}_{\mathrm{m}}$ 's of either DMSP removal or DMSP cleavage. As postulated in the case of Vineyard Sound, the shift in half saturation values may reflect changes in microscale dissolved DMSP concentrations.

Although the amplitude of seasonal DMSP concentration changes in the Sargasso Sea may appear small relative to changes in the apparent kinetic parameters governing microbial DMSP utilization, it is clear that the dissolved DMSP pool is dynamic. The two profiles collected five days apart in November of 1990 are a case in point. Soluble DMSP was less than $4 \mathrm{nM}$ throughout the entire depth sampled on November 1, but by November 6 a maximum of $18 \mathrm{nM}$ had developed between 60 and 80 meters, while DMS and particulate DMSP remained low. The rate data for DMSP removal also indicate that soluble DMSP is rapidly cycled; soluble DMSP must be produced on timescales of at least a day to keep pace with consumption. Because DMSP is a zwitterionic compound, lytic events are generally considered to govern its 
release to the dissolved phase. By definition, then, soluble DMSP production would be episodic, consistent with the variability in its concentration. (If this is the case, it is puzzling that particulate DMSP does not seem as dynamic as its soluble counterpart. This could conceivably be due to undersampling of large, rare particles high in DMSP.) Comparatively small short-term fluctuations in DMS, on the other hand, may indicate that production and consumption of this compound are more tightly coupled than in the case of DMSP. The data presented here suggest that microbially mediated DMS production and consumption occur on reasonably similar timescales, and some of the low-level addition experiments, particularly in January 1992, support the concept that these processes are efficiently coupled.

Little is known about pathways of DMSP utilization other than cleavage to form DMS. Taylor and Gilchrist (21) suggest that demethylation to form 3methiolpropionate may be important. Although experiments with pure cultures of marine bacteria are of limited utility because the in situ ecological significance of isolated strains is unknown, they may still convey useful pathway information. In this regard, it is interesting that none of the January Sargasso Sea bacterial isolates assayed produced DMS from DMSP. A previous enrichment with November 1990 Sargasso Sea water yielded one DMS-producing isolate, but the majority of isolates produced methanethiol from DMSP. The enrichment technique used in this study may select for MeSH-producing bacteria, in which case these isolates would not be representative of in situ DMSP-utilizing bacteria. A DMS-producing bacterium has been isolated from Sargasso Sea water (4), and phylogenetic characterization of this isolate places it in the $\alpha$ proteobacteria (Chapter 6). Members of this group have been inferred to be 
ubiquitous in the oligotrophic marine environment $(3,8,20)$, but are not isolated from seawater by common enrichment techniques. If other DMS-producing bacteria in Sargasso Sea water belong to this group, they may be similarly selected against in enrichments such as the one used in this study.

Traditionally low estimates of total production in Sargasso Sea $(5,18,19)$ have grown higher with the advent of trace metal-clean techniques for assaying $\mathrm{H}^{14} \mathrm{CO}_{3}^{-}$ uptake (7). Asper et al. (2) recently assessed total production in the Sargasso at 200$400 \mathrm{mg} \mathrm{C} \mathrm{m}^{-2} \mathrm{~d}^{-1}$, with peaks during the spring bloom of $600-800 \mathrm{mg} \mathrm{C} \mathrm{m}^{-2} \mathrm{~d}^{-1}$. However, consideration of oxygen cycling within and below the photic zone $(12,13)$ indicates that new production alone may be on the order of current estimates of total production by conventional methods, about $140 \mathrm{mg} \mathrm{C} \mathrm{m}^{-2} \mathrm{~d}^{-1}$ (12). These results have stimulated speculation that standard incubation methods significantly underestimate new and total production, possibly by failing to sample patchiness adequately. A duallayer euphotic zone has been proposed that would account for both high new and total production (9). In this model, well-lit surface water is dominated by a highly efficient food web whose activity results in extremely low steady-state levels of chlorophyll and nutrients. Goldman et al. (10) compare this portion of the system to a chemostat, in which bacterial nutrient regeneration and zooplankton grazing of phytoplankton act respectively as the "input and overflow mechanisms," and cite high phytoplankton growth rate data for the oligotrophic ocean in support of their contention that nutrient availability does not limit algal growth in this environment. Production toward the base of the photic zone, in contrast, would be fueled by upwelled nitrate and dominated by larger algae, thus sustaining a significant flux of sinking carbon even 
while regeneration in much of the surface water is extremely high. If this conceptualization is accurate, and our estimates of total production are low due to inability to sample patchy seawater representatively, we have no checks on just how fast the "spinning wheel" (9) is turning in the upper layer of this system; the need to relate new to total production by the $f$-ratio established for oligotrophic systems ( 6 ) would be largely obviated by the uncoupling between these putative zones. The true magnitude of new and total production in the oligotrophic gyres, and the structure of the photic zone, are issues that remain unresolved. However, it is becoming clear that, in spite of their low phytoplankton standing stock, the oligotrophic subtropical gyres are considerably more productive than once thought.

Because soluble DMSP concentrations are presumably supported by lytic rather than diffusive release from algae, the processes discussed here may have implications for turnover of algal biomass. This study indicates that soluble DMSP appears to be turned over by uptake on timescales of a few days to less than a day, requiring that it be produced from the particulate pool on a similar timescale. Whether or not soluble DMSP production occurs via "sloppy feeding" by zooplankton or zooplankton excretion, it is probably a fair proxy for algal cell death. Although not all algae synthesize DMSP, we may assume that the fraction of the algal community that does is grazed representatively. By this reasoning, the phytoplankton must turn over on a timescale similarly short to that of soluble DMSP, in agreement with the higher-end estimates of phytoplankton growth rates in oligotrophic environments, which are on the order of $>1$ doubling per day (10, and references therein).

To the extent that the Vineyard Sound and Sargasso Sea data sets are 
comparable, the similarity between these two marine environments with respect to aspects of DMS and DMSP turnover is notable. Although ambient concentrations of both DMS and dissolved DMSP are generally higher year-round in coastal seawater, calculated turnover times for both DMSP and DMS are similar. It is tantalizing to speculate that the "spinning wheel" of microbial DMS cycling parallels that of productivity in the oligotrophic Sargasso Sea. Analogous to the low net chlorophyll resulting from fast but efficient food-web interactions, small and relatively invariant steady-state concentrations of DMS or DMSP in the Sargasso Sea may belie rapid cycling of these compounds. 


\section{REFERENCES}

1. Andreae, M. O. 1990. Ocean-atmosphere interactions in the global biogeochemical sulfur cycle. Mar. Chem. 30:1-29.

2. Asper, V. L., W. G. Deuser, G. A. Knauer, and S. E. Lohrenz. 1992. Rapid coupling of sinking particle fluxes between surface and deep ocean waters. Nature 357:670-672.

3. Britschgi, T. B., and S. J. Giovannoni. 1991. Phylogenetic analysis of a natural marine bacterioplankton population by rRNA gene cloning and sequencing. Appl. Environ. Microbiol. 57:1707-1713.

4. Dacey, J. W. H., and N. V. Blough. 1987. Hydroxide decomposition of dimethylsulfoniopropionate to form dimethylsulfide. Geophys. Res. Let. 14:1246-1249.

5. Eppley, R. W. 1980. Estimating phytoplankton growth rates in the central oligotrophic oceans, pp. 231-242. In: P. G. Falkowski (ed.), Primary productivity in the sea. Plenum Press, New York.

6. Eppley, R. W., and B. J. Peterson. 1979. Particulate organic matter flux and planktonic new production in the deep ocean. Nature 282:677-680.

7. Fitzwater, S. W., G. A. Knauer, and J. M. Martin. 1982. Metal contamination and its effect on primary production measurements. Limnol. Oceanogr. 27:544-551.

8. Giovannoni, S. J., T. B. Britschgi, C. L. Moyer, and K. G. Field. 1990. Genetic diversity in Sargasso Sea bacterioplankton. Nature 345:60-62.

9. Goldman, J. C. 1988. Spatial and temporal discontinuities of biological processes in pelagic surface waters, pp. 273-296. In: B. J. Rothschild (ed.), Towards a theory on biological and physical processes in the world ocean. Kluwer Academic Publishers, Dordrecht, The Netherlands.

10. Goldman, J. C., J. J. McCarthy, and D. G. Peavey. 1979. Growth rate influence on the chemical composition of phytoplankton in oceanic waters. Nature 279:210-215. 
11. Hobbie, J. E., R. J. Daley, and S. Jasper. 1977. Use of Nuclepore filters for counting bacteria by fluorescence microscopy. Appl. Environ. Microbiol. 33: $1225-1228$.

12. Jenkins, W. J. 1982. Oxygen utilization rates in the North Atlantic Subtropical Gyre and primary production in oligotrophic systems. Nature 300:246-248.

13. Jenkins, W. J., and J. C. Goldman. 1985. Seasonal oxygen cycling and primary production in the Sargasso Sea. J. Mar. Res. 43:465-491.

14. Keller, M. D., W. K. Bellows, and R. R. L. Guillard. 1989. The importance of taxonomy in the production of dimethyl sulfide by marine phytoplankton, pp. 167-182. In: E. S. Saltzman and W. J. Cooper (eds.), Biogenic sulfur in the environment. ACS Symposium Ser. 393, American Chemical Society, Washington, D.C.

15. Kiene, R. P. 1990. Dimethyl sulfide production from dimethylsulfoniopropionate in coastal seawater samples and bacterial cultures. Appl. Environ. Microbiol. 56:3293-3297.

16. Kiene, R. P., and T. S. Bates. 1990. Biological removal of dimethyl sulphide from sea water. Nature 345:702-705.

17. Kiene, R. P., and S. K. Service. 1991. Decomposition of dissolved DMSP and DMS in estuarine waters: Dependence on temperature and substrate concentration. Mar. Ecol. Prog. Ser. 76:1-11.

18. Menzel, D. W., and J. H. Ryther. 1960. The annual cycle of primary production in the Sargasso Sea off Bermuda. Deep-Sea Res. 6:351-367.

19. Menzel, D. W., and J. H. Ryther. 1961. Annual variations in primary production of the Sargasso Sea off Bermuda. Deep-Sea Res. 7:282-288.

20. Schmidt, T. M., E. F. DeLong, and N. R. Pace. 1991. Analysis of a marine picoplankton community by $16 \mathrm{~S}$ rRNA gene cloning and sequencing. J. Bacteriol. 173:4371-4378.

21. Taylor, B. F., and D. C. Gilchrist. 1991. New routes for aerobic degradation of dimethylsulfoniopropionate. Appl. Environ. Microbiol. 57:3581-3584.

22. Wakeham, S. G., B. L. Howes, and J. W. H. Dacey. 1987. Biogeochemistry of dimethylsulfide in a seasonally stratified coastal salt pond. Geochim. Cosmochim. Acta 51:1675-1684. 
23. Wakeham, S. G., and J. W. H. Dacey. 1989. Biogeochemical cycling of dimethylsulfide in marine environments, pp. 152-166. In: E. S. Saltzman and W. J. Cooper (eds.), Biogenic sulfur in the environment. ACS Symposium Ser. 393, American Chemical Society, Washington, D.C.

24. Waterbury, J. B., S. W. Watson, F. W. Valois, and D. G. Franks. 1986.

Biological and ecological characterization of the marine unicellular cyanobacterium Synechococcus. In: T. Platt and W. K. Li (eds.), Photosynthetic picoplankton. Can. Bull. Fish. Aquatic Sci. 214:71-120. 


\section{CHAPTER 5}

\section{DIMETHYLSULFIDE PRODUCTION FROM DIMETHYLSULFONIOPROPIONATE BY A MARINE BACTERIUM}

The early isolation of dimethylsulfoniopropionate (DMSP) from a marine alga (7) and report of an algal DMSP-lyase (6) generated an extensive literature on the occurrence of DMSP in phytoplankton and macroalgae. However, considering the substantial energy that has been invested in attempts to correlate DMS with phytoplankton activity in the ocean (2), relatively few laboratory studies of DMS production by algae have been initiated $(1,8,26)$. Dacey and Wakeham $(8)$ observed that copepod grazing on a dinoflagellate culture significantly enhances DMS production, and at least two field studies to date $(4,21)$ have provided evidence that grazing may stimulate algal DMS production. Vairavamurthy et al. (26) showed that salinity stress increases both DMSP content and the rate of DMS production in the coccolithophorid Pleurochrysis carterae. These two laboratory studies have furnished the only estimates of algal DMS production rates in the literature. Thus, although DMSP lyases from a red macroalga and a heterotrophic dinoflagellate have been partially isolated and characterized $(6,17)$, we have a limited understanding of the factors controlling the rate of DMS production by algae in the marine environment, and no reliable way to quantify these rates in situ.

In contrast, microbial formation of DMS from dissolved DMSP (as distinct from algal formation of DMS from internal reserves of DMSP) has only recently begun to receive attention as a possibly important mode of DMS formation in the marine 
environment, and no biochemical work has been done on DMSP lyase in marine bacteria. However, this process exhibits quantifiable concentration dependence in seawater incubation experiments (20; Chapters 3 and 4) and therefore holds out the hope that it may prove amenable to modeling. As a result of these investigations comparatively more is known about soluble than algal (particulate) DMSP as a precursor for marine DMS, although the former is a far more recent field of study.

In an attempt to address questions raised by the field data in preceding chapters about the mechanism and rates of dissolved DMSP metabolism in marine microbiota, this chapter examines the whole-cell kinetics of DMSP uptake and cleavage, and other aspects of DMS production, in a bacterium isolated from Sargasso Sea water.

\section{MATERIALS AND METHODS}

Isolation and stock culture maintenance. The bacterium, designated strain LFR, was isolated from Sargasso Sea surface $(1 \mathrm{~m})$ water. A full description of its isolation and culture is provided in Chapter 6.

Analytical. Cells were counted by acridine orange epifluorescence microscopy (16). Protein was determined by the Lowry assay (5). DMS was analyzed by sulfurspecific gas chromatography according to the protocol described in Chapter 2. Most determinations of DMS were by direct injection of headspace.

Assay of DMS production from DMSP. Table 5-1 summarizes the experiments described below.

Early in timecourses of DMS production from DMSP by LFR, a rapid increase in rate was observed, as evidenced by a pronounced concave-upward curvature of the 


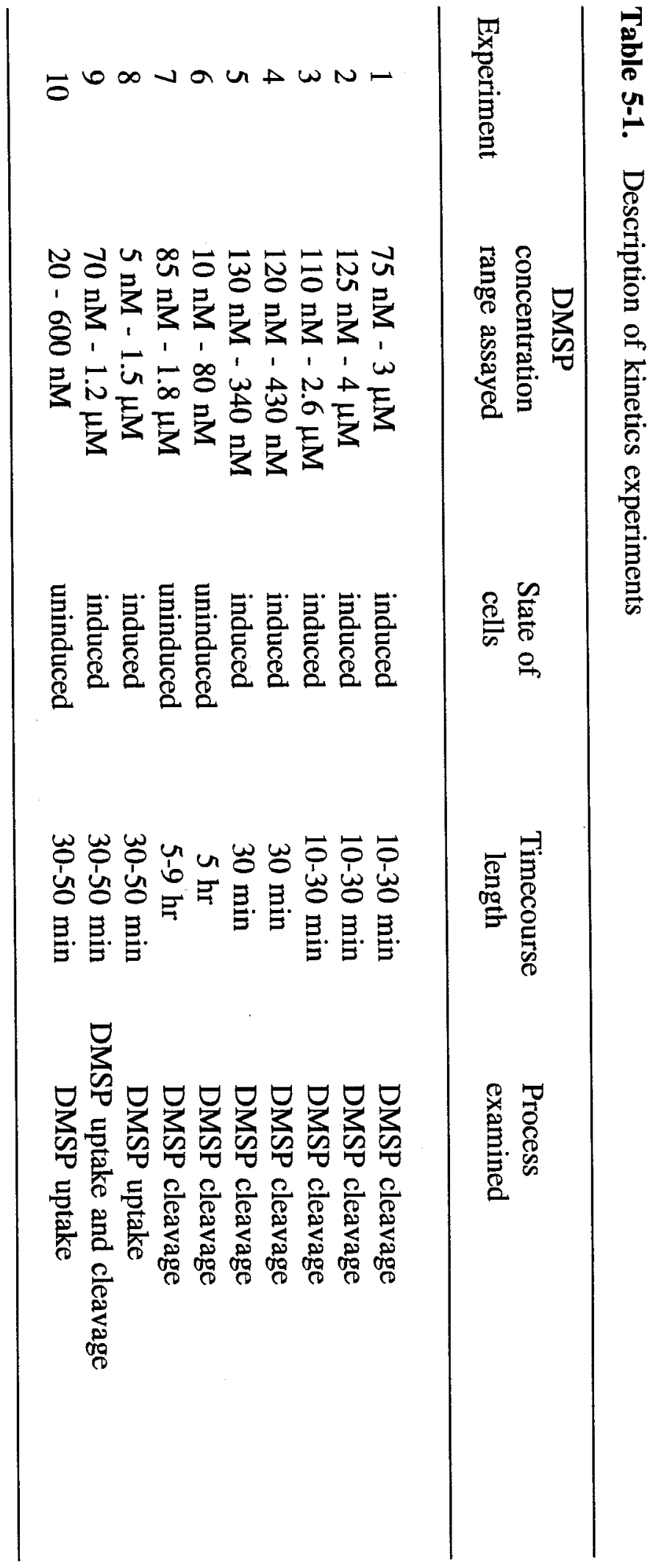


plot of DMS accumulated per cell versus time. This rate increase was suppressed by the addition of $100 \mu \mathrm{M}$ chloramphenicol to the medium (Figure 5-1). These observations are consistent with the concept that DMS production from DMSP in LFR is inducible. Hereafter, "induced" refers to cells grown on DMSP, while "uninduced" refers to cells grown on mannitol or marine medium 2216.

In order to avoid the effect of changing rate on rate estimations, cells were induced (grown on DMSP) prior to assays in Experiments 1-6. Assays of DMS production from DMSP were conducted in silylated, sterile serum bottles capped with Teflon-faced butyl rubber septa, each containing $145 \mathrm{~mL}$ of the modified $\mathrm{f} / 2$ medium described in Chapter 6 and varying concentrations of DMSP. Cells were grown on 1 $\mathrm{mM}$ DMSP and harvested in exponential phase by centrifugation at $7,700 \times g$ for 8 minutes at $15^{\circ} \mathrm{C}$. They were washed three times and resuspended in sterile seawater. This suspension served as the inoculum for simultaneously conducted assays. Cell density in the sample bottles was approximately $10^{6}$ cells $\mathrm{mL}^{-1}$. Cells were freshly harvested for each set of assays to minimize potential differences among inocula due to storage. At the end of a timecourse, $1-\mathrm{mL}$ aliquots were withdrawn from each sample bottle and fixed by addition of glutaraldehyde $(0.5 \%)$ for later cell counts. The amounts of DMS and DMSP added with inocula were always negligible $(<5 \mathrm{nM})$. Preliminary assays were carried out to determine the appropriate range of DMSP addition. To provide an estimate of replication both within and between experiments, duplicate assays of each concentration were carried out in one of three experiments covering the concentration range between $100 \mathrm{nM}$ and $4 \mu \mathrm{M}$ (experiments 1-3). In the second two, only single determinations were made. Two additional experiments (4 


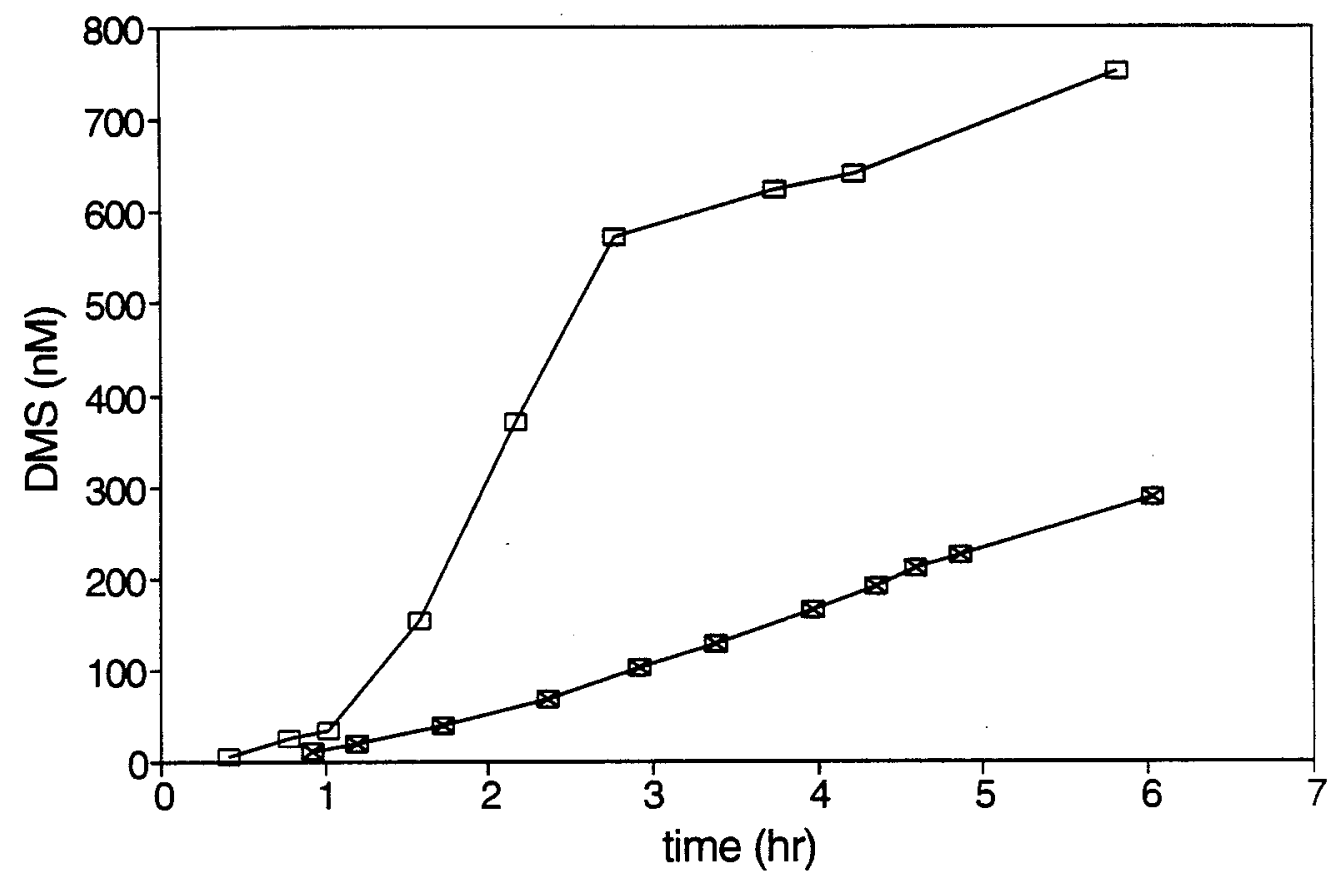

$\square$ untreated $\quad-500$ uM CAP

Figure 5-1. Effect of $100 \mu \mathrm{M}$ chloramphenicol on production of DMS from $1 \mu \mathrm{M}$ DMSP by LFR. Chloramphenicol suppresses the increase in DMS production rate apparent in untreated cells, suggesting that de novo protein formation may be responsible for this change. 
and 5) with internal duplicates repeated the assays at DMSP concentrations between 100 and $400 \mathrm{nM}$, and experiment 6 examined the concentration range between 10 and $80 \mathrm{nM}$.

The time required for equilibration of DMS between the solution and gas phases in a sample bottle introduces a complicating kinetic factor into timecourses of DMS evolution measured by real-time headspace analysis. On the other hand, preconcentration of DMS by sparging provides a true measure of solution-phase DMS but imposes serious constraints on sampling frequency. For the short (10-30 minutes) higher-level assays, a preservation scheme was utilized that permitted sampling at halfminute intervals and accurate quantification of solution-phase DMS. 4-mL aliquots were removed by syringe from the sample bottle at each timepoint and transferred to $10-\mathrm{mL}$ serum bottles. (Headspace volume in the sample bottles before sampling began was $15 \mathrm{~mL}$ and increased to no more than $55 \mathrm{~mL}$ by the time sampling was complete. On the short timescale of high-level, induced assays, this caused negligible adjustments in the partitioning of DMS between solution and gas phase.) The aliquot bottles contained $40 \mu \mathrm{L} 10 \%$ sodium dodecyl sulfate (SDS), which terminated DMS production instantly and did not interfere with DMS analysis (Figure 5-2). DMS in the dispensed aliquots was allowed to equilibrate completely with the gas phase and then analyzed in the aliquot bottle headspace. DMS standards were prepared identically to aliquot bottles with respect to dispensing and SDS concentration. Where it was necessary to analyze DMS in SDS-preserved aliquots by sparging, $30 \mu \mathrm{L}$ halfstrength Antifoam A (Sigma) was added immediately prior to analysis to reduce foaming of the sample. 


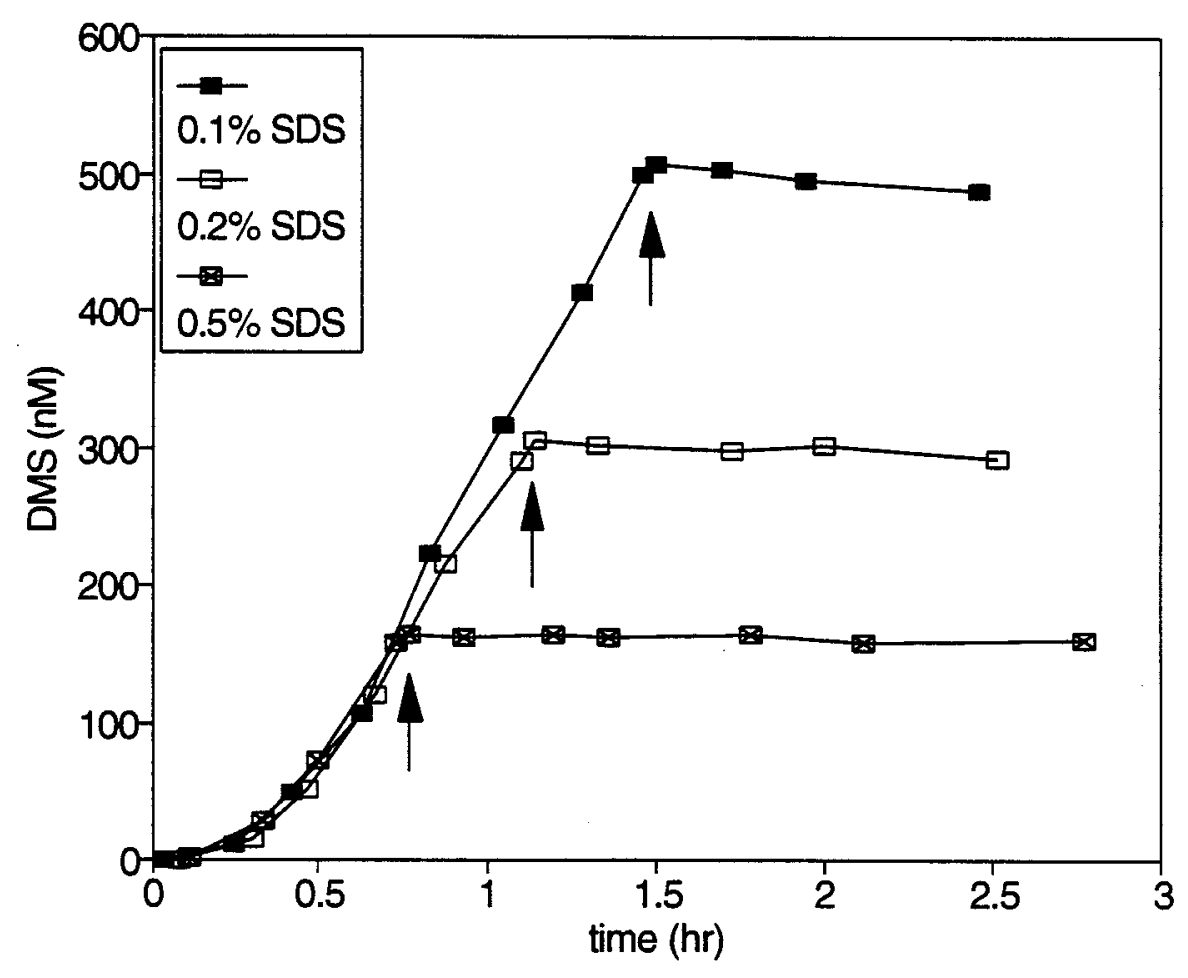

Figure 5-2. Effect of addition of $0.1,0.2$, and $0.5 \%$ SDS on DMS production from DMSP by marine isolate. Arrows indicate time of sodium dodecyl sulfate (SDS) addition to each timecourse. All levels of SDS instantly terminated DMS production. 
Rates were estimated from the linear portion of the timecourse of DMS accumulation in the culture medium. A brief lag of 2-4 minutes, reflecting the time required for DMSP uptake, was observed at the start of the timecourse, after which the rate of DMS accumulation remained constant for at least 5-20 minutes, depending on the initial DMSP concentration (Figure 5-3). For experiment 6, cells were grown on marine medium 2216 rather than DMSP, and therefore were "uninduced" by our definition. In this case, induced rates were calculated from the maximum, rather than initial, rate of DMS production.

In experiment 7, uninduced cells were harvested as above and assayed in the 80 nM-2 $\mu \mathrm{M}$ concentration range. DMS accumulation was considerably slower than in the case of induced cells, such that timecourse length increased to five hours. DMS was quantified by real-time headspace analysis. As mentioned above, in these assays an increase in the rate of DMS production, possibly due to de novo synthesis of the DMSP lyase, was observed. To the extent possible, the initial linear part of the DMS versus time plot was used.

Assay of DMSP uptake. The kinetics of DMSP uptake were also examined in induced (experiments 8 and 9) and uninduced (experiment 10) cells. Note that "uptake" here refers to removal of DMSP from the dissolved phase. Experiment 9 simultaneously assayed DMSP uptake and DMS production. Preparation of cells and sample bottles was as above. However, because filtration substantially increased the time required to process each sample, it was necessary to lower experimental cell densities by approximately an order of magnitude to obtain linear portions of the timecourse sufficient for rate estimation. Removal of DMSP from the dissolved phase 


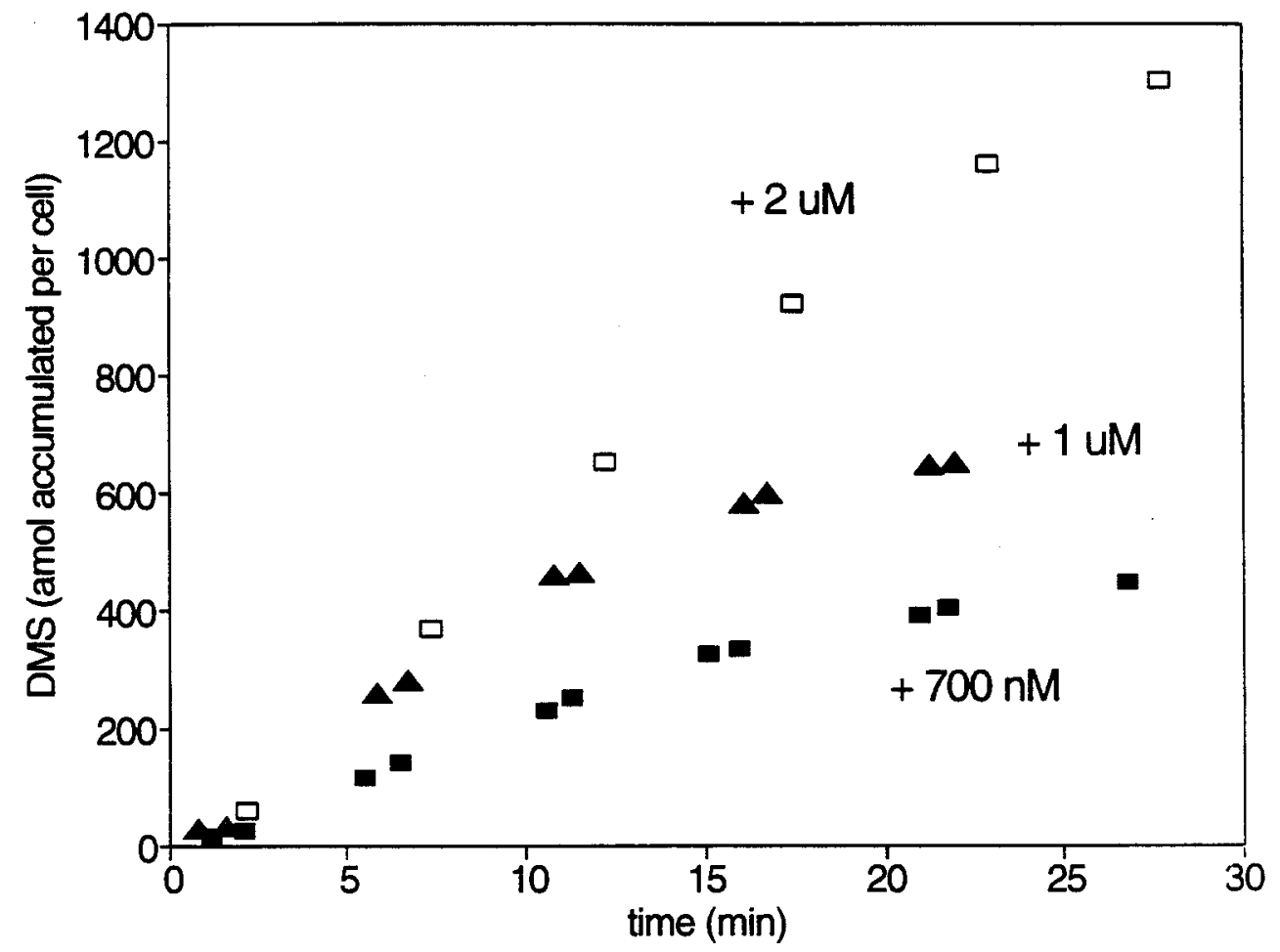

Figure 5-3. DMS production by induced cells from $700 \mathrm{nM}, 1 \mu \mathrm{M}$, and $2 \mu \mathrm{M}$ DMSP. A lag of 2-4 minutes precedes the linear part of the timecourse. Duplicate treatments are shown for $700 \mathrm{nM}$ and $1 \mu \mathrm{M}$ additions. 
was monitored as follows. 4-mL aliquots of culture medium were withdrawn into a 10-mL B-D Plastipak syringe (Becton-Dickinson), expelled into a 25-mm glass filtration unit (Millipore) and filtered by vacuum through a $0.2 \mu \mathrm{m}$ Gelman Supor-200 filter directly into a $10-\mathrm{mL}$ serum bottle. $0.2 \mu \mathrm{m}$-filtration instantly terminated DMSP cleavage and additionally served the purpose of separating intracellular from extracellular DMSP. Filtered aliquots were then stripped of DMS for 10 minutes by a flow of nitrogen, and $\mathrm{KOH}$ added to a final concentration of $1 \mathrm{~N}$. Aliquots reacted overnight at room temperature, and the resulting DMS was analyzed either by headspace or sparging, depending on sample concentration.

Kinetic parameters for DMS production and DMSP uptake in the induced and uninduced systems were estimated by the Eadie-Hofstee (single reciprocal) plot (13), and DMS production kinetics in most cases additionally examined by the graphical technique of Eisenthal and Cornish-Bowden (12). The Eadie-Hofstee plot was preferred over the Lineweaver-Burk (double reciprocal) plot, as the latter tends to compress the rate data at high substrate levels and exaggerate the importance of the data points at lower concentrations (13). The direct linear plot of Eisenthal and Cornish-Bowden (12), which does not involve linearization of the data and therefore avoids the statistical pitfalls of both the Lineweaver-Burk and Eadie-Hofstee plots, was examined for agreement with the results of the single-reciprocal plot. The halfsaturation value for DMSP uptake is symbolized by $\mathrm{K}_{\mathrm{m}}$. However, the half-saturation value for DMSP cleavage is here termed $\mathrm{K}_{\mathrm{mapp}}$, as evidence presented below indicates that DMSP cleavage in this isolate is an intracellular process, and that therefore the DMSP-lyase responds to physiological, rather than extracellular, DMSP concentrations. 
Induction of DMSP-lyase. The effect of chloramphenicol, an inhibitor of protein synthesis (15), on DMSP-lyase activity was examined by suspending uninduced cells in modified $\mathrm{f} / 2$ medium and allowing them to preincubate for 2.5 hours with or without $1 \mu \mathrm{M}$ chloramphenicol. $1 \mu \mathrm{M}$ DMSP was then added and headspace monitored for DMS accumulation.

The ability of a number of different compounds to act as inducers of DMSPlyase activity in LFR was tested. DMS and acrylic acid were examined because they are products of the cleavage. Methionine was also examined because LFR has been found to produce methanethiol from methionine (Chapter 6), although the lyases mediating DMSP and methionine cleavage are probably distinct. Cells were grown to mid-logarithmic phase on mannitol, washed twice in sterile seawater and resuspended in medium containing, as the sole carbon source, $20 \mu \mathrm{M}$ of either DMSP, acrylic acid, DMS, methionine, or mannitol. After a four-hour incubation, cells from each treatment were washed three times in sterile seawater, resuspended in serum bottles containing medium $1 \mu \mathrm{M}$ in DMSP, and headspace monitored for DMS production. Incubations with DMSP and mannitol served as positive and negative controls for induction, respectively, based on past results.

Inhibition of DMSP lyase by sulfhydryl-specific inhibitors. Based on evidence of an active-site sulfhydryl in the algal DMSP-lyase $(6,17)$, the effect of cell-impermeant sulfhydryl-specific inhibitors was examined. Both $p$-hydroxymercuriphenylsulfonate (PHMPS) and iodoacetamide covalently modify sulfhydryl groups. PHMPS was investigated for its ability to inhibit DMS production from DMSP. Cells grown to mid-logarithmic phase on mannitol were suspended in medium containing 0,5 or 10 
$\mu \mathrm{M}$ PHMPS, preincubated for one hour, and then monitored for DMS production from $1 \mu \mathrm{M}$ added DMSP. Assays were carried out in duplicate. In the case of lucifer yellow iodoacetamide (LYI), a fluorescently-tagged iodoacetamide, binding of $5 \mu \mathrm{M}$ LYI to the exterior of cells was compared in an induced and an uninduced cultures of LFR. After a thirty-minute preincubation, cells were examined by epifluorescence to detect bound reagent. These assays were assumed to inhibit or detect only surfaceassociated activity.

Reagents and chemicals. DMS and DMSP were obtained as in Chapter 2. Chloramphenicol and PHMPS were purchased from Sigma. Lucifer yellow iodoacetamide was obtained from Molecular Probes, Eugene, OR. Prepared media and media components were from Becton Dickinson Microbiology Systems, Cockeysville, MD.

\section{RESULTS}

Aspects of DMSP utilization. LFR displayed a low level of constitutive DMSPlyase activity, as evidenced by the modest (relative to uninhibited cells) but constant rate of DMS production from DMSP by uninduced cells in the presence of chloramphenicol (Figure 5-1).

In testing the capacity of various compounds to induce DMSP lyase, stimulation of the initial rate of DMS production from DMSP was considered a measure of induction. Preincubation with acrylate greatly increased the initial rate of DMS production from DMSP relative to that of cells grown on mannitol, while cells incubated with DMS and methionine produced DMS at rates indistinguishable from that of mannitol-incubated cells (Figure 5-4). 
The DMSP-lyase produced by LFR does not appear to be released into solution; DMS production from DMSP is terminated by filter-sterilization. PHMPS, a cellimpermeant alkylating agent specific for sulfhydryl groups (24), did not inhibit DMS production from DMSP. Neither uninduced nor induced cells incubated with lucifer yellow iodoacetamide fluoresced in response to illumination by a $100 \mathrm{~W}, 12 \mathrm{~V}$ halogen lamp, although these cells could be visualized by double-staining with acridine orange. Although a positive control for binding was not available, lucifer yellow iodoacetamide did appear to stain fibers present in the culture medium, indicating that the reagent was functioning properly and that bound stain was detectable under the conditions used.

Kinetics of DMSP cleavage. Half-saturation $\left(\mathrm{K}_{\mathrm{m}}, \mathrm{K}_{\mathrm{m} a p p}\right)$ and maximum velocity $\left(\mathrm{V}_{\max }\right)$ values estimated from induced and uninduced rates are provided in Table 5-2. Rates are expressed as femtomoles per cell per hour. For strain LFR, a conversion factor of $2.4 \times 10^{-7} \mu \mathrm{g}$ protein per cell can be used to calculate protein-normalized rates.

An apparent half-saturation value for DMSP cleavage of $465 \mathrm{nM}$ and $\mathrm{V}_{\max }$ of $0.04 \mathrm{fmol} \mathrm{cell}^{-1} \mathrm{hr}^{-1}$ were obtained for uninduced cells (Figure 5-5). These estimates are fairly uncertain, as they are based on a regression of only four rates. Moreover, the rate estimates themselves are prone to considerable error due to the difficulty of determining the point at which induction begins to affect seriously the rate of DMS accumulation.

Saturation curves for DMSP-lyase activity in induced cells are shown in Figure 5-6. Production of DMS from DMSP in the concentration range between $350 \mathrm{nM}$ and 


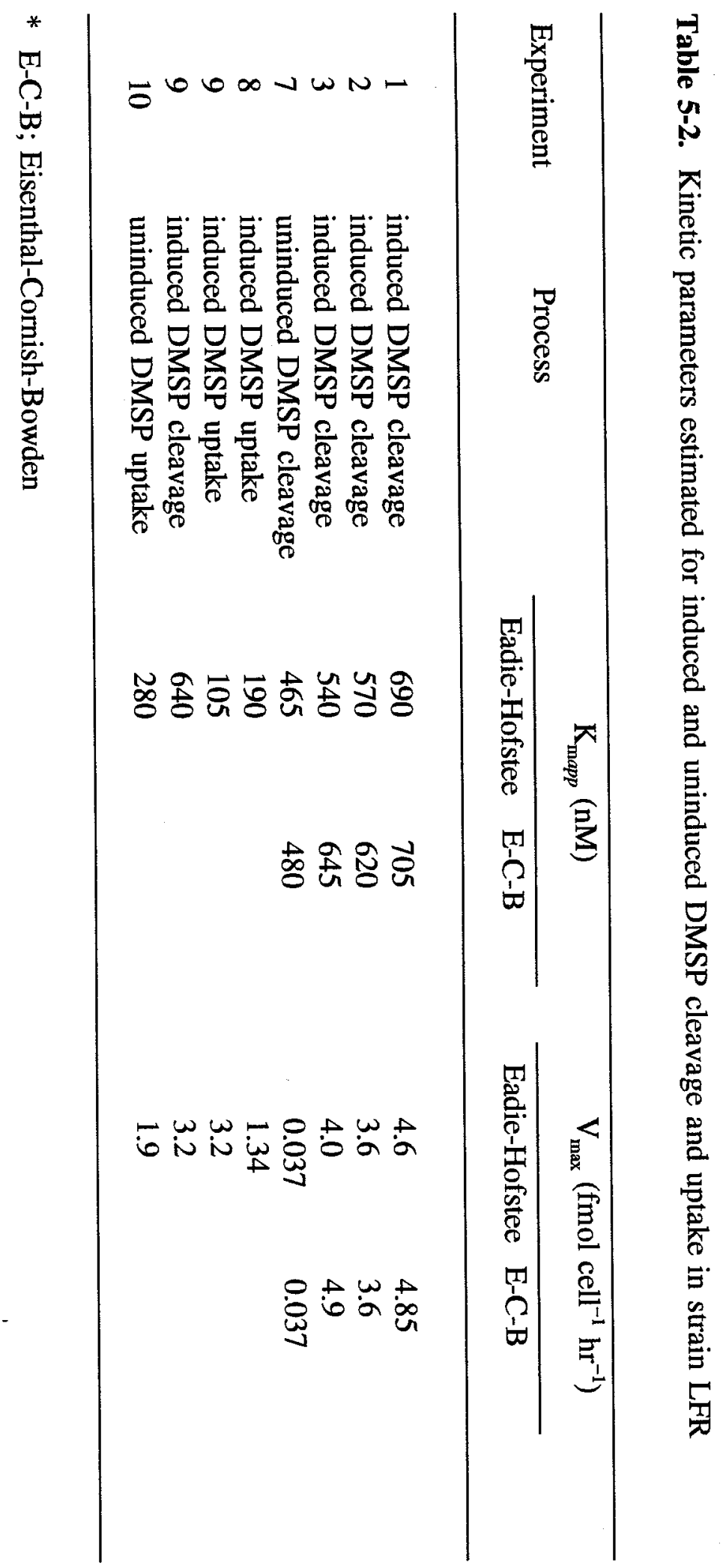




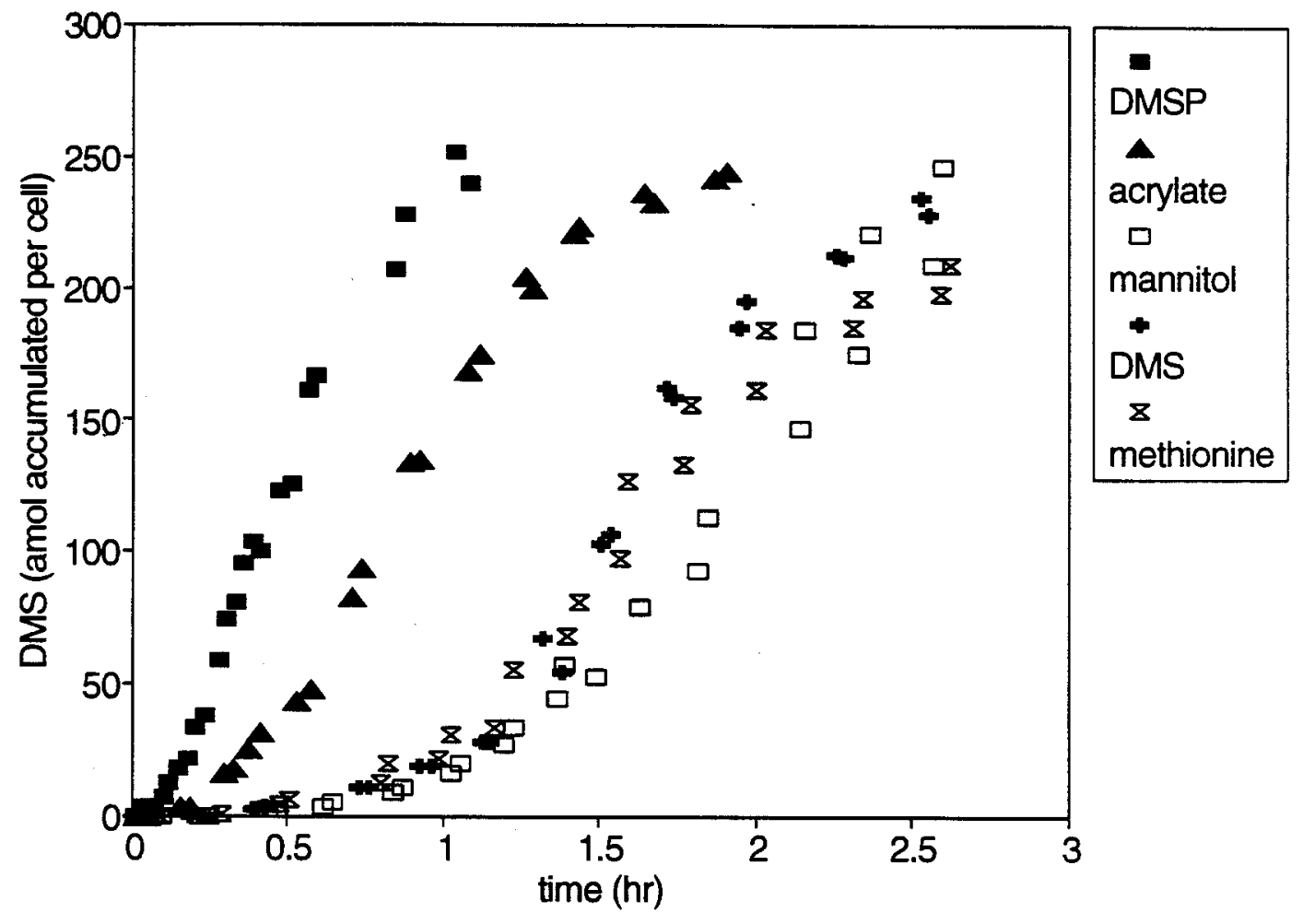

Figure 5-4. Timecourse of DMS production from $1 \mu \mathrm{M}$ DMSP following preincubation of cells with $20 \mu \mathrm{M}$ DMSP, acrylic acid, mannitol, DMS or methionine. Preincubation with DMSP or acrylic acid enhances the initial rate of DMS production, while DMS and methionine do not. Duplicate treatments shown. 
(a)

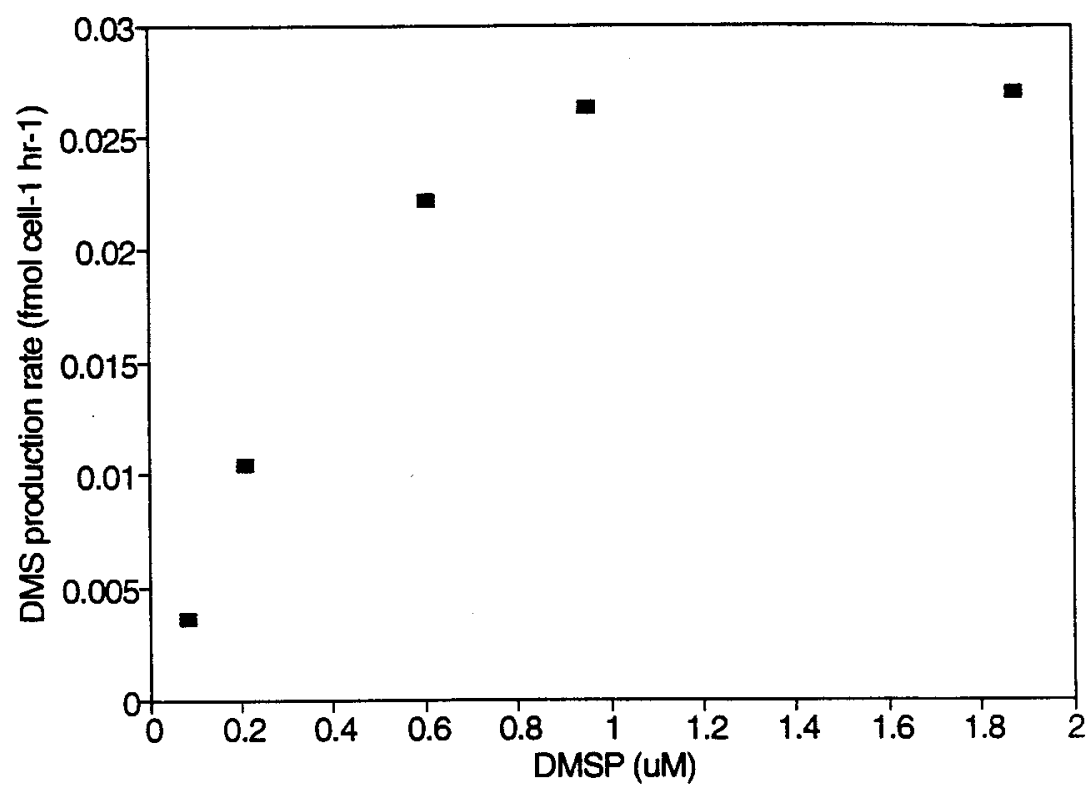

(b)

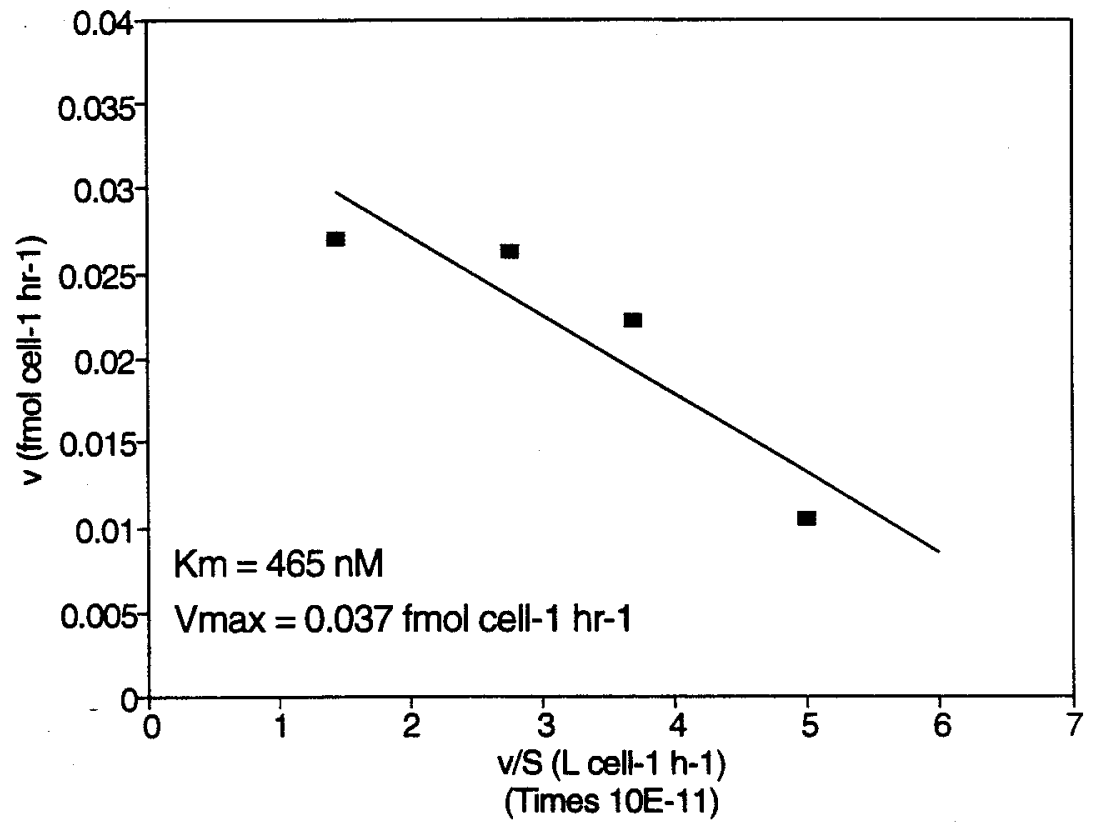

Figure 5-5. (a) Saturation curve for DMS production from DMSP by uninduced cells (experiment 7). (b) Eadie-Hofstee regression of rates for DMSP $>300 \mathrm{nM}$. 


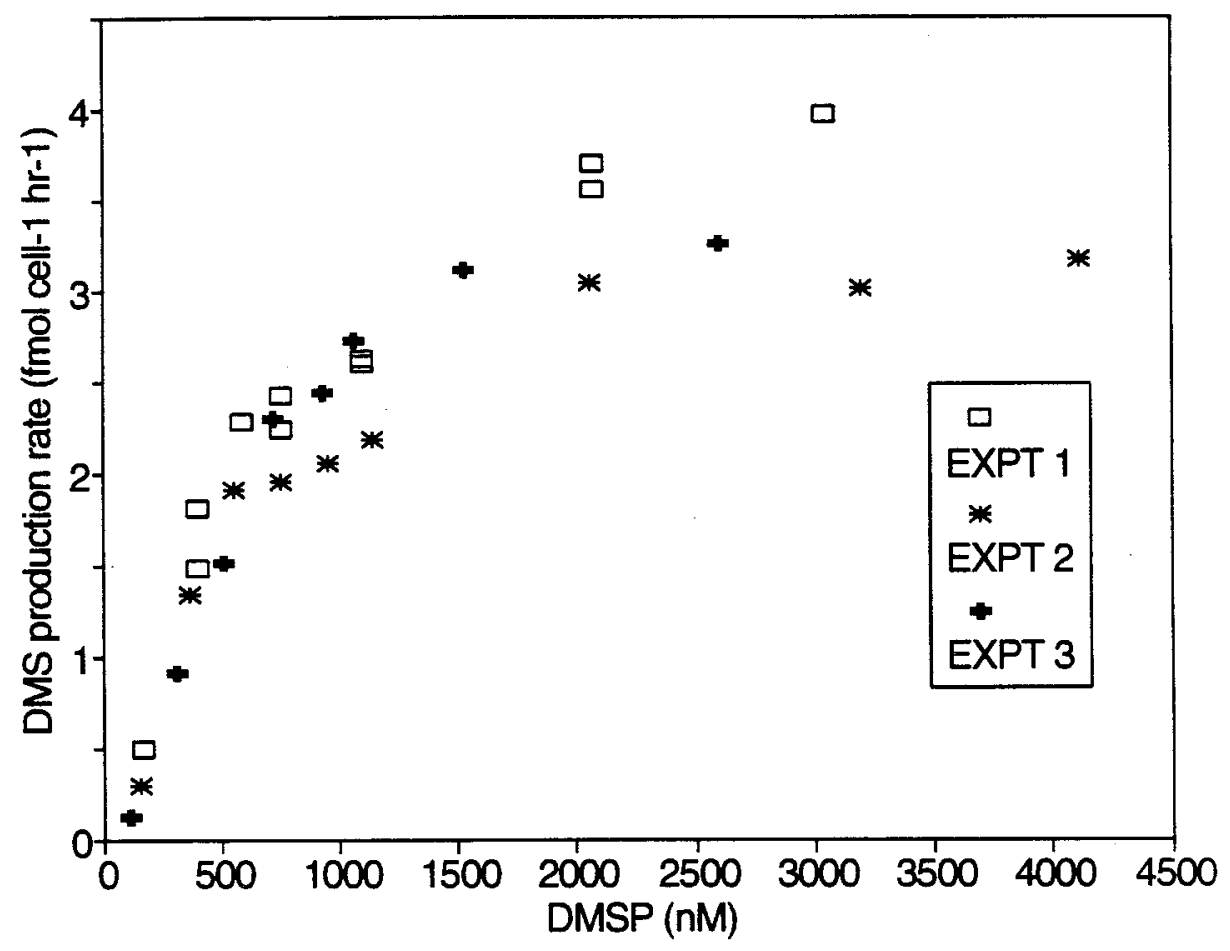

Figure 5-6. Saturation curve of DMSP-lyase activity data from high-level induced kinetics experiments (experiments 1,2 and 3). 
$4 \mu \mathrm{M}$ could be modelled by Michaelis-Menten kinetics, with the exception of experiment 3, where only rates estimated for DMSP concentrations above $500 \mathrm{nM}$ were used in the regression. These analyses yield apparent half-saturation values ranging between 540 and $690 \mathrm{nM}$ (mean \pm 1 sd: $610 \pm 68$ ), and $\mathrm{V}_{\max }$ values of 3.2$4.6 \mathrm{fmol} \mathrm{cell}^{-1} \mathrm{hr}^{-1}(3.85 \pm 0.60)$ (Figure 5-7) as determined by Eadie-Hofstee plots. The graphical analysis of Eisenthal-Cornish-Bowden yielded values in the same range). However, because rates of DMS production measured in response to DMSP additions below $350 \mathrm{nM}$ deviated noticeably from the linearizations based on the higher-level rates, the accuracy of these kinetic parameters is questionable. This departure from the Michaelis-Menten model can be seen in the concentration dependence of DMS production from DMSP by induced cells at DMSP levels between 0 and $250 \mathrm{nM}$ (Figure 5-8), which shows a marked concave-upward shape. Because of this, the initial slope of the rate versus concentration curve for induced cells above $350 \mathrm{nM}$ does not extrapolate to zero but rather has a significantly negative y-axis intercept.

The timecourse of DMSP uptake by uninduced cells clearly indicates that DMSP uptake precedes DMS production in strain LFR. In Figure 5-9, an assay with a low cell density $\left(10^{5}\right.$ cells $\left.\mathrm{mL}^{-1}\right)$ shows that $65 \mathrm{nM}$ DMSP is almost completely taken up into cells before any significant DMS production is observed. In induced timecourses a short lag is also observed; however, the rate of production following this lag is significantly elevated compared to that of uninduced cells. The fact that DMSP uptake precedes DMS production suggests that cells grown on DMSP, used for induced kinetics experiments, will still contain some internal level of DMSP after washing that could potentially interfere with rate estimation. Cell controls were carried out during 

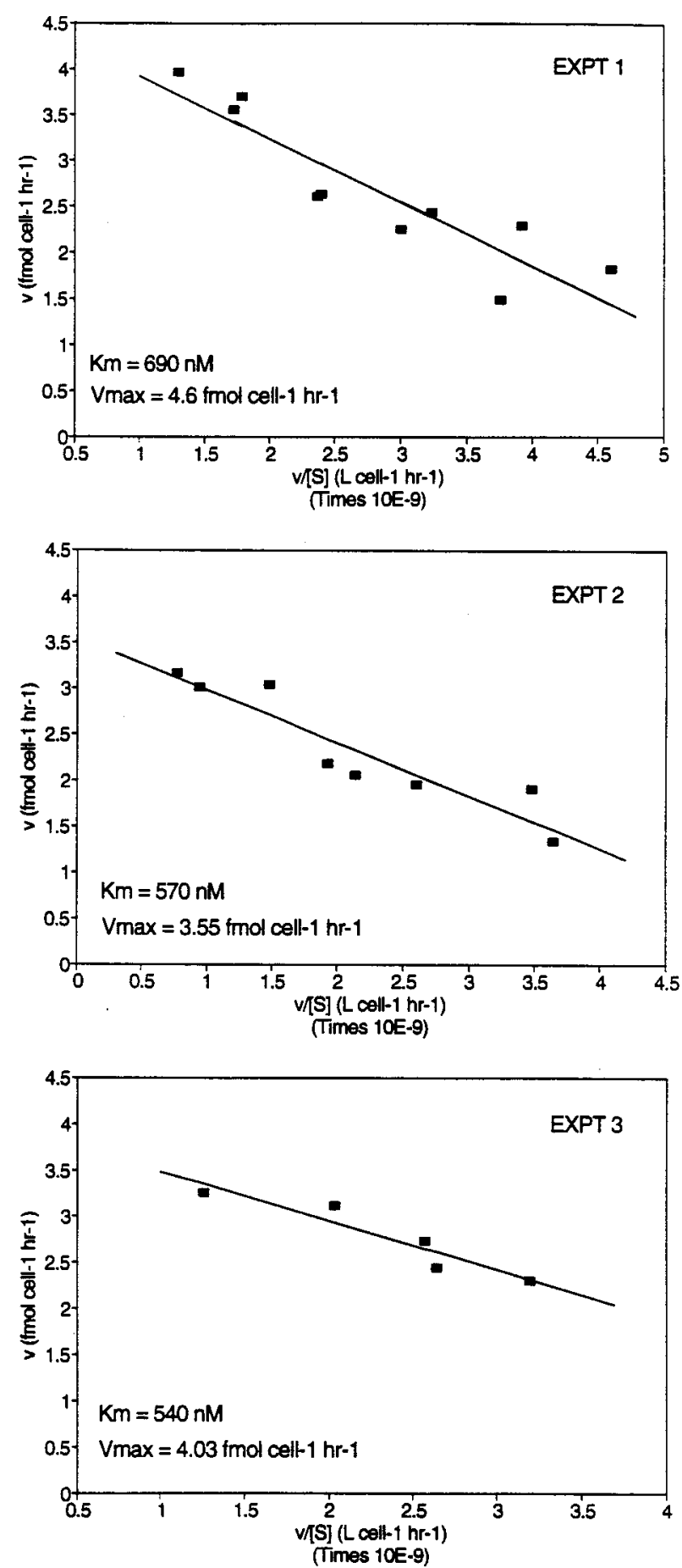

Figure 5-7. Eadie-Hofstee regressions and kinetic parameters calculated for experiments 1 and 2 (DMSP $>350 \mathrm{nM}$ ) and experiment 3 (DMSP $>500 \mathrm{nM}$ ). 


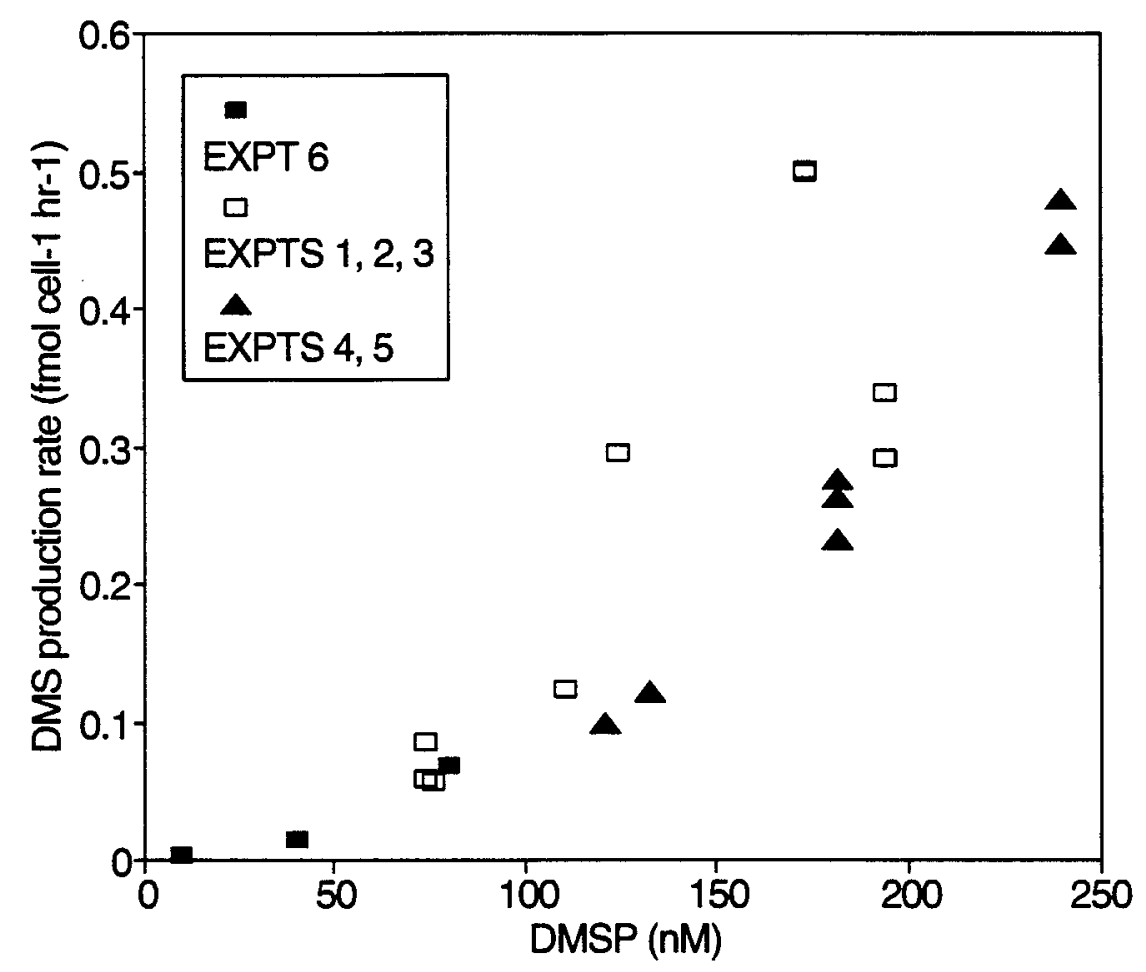

Figure 5-8. DMS production rate data for induced cells in the $0-250 \mathrm{nM}$ concentration range, showing consistency of results from experiments 4, 5 and 6 with rates obtained in separate higher-level kinetics experiments 1, 2 and 3. 


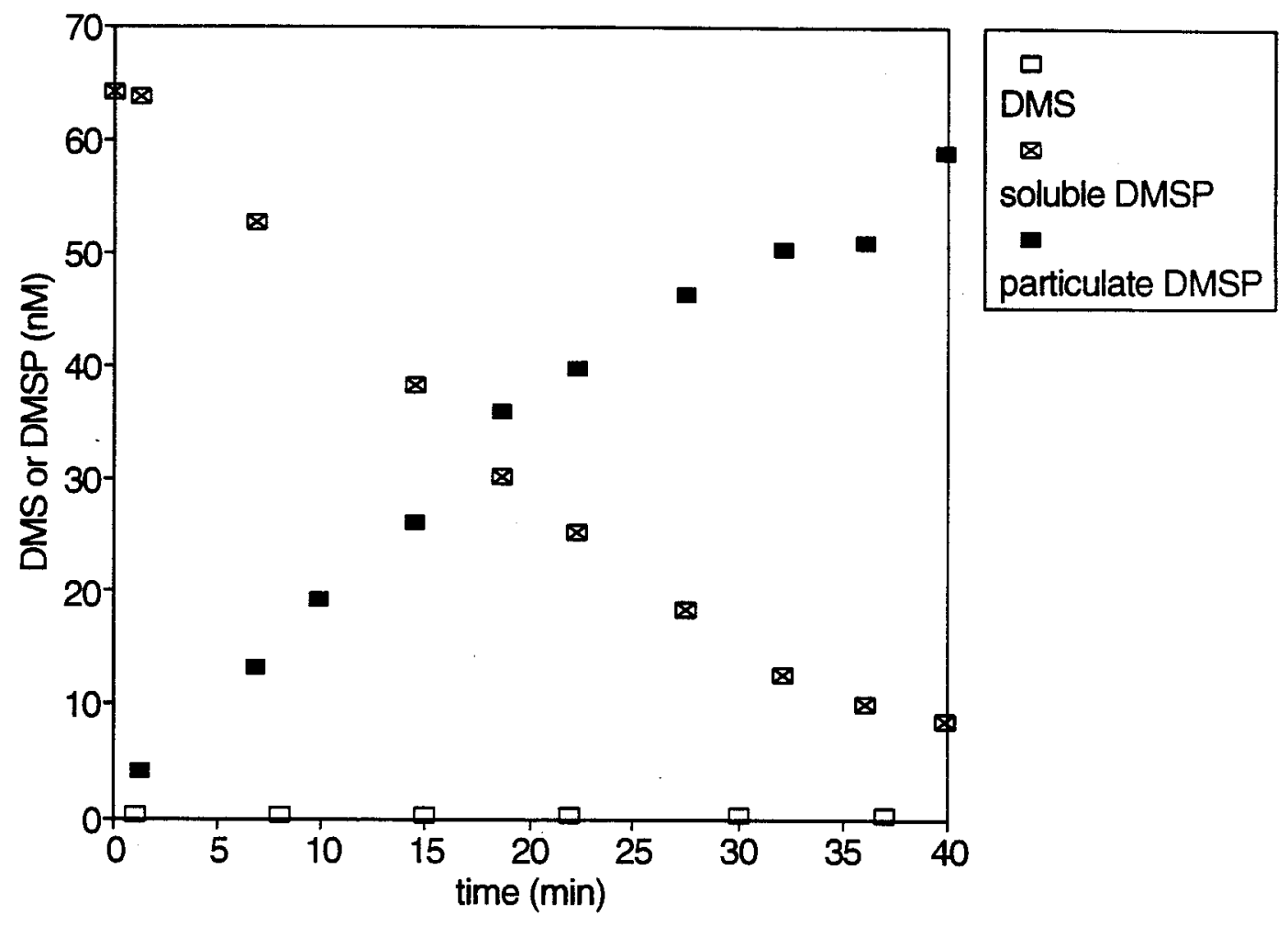

Figure 5-9. DMSP uptake and accumulation, and DMS production, in uninduced cells of strain LFR in response to a $65 \mathrm{nM}$ DMSP addition. Uptake of DMSP from the dissolved phase is mirrored by its accumulation in cells; by the time most of the added DMSP has been taken up, DMS production has not begun. The rate of uptake is equal to the rate of accumulation, $0.22 \mathrm{fmol} \mathrm{cell}^{-1} \mathrm{hr}^{-1}$. 
all DMS production kinetics experiments to quantify the level of DMS production from this source. In some experiments, DMSP blanks in the medium prevented accurate estimation of DMS production from purely internal reserves. However, estimates of this rate in experiments where this was not the case yielded DMS production "blank" estimates ranging on average between 2 and $10 \mathrm{amol} \mathrm{cell}^{-1} \mathrm{hr}^{-1}$. This would not be expected to cause significant overestimates at concentrations above $80 \mathrm{nM}$ (rates $>100$ amol cell hr$r^{-1}$ ). Furthermore, three of the six rates in the range below $80 \mathrm{nM}$ (see experiment 6 in Figure 5-8), including the two lowest rates, were not calculated using cells that had been grown on DMSP. Finally, the difficulties experienced in fitting the rate data below $350 \mathrm{nM}$ using a Michaelis-Menten model cannot derive from DMS production blanks; the initially concave-upward slope of the DMS production saturation curve (Figure 5-8) implies that the rates calculated for low DMSP concentrations are too low, rather than too high.

Kinetics of DMSP uptake. Kinetic parameters estimated for DMSP uptake by induced and uninduced cells (experiments 8, 9 and 10) are summarized in Table 5-2. Saturation curves and Eadie-Hofstee regressions of the induced uptake data are shown in Figures 5-10 and 5-11. Two separate estimates of the $K_{m}$ for DMSP uptake by induced cells yielded 190 and $105 \mathrm{nM}$, with maximum velocities of 1.3 and $3.2 \mathrm{fmol}$ cell $^{-1} \mathrm{hr}^{-1}$. The $\mathrm{K}_{\operatorname{mapp}}$ and $\mathrm{V}_{\max }$ estimated for uninduced cells were $280 \mathrm{nM}$ and 1.9 fmol cell ${ }^{-1} \mathrm{hr}^{-1}$, respectively (Figure 5-12). In experiment 9, where induced DMSP uptake and DMS production were monitored simultaneously, an identical $\mathrm{V}_{\max }$ but differing $\mathrm{K}_{\mathrm{mapp}}$ were obtained for the two processes. 
(a)

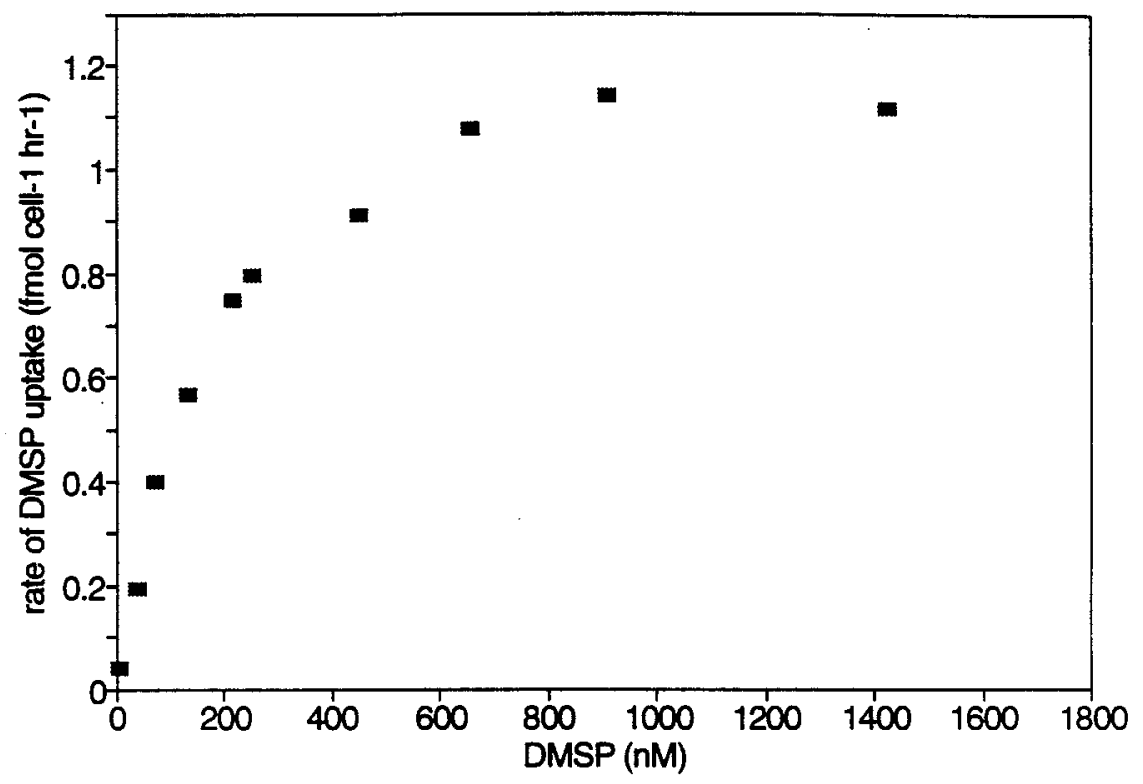

(b)

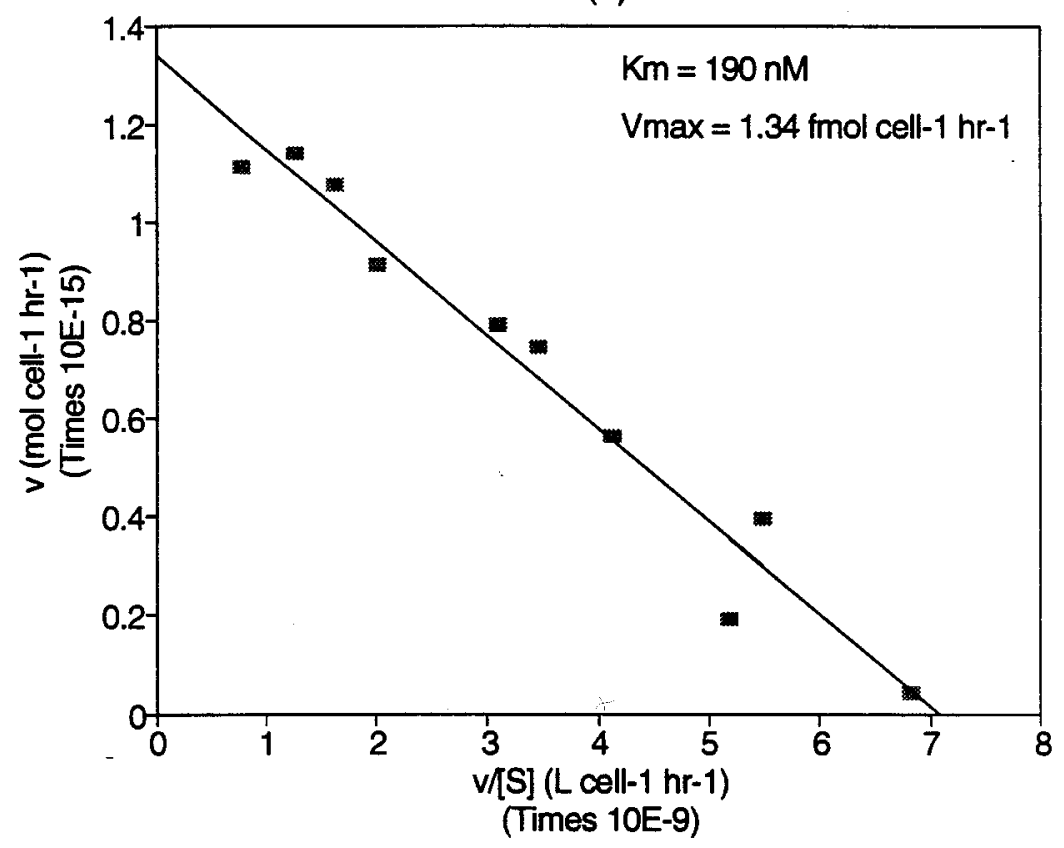

Figure 5-10. Kinetics of DMSP uptake by induced cells. (a) Saturation curve and (b) Eadie-Hofstee plot for experiment 8 . 
(a)

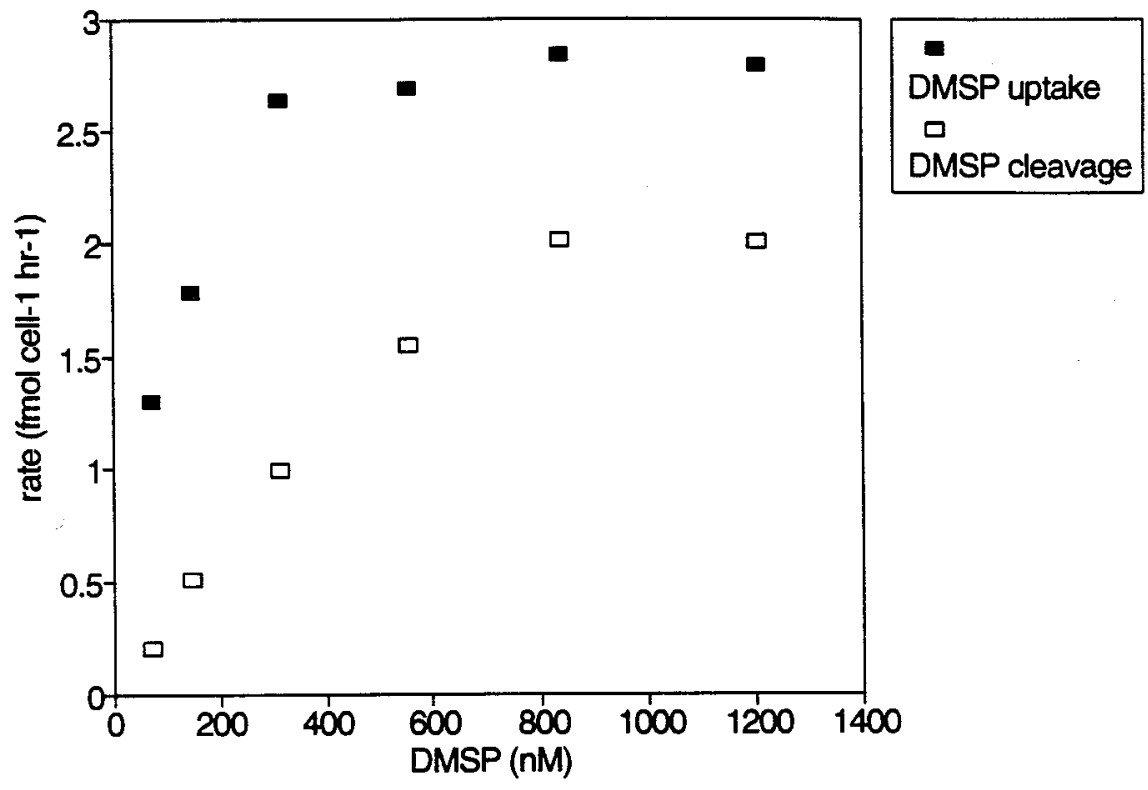

(b)
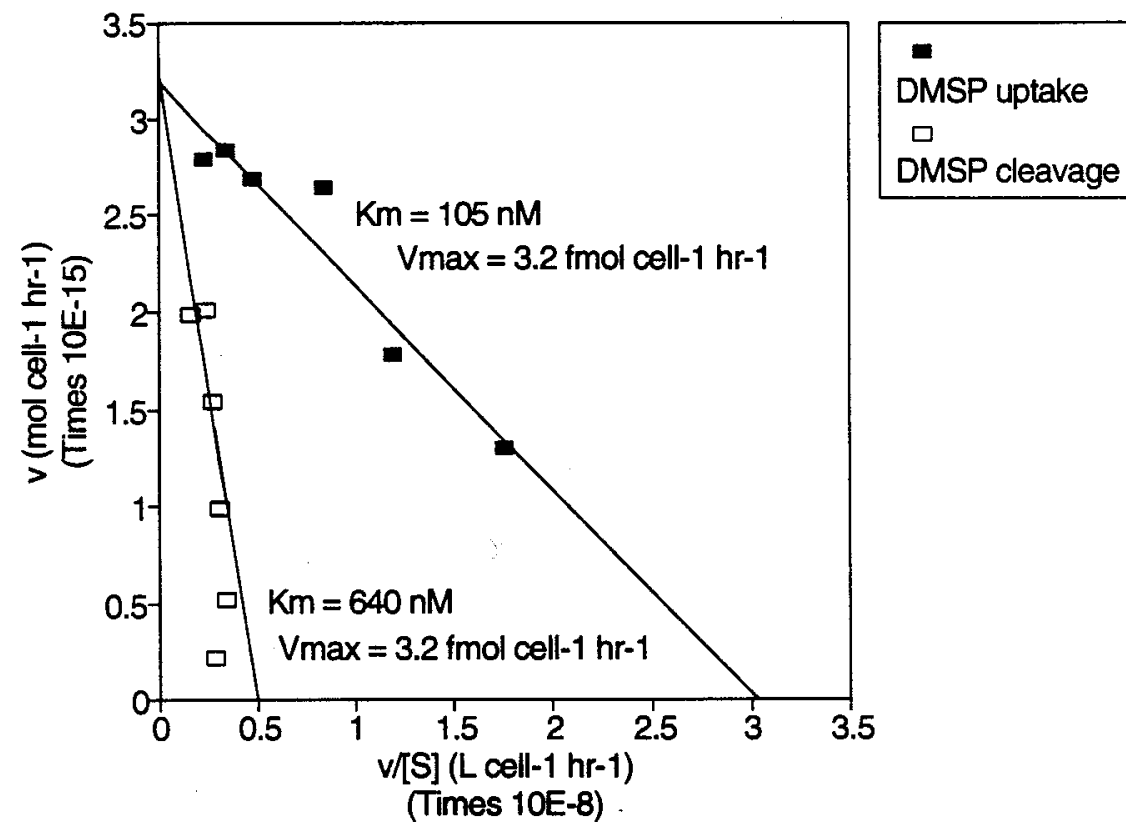

Figure 5-11. Kinetics of DMSP uptake and cleavage by induced cells.

(a) Saturation curves and (b) Eadie-Hofstee plots for simultaneously quantified kinetics of DMSP uptake and DMS production in experiment 9. The regression for DMSP cleavage is based on the rate data for DMSP concentrations above $300 \mathrm{nM}$. Note the similarity of (b) to the Eadie-Hofstee plot in Figure 3-4b. 
(a)

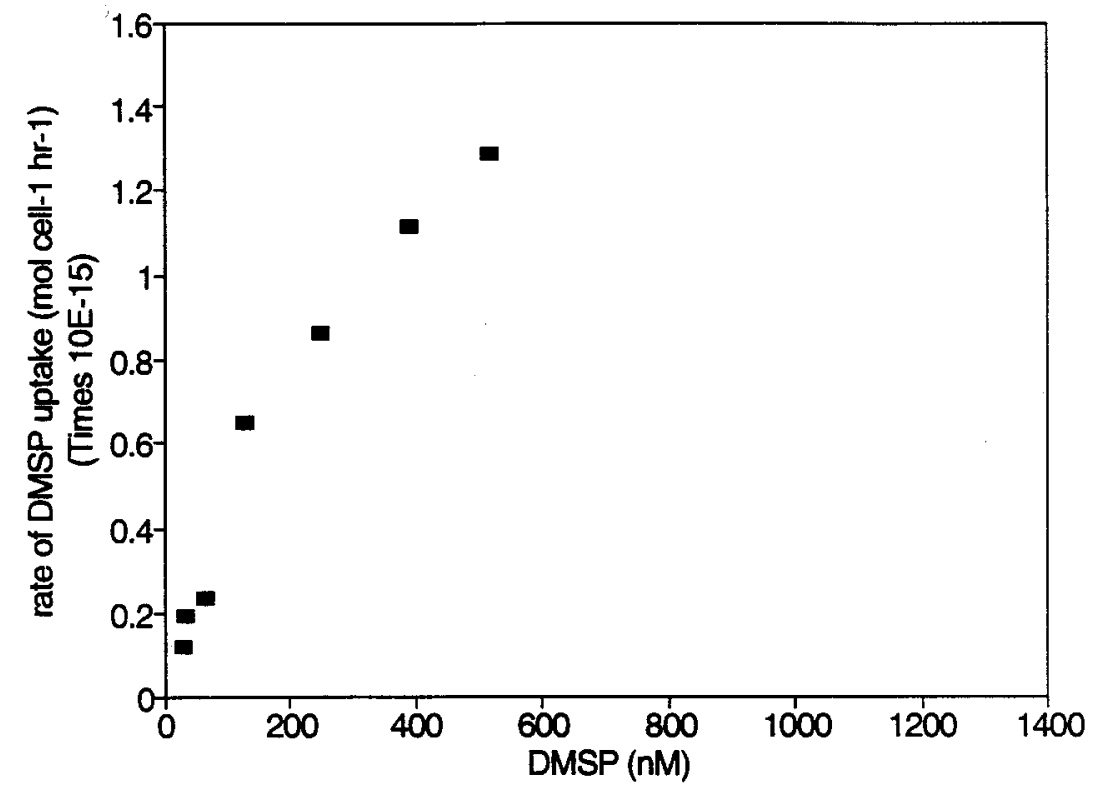

(b)

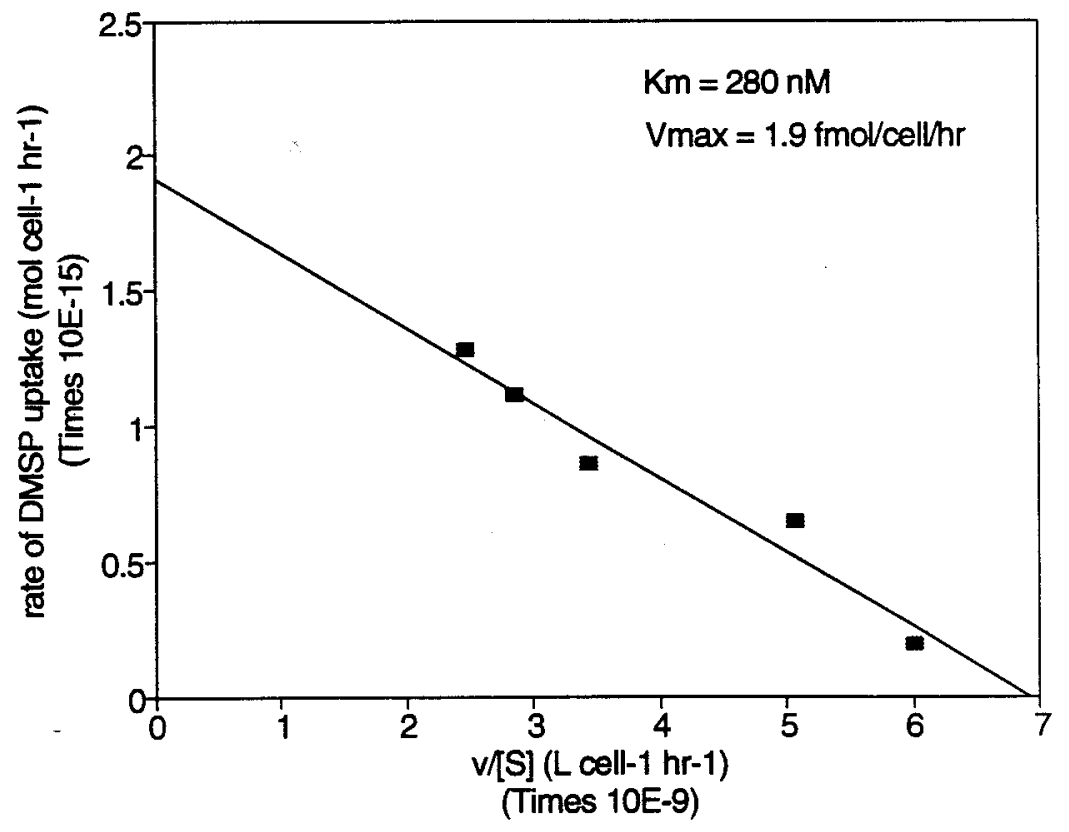

Figure 5-12. Kinetics of DMSP uptake by uninduced cells. (a) Saturation curve and (b) Eadie-Hofstee plot. 


\section{DISCUSSION}

Examination of the concentration dependence of microbial DMS production from DMSP in Chapters 3 and has yielded some insight into the kinetics of this process as mediated by microbial assemblages. Kinetics experiments with natural seawater show that the apparent affinity of microorganisms for DMSP, and the maximal rates of conversion of dissolved DMSP to DMS, can vary by more than an order of magnitude throughout the year. While more work remains to be done to verify the seasonal nature of the observed changes, the combined results from the Sargasso Sea and Vineyard Sound, MA indicate that microbial populations of these environments are dominated by a high-affinity, low- $\mathrm{V}_{\max }$ component in the winter, but that kinetic parameters reflect a lower-affinity, high- $\mathrm{V}_{\max }$ element in the spring and fall (data are not available for the summer). An intriguing aspect of the shift is that while "winter" $\mathrm{K}_{\mathrm{mapp}}$ 's for DMSP cleavage tended to be on the order of ambient soluble DMSP concentrations, spring and fall $\mathrm{K}_{\mathrm{m}}$ 's far exceeded them. Over a period of a month during the winter-spring transition in Vineyard Sound, the apparent half-saturation value for DMSP cleavage rose sharply, from $24 \mathrm{nM}$ to $575 \mathrm{nM}$. In the Sargasso Sea, the $\mathrm{K}_{\text {mapp }}$ for DMSP cleavage was approximately $20 \mathrm{nM}$ in January 1992, but in April of the same year little or no saturation of this activity was observed at DMSP concentrations up to a micromolar. Similar results were obtained in fall of 1990 .

Without knowledge of the mechanism of microbial cleavage of dissolved DMSP, these observations are difficult to interpret. As discussed in Chapter 3, it is possible that the observed changes in kinetic parameters of the microbial population with respect to DMSP cleavage reflect changes in ambient soluble DMSP that our 
measurement techniques cannot detect. However, it is also possible that the kinetics of DMSP decomposition to form DMS are determined by physiological (intracellular) rather than ambient (extracellular) DMSP concentrations. This interpretation is supported by the fact that in the previously-mentioned example of Vineyard Sound water, the $\mathrm{K}_{\mathrm{mapp}}$ for DMSP cleavage increases from 24 to $575 \mathrm{nM}$ while that for DMSP uptake only increases from 48 to $157 \mathrm{nM}$ - a 3-fold as opposed to 24 -fold change. If the change in environmental DMSP cleavage kinetics were solely a function of changes in ambient soluble DMSP, we would expect the shift in both processes to be similar.

The latter result implies that uptake of DMSP precedes cleavage, such that physiological rather than ambient concentrations would determine the kinetic parameters of DMS production. Dacey and Wakeham (unpublished data) have observed a transient build-up of acrylic acid (the other product of DMSP cleavage) in response to a high-level addition of DMSP to coastal salt pond water. They note that acrylate does not accumulate to detectable levels until DMS production reaches its maximal rate. Their observations are consistent with a model in which DMSP cleavage occurs at the cell surface and is closely coupled to acrylate uptake, except when the rate of cleavage exceeds that of uptake, at which time acrylate begins to accumulate in solution. Since one product of the cleavage reaction, DMS, does not appear to be utilized by these organisms, and a surface-associated enzyme would obviate the need to transport DMSP across the cell membrane, this scenario makes a certain amount of energetic sense. LFR has been shown to be capable of acrylate uptake (Chapter 6). However, the observations of Dacey and Wakeham could also be 
interpreted to signify DMSP uptake and internal cleavage, followed by a leakage of acrylic acid back out of the cell when it cannot be processed with sufficient rapidity. Uptake of DMSP might not be more energetically expensive than acrylate uptake, and the location of DMS release may not be important if it can diffuse passively from the cell.

In support of the latter model, the Sargasso Sea bacterial isolate examined here demonstrates unambiguous uptake of DMSP. Other lines of evidence are consistent with an intracellular location for the DMSP-lyase in this organism. If the enzyme has a sulfhydryl at the active site, as does the algal DMSP-lyase, the negative results obtained here with cell-impermeant modifiers of sulfhydryl groups indicate that it is not accessible to these inhibitors. Furthermore, unpublished data of J. Dacey demonstrate that anaerobiosis and treatment with dinitrophenol, an uncoupler of mitochondrial respiration, suppress DMS production from DMSP, consistent with a requirement for active uptake of DMSP.

Several observations can be made regarding the kinetics of DMSP uptake and cleavage in strain LFR. The $\mathrm{K}_{\mathrm{m}}$ for DMSP uptake was between 100 and $200 \mathrm{nM}$ for induced cells, and the $K_{m}$ of $280 \mathrm{nM}$ calculated for uninduced cells was not dramatically different. $V_{\max }$ values for both induced and uninduced cells were on the order of a few fmol cell-1 $\mathrm{hr}^{-1}$. The similarity between induced and uninduced cells with respect to kinetic parameters of DMSP uptake implies that it is the cleavage rather than the uptake system that is inducible. The difficulties experienced with modelling DMSP cleavage might be attributable to interference from DMSP uptake kinetics. The assignment of an apparent $\mathrm{K}_{\mathrm{m}}$ of about $600 \mathrm{nM}$ to DMSP cleavage 
activity, based on rates measured at DMSP concentrations exceeding $350 \mathrm{nM}$, is highly tentative due to the potentially complicated interaction between these two processes. Simultaneous timecourses of DMSP uptake and DMS production in highlevel induced assays show that induced cells start forming DMS before they have completely taken up the DMSP in their medium; therefore the intracellular DMSP concentration will change with time due not only to removal by cleavage, but to continuing accumulation. DMSP uptake kinetics determine the maximum amount of DMSP the cell can accumulate before DMSP cleavage causes a net decline in intracellular concentration, and therefore must determine the maximum rate of DMS production. Consistent with this hypothesis, $\mathrm{V}_{\max }$ values calculated for DMSP uptake and cleavage are similar, especially when the two are assessed simultaneously, as in experiment 9. To circumvent this interference, the kinetics of bacterial DMSP-lyase activity must ultimately be studied in a cell-free system.

It is interesting to compare the DMSP uptake affinity estimated for LFR with $\mathrm{K}_{\mathrm{m} a p p}$ values derived from experiments with bulk seawater. As previously noted, although soluble DMSP concentrations in the hundreds of nanomolar have been documented in seawater $(14,25)$, concentrations in this range are not typical of either the Sargasso Sea or Vineyard Sound. The existence of "microzones" containing high concentrations of algal intracellular compounds in the immediate vicinity of phytoplankton cells has been postulated $(3,23)$, although theoretical calculations support their occurrence only under extremely favorable conditions (22). The zwitterionic nature of DMSP has invited speculation that it functions in algae as an osmoregulant or osmoprotectant $(9-11,26)$, by definition designed to be retained by the 
cell at very high physiological concentrations. While documented intracellular concentrations in algae can reach several hundred millimolar (18), soluble DMSP is usually present in seawater at nanomolar levels. The impermeability of the cell membrane to DMSP is likely to maintain a steep gradient between the cell interior and surrounding seawater. When this barrier is breached, extremely high local concentrations of free DMSP may result. As the algal DMSP source becomes stronger, instances of this will increase in frequency. At the same time, especially if microbial affinity for DMSP is high and can rapidly dissipate these spikes, measurements of soluble DMSP in bulk seawater will tend to underrepresent the maximum concentrations attained on volume scales relevant to bacterial and algal cells. The relatively high apparent half-saturation values for dissolved DMSP removal estimated for LFR (105-280 nM) and seawater populations in Woods Hole coastal water might reflect a situation of this sort. The apparent inducibility of the bacterial DMSP lyase in this study is also consistent with the scenario described above; under low-concentration conditions, little energy is expended on synthesis of DMSP lyase, but when high DMSP concentrations are encountered, enzyme induction may confer rapid enhancement of processing capabilities. The maximal velocity of DMS production in uninduced and induced cells of the bacterium examined here differs by two orders of magnitude.

Cantoni and Anderson (6) demonstrated that the products of DMSP cleavage catalyzed by partially isolated lyase from Polysiphonia lanosa are DMS and acrylic acid. Identification of the non-DMS product(s) of DMSP cleavage in bacteria will also require in vitro study, since, at least in the isolate examined here, this product 
was taken up by cells to provide carbon for growth (Chapter 6). In the absence of such a study we do not have direct evidence that the other product of the reaction is acrylate. However, several observations strongly favor this possibility. Not only did LFR take up and grow on acrylate as the sole source of carbon and energy, but acrylate appeared to stimulate production of DMSP lyase (Figure 5-4). Moreover, bacteria able to cleave DMSP to form DMS can be isolated from acrylate-enriched coastal seawater (19).

The data presented here extend field observations of microbial DMS production to an examination of the rates and mechanism of this process in a pure culture of a marine bacterium. Strain LFR clearly takes up DMSP prior to breaking it down to DMS, and uptake kinetics may in fact obscure accurate assessment of the kinetics of DMS production. The $\mathrm{K}_{\text {mapp }}$ for DMSP uptake in strain LFR is similar to that determined for a seawater microbial assemblage in Vineyard Sound seawater on 5/26/92 (Chapter 3). In fact, the results of experiment 9 (Figure 5-11), in which DMSP uptake and DMS production were determined simultaneously, show that the relative kinetics of both processes are similar to those determined in seawater on 5/26. The difference observed between DMSP uptake and cleavage kinetics in the field has been partially attributed (Chapter $3 ; 20$ ) to the supposition that only a fraction of the microbial population taking up DMSP converts it to DMS. The results of this study raise the intriguing possibility that it may not always be necessary to invoke population composition to explain this difference, and should be taken into account in future investigations of in situ microbial DMS production from dissolved DMSP.

This bacterium is only one component of a Sargasso Sea microbial assemblage, 
and we do not know the extent to which these observations can be extended to other DMS-producing marine bacteria. As is often the case, we confront a sizable gap between measurements on a bulk population, which tell us the results of a process but not its mechanism, and culture studies, which reveal details of the process in one organism, but not how well it represents environmental assemblages. However, pure culture studies such as this provide us with models whose validity can at least be checked for consistency with environmental results, and which can even, on occasion, shed light on puzzling aspects of field data. 


\section{REFERENCES}

1. Andreae, M. O. 1980 . The production of methylated sulfur compounds by marine phytoplankton, pp. 253-259. In P. A. Trudinger, M. R. Walter, and B. J. Ralph (eds.), Biogeochemistry of ancient and modern environments. Springer-Verlag, New York.

2. Andreae, M. O. 1990. Ocean-atmosphere interactions in the global biogeochemical sulfur cycle. Mar. Chem. 30:1-29.

3. Bell, W., and R. Mitchell. 1972. Chemotactic and growth responses of marine bacteria to algal extracellular products. Biol. Bull. 143:265-277.

4. Belviso, S., S.-K. Kim, R. Rassoulzadegan, B. Krajika, B. C. Nguyen, N. Mihalopoulos, and P. Buat-Menard. 1990. Production of dimethylsulfonium propionate (DMSP) and dimethylsulfide (DMS) by a microbial food web. Limnol. Oceanogr. 35:1810-1821.

5. Bollagt, D. M., and S. J. Edelstein. 1991. Protein methods. Wiley-Liss, New York.

6. Cantoni, G. L., and D. G. Anderson. 1956. Enzymatic cleavage of dimethylpropiothetin by Polysiphonia lanosa. J. Biol. Chem. 222:171-177.

7. Challenger, F., and M. I. Simpson. 1948. Studies on biological methylation. J. Chem. Soc. 1948:1591-1597.

8. Dacey, J. W. H., and S. G. Wakeham. 1986. Oceanic dimethylsulfide: production during zooplankton grazing on phytoplankton. Science 233:1314-1316.

9. Dickson, D. M. J., and G. O. Kirst. 1986. The role of $\beta$-dimethylsulfoniopropionate, glycine betaine and homarine in the osmoacclimation of Platymonas subcordiformis. Planta 167:536-543.

10. Dickson, D. M. J., and G. O. Kirst. 1987. Osmotic adjustment in marine eukaryotic algae: the role of inorganic ions, quaternary ammonium, tertiary sulphonium and carbohydrate solutes I. Diatoms and a rhodophyte. New Phytol. 106:645-655.

11. Dickson, D. M. J., and G. O. Kirst. 1987. Osmotic adjustment in marine eukaryotic algae: the role of inorganic ions, quaternary ammonium, tertiary sulphonium and carbohydrate solutes II. Prasinophytes and haptophytes. New Phytol. 106:657-666. 
12. Eisenthal, R., and A. Cornish-Bowden. 1974. The direct linear plot: a new graphical procedure for estimating enzyme kinetic parameters. Biochem. J. 139:715-720.

13. Fersht, A. 1985. Enzyme structure and mechanism, pp. 106-107. W. H. Freeman and Company, New York.

14. Gibson, J. A. E., R. C. Garrick, H. R. Burton, and A. R. McTaggart. 1990. Dimethylsulfide and the alga Phaeocystis pouchetii in Antarctic coastal waters. Mar. Biol. 104:339-346.

15. Hahn, F. E. (ed.). 1983. Antibiotics, Vol. 6: Modes and mechanisms of microbial growth inhibitors. Springer-Verlag, Berlin.

16. Hobbie, J. E., R. J. Daley, and S. Jasper. 1977. Use of Nuclepore filters for counting bacteria by fluorescence microscopy. Appl. Environ. Microbiol. 33:1225-1228.

17. Kadota, H., and Y. Ishida. 1968. Effect of salts on enzymatical production of dimethyl sulfide from Gyrodinium cohnii. Bull. Jap. Soc. Sci. Fish. 34:512-518.

18. Keller, M. D., W. K. Bellows, and R. L. Guillard. 1989. Dimethyl sulfide production in marine phytoplankton, pp. 167-182. In: E. S. Saltzman and W. J. Cooper (eds.), Biogenic sulfur in the environment. ACS Symposium Ser. 393, American Chemical Society, Washington, D.C.

19. Kiene, R. P. 1990. Dimethyl sulfide production from dimethylsulfoniopropionate in coastal seawater samples and bacterial cultures. Appl. Environ. Microbiol. 56:3292-3297.

20. Kiene, R. P., and S. K. Service. 1991. Decomposition of dissolved DMSP and DMS in estuarine waters: dependence on temperature and substrate concentration. Mar. Ecol. Prog. Ser. 76:1-11.

21. Leck, C., U. Larsson, L. E. Bagander, S. Johannson, and S. Hajdu. 1990. DMS in the Baltic Sea: Annual variability in relation to biological activity. J. Geophys. Res. 95:3353-3363.

22. Mitchell, J. G., A. Okubo, and J. A. Fuhrman. 1985. Microzones surrounding phytoplankton form the basis for a stratified marine microbial ecosystem. Nature 316:58-59. 
23. Sjoblad, R. D., and R. Mitchell. 1979. Chemotactic responses of Vibrio alginolyticus to algal extracellular products. Can. J. Microbiol. 25:964-967.

24. Tinsberg, H. M., and L. Packer. 1976. Chemical modification of membranes, pp. 171-198. In: The enzymes of biological membranes, Vol. 1: Physical and chemical techniques. Plenum Press, New York.

25. Turner, S. M., G. Malin, P. S. Liss, D. S. Harbour, and P. M. Holligan. 1988. The seasonal variation of dimethylsulfide and dimethylsulfoniopropionate concentrations in nearshore waters. Limnol. Oceanogr. 33:364-375.

26. Vairavamurthy, A., M. O. Andreae, and R. L. Iverson. 1985. Biosynthesis of dimethylsulfide and dimethylpropiothetin by Hymenomonas carterae in relation to sulfur source and salinity variations. Limnol. Oceanogr. 30:59-70. 


\section{CHAPTER 6}

\section{PHYSIOLOGICAL AND PHYLOGENETIC CHARACTERIZATION OF A MARINE DMSP-DEGRADING BACTERIAL ISOLATE}

Dimethylsulfide (DMS) in marine surface waters is ultimately of algal origin, as the presumed major precursor of DMS in the ocean is the algal product dimethylsulfoniopropionate (DMSP). DMSP is broken down intracellularly in at least some of the phytoplankton that synthesize it $(1,6,16,17)$ by an enzymatic cleavage reaction whose products are acrylic acid and DMS. The function of this reaction in algal metabolism is not understood, and we do not know the extent of its contribution to oceanic dimethylsulfide levels. However, it is now apparent that cleavage of DMSP to form DMS (DMSP-lyase activity) in the marine environment is not restricted to algae. Dissolved DMSP, presumably released from algal cells into seawater by lytic processes, acts as a substrate for aerobic bacteria and possibly other organisms in marine microbial consortia $(8,18,39$, this thesis). Although DMSP is generally assumed to be restricted to marine environments because it has not been isolated from freshwater algae, DMSP cleavage to form DMS may also be mediated by non-marine bacteria. In fact, the earliest reference to bacterial DMSP cleavage documents this process in a clostridium isolated from river mud (42).

Although the culture studies cited above implicate bacteria in marine DMS production, we know do not know the identity of these bacteria, or how widely distributed DMSP-lyase activity is likely to be. Dacey and Blough (8) originally reported the isolation from seawater of a bacterium able to cleave DMSP to form 
DMS and grow on DMSP as the sole source of carbon and energy. This study reports the physiological and phylogenetic characterization of this bacterium, strain LFR.

\section{MATERIALS AND METHODS}

Isolation. LFR was isolated from Sargasso Sea surface $(1 \mathrm{~m})$ water collected in an acid-washed plastic carboy. Collection methods were not axenic, as water was not intended for isolation purposes. This seawater was $0.2 \mu \mathrm{m}$-filtered in an unrelated experiment, amended with a sterile stock of DMSP to a final concentration of $0.5 \mathrm{mM}$ and incubated at room temperature $\left(20-25^{\circ} \mathrm{C}\right)$ for a two-week period. A population of rod-shaped bacteria, which rapidly produced DMS, developed in the incubation. This enrichment was inoculated (1:50) into f/2 medium (11) lacking silicate and supplemented with $0.4 \mathrm{mM}$ ammonium chloride and $0.5 \mathrm{mM}$ DMSP. $\mathrm{f} / 2$ is a fullstrength seawater mineral medium containing an EDTA-chelated trace metal mix and a vitamin mix, originally designed for algal culture. After 2-3 days transfers were streaked on solid medium of the same type containing 1.5\% Bacto-agar (Difco). Individual colonies, which were predominantly salmon-colored, soft and round, were suspended in sterile seawater in serum bottles fitted with Teflon-faced butyl rubber septa (Regis Chemical Corp.) and aluminum crimpseals. Assays of DMS production from DMSP were carried out as described below using uninoculated DMSP solutions and unamended suspensions as controls. Suspensions displaying activity were repeatedly restreaked as above until only one colony type was observed.

Stock culture maintenance. Cultures were maintained at room temperature $\left(20-25^{\circ} \mathrm{C}\right)$ at subdued light levels. Liquid cultures were grown in the medium 
described above with DMSP as the sole added carbon source, sterilized by autoclaving before addition of sterile-filtered DMSP. Liquid cultures were maintained in semicontinuous fashion, by addition of $400 \mu \mathrm{M}$ DMSP to a $100-\mathrm{mL}$ flask culture every 7 10 days up to four times, until nutrient depletion occurred and cultures attained an appreciable turbidity. Cultures were transferred by inoculating $1 \mathrm{~mL}$ into $100 \mathrm{~mL}$ of media. Solid cultures were maintained on either the above medium (Bacto-agar or granular agar, $1.5 \%$ ) or on marine medium 2216 (Difco) agar. Stock cultures were also stored frozen at $-80^{\circ} \mathrm{C}$ and in liquid nitrogen.

Morphological, biochemical and physiological tests. Morphology and cell size were observed by phase contrast microscopy using an Olympus BHTU microscope, and by transmission electron microscopy. Cells prepared for EM were harvested in mid-logarithmic phase by centrifugation, fixed in $0.5 \%$ neutralized glutaraldehyde and $1 \%$ osmium tetroxide, stained with $0.5 \%$ uranyl acetate and embedded in Spurr's epoxy prior to sectioning with a diamond knife. Electron micrographs were taken using a Philips EM-300 with an accelerating voltage of $60 \mathrm{kV}$.

Motility of exponential and early stationary-phase cells grown in both liquid medium on DMSP and on marine agar 2216 was examined by the hanging drop method. Gram staining was carried out using a BBL Microbiology Systems kit. Flagellar staining was by the method of Mayfield and Inniss (22). Polyhydroxybutyrate (PHB) accumulation was examined in late exponential-phase cells grown in liquid medium with glucose $(0.1 \%)$ as the sole carbon source by the method of Burdon (5). Catalase production was assayed using 3\% hydrogen peroxide.

Fermentation of D-glucose and denitrification were tested according to Baumann 
and Baumann (3). Vibrio fischerii and Pseudomonas nautica were used as positive controls for D-glucose fermentation and denitrification, respectively. Ability to respire using nitrate was additionally checked by monitoring growth in anaerobic medium (nitrogen headspace) otherwise identical to usual growth conditions (approximately 0.9 $\mathrm{mM}$ nitrate) relative to aerobic controls. Cells were enumerated by direct counts using acridine orange epifluorescence microscopy (14). Anaerobic medium was prepared and aliquots were removed for cell counts by Hungate technique.

$\mathrm{Na}^{+}$requirement and growth on defined media were tested by a modification of the method of Baumann and Baumann (3). DMSP was used as the carbon source and growth quantified by direct microscopic counts rather than optical density.

Ability to grow with a number of carbon sources (Table 6-1) as the sole source of carbon and energy was tested. Cells were grown to exponential phase on DMSP from a single colony and inoculated 1:100 into the minimal medium described above (lacking DMSP) supplemented with $0.1 \%$ of the appropriate carbon source. DMSP, acrylate and glycinebetaine were added to a level of $1 \mathrm{mM}$. Duplicate treatments were set up for each carbon source and one of each duplicate pair monitored for growth for 3-4 days by acridine orange direct counts (AODC), while the other was observed visually for turbidity and for agreement with the first. Negative controls consisted of inoculated flasks with no added carbon source and uninoculated flasks containing added carbon source. Inoculated flasks $1 \mathrm{mM}$ in DMSP served as a positive control. Growth on complex media (trypticase soy broth (Difco), SWC (24), and yeast extract) and in a defined medium (BM/ASW, 3) was also examined.

Ability to grow at $4,8,23,35$ and $40^{\circ} \mathrm{C}$ was tested both on 2216 agar (for three 
lowest temperatures only) and in liquid minimal media with DMSP as the carbon source (all temperatures).

Cells for fatty acid analysis were grown on marine medium 2216 agar for 48 hours. Fatty acids were extracted and analyzed by gas-liquid chromatography of their methyl ester derivatives according to MIDI Microbial Identification System methods (MIDI, Newark, DE).

For spectroscopic examination of pigment, cells were harvested in exponential phase by centrifugation $\left(7,700 \times g, 8\right.$ minutes, $\left.15^{\circ} \mathrm{C}\right)$ during growth on either DMSP, marine broth 2216 or mannitol on a rotary shaker $(100 \mathrm{rpm})$, or suspended from marine medium 2216 or SWC agar. Cells were grown either in the dark or received indirect illumination from overhead fluorescent lights. $50-60 \mathrm{mg}$ wet weight was resuspended in sterile seawater and filtered onto a $25 \mathrm{~mm}$ Whatman $\mathrm{GF} / \mathrm{F}$ filter. The filter was suspended in $5 \mathrm{~mL}$ methanol and allowed to extract in the dark for 30 minutes. The filter with attached cells and methanol were then homogenized with a tissue grinder and passed through a $25 \mathrm{~mm}$ Whatman GF/C filter. Absorbance of this extract was recorded on a dual-beam spectrophotometer (Shimadzu UV-visible recording spectrophotometer UV-260) in the $350-900 \mathrm{~nm}$ wavelength range.

DNA base composition. DNA was isolated and purified, and its base composition calculated, according to a modification of Herdman et al. (13). The temperature dependence of thermal denaturation was determined in a microprocessorcontrolled recording spectrophotometer with an attached temperature programmer (Gilford Instruments Laboratory, Inc., model 2600). Four melting curves were generated. The mean and standard deviation of three determinations (separate 
denaturations of a single extract) of the $\mathrm{mol} \% \mathrm{G}+\mathrm{C}$ of two $E$. coli $\mathrm{K}-12$ standards was $53 \pm 0.51 \%$.

Sequencing and comparative analysis of $16 S$ rDNA. Approximately twenty colonies were removed from a culture grown on marine agar 2216 and suspended in $0.45 \mathrm{~mL}$ of a lysis buffer consisting of $50 \mathrm{mM}$ TRIS, $\mathrm{pH} 8.3,40 \mathrm{mM}$ EDTA and 0.75 M sucrose. $10 \mu \mathrm{L}$ of a $50 \mathrm{mg} / \mathrm{mL}$ lysozyme stock was added and the suspension incubated at $37^{\circ} \mathrm{C}$ for 30 minutes. Following addition of $80 \mu \mathrm{g}$ proteinase $\mathrm{K}$ and sodium dodecyl sulfate (SDS) to a final concentration of $5 \%$, the mixture was incubated at $37^{\circ} \mathrm{C}$ for an additional 30 minutes. DNA was phenol-extracted and purified by $\mathrm{Cs}-\mathrm{Cl}$ equilibrium density gradient centrifugation (21). Small-subunit ribosomal RNA (rRNA) was amplified by the polymerase chain reaction (PCR) $(23,29)$ using universal oligonucleotide primers specific for eubacterial ribosomal RNA-encoding DNA (rDNA) (19). One of the primers used for amplification was biotinylated at the 5' end. Following amplification the biotinylated strand of the PCR product was purified using avidin-coated magnetic beads (DYNAL, Inc., Great Neck, NY) as previously described by Hultman et al. (15). The single-stranded DNA was sequenced using Sequenase 2.0 (U.S. Biochemicals) and universal rRNA sequencing primers (19) following manufacturer's instructions. Sequence data were analyzed using the sequence alignment and phylogenetic analysis of Olsen et al. (28). Least squares distance matrix analyses (27) were used to infer phylogenetic relationships. Approximately 1500 highly to moderately conserved nucleotides were compared.

Analytical. Dimethylsulfide was determined in headspace samples by sulfurspecific gas chromatography. A Varian 3700 gas chromatograph fitted with a sulfur- 
specific flame photometric detector was used to quantify high-level DMS production during isolation procedures, and an SRI 8610 gas chromatograph and Sievers 350A sulfur chemiluminescence detector (SCD) for other experiments. Volatile sulfur compounds were separated on a 2 m FEP column of Chromosil 330 (Supelco) at a column temperature of $75^{\circ} \mathrm{C}$ using helium as the carrier $\left(35 \mathrm{~mL} \mathrm{~min}^{-1}\right)$. We estimate the detection limit of the SCD at about 0.5 pmol, while that of the FPD is about fifty times higher. Aqueous DMS standards were prepared fresh for each experiment. Methanethiol was separated and detected by GC/SCD and identified by coelution with genuine methanethiol, but was not standardized due to rapid abiotic oxidation of aqueous standards.

Assays of volatile sulfur production. Cells were removed from three-day plates of 2216 and suspended in modified $\mathrm{f} / 2$ in sterile $125-\mathrm{mL}$ serum bottles capped with Teflon-faced butyl rubber septa. The medium was amended with sterile-filtered methionine or DMSP to a final concentration of 1 or $2 \mu \mathrm{M}$, respectively, and $1 \mathrm{~mL}$ headspace periodically withdrawn to monitor accumulation of volatile sulfur compounds in the headspace. Controls consisted of methionine- or DMSP-amended medium lacking cells.

Reagents and chemicals. Media and diagnostic reagents used for biochemical tests were obtained from Becton Dickinson Microbiology Systems, Cockeysville, MD. Dimethylsulfide and methanethiol were purchased from Fluka Chemical Corp., Ronkonkoma, NY. DMSP, as the HBr salt, was synthesized according to the method of Challenger and Simpson (7) and checked for purity by melting point determination and by comparison to standards of known DMS concentration. All other reagents and 
chemicals were of analytical grade, and of molecular biology grade where needed.

\section{RESULTS}

Table 6-1 summarizes many of the results below.

Morphology and growth characteristics. Cell morphology during growth in liquid media is that of a short rod of uniform size (Figure 6-1), with average cell dimensions of $1 \mu \mathrm{m} \times 3 \mu \mathrm{m}$. When cells were grown on solid media some lengthening of rods was observed, as well as a greater range of cell dimensions. Cells stained Gram-negative, and the presence of an outer membrane could be confirmed in transmission electron micrographs. Upon isolation cells were motile, but appeared to lose motility after repeated subculture. Cells prepared for transmission electron microscopy by a negative staining technique completely lacked flagella. Flagella appeared to detach very easily in both liquid and solid culture, and cells visualized by a flagellar stain usually lacked flagella. On one occasion, flagellar staining of cells grown on solid media revealed 1-4 polar flagella per cell, with lengths about 10-20x the long dimension of the rods. Multiplication is by binary fission. Grown on solid media, the isolate formed soft, round, salmon-colored colonies with a slightly raised center. The color of these colonies varied from dull pink to a more intense reddishorange as the culture aged.

LFR grew with either nitrate or ammonium as the nitrogen source. As evidenced by growth in BM/ASW medium, and in $\mathrm{f} / 2$ lacking the vitamin mix (which contains thiamine, biotin, and $\mathrm{B}_{12}$ ) there was no vitamin requirement for growth. Both liquid and solid cultures remained viable for up to two months at room temperature. 
Table 6-1. Growth and physiological characteristics of strain LFR.

Trait

Utilization of:

$\begin{array}{lc}\text { glucose } & + \\ \text { fructose } & + \\ \text { sucrose } & + \\ \text { galactose } & + \\ \text { trehalose } & + \\ \text { lactate } & + \\ \text { succinate } & + \\ \text { tartrate } & + \\ \text { mannitol } & + \\ \text { acetate } & + \\ \text { pantothenate } & - \\ \text { methanol } & - \\ \text { DMSP } & + \\ \text { acrylate } & + \\ \text { dimethylsulfide } & - \\ \text { glycinebetaine } & -\end{array}$

Growth at:

$\begin{array}{cc}4^{\circ} \mathrm{C} & \mathrm{W}^{*} \\ 8^{\circ} \mathrm{C} & + \\ 23^{\circ} \mathrm{C} & ++ \\ 35^{\circ} \mathrm{C} & + \\ 40^{\circ} \mathrm{C} & \text { W }\end{array}$

Catalase

PHB accumulation

D-glucose fermentation

$+$

Denitrification

Major fatty acid

$+$

$+$

$+$

$+$

$+$

$+$

$+$

$+$

$+$

$+$

-

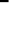

$+$

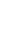

$\mathrm{Mol} \% \mathrm{G}+\mathrm{C}$

* W, weak 


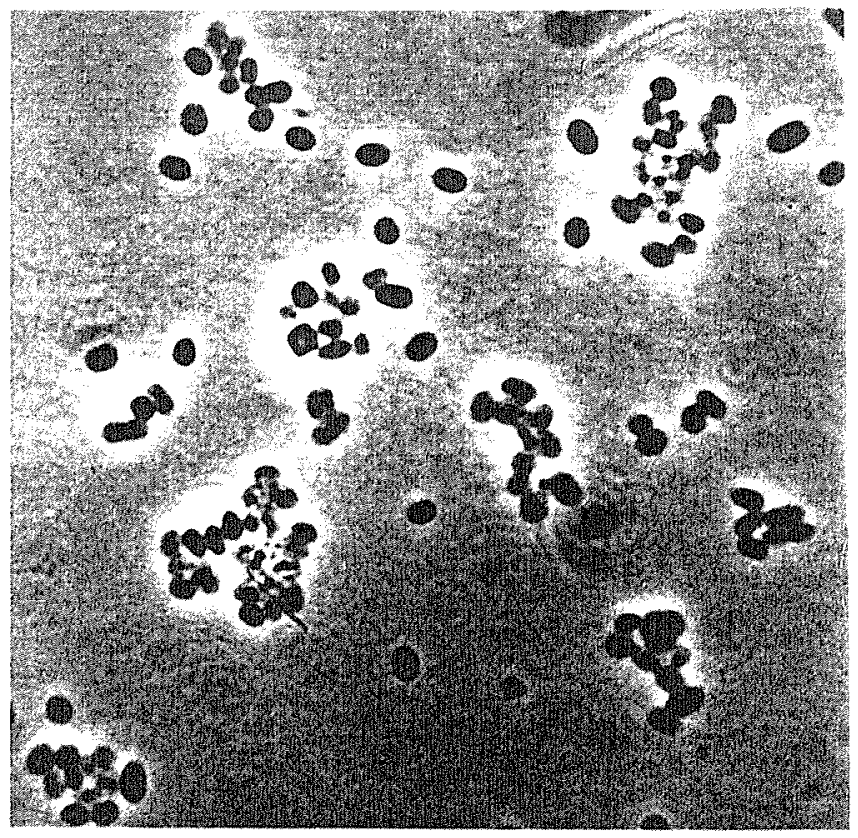

Figure 6-1. Phase contrast micrograph of strain LFR. 
With the exception of dimethylsulfide, methanol, glycinebetaine and pantothenate, LFR could grow with all of the carbon sources tested as the sole source of carbon and energy. Growth on DMSP and acrylate (the byproduct of DMSP cleavage to form DMS) are compared in Figure 6-2. Trypticase soy broth (Difco), with or without added salts, did not support growth, while yeast extract did. LFR also grew on SWC medium, although it appeared too rich for optimal growth. $\mathrm{Na}^{+}$is required; no growth was observed in BM/ASW medium lacking $\mathrm{Na}^{+}$, although similar growth rates and final cell densities were attained in treatments containing $85,170,340$ and $510 \mathrm{mM}$ $\mathrm{NaCl}$. Growth was observed at 4,8 , and $23^{\circ} \mathrm{C}$, with fastest growth at room temperature. Although initial growth was most rapid at $35^{\circ} \mathrm{C}$, cells quickly became elongated and appeared to have difficulty dividing. Cultures incubated at $40^{\circ} \mathrm{C}$ lysed.

Physiological tests. Strain LFR was found to be catalase positive. It did not ferment glucose in either of the two tests for this activity, did not grow or produce gas in denitrifying medium, and could not grow anaerobically with nitrate as the electron acceptor. LFR had a mol \% G $+\mathrm{C}$ of $70 \pm 1$. Polyhydroxybutyrate (PHB) was accumulated. PHB storage may account for unstained inclusions frequently observed in stationary-phase acridine orange-stained cells. Fatty acid analysis revealed the presence of short-chained $\beta$-hydroxy fatty acids, characteristic components of lipid A in the outer membrane of Gram-negative bacteria. A summed feature composed of 18:1 peaks that could not be individually resolved made up $82.2-82.8 \%$ of the fatty acids present.

Pigmentation. Cells produced a characteristic salmon-colored pigment when grown in subdued, indirect fluorescent light, incandescent light, or in the dark. 


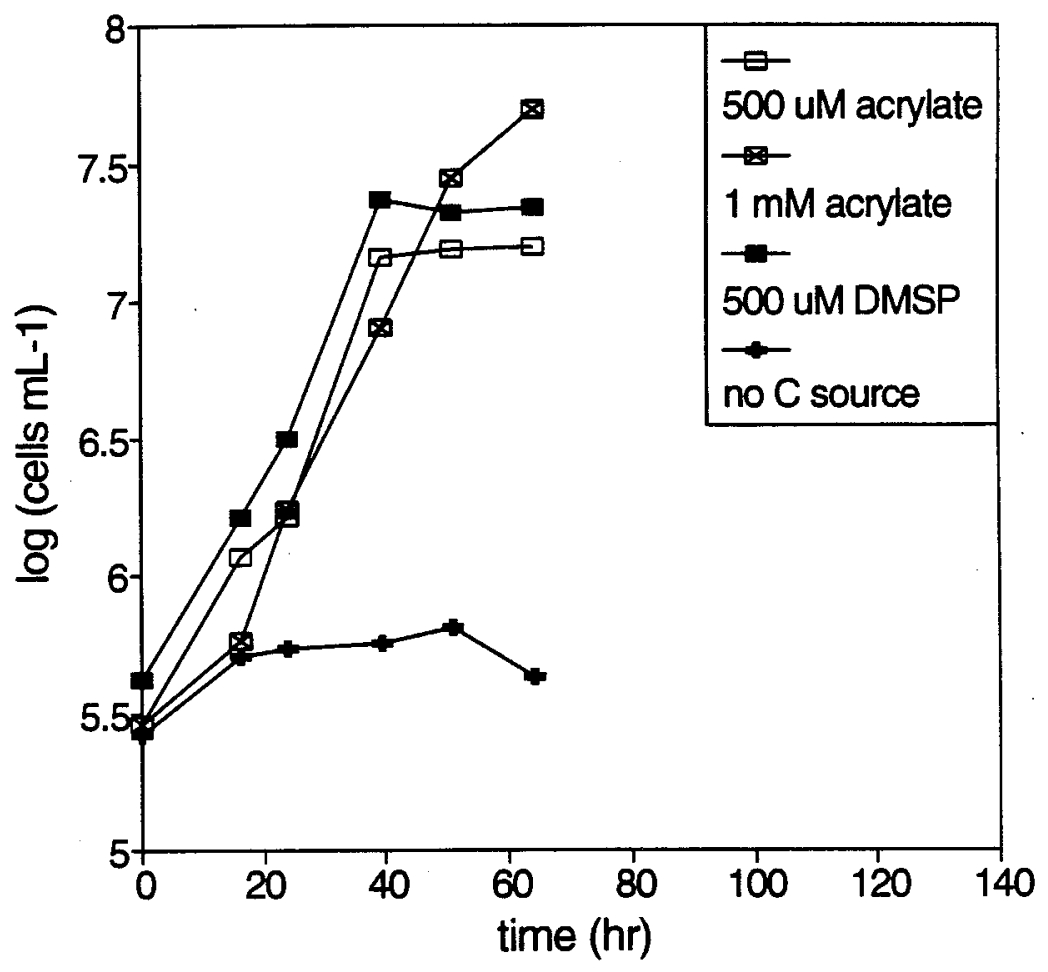

Figure 6-2. Comparison of LFR growth on acrylate and DMSP. 
Coloration was most intense in cultures grown on solid medium; pellets harvested from liquid cultures ranged from light salmon in color to almost colorless. Some strains appeared to lose the ability to form pigment. This was manifested either by colony sectoring (Figure 6-3) or colonies of a uniform pale tan color. Unpigmented and pigmented colonies, and cells from those colonies, were morphologically identical. Repeated restreaking of tan colonies on 2216 agar (up to ten transfers) failed to result in reversion to pigmented growth. When dilute suspensions of exponential-phase cells were spread on 2216 plates, approximately $0.27 \%$ of $7.5 \times 10^{3}$ colonies screened were observed to lack pigment completely.

The absorbance spectrum of a methanol extract of late stationary-phase cells grown on SWC solid medium in subdued light is shown in Figure 6-4. The unidentified absorbance at $414 \mathrm{~nm}$ was present, but not as pronounced, in cultures grown on 2216 or minimal media. The unresolved group of absorbance maxima at 502, 536 and $580 \mathrm{~nm}$ is typical of a carotenoid. The carotenoid absorbances were observed in methanol extracts of cells grown in both subdued light and dark and in liquid and solid culture. There was no detectable absorbance in the wavelength region between 650 and $900 \mathrm{~nm}$ under any of the growth conditions tested.

Phylogenetic characterization. Comparison of the 16S rDNA sequence to that of other eubacteria placed this isolate in the $\alpha$ subdivision of the proteobacteria (38). The region of $16 \mathrm{~S}$ rRNA between positions 180 and 220 (E. coli numbering) preserved the characteristic sequence of the $\alpha$ subdivision, and the sequence signature of $\alpha$ proteobacteria (44) was also present . The isolate has the highest small-subunit rRNA sequence similarity (91\% unrestricted sequence similarity) with Erythrobacter longus 


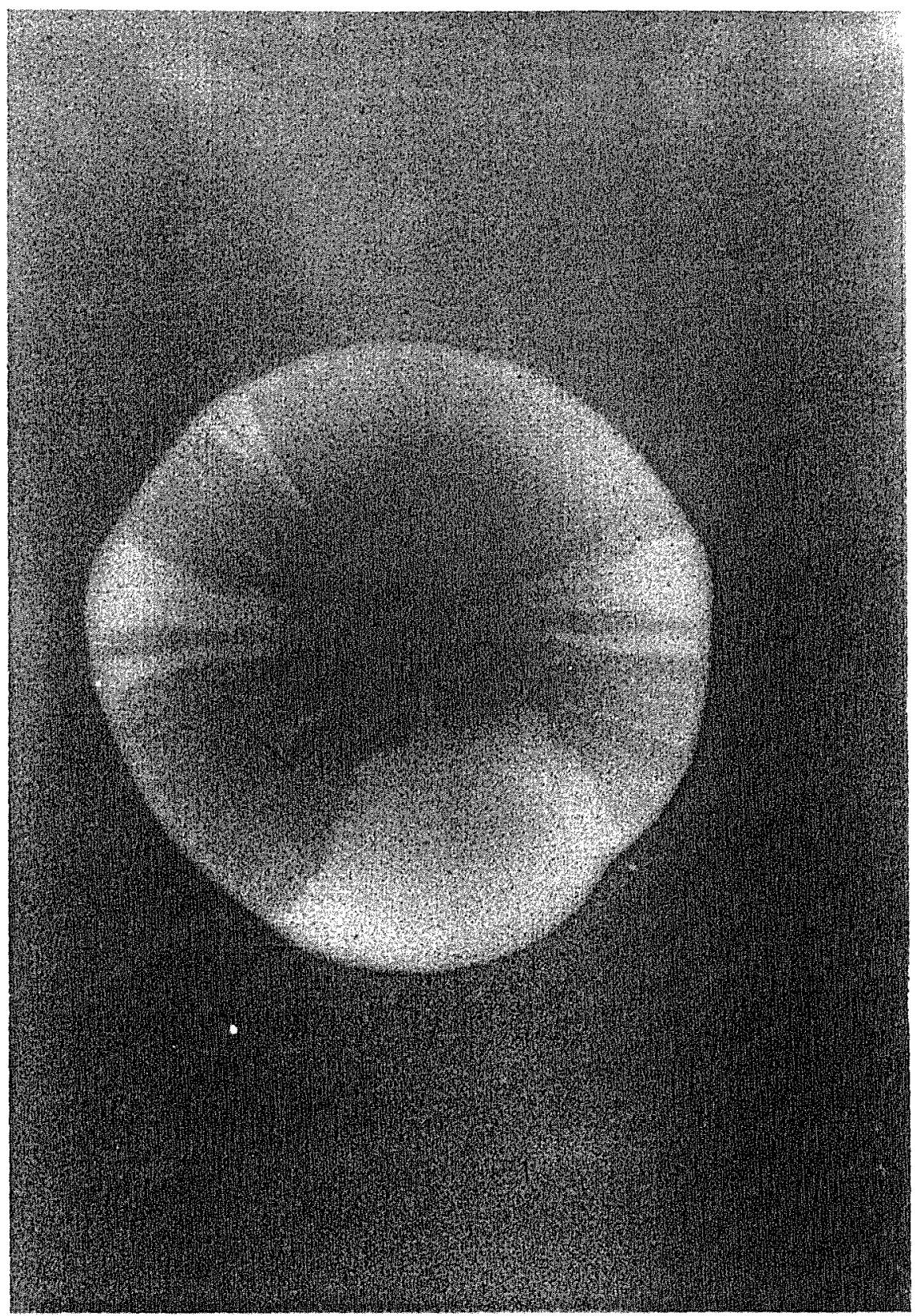

Figure 6-3. Sectoring colony on marine agar 2216. 


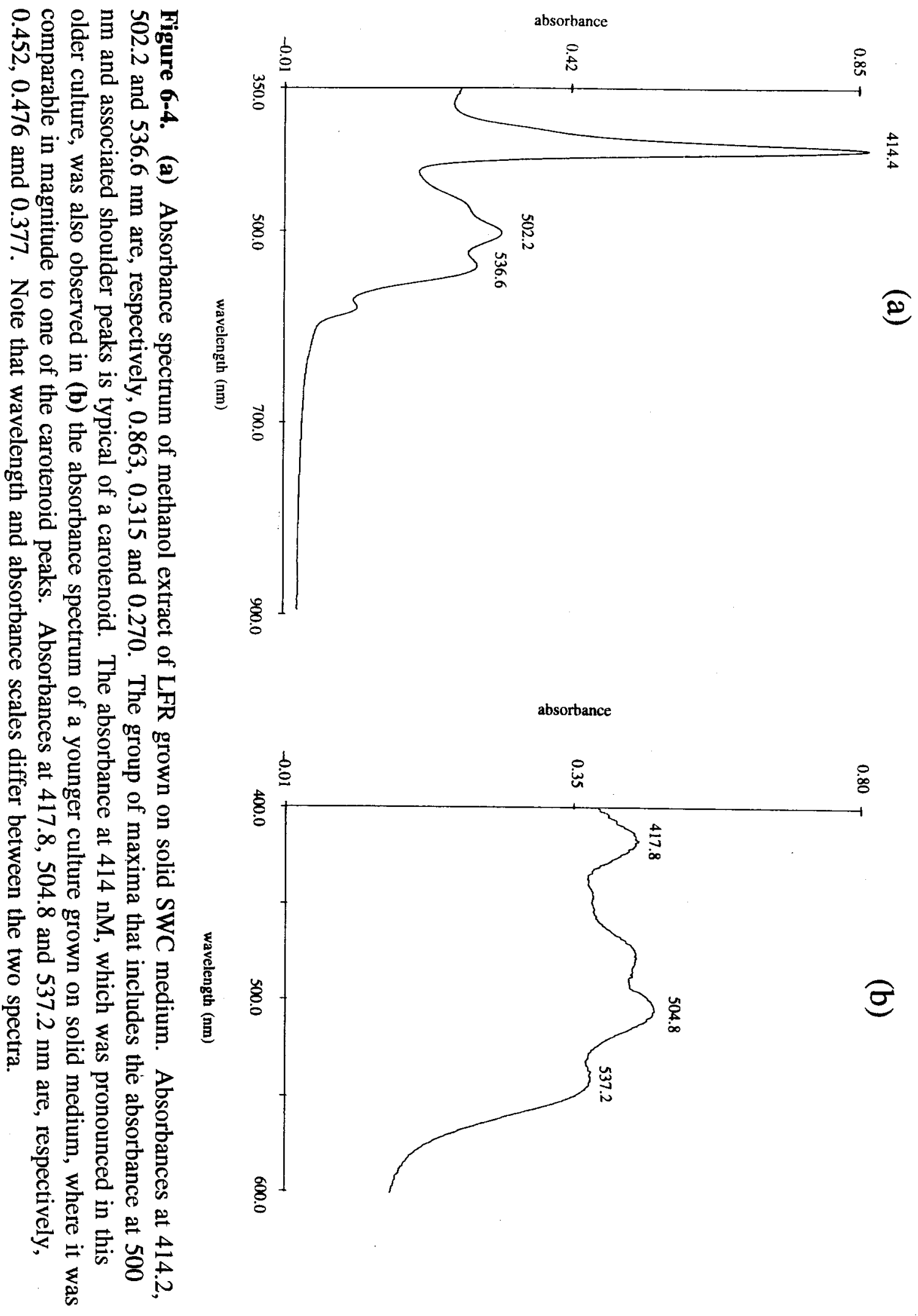


(OCh101), the type strain of this recently-proposed genus (37). LFR also displays a high degree of similarity (88\%) to the SAR 83 group described by Britschgi and Giovannoni (4). Weighted similarities to Erb. longus and SAR 83 are $94 \%$ and $90 \%$, respectively. These results are displayed in Figure 6-5.

Volatile sulfur production. LFR released DMS to the medium quantitatively during DMSP cleavage (Figure 6-6), implying that DMS was not utilized as a source of carbon, sulfur, or energy. Carbon for growth was presumably taken up from the other product of the cleavage reaction. While we do not have direct proof that the latter is acrylic acid, as is the case in the algal cleavage reaction (6), cells were able to take up and grow on acrylate at a comparable rate to DMSP (Figure 6-2). Strains lacking pigment produced DMS from DMSP at a rate indistinguishable from that of pigmented strains. LFR produced methanethiol (MeSH) from methionine (Figure 6-7), although quantitative conversion could not be confirmed due to rapid oxidation of MeSH.

\section{DISCUSSION}

Production of DMS in the marine environment, until recently considered the exclusive province of algae, is now understood to be additionally mediated by bacteria. Several characterized heterotrophic marine bacteria from the genera Deleya, Alteromonas, Pseudomonas, Shewanella, Vibrio and Photobacterium were found not to produce DMS from DMSP, with the exception of Pseudomonas doudoroffii (Chapter 2). This indicates that DMSP-lyase activity is not common to all marine bacteria although we do not know the quantitative importance of the above genera in natural 
Planctomyces staleyi

\section{LFR}

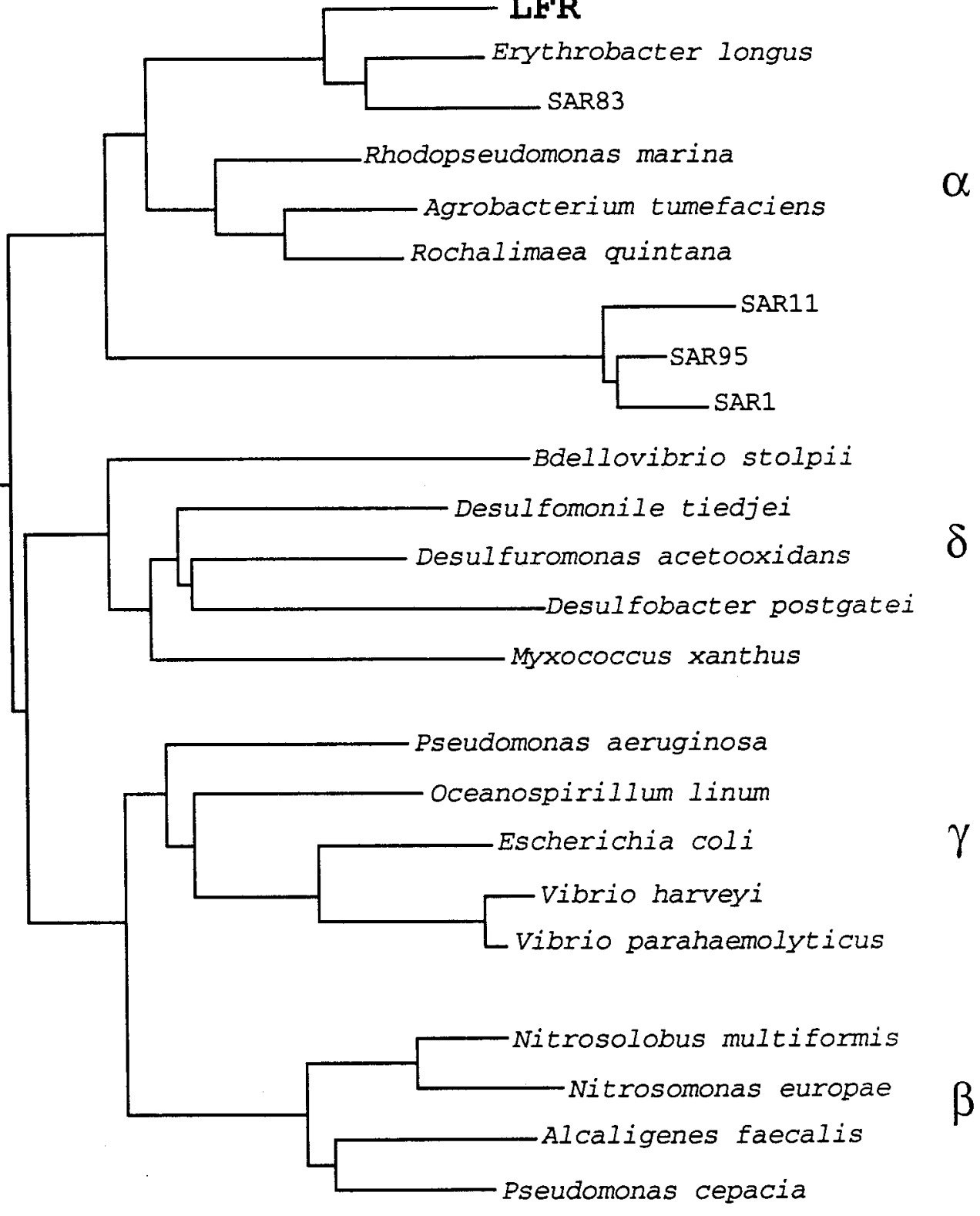

Figure 6-5. Phylogenetic tree based on 16S rRNA sequence similarity showing relatedness of LFR to other proteobacteria and to SAR 83 cluster described in (4). 


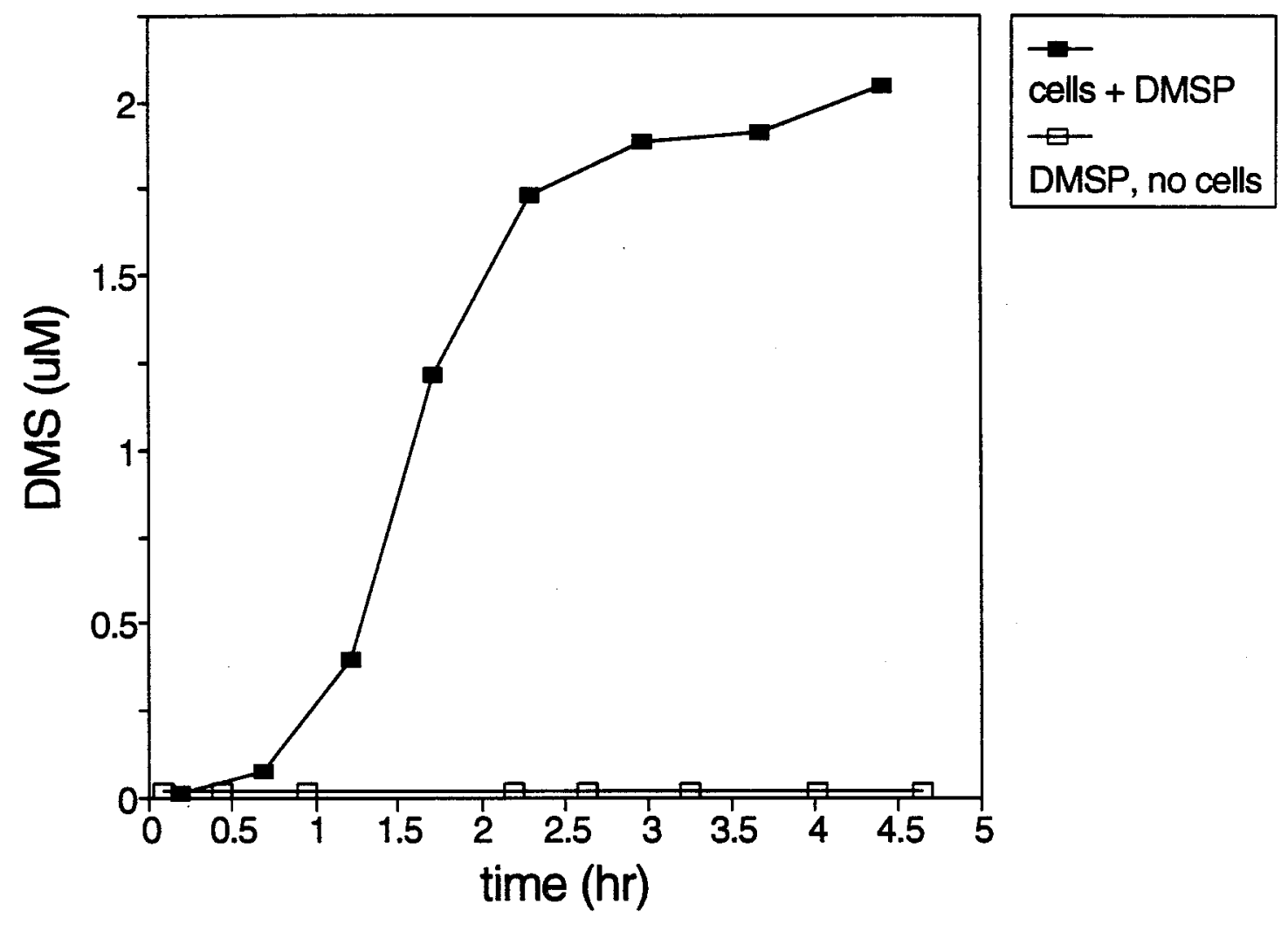

Figure 6-6. Quantitative conversion of a $2 \mu \mathrm{M}$ DMSP addition to DMS by LFR. The cell density is $3.8 \times 10^{6}$ cells $\mathrm{mL}^{-1}$. 


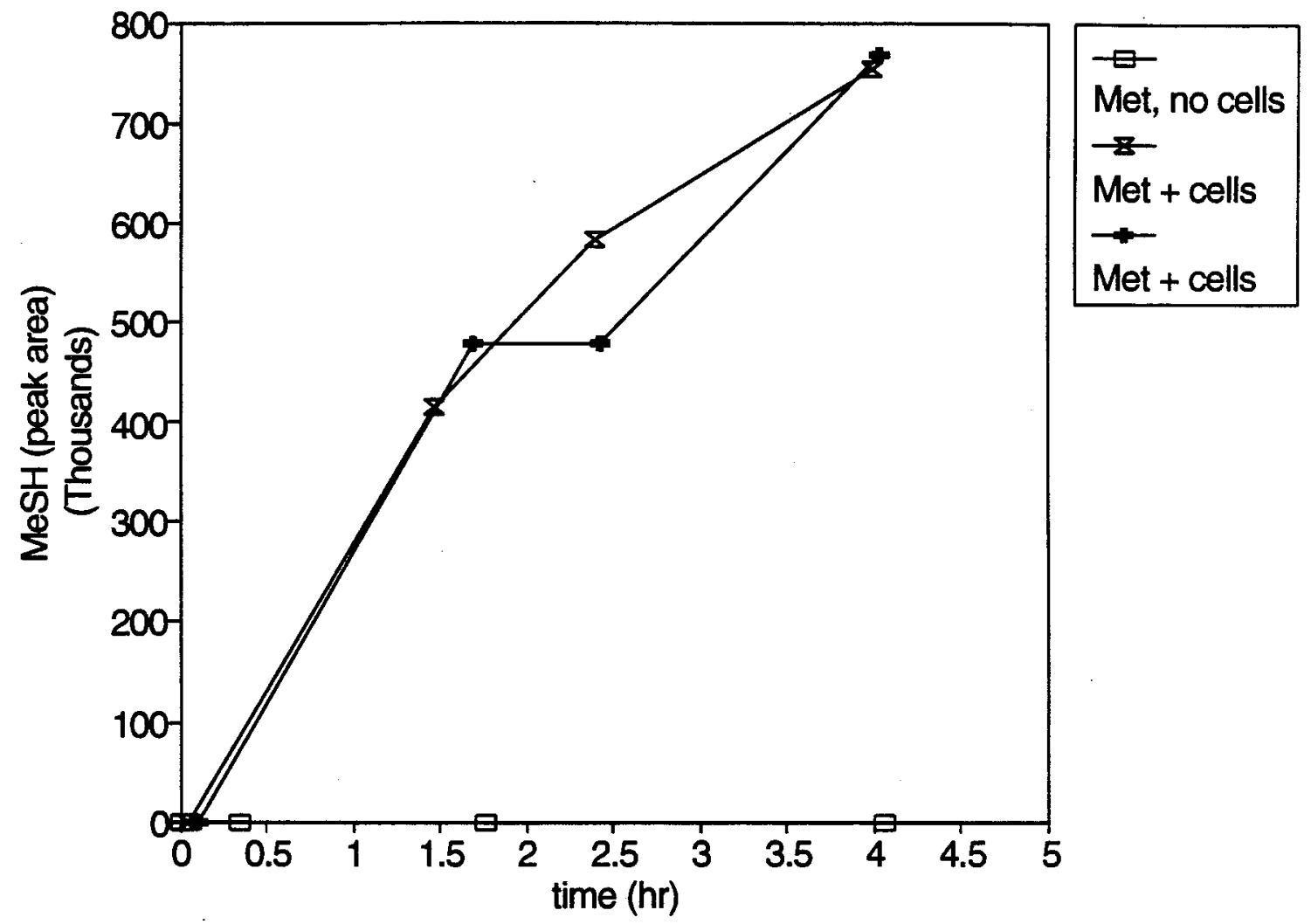

Figure 6-7. Production of methanethiol from $1 \mu \mathrm{M}$ methionine by LFR. The cell density is $10^{7}$ cells $\mathrm{mL}^{-1}$. 
marine assemblages. Phylogenetic characterization of the DMSP-degrading isolate described in this report places it in the $\alpha$ subdivision of the proteobacteria. Specifically, it appears most closely related to the single representative of the $\alpha-4$ subgroup, Erythrobacter longus (44). Ps. doudoroffii, on the other hand, has been placed by DNA:rRNA hybridization (9) in the rRNA branch of Aeromonadaceae, an enteric genus in the $\gamma-3$ subgroup. Although representing only two genera, these bacteria are divergent enough to suggest that DMSP-lyase activity is distributed fairly nonspecifically among marine representatives of the proteobacteria.

Phylogenetic analyses of bacterioplankton populations in the oligotrophic Atlantic and Pacific have confirmed that standard isolation techniques using rich media yield a limited, and possibly skewed, perspective on the bacterial diversity in seawater. While the majority of marine heterotrophic bacteria isolated to date (2) belong to the $\gamma$-subdivision of the proteobacteria, molecular approaches $(4,10,31)$ have revealed the apparent ubiquity of $\alpha$ proteobacteria in seawater. Using an oligonucleotide probe approach, Giovannoni et al. (10) were able to demonstrate that one group of closely related sequences within the $\alpha$ subdivision, the SAR 11 cluster, made up $15 \%$ of the prokaryotic RNA in a Sargasso Sea water sample. Another $\alpha$-proteobacterial phylogenetic group cloned from Sargasso Sea bacterioplankton, SAR 83 (4), appears closely related to Erythrobacter longus and to the bacterial isolate described here.

Erythrobacter and Roseobacter are genera that have been developed to accomodate the discovery of aerobic photosynthetic bacteria, which are defined as performing anoxygenic photosynthesis under aerobic conditions (32). These organisms have been reported to make up a sizable fraction of the bacterial population on the 
surfaces of sea sand and high-tidal seaweeds (37), but have not been isolated from seawater. The representatives of these genera that have received the most attention are Erythrobacter longus (OCh101) and Roseobacter denitrificans (formerly Erythrobacter species OCh114) $(34,36)$. These bacteria were initially grouped together on the basis of their bacteriochlorophyll (Bchl) content. However, Roseobacter denitrificans has since been placed in the $\alpha-3$ subgroup of the proteobacteria based on the amino acid sequence of its cytochrome $c_{551}(26)$, while the small-subunit rRNA sequence of $E r b$. longus sets it sufficiently apart from other $\alpha$ proteobacteria to warrant a completely separate subgroup (43). Although these bacteria can use light energy to synthesize ATP and fix carbon, photoautotrophic growth has not been demonstrated $(25,36)$. However, they are able to use light energy to enhance heterotrophic growth (12) following incubation in the dark, during which Bchl $a$ is synthesized. These observations, coupled with evidence of the presence of $\alpha$ proteobacteria in oligotrophic marine environments $(4,10,31)$ have led to speculation that a photoheterotrophic mode of existence may allow these organisms to compete effectively with purely heterotrophic bacteria for scarce dissolved organics in oligotrophic environments (4). To date, however, the aerobic Bchl-containing bacteria brought into culture have been isolated from the organic-rich surfaces of sand and seaweed, and not from adjacent seawater. This leads Shiba (33) to question the need for these organisms to photoassimilate carbon, and to doubt the environmental significance of the photosynthetic activity exhibited by cultures. Strain LFR, which was isolated from the open ocean water column and does not appear to synthesize Bchl, would seem to represent the opposite deviation from this scheme. However, these observations do 
not preclude the possibility that photoheterotrophy is a valid mode of survival for asyet-uncultured $\alpha$ proteobacteria present in the oligotrophic ocean.

As in both Erythrobacter longus and Roseobacter denitrificans, the major cellular fatty acids of LFR are 18:1, and carotenoid(s) are present. However, there was no evidence of Bchl $a$ in methanol extracts of cells grown under light or dark conditions, whether aerated or semi-aerobic (grown on solid medium). Certain facultatively methylotrophic bacteria, also in the $\alpha$ subdivision of the proteobacteria but not closely related to Erythrobacter longus, contain bacteriochlorophyll $a$ (30). The necessity of establishing separate genera for Erythrobacter species OCh101 and OCh114 is an additional indication that aerobic Bchl-containing bacteria may be distributed throughout the $\alpha$-subdivision rather than forming a phylogenetically distinct . subgroup. Woese et al. (43) note that the $\alpha$ proteobacteria are a mixture of photosynthetic and nonphotosynthetic bacteria which probably share a photosynthetic ancestor, and that bacteria such as Erb. longus may represent an intermediate stage in the loss of photosynthetic capabilities. The presence of Bchl $a$ may prove a doubtful basis on which to establish generic affiliations, in which case the current description of Erythrobacter as "aerobic, orange-pigmented bacteria which contain bacteriochlorophyll $a^{\prime \prime}$ (35) will need to be modified. In spite of its apparent lack of Bchl, the high sequence similarity of the small-subunit rDNA of this isolate with that of Erythrobacter longus indicates that these bacteria are closely related. However, the $\alpha-4$ subgroup is not well enough defined to justify assignment of LFR to the genus Erythrobacter at this time.

Although LFR was isolated from Sargasso Sea water, the fact that axenic 
techniques were not used to collect the water, and that it was subsequently filtered through a $0.2 \mu \mathrm{m}$ pore size, leaves open the possibility that the bacterium was a contaminant from a non-marine source. However, while $0.2 \mu \mathrm{m}$ filtration is generally assumed to remove bacteria quantitatively, bacterial cells smaller than this may be present, particularly in oligotrophic seawater $(20,40)$. The finding of a sodium requirement in LFR, as well as its close phylogenetic relation to a characterized marine bacterium and to as yet uncharacterized marine bacteria from the Sargasso Sea, is consistent with a seawater origin for this isolate.

Marine heterotrophic $\alpha$ proteobacteria are not commonly isolated from the water column by enrichment techniques. In this regard, enrichments with modest levels of a natural marine substrate such as DMSP may be preferable to those using rich media. Although DMSP-utilizing bacteria are easily isolated from seawater (Chapter 2), they may form a distinct, and perhaps small, subset of the bacterial population in seawater. Filtration of the seawater used for isolation prior to enrichment with DMSP, although also reducing the effective strength of the inoculum, would be expected to remove the bulk of the bacterioplankton competition. The combined effect of these two factors may have led to the virtual monoculture observed upon DMSP enrichment, and the isolation of a bacterium that might in other circumstances have been outcompeted by faster-growing, commonly-isolated strains. 


\section{ACKNOWLEDGEMENTS}

Linda Hare was responsible for the initial isolation of LFR, and is additionally thanked for assistance with culture work. Determination of DNA base composition, phase contrast and electron microscopy and many other aspects of the physiological characterization were carried out in John Waterbury's lab with the assistance of Freddie Valois and Diana Franks. Freddie Valois and John Waterbury are acknowledged for many helpful discussions. Larry Madin helped with photomicrography of sectoring colonies. I am grateful to Mike Klug and Helen Garchow for carrying out the fatty acid analyses. Ed DeLong is acknowledged for assistance with phylogenetic analysis, and he and Dan Distel are thanked for advice and considerable help with sequencing procedures. 


\section{REFERENCES}

1. Andreae, M. O. 1980. The production of methylated sulfur compounds by marine phytoplankton, pp. 253-259. In P. A. Trudinger, M. R. Walter, and B. J. Ralph (eds.), Biogeochemistry of ancient and modern environments. Springer Verlag, New York.

2. Baumann, L., P. Baumann, M. Mandel, and R. D. Allen. 1972. Taxonomy of aerobic marine eubacteria. J. Bacteriol. 110:402-429.

3. Baumann, P., and L. Baumann. 1981. The marine Gram-negative eubacteria: Genera Photobacterium, Beneckea, Alteromonas, Pseudomonas, and Alcaligenes, pp. 1302-1331. In: M. P. Starr, H. Stolp, H. G. Truper, A. Balows, and H. G. Schlegel (eds.), The prokaryotes. Springer-Verlag, Berlin.

4. Britschgi, T. B., and S. J. Giovannoni. 1991. Phylogenetic analysis of a natural marine bacterioplankton population by rRNA gene cloning and sequencing. Appl. Environ. Microbiol. 57:1707-1713.

5. Burdon, K. L. 1946. Fatty material in bacteria and fungi revealed by staining dried, fixed slide preparations. J. Bacteriol. 52:665-678.

6. Cantoni, G. L., and D. G. Anderson. 1956. Enzymatic cleavage of dimethylpropiothetin by Polysiphonia lanosa. J. Biol. Chem. 222:171-177.

7. Challenger, F., and M. I. Simpson. 1948. Studies on biological methylation. J. Chem. Soc. 1948:1591-1597.

8. Dacey, J. W. H., and N. V. Blough. 1987. Hydroxide decomposition of dimethylsulfoniopropionate to form dimethylsulfide. Geophys. Res. Let. 14:1246-1249.

9. De Vos, P., A. Van Landschoot, P. Segers, R. Tytgat, M. Gillis, M. Bauwens, R. Rossau, M. Goor, B. Pot, K. Kersters, P. Lizzaraga, and J. De Ley. 1989. Genotypic relationships and taxonomic localization of unclassified Pseudomonas and Pseudomonas-like strains by deoxyribonucleic acid:ribosomal ribonucleic acid hybridizations. Int. J. Syst. Bacteriol. 39:35-49.

10. Giovannoni, S. J., T. B. Britschgi, C. L. Moyer, and K. G. Field. 1990. Genetic diversity in Sargasso Sea bacterioplankton. Nature 345:60-62.

11. Guillard, R. R. L. 1975. Culture of phytoplankton for feeding marine invertebrates, pp. 29-60. In: W. L. Smith and M. H. Chanley (eds.), Culture of marine invertebrate animals. Plenum Press, New York. 
12. Harashima, K., K. Kawazoe, I. Yoshida, and H. Kamata. 1987. Lightstimulated aerobic growth of Erythrobacter species OCH 114. Plant Cell Physiol. 28:365-374.

13. Herdman, M., M. Janvier, J. B. Waterbury, R. Rippka, R. Y. Stanier, and M. Mandel. 1979. Deoxyribonucleic acid base composition of cyanobacteria. J. Gen. Microbiol. 111:63-71.

14. Hobbie, J. E., R. J. Daley, and S. Jasper. 1977. Use of Nuclepore filters for counting bacteria by fluorescence microscopy. Appl. Environ. Microbiol. 33:1225-1228.

15. Hultman, T., S. Stahl, E. Hornes, and M. Uhlen. 1989. Direct solid phase sequencing of genomic and plasmid DNA using magnetic beads as solid support. Nucleic Acids Res. 17:4937-4946.

16. Ishida, Y. 1968. Physiological studies on evolution of dimethyl sulfide from unicellular marine algae. Mem. Coll. Agric. Kyoto 94:47-82.

17. Kadota, H., and Y. Ishida. 1968. Effect of salts on enzymatical production of dimethyl sulfide from Gyrodinium cohnii. Bull. Jap. Soc. Sci. Fish. 34:512-518.

18. Kiene, R. P. 1990. Dimethyl sulfide production from dimethylsulfoniopropionate in coastal seawater samples and bacterial cultures. Appl. Environ. Microbiol. 56:3292-3297.

19. Lane, D. J. 1991. 16S/23S rRNA sequencing, pp. 115-147. In: E. Stackebrandt and M. Goodfellow (eds.), Nucleic acid techniques in bacterial systematics. John Wiley and Sons, New York.

20. MacDonnell, M. T., and M. A. Hood. 1982. Isolation and characterization of ultramicrobacteria from a Gulf Coast estuary. Appl. Environ. Microbiol. 43:566-571.

21. Maniatis, T., E. F. Fritsch, and J. Sambrook. 1982. Molecular cloning: A laboratory manual. Cold Spring Harbor Laboratory, Cold Spring Harbor, New York.

22. Mayfield, C. I., and W. E. Inniss. 1977. A rapid, simple method for staining bacterial flagella. Can. J. Microbiol. 23:1311-1313.

23. Medlin, L., H. J. Elwood, S. Stickel, and M. L. Sogin. 1988. The characterization of enzymatically amplified eukaryotic 16S-like rRNA coding regions. Gene 71:491-499. 
24. Nealson, K. H. 1978. Isolation, identification, and manipulation of luminous bacteria. Meth. Enzymol. 57:153-166.

25. Okamura, K., K. Takamiya, and M. Nishimura. 1985. Photosynthetic electron transfer system is inoperative in anaerobic cells of Erythrobacter species strain OCh114. Arch. Microbiol. 142:12-17.

26. Okamura, K., T. Miyata, S. Iwanaga, K. Takamiya, and M. Nishimura. 1987. Complete amino acid sequence of cytochrome $c_{551}$ from Erythrobacter species OCh114. J. Biochem. 101:957-966.

27. Olsen, G. J. 1988. Phylogenetic analysis using ribosomal RNA sequences. Meth. Enzymol. 164:793-812.

28. Olsen, G. J., R. Overbeek, N. Larsen, and C. R. Woese. 1991. The ribosomal RNA database project: an updated version. Nucleic Acids Res. 19:4817.

29. Saiki, R. K., D. H. Gelfand, S. Stoffel, S. J. Scharf, R. Higuchi, G. T. Horn, K. B. Mullis, and H. A. Erlich. 1988. Primer-directed enzymatic amplification of DNA with a thermostable DNA polymerase. Science 239:487-491.

30. Sato, K. 1978. Bacteriochlorophyll formation by facultative methylotrophs, Protaminobacter ruber and Pseudomonas AM1. FEBS Let. 85:207-210.

31. Schmidt, T. M., E. F. DeLong, and N. R. Pace. 1991. Analysis of a marine picoplankton community by $16 \mathrm{~S}$ rRNA gene cloning and sequencing. J. Bacteriol. 173:4371-4378.

32. Shiba, T. 1989. Overview of the aerobic photosynthetic bacteria, pp. 1-8. In: K. Harashima, T. Shiba, and N. Murata (eds.), Aerobic photosynthetic bacteria. Japan Scientific Societies Press, Tokyo, and Springer-Verlag, Berlin.

33. Shiba, T. 1989. Taxonomy and ecology of marine bacteria, pp. 9-24, ibid.

34. Shiba, T. 1991. Roseobacter litoralis gen. nov., sp. nov., and Roseobacter denitrificans sp. nov., aerobic pink-pigmented bacteria which contain bacteriochlorophyll $a$. System. App. Microbiol. 14:140-145.

35. Shiba, T. 1992. The genus Erythrobacter, pp. 2485-2489. In: M. P. Starr, H. Stolp, H. G. Truper, A. Balows, and H. G. Schlegel (eds.), The prokaryotes. Springer-Verlag, Berlin.

36. Shiba, T., and U. Simidu. 1982. Erythrobacter longus gen. nov., sp. nov., an aerobic bacterium which contains bacteriochlorophyll $a$. Int. J. Syst. Bacteriol. 32:211-217. 
37. Shiba, T., U. Simidu, and N. Taga. 1979. Distribution of aerobic bacteria which contain bacteriochlorphyll a. Appl. Environ. Microbiol. 38:43-45.

38. Stackebrandt, E., R. G. E. Murray, and H. G. Truper. 1988. Proteobacteria classis nov., a name for the phylogenetic taxon that includes the "purple bacteria and their relatives." Int. J. Syst. Bacteriol. 38:321-325.

39. Taylor, B. F., and D. C. Gilchrist. 1991. New routes for aerobic biodegradation of dimethylsulfoniopropionate. Appl. Environ. Microbiol. 57:3581-3584.

40. Torella, F., and R. Y. Morita. 1981. Microcultural study of bacterial size changes and microcolony and ultramicrocolony formation by heterotrophic bacteria in seawater. Appl. Environ. Microbiol. 41:518-527.

41. Turner, S. M., G. Malin, P. S. Liss, D. S. Harbour, and P. M. Holligan. 1988. The seasonal variation of dimethylsulfide and dimethylsulfoniopropionate concentrations in nearshore waters. Limnol. Oceanogr. 30:364-375.

42. Wagner, C., and E. R. Stadtman. 1962 . Bacterial fermentation of dimethyl- $\beta$ propiothetin. Arch. Biochem. Biophys. 98:331-336.

43. Woese, C. R., E. Stackebrandt, W. G. Weisburg, B. J. Paster, M. T. Madigan, V. J. Fowler, C. M. Hahn, P. Blanz, R. Gupta, K. H. Nealson, and G. E. Fox. 1984. The phylogeny of purple bacteria: The alpha subdivision. System. Appl. Microbiol. 5:315-326.

44. Woese, C. R. 1987. Bacterial evolution. Microbiol. Rev. 51:221-271. 


\section{CHAPTER 7}

\section{SUMMARY AND CONCLUSIONS}

The goal of this work has been to examine the rates and mechanisms of marine biological conversion of dissolved DMSP to DMS. DMS appears to be turned over by production and consumption on similar timescales; the shortest turnover times observed were on the order of less than a day in both the Sargasso Sea and Vineyard Sound, MA. Turnover of DMSP with respect to uptake was always more rapid than turnover due to cleavage, although the extent of the difference varied, possibly as a function of season. These results are briefly summarized in Table 7-1. The $\mathrm{K}_{\mathrm{m}}$ of DMSP uptake in coastal water could be related to the ambient soluble DMSP regime, but the kinetics of DMSP cleavage (DMS production from DMSP) in both Vineyard Sound and Sargasso Sea appeared to reflect other factors. These general observations seemed to apply equally well to productive Vineyard Sound coastal water and to oligotrophic Sargasso Sea water, i.e., turnover times were not appreciably shorter in the more productive environment.

The kinetics of DMSP uptake and cleavage were also investigated in pure cultures of a bacterium isolated from Sargasso Sea water. The apparent half-saturation value for DMSP uptake in this bacterium (100-200 nM) was within the range of previous environmental estimates, although no "typical" kinetic parameters for uptake and cleavage in seawater can be specified, since they appear to vary dramatically throughout the year. DMSP cleavage could not be modelled by Michaelis-Menten 
Table 7-1. Rates of dissolved DMSP removal, DMS production and DMS removal, and turnover times of DMS and DMSP, in the Sargasso Sea and Vineyard Sound, calculated for both ambient and amended DMS and DMSP concentrations $<15 \mathrm{nM}$. $\tau_{\mathrm{DMS}}$ with respect to DMSP cleavage is calculated only from rates measured at ambient concentrations. Use of the symbol $\tau$ in place of the term "turnover time" follows the convention established in Chapters 3 and 4.

Sargasso Sea

Vineyard Sound

DMSP removal

$\begin{array}{lll}\text { rate } & 0.06-0.67 \mathrm{nM} \mathrm{hr}^{-1} & 0.16-1.6 \mathrm{nM} \mathrm{hr}^{-1} \\ \text { DMSP turnover time } & 0.42-2.8 \mathrm{~d} & 0.24-2.9 \mathrm{~d}\end{array}$

DMSP cleavage

rate

0.009-0.14 $\mathrm{nM} \mathrm{hr}^{-1}$

$0.11-1.5 \mathrm{nM} \mathrm{hr}^{-1}$

$\tau_{\text {DMSP }}$

$1.3-21 \mathrm{~d}$

$0.9-2.9 \mathrm{~d}$

$\tau_{\mathrm{DMS}}$

$0.8-5.8 \mathrm{~d}$

$0.61-2.1 \mathrm{~d}$

DMS removal

$\begin{array}{lll}\text { rate } & 0.02-0.13 \mathrm{nM} \mathrm{hr}^{-1} & 0.05-0.12 \mathrm{nM} \mathrm{hr}^{-1} \\ \tau_{\mathrm{DMS}} & 0.21-7.4 \mathrm{~d} & 0.81-12 \mathrm{~d}\end{array}$


kinetics over the whole concentration range assayed, and a half-saturation value for this activity $(610 \mathrm{nM})$ based on the concentration range above $350 \mathrm{nM}$ was tentatively estimated. This difficulty of modelling DMSP cleavage activity was attributed, in part, to the interference of uptake kinetics; resolution of the problem will require study of the DMSP-lyase in a cell-free system. Chloramphenicol inhibition of DMS production suggested that DMSP-lyase activity in this isolate is inducible. The wholecell kinetics of DMSP uptake and cleavage in this bacterium, although they may simply reflect the limitations of working with whole cells, highlight an interesting issue: In the environment, rates of DMSP uptake and cleavage measured in response to a DMSP addition may differ for reasons that have little to do with population composition, although the latter explanation has been invoked both in this and other work to explain the observed lack of (simultaneous) stoichiometry between the two processes in seawater.

The phylogenetic relation of this bacterial isolate to other eubacteria was established by sequencing and comparison of $16 \mathrm{~S}$ rRNA. This approach placed the isolate in the $\alpha$ proteobacteria, and showed that it was most closely related to the sole member of the $\alpha-4$ subgroup, Erythrobacter longus, an aerobic, bacteriochlorophyllcontaining bacterium. This is an extremely interesting finding, since, although the presence of $\alpha$ proteobacteria has been inferred by molecular techniques, they are not commonly isolated from seawater.

Evidence has accumulated implicating DMS as the major precursor of non-seasalt sulfate aerosol in the marine atmosphere. At present, both our knowledge of the 
biological cycling of dimethylsulfide in the surface ocean and our ability to calculate its sea-to-air flux are critical. The latter is required for an accurate assessment of the current magnitude of DMS emissions from the ocean as well as for predictive purposes. The former is equally important, as it influences our ability to predict the concentrations on which flux calculations are based. In this regard, I will attempt to point out some of the insights conferred by the results in this thesis, and to point out areas of future research.

Two main observations emerge from this work. The first concerns the striking similarity between the coastal and oligotrophic environments in terms of the turnover times for DMS and DMSP. However, probably due to both a larger algal DMSP source and a more loosely coupled food web in the coastal environment, the average concentrations of DMS are somewhat higher in coastal than in open ocean seawater, even though the wheels of the DMS cycle in these two environments appear to be spinning at comparable speeds. Thus, in spite of rapid microbial production and consumption of DMS in both environments, the size of the original algal source is still reflected in DMS concentrations. This hypothesis is supported by the observation that bulk population kinetic parameters for DMSP uptake and cleavage vary throughout the year, possibly on a seasonal basis that reflects changes in phytoplankton production. In other words, rather than maintaining a dynamic position on a fixed rate-versusconcentration curve (turnover time changes with season or environment), the component of microbial assemblages which controls DMS cycling appears to occupy a fixed position on a curve whose shape is fluid (turnover time remains the same, at 
ambient levels, regardless of season or environment), driven by the need to exploit optimally the range of DMSP concentrations to which it is exposed. This interpretation implies that the DMS "residual," which determines the sea-to-air flux, will in the last analysis be a function of algal DMSP, bringing us to the second observation.

The rates of DMSP uptake, DMS production from DMSP and DMS uptake measured here, which can be assumed to be minimum estimates, imply that DMS is produced and consumed by microorganisms at rates that, in most cases, appreciably exceed those of ventilation. This is especially true if we have overestimated the DMS sea-to-air flux by a factor of two, as seems to be the case. Therefore, although the previous paragraph implies that DMS concentrations will ultimately reflect the relative strength of the algal source, the buffering effect of the microbial loop is large. As with any process through which a large flux of energy and matter is directed, a small change in the rate of this "buffering" has the potential to effect sizable changes in DMS concentration. A breakdown in the buffering effect of microbial processes, for instance, is likely to happen during events such as blooms, when a rapid input of soluble DMSP may stimulate DMS production to such an extent that DMS temporarily accumulates due to a lag in microbial consumption.

Much work remains to be done on the controls of DMS cycling in the marine environment. With respect to microbial production and consumption of DMS, a more complete seasonal cycle of DMSP uptake and cleavage kinetics needs to be established for the oligotrophic and coastal ocean. The difficulty of quantifying in situ rates of 
simultaneously-occurring DMS production and consumption awaits the application of radiolabelling techniques. Double-labelling to examine the fate of DMSP carbon and sulfur would be particularly enlightening. Since evidence has accumulated both in this and other work that DMSP is broken down via pathways that do not result in DMS production, these experiments would be extremely useful in gauging the extent and nature of alternative pathways. Microbial DMS consumption, which has received only peripheral attention in this work, is a vastly understudied process, and elucidation of its kinetics is problematic due to the apparently long lag times observed in this and other studies. Our ignorance of the predominant mechanisms of DMS consumption would be mitigated somewhat by isolation of DMS-transforming microorganisms from seawater and examination of their activity in pure culture.

At present, significant gaps in our knowledge of other aspects of the marine water-column cycle of DMS exist. For example, there is a dearth of research on in situ photochemical destruction of DMS. We also lack an understanding of the extent of environmental DMS production by algae, in part because we have not yet been able to elucidate its physiological basis, and in part because it is an extremely difficult phenomenon to monitor in situ. While the evidence presented here implies that microbial DMS production from dissolved DMSP is a ubiquitous and quantitatively significant source of marine DMS, it is only one component of the complex web of biological, chemical and physical processes controlling dimethylsulfide levels in the surface ocean. 